\title{
DECISION SUPPORT SYSTEM FOR CONJUNCTIVE STREAM-AQUIFER MANAGEMENT
}

\author{
by \\ Jeffrey W. Fredericks and John W. Labadie \\ Department of Civil Engineering \\ Colorado State University
}

\begin{abstract}
August 1995
Grant No. 14-08-0001-G1551-04

Project No. 03
\end{abstract}

The research on which this report is based was financed in part by the U.S. Department of the Interior, Geological Survey, through the Colorado Water Resources Research Institute; and the contents of this publication do not necessarily reflect the views and policies of the U.S. Department of the Interior, nor does mention of trade names or commercial products constitute their endorsement by the United States Government

COLORADO WATER RESOURCES RESEARCH INSTITUTE

Colorado State University

Fort Collins, Colorado 80523

Robert C. Ward, Director 


\section{PREFACE}

Although much progress has been made in the development of regional groundwater models and river basin simulation models, previous attempts at linking these two types of models into a workable conjunctive use decision support system for use in comprehensive river basin planning, management, and administration, have not been successful. With recent advances in computer hardware and software technology such as geographic information systems (GIS) and data base management system technology (DBMS), it is now possible to develop a computer based river basin decision support system for improved conjunctive use management of groundwater and surface water by linking a finite difference groundwater flow model with a river basin network model.

A microcomputer based decision support system is presented for conjunctive stream-aquifer management under prior appropriation. This has been accomplished through a synthesis of existing technology rather than development of new models. The computer-aided design and drafting package, AUTOCAD, and a powerful, low-cost, raster GIS package for PC's called IDRISI, are used for preparing and processing grid-based spatial data. These data are processed for input into MODRSP, a modified version of the USGS three-dimensional finite difference groundwater model, MODFLOW, to generate numerical groundwater response coefficients for considering distributive aquifer characteristics and realistic aquifer boundary conditions. These response coefficients are provided as input to the generalized river basin network model, MODSIM, to simulate spatially varied and timelagged return/depletion flows from stream-aquifer interaction. The integration of GIS, DBMS, MODFLOW, and MODSIM allows analysis of conjunctive use plans capable of considering decreed flow and storage rights, river calls, exchanges, trades, and plans for augmentation. The groundwater hydrologic components provided with MODSIM include reservoir seepage, irrigation infiltration, well pumping, channel loss, channel routing, return flows, river depletion due to pumping, and aquifer storage.

To demonstrate the capabilities of the Stream Aquifer Management Decision Support System (SAMDSS), a case study is presented for a portion of the Lower South Platte River Basin, Colorado. A 370 by 140 groundwater grid network ( $1000 \mathrm{ft} \times 1000 \mathrm{ft}$ cell) was prepared for the case study area using GIS techniques. Groundwater response coefficients were generated using MODRSP for the 200 wells and over 30 recharge sites of the Bijou Irrigation Company groundwater augmentation plan. The water right return/depletion flow account for the Bijou augmentation plan was simulated using MODSIM. A separate MODSIM network was set up for a 70 mile section of the Lower South Platte River, Colorado, between the Kersey and Balzac river gage stations, under administrative control of State Engineer's Water District \#1, to simulate daily administration of a river regulated under prior appropriation water right laws. The river system network model, which included 11 existing or proposed reservoirs, 18 diversion points, 25 direct decree diversions, 10 storage decree diversions, and 75 separate water rights, was used to simulate a daily administrative river call. The effects of the Bijou augmentation plan were included in the daily simulation. Two separate prototype user interfaces, one using the Bijou augmentation plan flow account network and the other using the daily administration example, were prepared using the desktop mapping software, MAPINFO, to demonstrate some of the capabilities inherent in a successful decision support system. Computerized data available from databases maintained by the Colorado State Engineer (e.g., water rights, diversions, groundwater, and streamflow); USGS (e.g., groundwater, digital line graphs, digital land 
use, digital elevation data, and streamflow); and Bureau of Census (TIGER files) were used for the study.

Results of the case study indicate that there are major differences between using groundwater response coefficients developed from preassigned stream depletion factor (SDF) values, as currently used in the basin, and those generated using a finite-difference groundwater model for the Bijou study area. An important factor not accounted for in the SDF derived coefficients is the influence of tributary flows, which account for a significant percentage of the retum/depletion flows estimated from the coefficients generated from the finite-difference model. 


\section{ACKNOWLEDGMENTS}

This research was partially funded through a grant from the Colorado Water Resources Research Institute. Recognition is given to several organizations and individuals whose cooperation and assistance provided many of the concepts and data necessary for successful completion of this project. The authors are especially grateful to Stan Robeson (US Geological Survey), Jack Fordham (US Geological Survey), Betty Cochran (US Geological Survey), George Fosha (WW Wheeler and Associates), Manuel Montoya (FRICO Irrigation Company), Allen Barryman (Office of the State Engineer, Colorado), Daryl Zimbelman (Northern Colorado Water Conservancy District), Eric Wilkinson (Northern Colorado Water Conservancy District), Roger Weidelman (US Bureau of Reclamation), and Mack Best (CDOT).

A special note of gratitude is extended to Jon Altenhofen (Northern Colorado Water Conservancy District) for his valuable help and insights in the South Platte River Basin case study application. Les Dalby and Mabel Cunning (Office of the State Engineer, Colorado) also provided extra support and effort on behalf of this project.

The authors are also grateful for the valuable support of the first author by his Ph.D graduate committee, Department of Civil Engineering, including Timothy Gates, Tom Sheng, Alan Early, and Robert Young. 


\section{TABLE OF CONTENTS}

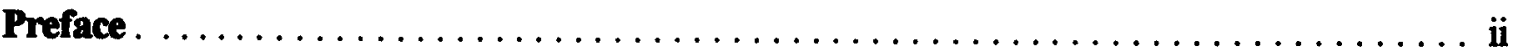

Acknowledgments $\ldots \ldots \ldots \ldots \ldots \ldots \ldots \ldots \ldots \ldots \ldots \ldots \ldots \ldots \ldots \ldots$ iv

List of Tables $\ldots \ldots \ldots \ldots \ldots \ldots \ldots \ldots \ldots \ldots \ldots \ldots \ldots \ldots \ldots \ldots$ viii

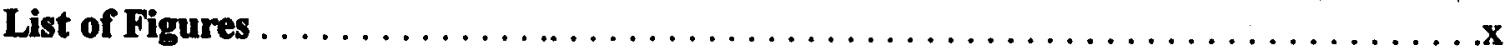

1. NTTRODUCTION $\ldots \ldots \ldots \ldots \ldots \ldots \ldots \ldots \ldots \ldots \ldots \ldots \ldots \ldots$

1.1 Water Rights, Conjunctive Use and Water Management in the West . . . . . . . 1

1.2 Decision Support Systems in River Basin Management . . . . . . . . . . . . . 3

1.3 River Basin Management Models . . . . . . . . . . . . . . . . . 4

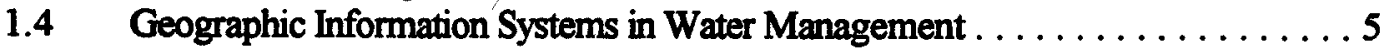

1.5 Objectives .............................. 6

2. STREAM-AQUIFER MANAGEMENT DECISION SUPPORT

SYSTEM (SAMDSS). . . $\ldots \ldots \ldots \ldots \ldots \ldots \ldots \ldots \ldots \ldots \ldots \ldots$

$2.1 \quad$ Basic Framework . . . . . . . . . . . . . . . . . .

2.2 Capabilities . . . . . . . . . . . . . . . . . . . . . . 8

2.3 Graphical User Interface Design $\ldots \ldots \ldots \ldots \ldots \ldots \ldots \ldots \ldots \ldots \ldots$

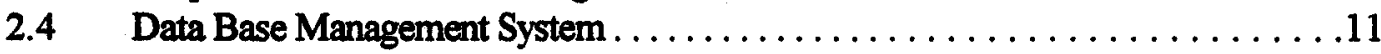

2.5 Model Base Management System . . . . . . . . . . . . . . . . . . 12

3. MODSIM RIVER BASIN NETWORK FLOW MODEL $\ldots \ldots \ldots \ldots \ldots \ldots \ldots$

3.1 Network Flow Approach to River Basin Modeling ...............13

3.2 Basic Assumptions . . . . . . . . . . . . . . . . . . . . . 14

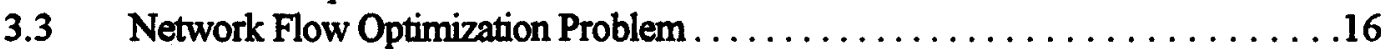

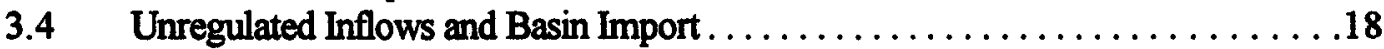

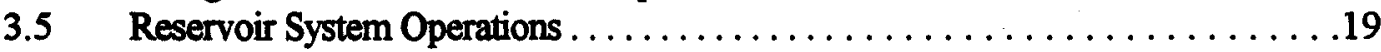

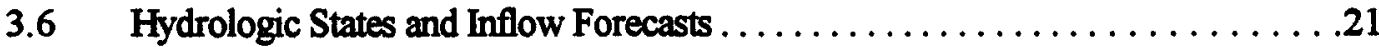

3.7 Evaporation Loss . . . . . . . . . . . . . . . . . . . . . . . .

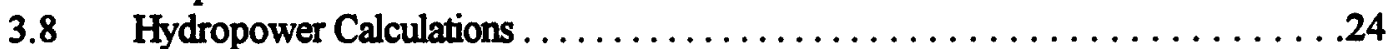

3.9 Consumptive Demands and Instream Flow Requirements . . . . . . . . . 24

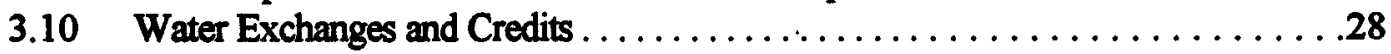

3.11 Link Capacities and Losses . . . . . . . . . . . . . . . . . . . . 29

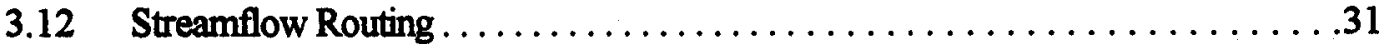

3.13 Reservoir Storage Rights and Accounts .....................

4. STREAM-AQUIFER MODELING COMPONENTS $\ldots \ldots \ldots \ldots \ldots \ldots \ldots$

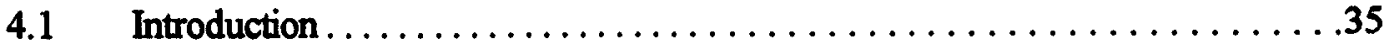

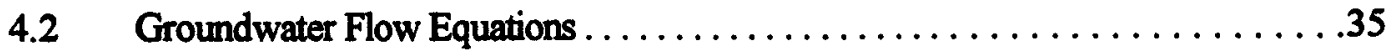




\section{TABLE OF CONTENTS (Cont.)}

4.3 Discrete Kemel/Response Functions . . . . . . . . . . . . . . . . . 37

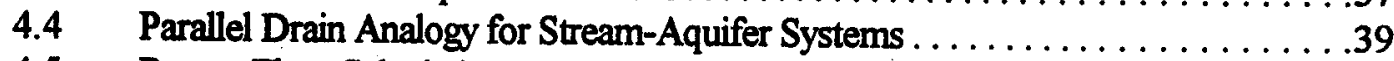

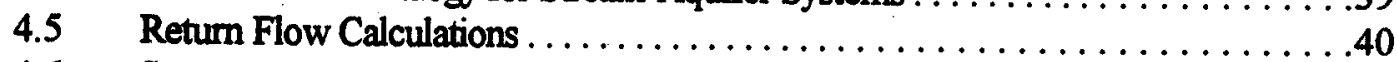

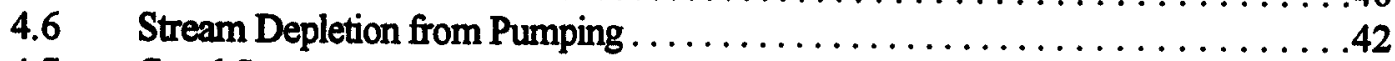

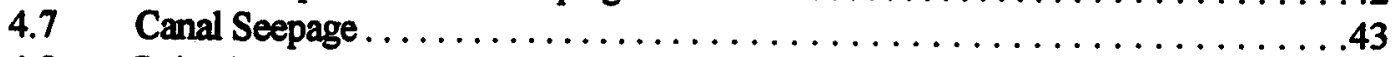

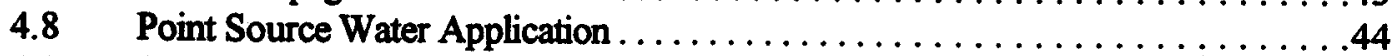

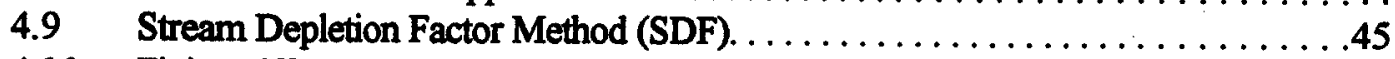

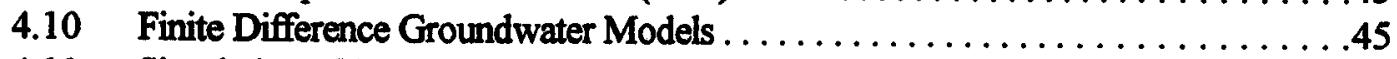

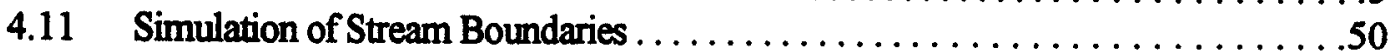

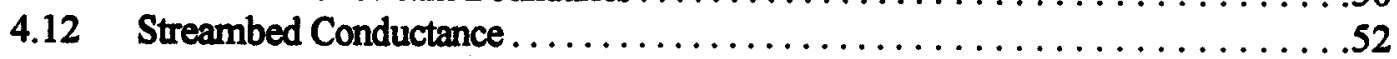

4.13 Calibration of Stream-Aquifer Models $\ldots \ldots \ldots \ldots \ldots \ldots \ldots \ldots \ldots \ldots \ldots \ldots$

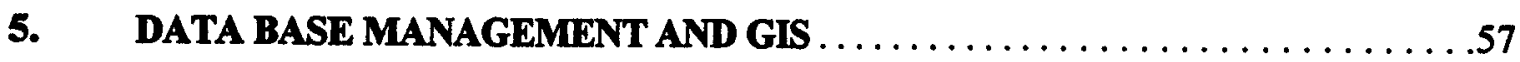

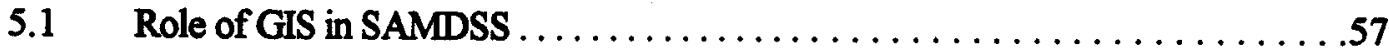

5.2 Data Sources ..................................58

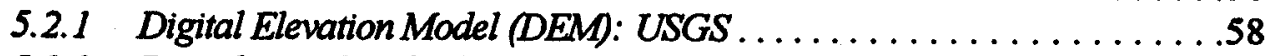

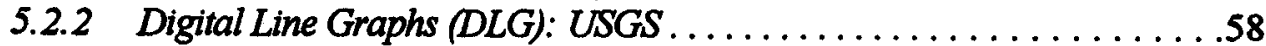

5.2 .3 Land Use and Land Cover (LULC): USGS . . . . . . . . . . . . . . .59

5.2.4 Geographic Names Information System (GNIS): USGS . . . . . . . . . 59

5.2 .5 LANDSAT: USGS/EOSAT .....................60

5.2.6 Topographically Integrated Geographic Encoding and Referencing System (TIGER): Census Bureau . . . . . . . . . . . .60

$5.3 \quad$ Data Conversion .....................................60 60

5.4 Using GIS to Prepare Data for MODFLOW/MODRSP .................63

5.5 Generating Stream-Aquifer Response Coefficients Using MODRSP . . . . . . . .65

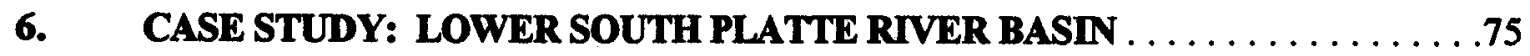

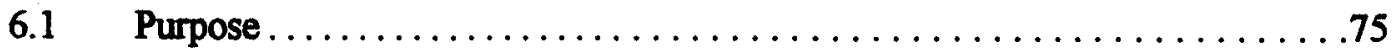

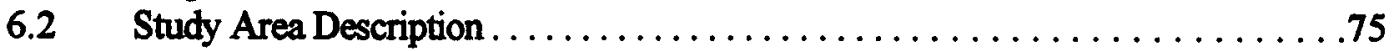

6.3 Water Rights Administration. .............................77

6.4 Bijou Irrigation System .................................

6.5 Groundwater Management Issues . . . . . . . . . . . . . . . . . . . .79

6.6 Inventory of Data Resources . . . . . . . . . . . . . . . . . . . . . 80

6.7 Generating Response Coefficients Using MODRSP ..................81

6.7 .1 Groundwater Network . . . . . . . . . . . . . . . . . . . . .81

6.7 .2 Hydrography Data ..............................83

6.7 .3 Transmissivity Data File $\ldots \ldots \ldots \ldots \ldots \ldots \ldots \ldots \ldots \ldots \ldots \ldots . \ldots \ldots \ldots$

6.7 .4 Boundary Data File ...........................8. 84

6.7 .5 Well Data Files . . . . . . . . . . . . . . . . . . . . . . . . . . . . . .84

6.7 .6 River Data File ....................................85

6.7 .7 Executing MODRSP ........................... 86

6.7.8 Post-Processing MODRSP Response Data Files . ... . . . . . . . . .87 


\section{TABLE OF CONTENTS (Cont.)}

$6.8 \quad$ Augmentation Water Right Account Using MODSIM $\ldots \ldots \ldots \ldots \ldots \ldots \ldots . \ldots 87$

6.8 .1 Introduction ...............................87

6.8 .2 MODSM Augmentation Network . . . . . . . . . . . . . . . . .87

6.8 .3 Simulation Using SDF Values ...........................89 . . . . . . . . .

6.8 .4 Simulation Using MODRSP Values . . . . . . . . . . . . . . . . .90

6.8 .5 Comparison of Simulation Results ..................... .90

6.8.6 Comparison of Response Coefficients ....................90

$6.9 \quad$ Augmentation Plan DSS . . . . . . . . . . . . . . . . . . . . . . . . . . . . .92

6.10 Daily River Administration Using MODSIM $\ldots \ldots \ldots \ldots \ldots \ldots \ldots \ldots \ldots . .95$

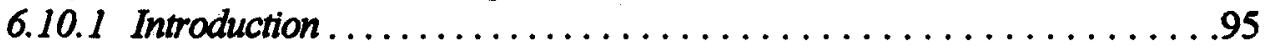

6.10 .2 MODSIM Daily Administration Network .................96

6.10.3 Integration of Augmentation and Daily Administration ...........101

6.10.4 Daily Administration DSS ......................... 103

6.11 Discussion of Results .....................................109

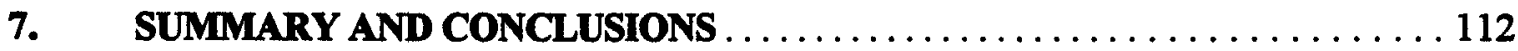

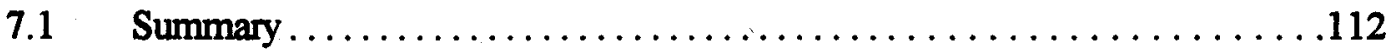

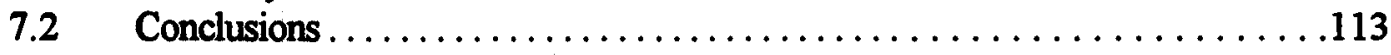

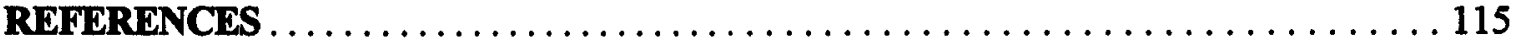

APPENDIX A: LAGRANGIAN RELAXATION ALGORITHM $\ldots \ldots \ldots \ldots \ldots \ldots$ A-1

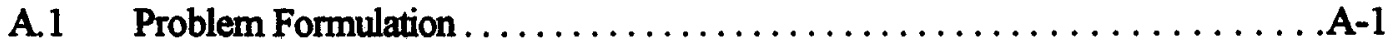

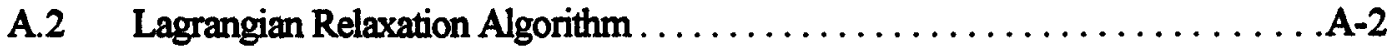

A.3 Typical Relaxation Iteration $\ldots \ldots \ldots \ldots \ldots \ldots \ldots \ldots \ldots \ldots \ldots \ldots \ldots \ldots$, A-4

A.4 Example Problem $\ldots \ldots \ldots \ldots \ldots \ldots \ldots \ldots \ldots \ldots \ldots \ldots \ldots$ A-6

APPENDIX B: PREPARING MODFLOW FILES USING DRISI $\ldots \ldots \ldots \ldots \ldots \ldots$ B-1

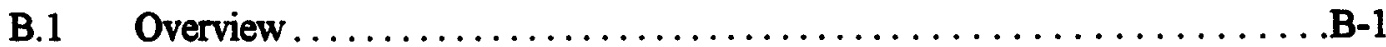

B.2 Background $\ldots \ldots \ldots \ldots \ldots \ldots \ldots \ldots \ldots \ldots \ldots \ldots \ldots \ldots \ldots \ldots \ldots$, B-1

B.3 Procedure $\ldots \ldots \ldots \ldots \ldots \ldots \ldots \ldots \ldots \ldots \ldots \ldots \ldots \ldots \ldots \ldots \ldots \ldots \ldots \ldots$, B-2

B.3 MODFLOW Output File: MODFLOW.OUT $\ldots \ldots \ldots \ldots \ldots \ldots \ldots \ldots \ldots, \mathrm{B}-10$

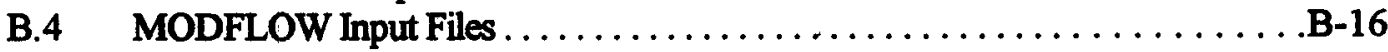

\section{APPENDIX C: GENERATING STREAM-AQUIFER COEFFICIENTS}

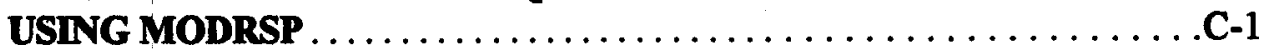

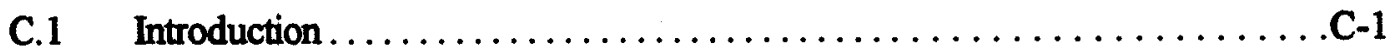

C.2 Data Preprocessing $\ldots \ldots \ldots \ldots \ldots \ldots \ldots \ldots \ldots \ldots \ldots \ldots \ldots \ldots, \mathrm{C}-1$

C.2.1 Aquifer Transmissivity . ..........................

C.2.2 Boundary File .............................. 


\section{TABLE OF CONTENTS (Cont.)}

C.2.3 Well File ...................................

C.2.4 Reservoir File .................................

C.2.5 Channel.......................................

C.2.6 River File ......................................

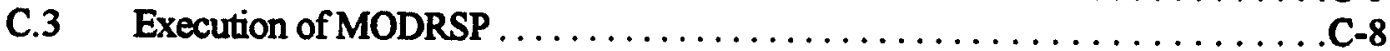

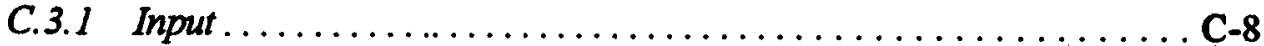

C.3.2 Output ................................. C-9

C.4 Data Postprocessing for MODRSP ........................

C.4.1 River Reach Summary .......................... C-10

C.4.3 MODSIM Coefficient File ......................... 10

APPENDIX D: CASE STUDY MODRSP FILES $\ldots \ldots \ldots \ldots \ldots \ldots \ldots \ldots \ldots \ldots$. 1

D.1 Example Screen for Input and Output Files Name Reading ..............D-1

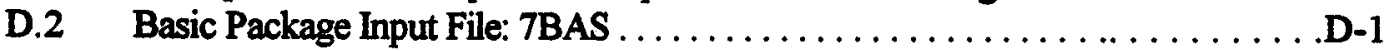

D.3 Block-Centered Flow Package Input File: 7 BCF $\ldots \ldots \ldots \ldots \ldots \ldots \ldots \ldots$.

D.4 Well Package Input File: Well.dat ...........................

D.5 Well Package Input File: Drain dat . . . . . . . . . . . . . . . . . . . . . D-2

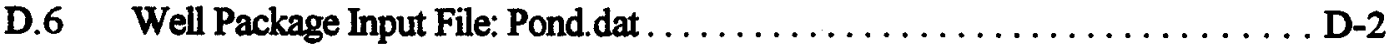

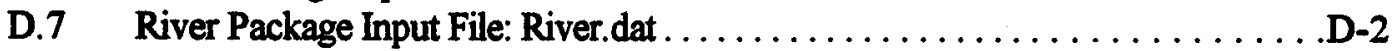

D.8 Preconditioned Conjugate Gradient Input File: PCG $\ldots \ldots \ldots \ldots \ldots \ldots \ldots$ D-2

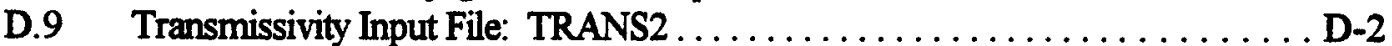

D.10 Boundary Input File: BOUND2 $\ldots \ldots \ldots \ldots \ldots \ldots \ldots \ldots \ldots \ldots \ldots \ldots \ldots \ldots \ldots \ldots, 2$

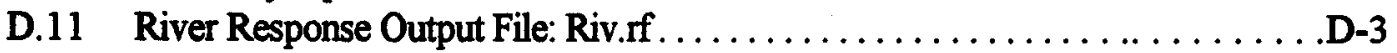

APPENDIX E: MODSIM AUGMENTATION PLAN INPUT FILES $\ldots \ldots \ldots \ldots \ldots$.E-1

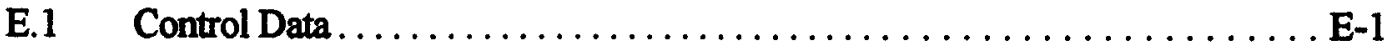

E.2 ADATA File: Bijou.ada ............................. E-2

E.3 Node Names: Nodes.dat (281 records). . . . . . . . . . . . . . . . . . . . . E-3

E.4 Reservoir Data File: Res.dat (9 records). . . . . . . . . . . . . . . . . . .E-9

E.5 Demand Data File: Demand.dat (Partial listing - 50/232 records). . . . . . . . . .E-10

E.6 Link Data File: Link dat (81 records) . . . . . . . . . . . . . . . . . . . E-11

E.7 Coefficient File Developed From MODRSP: SPLAT.cff (Partial listing- 50/1079 records, 5/89 fields). . . . . . . . . . . . . . . . . E-13

E.8 Return Data File: Rtn.dat (Partial listing 50/1079 records) . . . . . . . . . . E-14

APPENDIX F: BIJOU IRRIGATION COMPANY AUGMENTATION PLAN

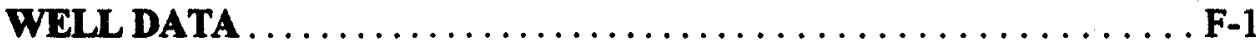

APPENDIX G: BIJOU AUGMENTATION PLAN ACCOUNTS $\ldots \ldots \ldots \ldots \ldots \ldots$ G-1

G.1 Net Return Flow Calculations: Using SDF Coefficient Values . . . . . . . . . G-1

G.2 Net Return Flow Calculations: Using MODRSP Coefficient Values . . . . . . . . . G-3 


\section{LIST OF TABLES}

4.1. Use of GIS for MODFLOW Input Data Requirements . . . . . . . . . . . . .48

4.2. MODRSP Response Coefficient Database Output $\ldots \ldots \ldots \ldots \ldots \ldots \ldots \ldots$

4.3. USBR PTFLOW Model Input Requirements $\ldots \ldots \ldots \ldots \ldots \ldots \ldots \ldots \ldots \ldots \ldots$

4.4. USBR PTFLOW Model Input Database Structure $\ldots \ldots \ldots \ldots \ldots \ldots \ldots \ldots \ldots$

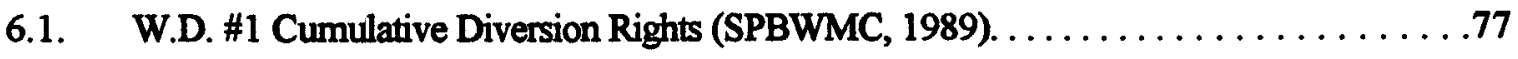

6.2. Bijou Augmentation Plan Recharge Sites . . . . . . . . . . . . . . . 89

6.3. Water Commissioner's Daily Report .......................97

6.4. SEO Diversion Database Data $\ldots \ldots \ldots \ldots \ldots \ldots \ldots \ldots \ldots \ldots \ldots \ldots \ldots$

6.5. Summary of Historical Daily Data $\ldots \ldots \ldots \ldots \ldots \ldots \ldots \ldots \ldots \ldots \ldots \ldots$

6.6. Augmentation Summary Table $\ldots \ldots \ldots \ldots \ldots \ldots \ldots \ldots \ldots \ldots \ldots \ldots$

6.7. Daily Admin Diversion Allocation-With/Without Bijou Augmentation ...........102 


\section{LIST OF FIGURES}

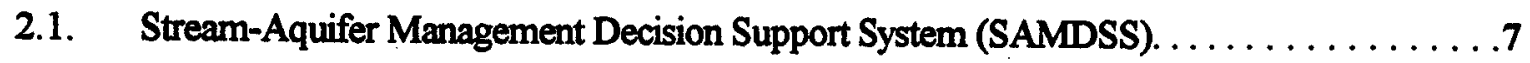

3.1. Network Structure for MODSIM with Accounting Nodes and Links ............ 18

3.2 Accounting Unregulated Inflow Links Plus Initial Storage ................ 19

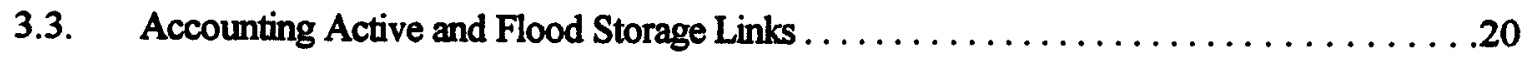

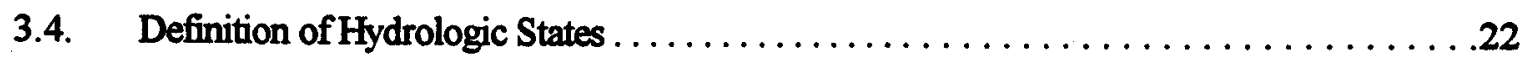

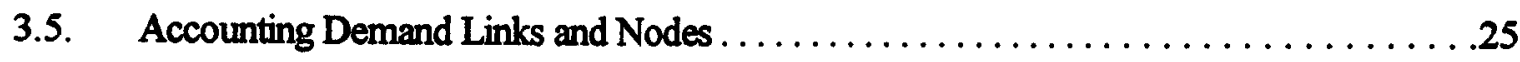

3.6. Use of Several Links for Multiple Water Rights ...................26

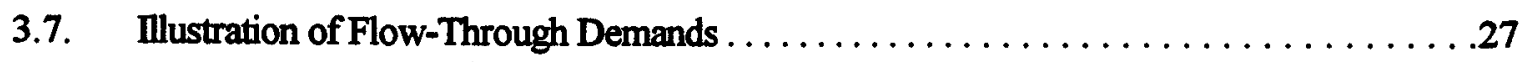

3.8. Flow-Through Demands with Bypass Credit Link $\ldots \ldots \ldots \ldots \ldots \ldots \ldots \ldots \ldots$

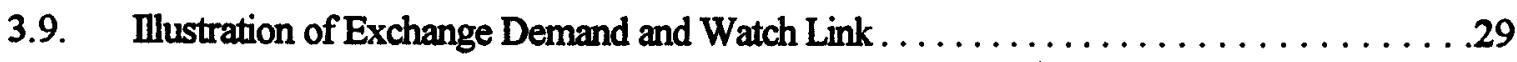

3.10. Iterative Procedure for Link Loss Calculations .....................30

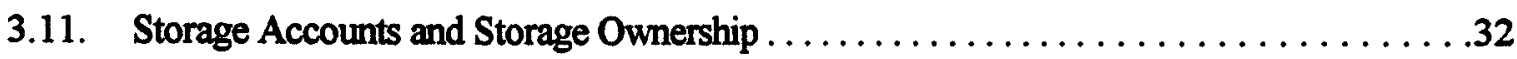

4.1. Parallel Drain Analogy for Stream-Aquifer Systems . . . . . . . . . . . . . . . . . . 39

4.2. Idealization of Stream-Aquifer System $\ldots \ldots \ldots \ldots \ldots \ldots \ldots \ldots \ldots \ldots \ldots \ldots \ldots \ldots \ldots$

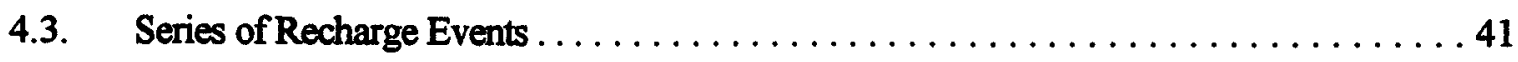

4.4. Illustration of Line Source for Canal Seepage $\ldots \ldots \ldots \ldots \ldots \ldots \ldots \ldots \ldots$

4.5. Comparison Between Network Model and Finite Difference

Grid Structure for River Basin . . . . . . . . . . . . . . . . . . . . . . . .47

5.1. Procedures for Converting TIGER Files into AUTOCAD.DXF Format ..........62

5.2. MODFLOW Input from Database $\ldots \ldots \ldots \ldots \ldots \ldots \ldots \ldots \ldots \ldots \ldots \ldots \ldots \ldots \ldots \ldots \ldots \ldots$

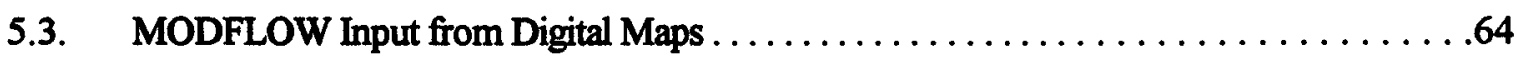

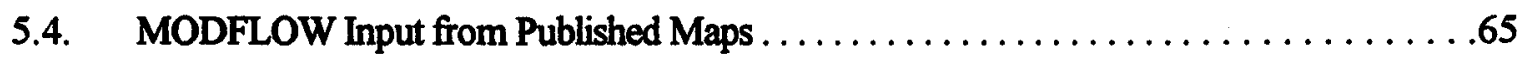

5.5. Using MODRSP to Create Response Coefficients ....................66 


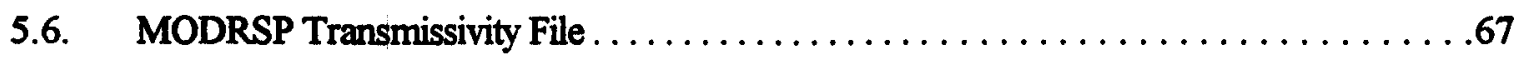

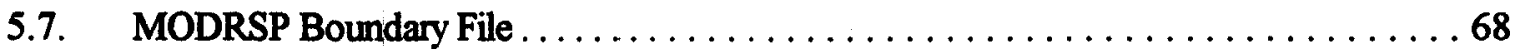

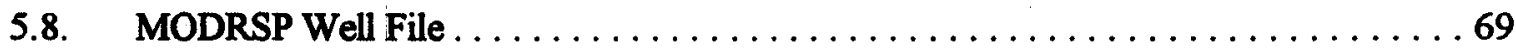

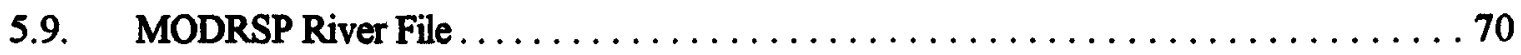

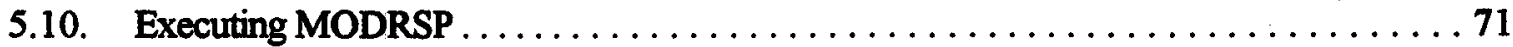

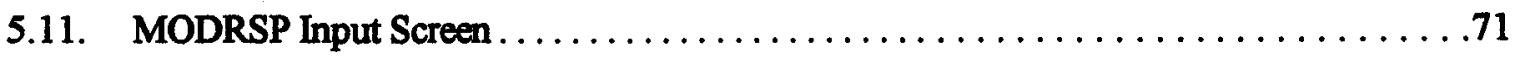

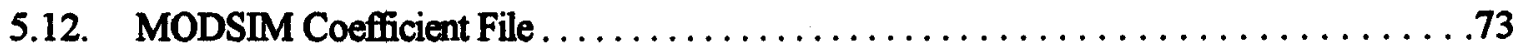

6.1. Map of Lower South Platte River Basin, Colorado;

Source: USGS 1:2,000,000 DLG Data . ........................76

6.2. Bijou Irrigation Company Augmentation Plan ....................... 79

6.3. Water District \#1, Lower South Platte River System ................. 82

6.4. Groundwater Model Finite Difference Grid $\ldots \ldots \ldots \ldots \ldots \ldots \ldots \ldots \ldots . \ldots . \ldots 2$

6.5. Lower South Platte Basin; Source: TIGER Files ....................83

6.6. Lower South Platte Transmissivity Map $\ldots \ldots \ldots \ldots \ldots \ldots \ldots \ldots \ldots . \ldots . \ldots \ldots$

6.7. Lower South Platte Saturated Thickness Map ......................86

6.8. MODSIM Network for Bijou Augmentation Plan $\ldots \ldots \ldots \ldots \ldots \ldots \ldots \ldots \ldots . \ldots 8$

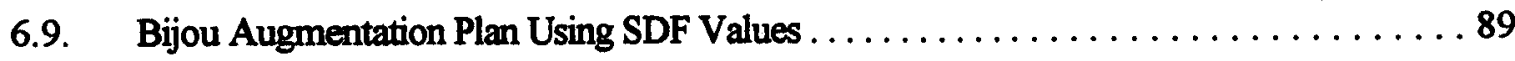

6.10. Bijou Augmentation Plan Using MODRSP Response Coefficients . . . . . . . . . . . 90

6.11. Comparison of Augmentation Plan Results (SDF vs. MODRSP) . . . . . . . . . . 91

6.12. Single Well Comparison of Response Coefficients (SDF vs. MODRSP) $\ldots \ldots \ldots \ldots \ldots 91$

6.13. Single Well Comparison of MODRSP Tributary and River Response Coefficients ......91

6.14. Bijou Irrigation Company Augmentation Plan Network $\ldots \ldots \ldots \ldots \ldots \ldots . \ldots 9$

6.15. Augmentation Plan DSS Output Options .......................... 94

6.16. Daily River Administration Using MODSIM $\ldots \ldots \ldots \ldots \ldots \ldots \ldots \ldots \ldots$ 
6.17. Daily Administration MODSIM Network ....................... 100

6.18. Network Structure for Daily Administration ...................... 101

6.19. Daily Administration DSS Main Menu ......................... 104

6.20. Daily Administration DSS Diversion Input Menu ................... 105

6.21. Daily Administration DSS Example Output $\ldots \ldots \ldots \ldots \ldots \ldots \ldots \ldots \ldots \ldots \ldots \ldots \ldots \ldots \ldots$

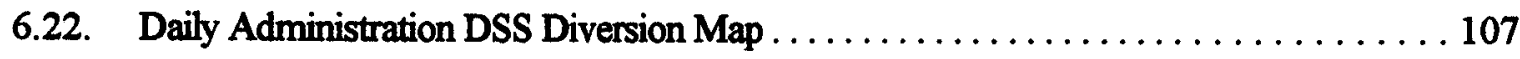

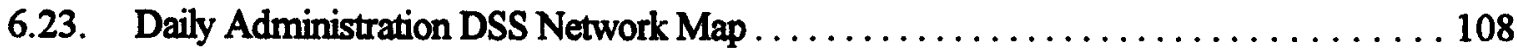




\section{CHAPTER 1}

\section{INTRODUCTION}

\subsection{Water Rights, Conjunctive Use and Water Management in the West}

Water has always played a vital role in the development of the Western U. S., and will continue to be crucial to future economic growth of the region. A common problem facing many Western states today is how to manage the intensifying competition for water by expanding urban centers, the traditional agricultural sector, and in-stream water uses dictated by environmental concerns. Confronted with the prospect of increased competition for available water and a moratorium on new large-scale water projects, water users must depend on better management of existing projects through integrated, basin-wide water management.

It is widely recognized that maximum water development in the West can only be achieved through conjunctive use of surface and groundwater resources. This is particularly important for a state such as Colorado, where $75 \%$ of the water is used for agriculture and $20 \%$ of the total water use comes from groundwater. In Colorado, $15 \%$ of the state population relies on groundwater for drinking. Irrigation is the largest user of groundwater, representing $96 \%$ of all total groundwater withdrawals. Of the 2.7 million acres irrigated in the Colorado, 1.6 million are irrigated in part with groundwater and 0.5 million acres receive groundwater as the sole source. Total groundwater withdrawals in 1980 were approximately 3 million acre feet. Kansas, Nebraska, and Idaho use about three times as much groundwater as Colorado. Wyoming, Utah, and New Mexico each use between a quarter to a half as much. In all cases, irrigation is the largest single user (Luecke,1990).

A major influence on water management in the Western States is water rights. Most Western States follow the Doctrine of Prior Appropriation, which requires that water first be delivered by decree to senior (in time) water right holders without regard to their location on the river (Andrews, 1987). River management and administration has become increasingly complicated as innovative water management strategies such as water exchanges, transfers, and groundwater augmentation plans have been developed which hhhelp make optimal use of water within the legal constraints.

Water law covering groundwater is less advanced than for surface water because of the complexity of the mechanics of groundwater movement, lack of specific information on the physical features of groundwater basins, and the relatively limited use of groundwater prior to fifty years ago. In almost all states, underground waters are accorded the same legal status as surface streams, with the more progressive states integrating their water laws for surface and groundwater. For example, Colorado places groundwater into tributary and non-tributary categories. Tributary groundwaters are those surface waters hydraulically connected to a natural stream and are administered under prior appropriation. Non-tributary subsurface waters are not hydraulically connected to natural streams and require special permits for withdrawal.

The complex task of river administration in Western states such as Colorado is the responsibility of the State Engineer, who supervises the day-to-day distribution of the surface waters of the state in accordance with water right priorities, statutory directives, court decisions, and interstate compacts (MacDonnell, 1988; SPBWMC, 1989). Water is withdrawn from streams under the supervision of a water commissioner assigned by the Division Engineer to a specific section of the 
stream. The duty of the commissioner is to monitor withdrawals in conformity with water right priorities in the stream section. The commissioner is responsible for determining where available water is to be allocated and for maintaining records on water availability and allocation. Each commissioner takes daily measurements of flows available from the river and determines eligibility of users to divert flows. Allowable diversions may be modified by deferral of water by some users, exchanges between users, availability of imported water belonging to specific users, and availability of stored water belonging to specific users. The Water Commissioner Handbook (Colorado Division of Water Resources, 1989) provides a list of the recognized types of river diversions: direct diversions, releases from reservoirs, diversion at an altemate point, ditch diverting from more than one stream, reservoir releasing to another reservoir, transmountain diversions, transmountain export, combined source, exchanges, trades, augmentation plans, and recharge.

When a senior water right holder is unable to divert a decreed water right, the water right holder contacts the water commissioner and places a call on the river (SPWMC, 1989). A call prohibits upstream junior water rights from diverting until the calling senior water rights have been satisfied. A water right on the main stem may place a call on the entire basin upstream of the calling right to ensure that the right is met before any upstream junior right diverts. A senior water right may also dry up the river during periods of low flow. When a call is placed by a senior right on a tributary, only the junior right upstream of the calling right within the same tributary or sub-tributary are affected by the call. A call is only placed on flows which can physically reach the senior right when that right is in priority.

The State Engineer has the authority to terminate well pumping if it results in depletion of surface flows which cause material injury to senior water rights. Serious difficulties arise in attempting to identify those pumping sources responsible for these depletions, and the amounts by which each is depleting the surface stream. It may be equally difficult to identify the surface rights that have been injured, since the stream may have been losing water to groundwater pumping over extended periods of time. The State regulates and monitors groundwater augmentation programs designed to allow pumping to continue by replacing streamflows that would otherwise be depleted.

The question of how best to achieve comprehensive river basin planning and voluntary water management through user participation is an interdisciplinary problem in which the water resource engineer plays an important role. The size and complexity of most major river basins, the administrative and legal constraints dictated by water rights issues, and the interdependence of surface and groundwater resources, has focused increasing attention on use of computer based models. Appropriate modeling technology can provide decision support for developing improved basin wide and regional strategies for daily water administration, drought contingency plans, evaluating groundwater exchange programs, managing recharge and augmentation projects, and for resolving conflicts between urban, agricultural, and environmental concerns.

\subsection{Decision Support Systems in River Basin Management}

There are a number of reasons why many important agencies and organizations directly responsible for water planning, management, and administration are not making routine use of computer based river basin models: 
- inability of many of computer modeling systems to adequately incorporate the legal realities of water allocation under the appropriation doctrine

- complexity of modeling interconnected stream-aquifer systems and differing opinions on model practicality versus scientific soundness

- imbalance between computer modeling needs and the costs of obtaining data necessary for model calibration and validation

- inability of practitioners to understand how to use the models and lack of userfriendly interfaces for enhancing model calibration and analysis of model results

- lack of portability of many proposed decision support systems to the type of computing equipment available to practitioners

- lack of efficient interfacing of proposed models with the data base management systems already in place by water agencies

The Office of Technical Management (OTA, 1982) conducted a survey of U.S. government agencies involved in water resource modeling and concluded that computer modeling had the potential to improve the accuracy and effectiveness of information available to managers, decision makers, and scientists, but that there were a number of constraints to effective model use. On the other hand, Rogers and Fiering (1986) expressed a negative view towards water resource modeling, targeting the supposed failure of optimization techniques in improving water resources planning and management. This was counteracted by the July 1986 issue of the ASCE Journal of Water Resources Planning and Management (Labadie and Sullivan, 1986b; Johnson, 1986) which was devoted entirely to actual use of computerized decision support systems by water organizations and agencies. A special followup workshop was held by the Operations and Management Technical Committee of ASCE at Colorado State University in 1988 on Computerized Decision Support Systems for Water Managers (Labadie, et al., 1989) which demonstrated how mathematical modeling was being successfully used by water managers and how the tools of decision support system theory were contributing to this process.

The classic definition of a decision support system (DSS) provided by Sprague and Carlson (1982) is "...an interactive computer-based support system that helps decision makers utilize data and models to solve unstructured problems." A framework for development of a DSS was proposed by Sprague (1980). The DSS software system is described as having three sets of technical capabilities: (i) data base management; (ii) model base management; and (iii) dialog generation and interface management.

The concept of computer-assisted DSS is gaining widespread acceptance in many water resource applications, such as wastewater treatment (Bertheoux, et al., 1989), river basin water management (Pinay et al., 1988), estuarine water water quality management (Camara, et al., 1990); multiple-purpose reservoir operation policies (Johnson, 1990), operation of urban water distribution networks (Boudon and Saunier, 1989), estuary water quality. management (Amold and Orlob,1989), hydropower optimization (Stover, 1991), reservoir system operations (Courtney and Whitlock, 1989), streamflow forecasting (Bradley, et al., 1989), lake water quality management (Fedra, 1988; Grobler, et al., 1987), drought management (Palmer and Holmes, 1988), and water distribution systems (Pingry, et al., 1992). 


\subsection{River Basin Management Models}

Yeh (1985) discussed management and operations models for river basin management, and identified two basic types of simulation model:

- capacitated network simulation models or quasi-simulation models which use optimization algorithms to solve the network flow problem, insuring that available system flows are allocated to user specified operational rules and demand priorities (Texas Water Development Board, 1972; Sigvaldason, 1976; Shafer, 1979; Graham, et al., 1986; Labadie, et al., 1986a; Labadie, 1988; Farley, et al., 1989; Vassilev, et al., 1989, Brendecke et al., 1989; Law and Brown, 1989; and Chung et al., 1989). network simulation models which use search techniques that require reservoir releases be made in accordance with fixed operation rules based on storage and demands (HEC, 1991; Loucks and Salewicz, 1990; USBR, 1991).

Shafer (1979) showed the advantages of the quasi-simulation model, particularly for use in preserving water diversion and storage priorities established by water rights. Although there are a number of models which incorporate water rights administration, many of these are accounting models that are unable to model physical responses within a river basin (Bethel, 1986; Rau, 1987; Wurbs and Walls, 1989). Of the more common simulation models, such as HEC5 (HEC, 1991), SSARR (USACE, 1986), IRIS (Loucks and Salewicz, 1991), HYDROSS (USBR, 1991) and MODSIM (Labadie, 1988) only MODSIM has the capability of effectively modeling both complex water rights and conjunctive-use of groundwater and surface water (Graham, et al., 1986; El-Kadi, 1989).

Other examples of quasi-simulation or network flow models include: the Acres model used on the Trent River Basin, Canada (Bridgeman et al., 1989), the California State Water Project Model DWRSIM (Chung et al., 1989), REGUSE, a real time regulation model used by the Inland Waters Directorate of Canada (Farley, et al., 1989), the CASTOR group model (Vassilev et al., 1989), and CRAM (Brendecke, et al., 1989).

During the 1970's, interest in conjunctive use and coordinated management of surface and subsurface water resources by water agencies resulted in the development of a new category of groundwater model: the stream-aquifer model (Van der Heijde, 1988). CONSIM (Labadie, et al.,1983) added a groundwater component to the river basin simulation model MODSIM (Shafer, 1979) by using analytical equations to develop response coefficients to describe the stream-aquifer return/depletion flows. SAMSON (Morel-Seytoux and Restrepo, 1987) modeled stream-aquifer interaction using response coefficients developed from a finite difference model. Although SAMSON was provided with a management capability, it was designed more as a conjunctive-use watershed model (El-Kadi,1989). Maddock and Lacher (1991b) prepared a model called MODRSP, which is a modification of the USGS MODFLOW finite difference model groundwater flow model MODFLOW (McDonald and Harbough, 1988). MODRSP can be used to calculate drawdown, velocity, storage losses, and capture response functions due to external excitations such as pumping, recharge, or infiltration for multi-aquifer groundwater flow systems. 


\subsection{Geographic Information Systems in Water Management}

Although geographic information systems (GIS) have been used extensively in a variety of water resource projects over the past 20 years, they are a relatively new tool to water managers and engineers. The reason for this is that only now are GIS systems becoming usable in a computational environment that is affordable and generally available to researchers and practitioners (Willeke, 1992). Goulter and Forest (1987) discuss how GIS can provide a number of capabilities which are useful to river basin operations and planning. They assert that GIS should not be considered a means of providing final answers to complex water resources planning issues, but view GIS as an important component of decision support systems. Capabilities recognized by Goulter and Forest (1987) include:

- ability to display and graphically summarize input data for analytical models, as well as results of application of management models using these data

- graphical display of georeferenced input data to assist in interpretation of conditions within a basin through depiction of spatial and temporal patterns

- reduction in the time required to enter data and improvement in data reliability through error reduction

- use of graphical display to improve man-machine interaction

- provide an efficient interface between the data base and operational computer models

Groundwater data bases and groundwater models have become prime targets for integration with GIS (Lanfear, 1992). Most groundwater mathematical models are based upon finite-element or finite-difference techniques composed of hundreds of grid cells. Assigning properties to cells is traditionally a time consuming and costly process. With GIS, distributed model parameters such as transmissivity or depth to bedrock can be regionalized, represented on a digital map, and related to the modeling grid. Regionalization is accomplished by digitizing existing maps or using GIS to develop maps of point data. Kilborn, et al. (1991) linked a GIS (i.e., SYSTEM 9, a vector-based GIS developed by Computer Vision, Inc.) to the U.S. EPA groundwater model designed for well head protection (WHPA) to demonstrate how GIS can extend the capabilities and usefulness of existing groundwater models.

Kernodle and Philip (1988) lists six advantages in using GIS to prepare input for a finite difference groundwater flow model:

1. attributes of area and perimeter of each polygon and attributes of arc length are automatically computed and updated by the GIS

2. both the hydrologic information being processed and the spatial discretization used in numerical model are identically distorted to any chosen map projection, allowing accurate overlay of information in a common coordinate system.

3. values are assigned to models on an objective basis; and yet information on which assignment is based is conveniently evaluated, interpreted, and revised by hydrologists to describe the geohydrologic framework

4. spatial discretization used in the model may be easily revised without concern for resultant subjective changes in representation of the geohydrologic framework

5. model input data and quality map products are essentially a single directed effort

6. data bases that are created are reusable and expandable for other investigations 
A number of GIS related activities have focused on support of the three-dimensional groundwater flow model, MODFLOW (Mcdonald and Harbaugh, 1988). The USGS has developed software for using the UNIX based version of the GIS package ARCINFO to read and write MODFLOW input and output files (Kernodle and Philip, 1987; Orzol and McGrath, 1992). An interface between the raster based GRASS GIS package and MODFLOW was developed for use in a UNIX environment as part of a proposed advanced decision support system; however, it was not applied to an actual case study (Pike, et al.,1990). A vector based GIS package GEOSQL was used as part of an integrated groundwater conjunctive use management model of the San Fernando Valley (Ozbilgin et al, 1991). Although MODFLOW was the groundwater model used in the study, GIS was applied only to referencing a well data base not to integrating data with MODFLOW.

\subsection{Objectives}

A prototype stream-aquifer management decision support system (SAMDSS) is presented herein which is designed as a computer-aided tool for:

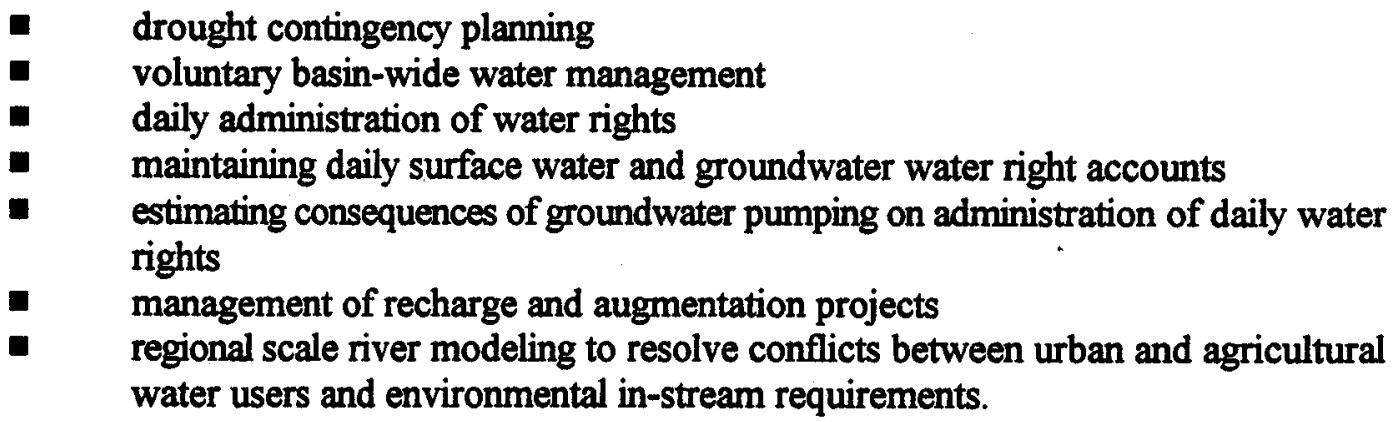

The SAMDSS is synthesized from existing technology, rather than requiring development of new models. Using a decision support system framework, interfaces are developed which connect the various modeling and data base components. The MODSIM river basin network flow modeling component provides the flexibility of allowing the user the option of familiar analytical procedures, or more data-intensive three-dimensional modeling techniques for stream-aquifer system management. Use of the latter is facilitated through linkage with GIS. The data base component interacts directly with existing hydrology, meteorology, water diversion, and water rights data bases actively maintained by the various agencies involved in water planning and administration. Procedures are established for simulating daily administration of conjunctive use schemes which consider decreed flow and storage rights, river calls, water exchanges, groundwater recharge measures, and the effects of well depletion SAMDSS is demonstrated on a portion of the Lower South Platte River basin in collaboration with a regional water management district. Impacts of a groundwater augmentation plan on river and tributary flow over time and space, are assessed, including the consequences of an augmentation plan on daily river administration. Although SAMDSS provides a powerful collection of tools, guidelines, and procedures that can be applied to any river basin, the sample interfaces are structured to satisfy input and output requirements for the case study only. 


\section{CHAPTER 2}

\section{STREAM-AQUIFER MANAGEMENT DECISION SUPPORT SYSTEM (SAMDSS)}

\subsection{Basic Framework}

A workable decision support system requires a framework that renders numerous computer modeling tools and techniques easily accessible to the water resource professional and creates a modeling environment that emphasizes the needs of the decision maker. The framework for the streamaquifer management decision support system (SAMDSS) has been prepared with these goals as the primary focus (Figure 2.1).

Although no single groundwater management model has been universally adopted by the water resource community, there are a number of well documented, technically sound, and generally accepted models for simulating most of the individual hydrologic and management components of the streamaquifer management problem. To avoid the traditional problems involved in the development and implementation oflarge, customized models, several generalized, public-domain water resourcemodels were identified and selected for use in SAMDSS.

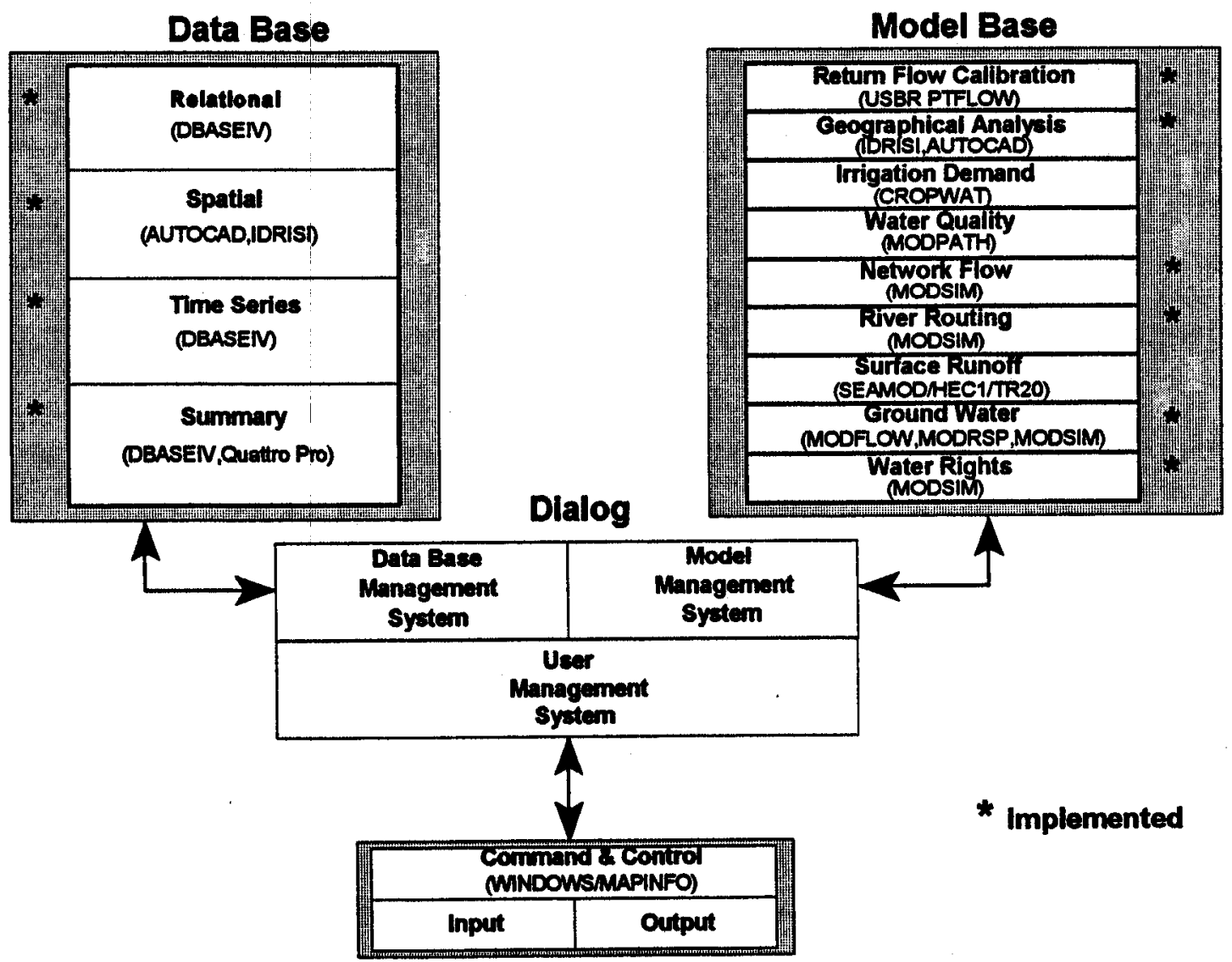

Figure 2.1 Stream-Aquifer Management Decision Support System (SAMDSS) 
In order to simplify the user interface and data file development process, a number of tools, templates, and guidelines were prepared. The use of commercially available spreadsheet, data base, and geographical information system (GIS) software packages provides flexibility in developing and tailoring output formats to meet individual requirements. The use of commercial software avoids the time consuming and too often unsuccessful process of preparing computer routines for constantly changing output reporting requirements.

The use of data base management technology allows storage, retrieval, and analysis of data in formats that are interchangeable between different computer based application packages. Unlimited access to data for preprocessing and postprocessing contributes greatly to the power of the decision support system. The process of interconnecting the data base management software, the model base management software, and dialog management software is facilitated by structured all data in database format with defined fields (columns) and records (rows) saved as DBASE data base files (*.DBF). Most commercial data base and spreadsheet software packages include functionality for reading and writing data base formatted files, including query, sorting, and extraction of data. The use of files organized in data base format permits direct access to data for preprocessing, postprocessing, and general review. The process of linking models to external computerized data bases is simplified, and allows development of a central data bank allowing reuse of data for a wide variety of purposes.

Most traditional water resource models have been written in the FORTRAN language and use formatted ASCII text files to input and output data. Reading and writing ASCII text files in formats compatible with commercial data base and spreadsheet software requires subroutine modules written for the water resource models used in the decision support system. It is easier and more convenient to prepare utilities capable of linking the various components of the decision support system. Model input and output formats and data bases are also structured to take full advantage of the spatial and time related nature of water resources data.

The SAMDSS is constructed around an open architecture framework that permits direct access to input and output data and allows modification and verification at all levels of the modeling process. This interactive capability enhances confidence in use of the decision support system. To maximize portability and minimize cost, all development work for SAMDSS was done on MS DOS/Windows-based microcomputer hardware. UNIX based versions of most of the computer models selected for use in SAMDSS are also available. Likewise, the geographic information system (GIS) and data base management system (DBMS) requirements for SAMDSS can be satisfied through commercial software available in a UNIX operating system environment.

\subsection{Capabilities}

The SAMDSS is designed to:

- assist in long term river basin planning activities, daily river administration, and river management options such as groundwater augmentation

- incorporate appropriation water right features such as decreed diversions, direct releases from a reservoir to a downstream diversion point, diversions at alternate points, exchanges, trades, recharge and augmentation plans.

- represent complex river basin systems as capacitated flow networks for which highly efficient solution methods are available 
- consider reservoir seepage, irrigation infiltration, channel loss, well pumping, return flows, river depletion due to pumping, and aquifer storage

- provide the option of modeling stream-aquifer return/depletion flows using groundwater response coefficients or discrete kernel values derived from analytical methods such as the Glover equations (Glover, 1977), the SDF method (Jenkins, 1968), or from numerical methods such as the finite difference model MODFLOW

- include effects of tributaries on return/depletion flow calculations in a river basin

- consider the spatial distribution of return/depletion flows along a stream

- tracks over time, from source to destination, individual return/depletion flows resulting from various geohydrologic activities

- maintains individual return/depletion flow water right accounts through identification of return and depletion flow events

- efficiently allocate river basin water resources according to user specified operational rules and demand priorities

- Interface with existing hydrologic, meteorologic, groundwater, water diversion, and water right data bases

- operate in a microcomputer environment under MS Windows

- incorporate commercial, non-proprietary, or supported public domain software. employ geographical information systems (GIS) and data base management system (DBMS) technology for preprocessing and postprocessing of data. processes data available from public domain data bases, published maps, or digital maps

\subsection{Graphical User Interface Design}

Simulation models predict the response of a physical system to a set of inputs, given a particular set of operating rules. With the aid of a simulation model, the consequences of variations in certain model inputs can be evaluated and the system operational characteristics modified to improve system output. This process is greatly enhanced by linkage with graphical user interfaces (GUI) with high degree of visualization capability (Fedra, 1990).

The stages of simulation can be classified as: during simulation, after simulation, and comparison of simulations. To represent the behavior of the system over time and to identify potential problems during simulation, it is necessary to display information during the simulation run. Display of information should be sufficiently general to allow the user to evaluate system performance against certain desired outcomes. After simulation, more detailed information can be displayed as necessary to provide valid post simulation evaluations and alterations. It should be possible to compare the results of different operating policies for the same physical system or different systems with the same geographic configuration.

Simulation output should present results in graphic or pictorial format in accordance with specified objectives. Three levels of output display have been identified: (i) the most general level involves comparison of performance against user defined threshhold values such as low, average, and high, with each node and linkage of a network schematic displayed in colors representing values of simulated variables related to specified threshold zones; (ii) the next level allows more detailed analysis and provides graphs such as time series and frequency of failure plots; and (iii) the final level 
provides traditional tabular output for a high degree of quantitative detail, with accompanying loss in visual and graphical clarity.

Since simulation models can be applied in many ways, users should be able to design output displays to reflect various model uses. For example, an output display demonstrating overall system performance against some desired outcome would be different than a display showing the effect of performance of an individual variable on overall system behavior, or displays tracking an individual variable performance given a selected operational policy. It is important to define study objectives and develop displays that aid in presenting output results that focus on those objectives.

In order to evaluate and improve operating policies, users should be provided with the ability to interactively change various aspects of the system. The user must have control over stopping, starting, continuing or restarting a simulation run. River basin simulation must easily accomodate changes in the physical system, as well as changes in operating policy. System evaluation with changing conditions over time are necessary when changes in the physical system and operating policy are made. Simulation systems that are dynamic in time should be capable of being halted and operating policies and system configurations altered. After changes have been made, the model process should be able to continue the simulation from the time period in which it was halted or be able to be reset back to time intervals already simulated under different conditions.

After completion of a simulation run, the GUI should allow more systematic analysis. Detailed information may be provided in the form of time series plots or display of failure frequency analysis. It should be possible to generate plots for any purpose, for any system element, and for any portion of the simulation time period. It is important to retain important aspects of the simulation output, while reducing the quantity of the information presented so that overall performance of the system can be easily evaluated. This is accomplished by creating a file during simulation and then selectively accessing data from the file for any portion of the simulation. Selected data can be stored in another file for later reading or printing. In this case, graphical display of results may not be appropriate, so tables can be displayed indicating the values and times of all failures in the specified time interval with their associated thresholds. These results are intended for more detailed analysis of the system. To assist in further analysis of simulation results, output should be available in a format that allows users to make comparisons visually, or allows more sophisticated statistical analysis. This may require output files which contain information from all streamflow sequences.

The desktop mapping software package MAPINFO for Windows (Mapinfo Corp., 1992) was selected as appropriate software to demonstrate these concepts in SAMDSS. Some of the features of MAPINFO that make it useful in the development of an effective DSS interface include:

- ability to access, update, join, and query spreadsheet, data base, and ASCII data base text files

- provide simultaneous display data tables interactively on-screen as a map view, graph or chart view, or a row and column (browse) view

- manipulate data in map or browse views

- geocode data bases to geographic or schematic maps

- thematically shade any object, line, point, polyline, or polygon

- conduct geographic searches such as within, contains, and intersects 
- draw or edit lines, polylines, polygons, rectangles, arcs, circles,symbols, and text using different fonts sizes, and colors

- reposition, zoom, and scroll contents of window map

- import/export graphics from/to ASCII, DXF, or ARC/INFO formats

- create custom menus and dialog boxes.

- call and execute external programs

\subsection{Data Base Management System}

Where possible, the input and output data files for the various models selected for use in the SAMDSS are structured as ASCII data base text files. There are several advantages to this approach: (i) it is convenient to use readily available data base or spreadsheet software to preprocess and postprocess data; (ii) study-specific user interfaces can be developed without having to access and modify original model source code; and (iii) data from existing data bases or output from other computer models can be read directly into models as input data files. Data base files used in SAMDSS are structured to satisfy the input and output requirements required by the SAMDSS support models.

The specific data base management packages utilized in SAMDSS include:

- DBASEIV: data base management package that can be used to create, organize, and access a data base (Ashton-Tate, 1990).

- QUATTRO PRO: spreadsheet package with graphics and data base support (Borland, Inc., 1992).

For geographic information systems (GIS) and spatial data base and analysis, the following packages are utilized:

- IDRISI: grid based geographic analysis system developed at Clark University, that is designed to provide inexpensive access to computer-assisted geographic analysis technology (Eastman, 1990)

- AUTOCAD: general purpose computer aided design(CAD) program that can be used to prepare a variety of two-dimensional drawings and three-dimensional models (Autodesk, Inc., 1990)

- SURFER: powerful and flexible tool for creating contour or surface plots of three dimensional data (Golden Software, Inc., 1987)

- GCTP: the USGS General Cartographic Transformation Package ia a system of FORTRAN subroutines designed to permit the transformation of coordinate pairs from one of 20 map projections to another; it is the standard computer software used by the National Mapping Division for map projection computations

A number of data conversion routines have been prepared for converting data between various formats and preparing the data base for input to the model base for SAMDSS:

WRTIGER: transforms Bureau of Census TIGER files to AUTOCAD DXF file format for use with AUTOCAD

DLG: transforms USGS Digital Line Graph Files to AUTOCAD DXF file format for use with AUTOCAD 
- CONVERT: adds carriage returns and line feed characters to the end of records on binary files; required for most digital data supplied by U.S. government agencies (i.e., Bureau of Census TIGER files, USGS Digital Line Graph files, USGS Digital Elevation Model files, etc.)

- IDRSS: retrieves data from IDRISI files and writes a data file for use by a spreadsheet

- SURF: reads a SURFER ASCII xxx.grd file and writes an IDRISI xxx.img file.

- MODCOEF: Reads MODRSP response coefficient data base output file and writes to tabular format for use by MODSIM

- ACDTOIDR Isp: AUTOLISP program provided with IDRISI to transform AutoCad drawing data into IDRISI vector format.

VECBRK.Isp: AUTOLISP program used to rasterize Autocad drawing line segments. VECDIST.Isp: AUTOLISP program used to output rasterized AutoCad line segment data as an IDRISI vector format or ASCII PRN format for use with a SPREADSHEET; line segment length is output as an attribute.

VECWIDTH.lsp: AUTOLISP program used to output rasterized AutoCad line segment data as an IDRISI vector format or ASCII PRN format for use with a SPREADSHEET; line segment width is output as an attribute.

\subsection{Model Base Management System}

The following modeling packages comprise the model base management system portion of SAMDSS:

MODSIM: River basin network simulation model developed at Colorado State University (Labadie, 1988)

MODFLOW: USGS Modular Three-Dimensional Finite-Difference Groundwater Flow Model (McDonald and Harbaugh, 1988); layers can be simulated as confined, unconfined, or a combination; flow associated with external stresses, such as wells, areal recharge, evaporation, drains, and streams can be simulated

- MODRSP: developed at Arizona State University; ia modification of the USGS MODFLOW finite difference model for calculate drawdown, velocity, storage losses, and capture response functions for multi-aquifer groundwater flow systems (Maddock and Lacher, 1991a)

- PTFLOW: USBR river water balance program that can be used to calculate reach gains and losses between stream gages given diversion and inflow data 


\section{CHAPTER 3}

\section{MODSIM RIVER BASIN NETWORK FLOW MODEL}

\subsection{Network Flow Approach to River Basin Modeling}

The simulation of large-scale, complex water resource systems requires efficient methodologies for analyzing system components in a fully integrated manner. The generalized river basin network model MODSIM employs a state-of-the-art network optimization algorithm for simultaneously assuring that water is allocated according to physical, hydrological, and institutional aspects of river basin management. The use of network flow optimization actually serves to enhance the ability to simulate complex river basin systems. Earlier versions of MODSIM have been successfully applied to a number of complex river basin systems, such as the Rio Grande River Basin (Graham, et al., 1986); the Poudre River Basin in Colorado (Labadie, et al., 1986a); the Upper Colorado River Basin (Law and Brown, 1989); and the Upper Snake River Basin (Frevert, et al., 1994). In all of these cases, some form of priority-based water allocation dominated management of the system.

MODSIM was originally an extension of the SIMYLD network simulation model developed by Texas Water Development Board (1972); hence giving the acronym MODified SIMyld (MODSIM) (Shafer, 1979). Since then, MODSIM has been extensively updated and extended far beyond the original structure of SIMYLD. SIMYLD and original versions of MODSIM employed the out-ofkilter algorithm (OKM) for solving the network flow optimization problem. The OKM is used in a number of other river basin network flow models, such as the Acres International Model (Bridgeman, et al, 1989) and the DWRSIM model employed by the California Department of Water Resources (Chung, et al, 1989).

Network flow models for river basin analysis have been criticized since it is assumed that precise objective functions must be defined for the optimization process. It is argued that it is difficult for water managers to define such functions in most cases, particularly if they require economic data. In fact, network flow optimization models may also be used for simulation purposes where only rankings or simple priority scales are provided for the optimization process. Detailed objective functions need not be defined, and the resulting simulation structure may be more efficient than standard approaches to constructing river basin simulation models. This allows analysis of large scale systems that would exceed the computational capabilities of other simulation approaches.

MODSIM currently offers a number of unique features for comprehensive river basin management and conjunctive use:

- can be used for long term planning (monthly), medium term management (weekly),and short term operations (daily) in river systems

- allows simulation of a wide variety of river basin configurations and operating conditions without requiring specification of complex IF-THEN rules governing system operation

- includes conjunctive use of surface water and groundwater and the modeling of stream aquifer interactions 

- capable of directly incorporating institutional and legal structures governing water allocation
- provides for separate analysis of direct flow or natural streamflow rights and seasonal storage rights, and includes provisions for exchanges, trades and plans for augmentation
- includes no a priori defined operating policies, but rather relies entirely on user input data describing system features and operational requirements, which are separated from the network modeling algorithmic structure
- capable of modeling complex looped and bifurcating water system features
- allows direct inclusion of flow constraints, including both lower bounds and time variable upper bounds
- calculates system losses as a function of averaged flows and storage, such as evaporation loss, channel loss, reservoir seepage and losses from water application includes hydrologic streamflow routing capabilities for daily simulation provides graphical plots of important model output variables reflecting system performance, as well as tabulated results showing storage levels, releases, inflows, energy generation, power capacity, system losses and spills, water deliveries, shortages, instream flow requirements, and flows in any reach of the system; extensive water right account information is also provided including storage right accounts under various fill priorities.
- utilizes a state-of-the-art network flow optimization algorithm based on Lagrangian relaxation (Bertsekas, 1991)
- allows simulation of synthetic or stochastically generated inflow/demand sequences for use in Monte Carlo analysis for developing flow-duration curves and exceedance probability estimates for key variables
- allows accurate calculation of hydropower generation capacity and energy production based on power plant efficiencies which can vary with flow, head, and load factor; calculates peak vs. nonpeak and firm vs. secondary energy production
- implemented on both UNLX-based Workstations operating under X-Window, as well as on microcomputers under MS Windows
- includes an interactive graphical user interface (GUT) for drawing and editing system features, as well as a spreadsheet-style data editing capability emulating an object- oriented data base management system
- includes mechanisms for directly linking MODSIM with existing data base management systems to provide access to timely data and forecast information for real-time river basin management

\subsection{Basic Assumptions}

The undertying principle in the operation of MODSIM is that most physical water resource systems can be simulated as capacitated flow networks. The term capacitated refers to specification of strict upper and lower bounds on all flows in the network. Components of the system are represented in the network as nodes, both storage (i.e., reservoirs, groundwater basins, and storage right accounts) and non-storage (i.e., river confluences, diversion points, and demand locations) and links or arcs (i.e., canals, pipelines, natural river reaches, and decreed water rights) connecting the nodes. 
In order to consider demands, inflows, and desired reservoir operating rules, several additional accounting nodes and linkages are created to insure the fully circulation of the network and guarantee satisfaction of flow mass balance throughout the entire system. A fully circulating network requires all nodes have both inflow and outflow links, although more than one link can connect any two nodes. It should be noted that MODSIM users are only responsible for defining the actual flow network. All accounting nodes and links are added automatically by the model.

A pure network optimization algorithm does not directly allow for system gains or losses as a function of flow or storage in the system. This is accounted for indirectly, however, by an iterative process which is described subsequently. Bertsekas and Tseng (1988) developed a network with gains minimum cost flow algorithm which is able to directly account for channel losses as a function of flow rate. Computational experience shows that computer processing time is about two to five times that of a pure network algorithm. Since return flows and stream depletions must still be computed by an iterative process on the network, it is considered more efficient to include channel loss, reservoir seepage, and infiltration losses in the iterative process and therefore be able to take advantage of the computational speed of the more efficient pure network algorithm.

There are a number of reasons why minimum cost network flow algorithms are particularly attractive for river basin modeling:

1. A network formulation of a river basin system provides a physical picture revealing the morphology of the system which is readily recognizable.

2. Network optimization techniques (particularly the Lagrangian relaxation algorithm employed in MODSIM) are specialized solution techniques which perform integer-based calculations on linear networks that are considerably more efficient than real number computations and matrix operations employed in standard linear programming codes based on extensions of the revised simplex method. Integer-based calculations are not a disadvantage since appropriate scaling of link flows can produce solutions for any desired order of accuracy.

3. Extremely large (in terms of network components) problems can be solved. Since network algorithms are highly efficient, it becomes feasible to perform several iterations so as to consider certain nonlinear or dynamic system features.

4. Changes in system components are easily accommodated by manipulation of the previously constructed network.

Important assumptions associated with MODSIM are listed as follows:

- All storage nodes and linkages must be bounded from below and above (i.e., minimum and maximum storage and flows must be given). The latter bounds are allowed to vary over time in the model.

- Each linkage must be unidirectional with respect to positive flow. Possible flow reversals can be modeled by assigning an additional reverse direction link between two nodes.

- All inflows, demands, system gains and losses must accumulate at nodes. Increasing the density of nodes in the network thereby increases simulation accuracy, but also increases computer time and data requirements.

- Import nodes can be designated for water entering the system from across system boundaries. 
- Each reservoir can be designated as a spill node for losses from the system proper. Spills from the system are the most expensive type of water transfer, such that the model always seeks to minimize unnecessary spill. Spills may be retained in the network by specification of an additional release link from a reservoir which can be labeled as a high cost link.

- Reservoir operating policies are provided by the user in the form of desired target end-of-period storage volumes for each reservoir. Maximum storage capacity can be designated as spill capacity or the bottom of the flood control pool in a reservoir.

\subsection{Network Flow Optimization Problem}

Although technically speaking, MODSIM is an optimization model, the attempt is to employ optimization methods as an efficient mechanism for performing simulation. The minimum cost network flow problem is solved iteratively in a sequential fashion over time, so it is not a fully dynamic optimization process. Within the confines of mass balance throughout the network, MODSIM sequentially solves the following linear optimization problem via an efficient minimum cost network flow optimization algorithm over each successive time period in the simulation:

$$
\text { minimize } \sum_{\ell \in A} c_{\ell} q_{\ell}
$$

subject to:

$$
\begin{gathered}
\sum_{j \in O_{i}} q_{j}-\sum_{k \in I_{i}} q_{k}=0 ; \text { for all } i \in N \\
l_{l} \leq q_{l} \leq u_{l} \text { for all } \ell \in A
\end{gathered}
$$

where $A$ is the set of all arcs or links in the network; $N$ is the set of all nodes; $O_{i}$ is the set of all links originating at node $i$ (i.e., outflow links); $I_{i}$ is the set of all links terminating at node $i$ (i.e., inflow links); $q$ is the integer valued flow rate in link $\ell ; c_{\ell}$ are the costs, weighting factors, or priorities per unit of flow rate in link $\ell ; l$, is the lower bound on flow in link $\ell$; and $u$, is the upper bound on flow in link $\ell$.

Equation 3.2 insures that total flow out of any node equals total flow into that node, and are referred to as node constraints. Equation 3.3 specifies finite lower and upper bounds on all arc or link flows, and are called arc constraints. The terms arc and link are used synonymously in this formulation. Notice also that this formulation allows several arcs to share the same node pair. All flows are assumed to be described in volume units per time interval selected for the simulation, and are assumed to be uniformly distributed over the time interval. Therefore, MODSIM is capable of modeling only average flow conditions rather than peak flow conditions over the specified time interval. The following sections describe how complex river basins can be simulated by appropriate definition of the variable bounds and costs associated with the above network flow optimization problem.

The data base for the network optimization problem is completely defined by the link parameters for each link $\ell:\left[l_{n} u_{n} c_{d}\right]$, as well as the sets $O_{i}, I_{i}, N$ and $A$. The link parameters are automatically defined by MODSIM, based on data provided by the user. 
An example fully circulating network is shown in Figure 3.1. Nodes 1, 2, and 3 are actual, physical system nodes. Node 1 is a reservoir, node 3 is a demand diversion, and node 2 is an intermediate node. Nodes and links which appear as dashed lines represent special accounting nodes and links. That is, they are not part of the physical system, but are included to properly account for mass bal ance throughout the entire system. Notice that there are always six accounting nodes, but the number of accounting links is directly related to the size of the physical system network.

The accounting nodes are designated as follows:

I: accounting inflow node: for collecting total system inflows and initial reservoir storage to be distributed to appropriate locations by accounting links

D: accounting demand node: accumulates all flows used to meet demands on the system

S: accounting storage node: accumulates all end-of-period or carryover storage from reservoirs

SP: accounting spill node: accumulates the total volume of spill from storage nodes in the system due to insufficient reservoir capacity; spills are assumed to be uncontrollable and unusable downstream

M: accounting mass balance node: maintains overall mass balance for the network

GW: accounting groundwater node: maintains interactions between groundwater and surface water, including return flows and stream depletions due to pumping; individual groundwater storage nodes may be created by the user.

MODS I M

employs an efficient primal-dual network optimizationalgorithm incorporating a dual coordinate ascent procedure based on Lagrangian relaxation, as developed by Bertsekas (1991). Comparative studies have shown Lagrangian relaxation to be far superior to the out-of-kilter (OKM) algorithm (Clausen, 1968), as well as other primalbased network algorithms (Bertsekas and Tseng, 1988). A detailed discussion of the Lagrangian

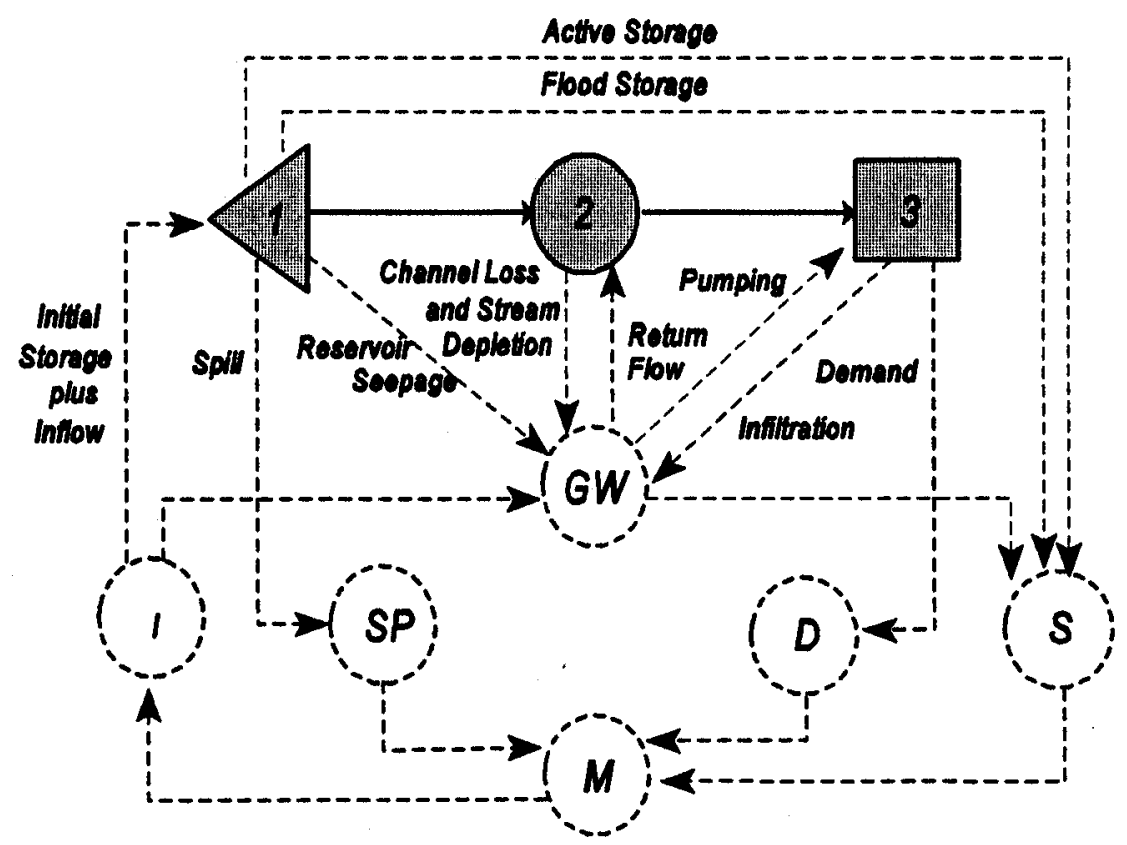

Figure 3.1 Network Structure for MODSIM with Accounting Nodes and Links

relaxation algorithm can be found in Appendix A of this Report. 
Most of the applications of network algorithms in river basin management have been applied in a sequential static mode. That is, anticipation of future conditions is not directly incorporated into current decisions. The network optimization is applied to the current period only. End-of-period storage from these calculations then provide the starting storage levels for the next period, and so on. This approach is advantageous in that there is no presumption of knowing with certainty what future inflows to the system will be. However, there are often seasonal water supply forecasts available from spring snow pack data and other information. A procedure is described subsequently in which these forecasts may be input into MODSIM, and reservoir operating targets adjusted according to this forecast information.

\subsection{Unregulated Inflows and Basin Import}

MODSIM does not incorporate a watershed runoff model, so all system inflows must be precalculated by the user and input to MODSIM. Unregulated inflows may be based on historical data, future forecasts, drought scenarios, or synthetic generation of streamflows. Any real node in the system can be an inflow node. They are comnected by accounting links which are directed from the accounting inflow node 1 to each point of inflow. Any node can be designated as an inflow node, including a reservoir. In Figure 3.2, real nodes 1, 2, 3, and 4 are automatically connected by MODSIM to accounting node $I$, which is automatically given a unique integer designation in the model (dashed lines represent accounting nodes or links). The inflows to nodes 3 and 4 are defined by setting the lower and upper bounds on these accounting links equal to the inflow $I_{j}$, thereby guaranteeing that exactly those specified inflows are input. A cost of zero is assigned to these links since these are natural inflows. For accounting links from the accounting inflow node $I$ to reservoirs, the links now include any carryover storage $S_{0}$ from the previous period, in addition to the unregulated inflow. That is, the available water for the current period in reservoir $j$ is $I_{j}+S_{j}$ for nodes $j=1,2$.

MODSIM allows consideration of up to 10 possible import nodes, representing nodes receiving water from transbasin diversion projects. In contrast with unregulated inflows, imported water is entered as annual, quarterly, or weekly total flows, depending on whether a monthly, weekly

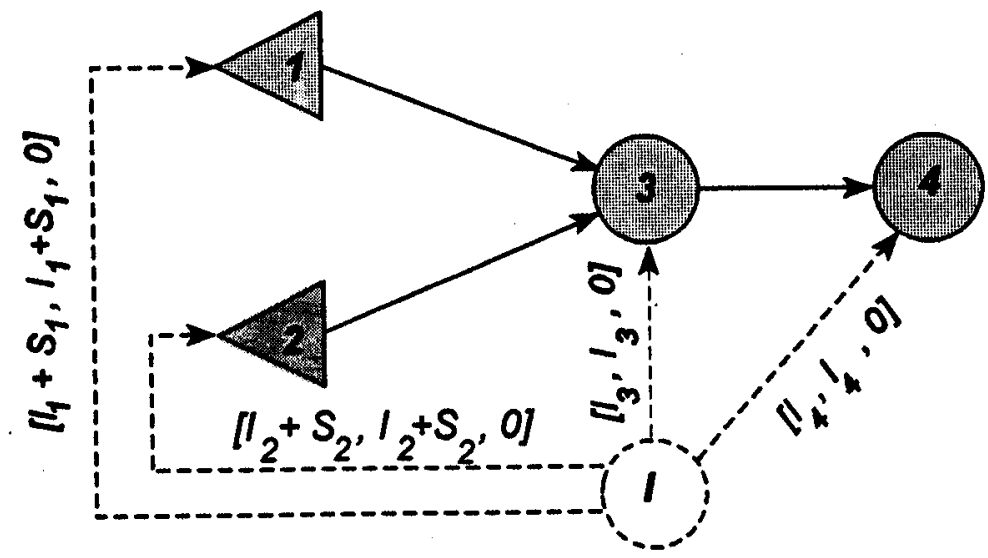

Figure 3.2. Accounting Unregulated Inflow Links Plus Initial Storage 
or daily time interval, respectively, is employed. Fractional coefficients are entered for each time period to reflect temporal distribution of imported water. These flows are simply added to the link bounds for accounting unregulated inflow links where basin import is occurring.

\subsection{Reservoir System Operations}

In addition to inflow links, the two reservoirs in Figure 3.2 are connected by two additional accounting links for specifying total carryover storage to the next time period. These links originate at each reservoir and accumulate at an accounting carryover storage node $\mathbf{S}$, as shown in Figure 3.3. Link [1] is called the accounting active storage link, and link [2] is the accounting flood storage link. The lower bounds on the active storage links are the minimum reservoir storage or dead storage $S_{i m i n}$ $(i=1,2)$. The upper bounds are user specified end-of-period target storages $T_{i}$ which represent ideal guidecurve levels for active storage for the current period. However, if the lower bound on the accounting inflow arc to the reservoir in question is less than the lower bound on the active storage arc, the lower bound on the active storage arc is replaced by the lower bound on the corresponding inflow arc. This condition is necessary to insure network feasibility and, subsequently, that mass balance is maintained.

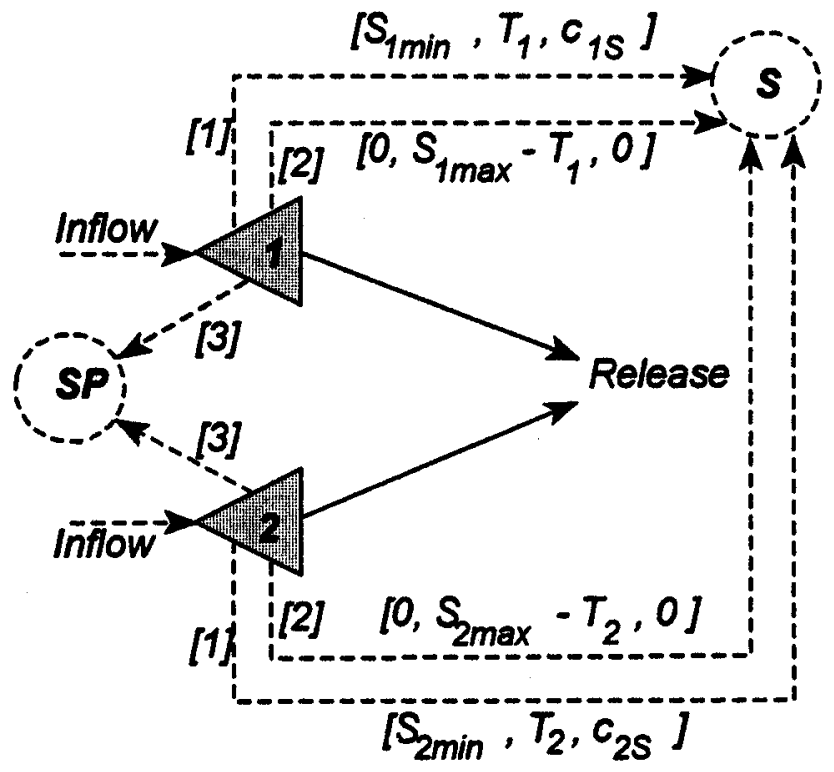

Figure 3.3. Accounting Active and Flood Storage Links

If a large inflow occurs, storage may exceed the target active storage level. Any excess storage is carried in link [2]. Its lower bound is zero (indicating no excess storage above target level $\left.T_{i}\right)$ and $\left(S_{\text {min }}-T_{i}\right)$ is its upper limit, which represents the maximum excess space above the target level. Note that an infeasibility can occur if the inflow to a reservoir, including carryover storage, is less than the dead storage level $S_{\text {iman. }}$. If this happens, $S_{\text {imen }}$ is automatically reset by MODSIM for that period to correspond to the actual inflow plus carryover storage. 
In some cases, it may be desirable to use operating rules which specify release guidelines rather than storage guide curves for each time period. This is easily accomplished by specifying an

$$
c_{i s}=-\left(1000-10 \cdot O P R P_{i}\right)
$$

additional flow-through demand node downstream of the reservoir with the desired release levels designated as flow-through demands. These releases can be dependent on storage levels by using the hydrologic state option for the flow-through demands. Flow-through demands are described in more detail in a subsequent section.

If inflows are large such that spillage must occur, the spills are carried in accounting link [3] and collected at the accounting artificial spill node SP. Its lower limit is zero and its upper limit is set at a very large default value. Again, spills are assumed to be lost from the water supply system. If this is not desirable, an additional spill link may be specified downstream of the reservoir and given a high cost by the user. This link can carry any additional spill flow above the downstream release or channel capacity.

The costs $c_{i s}$ on the accounting active storage links are computed as follows to reflect storage right priorities. For reservoir $i$, the user selects priority $O P R P_{i}$ as an integer number between -999 and +999 . Note that a lower number represents a higher priority; that is, a reservoir given a priority of -999 would receive the highest rank in the basin for conserving storage. MODSIM computes the actual a cost $c_{i s}$ associated with the accounting link for carryover storage as:

Notice that $c_{i s}$ is a negative number, which in a cost minimization objective, actually represents a benefit associated with carryover storage. It is actually possible to supply $O P R P_{i}$ values up to +999 , but it can be seen that values above +100 translate into actual positive costs on the accounting carryover storage links. The cost associated with flow in the accounting flood storage link is always set at zero. The costs on the accounting spill links are given the highest positive number of any link.

\subsection{Hydrologic States and Inflow Forecasts}

MODSIM computes the system hydrologic state by considering current reservoir storage levels and inflows to a certain user specified subset of reservoirs in the system that best represent hydrologic conditions in the basin. Associated with each of these states (classified as average, dry, and wet) is a corresponding set of operating rules with ranking priorities. These three hydrologic states are computed at the beginning of each period for the user selected reservoir subset through the following analysis:

$$
\begin{gathered}
R_{t}=\sum_{i \in H}\left[S_{i t}+I_{i t}\right] \\
W=\sum_{i \in H} S_{i \max }
\end{gathered}
$$

where $H$ is the set of node numbers of reservoirs in a specified subset defining the hydrologic state; $t$ is the current period of operation; $I_{i t}$ is the specified or forecasted unregulated inflow to reservoir $i$ for period $t ; S_{i t}$ is the beginning storage in reservoir $i$, period $t$, and $S_{\text {inax }}$ is the storage capacity for reservoir $i$. 
The user also specifies upper and lower bounds on the average state as fractions of the total subsystem storage capacity:

$$
\left.\begin{array}{l}
L B_{t}=x_{1 t} W \\
U B_{t}=x_{2 t} W
\end{array}\right\}
$$

where $L E_{t}$ is the lower bound on the average state for period $t ; U B$ is the upper bound on the average state for period $t, x_{l t}$ is the fraction defining the lower limit on average state for period $t$; and $x_{2 t}$ is the fraction defining the upper limit on average state for period $t$

The hydrologic states for period $t$ are defined as:

$$
\begin{array}{ll}
\text { Dry: } & R_{t}<L B_{t} \\
\text { Average: } & L B_{t} \leq R_{t} \leq U B_{t} \\
\text { Wet: } & R_{t}>U B_{t}
\end{array}
$$

Reservoir targets $T_{i t}$ are assumed to be constant with these hydrologic states, as shown in Figure 3.4. With the above method of calculating target operating rules, target storage levels can only vary within a computation cycle (e.g., one year for monthly analysis; one quarter for weekly analysis; or one week for daily analysis), although separate target storage levels can be specified for each hydrologic state. An option has been included in MODSIM, however, whereby the user can input separate target storage $T_{i t}$ levels for each reservoir $i$ and for each period $t$ throughout the entire simulation. This option is particularly valuable during model calibration and allows input of actual measured storage levels in the system over the historical period in order to compare computed downstream flows with gaged flows.

It is possible to utilize the hydrologic state option in MODSIM for incorporation of inflow forecasts on specification of reservoir target operating rules. This is accomplished by adding a dummy reservoir with zero capacity to the network, but not directly connecting it to the network proper. It is

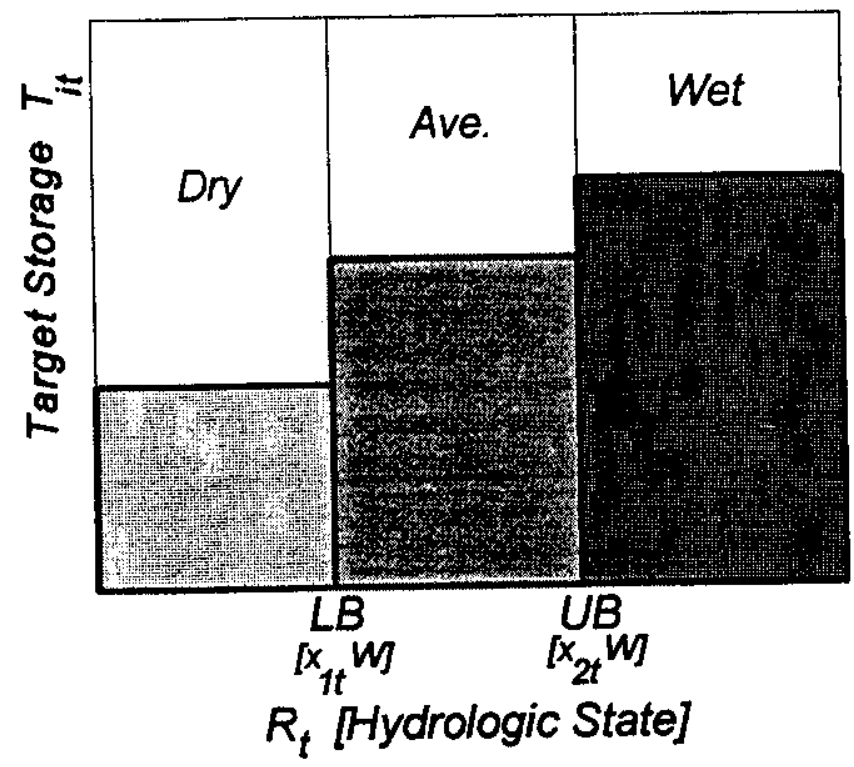

Figure 3.4 Definition of Hydrologic States 
of course indirectly connected via the accounting links and nodes. This reservoir may be included in the hydrologic state subsystem of reservoirs. Input files may be prepared representing seasonal forecast information that would be available at each subsequent time period of operation. MODSIM then utilizes this information to define the hydrologic state of the system, and therefore modify user selected reservoir operating targets accordingly.

MODSIM allows only three differing priorities for any node (storage and/or demand) corresponding to wet, average, or dry conditions as calculated by the above procedure. For analysis of drought contingencies, the user can consider these states as driest, drier, and average, if desired. An additional option has been included which enables the user to input a separate priority for any node for each cycle of the analysis. This expanded capability means that instead of a maximum of three priorities associated with a wet, average, or dry state, a varying priority can be input for each year, quarter, or week. A quarter is assumed to be 12 weeks long in the current version of MODSIM.

\subsection{Evaporation Loss}

Evaporation loss is calculated in MODSIM as a function of average surface area in the reservoir over the current period. Since average surface area in a reservoir is normally unknown until calculations are completed for the current period, an iterative process is usually required for accurate calculation of evaporation loss. A procedure is adopted in MODSIM, however, which does not required successive iterations to estimate evaporation loss. For each reservoir i, compute:

$$
\begin{aligned}
& E_{\text {imax }}=e_{i} \cdot\left[A_{i}\left(S_{i}\right)+A_{i}\left(S_{i \max )}\right] / 2\right. \\
& E_{\text {imin }}=e_{i} \cdot\left[A_{i}\left(S_{i}\right)+A_{i}\left(S_{i \min )}\right] / 2\right. \\
& E_{\text {itarget }}=e_{i} \cdot\left[A_{i}\left(S_{i}\right)+A_{i}\left(T_{i}\right)\right] / 2
\end{aligned}
$$

where $e_{i}$ is net evaporation rate (i.e., evaporation rate less rainfall rate) for reservoir $\mathrm{i}$ (e.g., feet per month) for the current period; $A_{i}\left(S_{i}\right)$ is the (interpolated) area-capacity table for reservoir $i, S_{i}$ is storage at the beginning of the current period, $S_{\text {imax }}$ is the maximum capacity, $S_{i \min }$ is dead storage, and $T_{i}$ is user supplied target level.

The storage link parameters are then adjusted as follows:

for active storage links:

$$
\left[0,\left(S_{\text {imax }}-T_{i}\right)+\left(E_{\text {imax }}-E_{\text {itarget }}\right), 0\right]
$$

for flood storage links:

$$
\left[\left(S_{\text {imin }}+E_{\text {imin }}\right),\left(T_{i}+E_{\text {itarget }}\right), c_{i S}\right]
$$

In this formulation, link upper bounds are adjusted to carry sufficient flow to include evaporation loss, and the lower bound on the active storage link is increased so that when evaporation is removed, it will not be violated. After calculations for the current period are completed, flows in the carryover storage links (i.e., the total end-of-period storage, plus evaporation loss) are adjusted such that evaporation loss is removed so as to provide carryover storage for the next period: 
1. An initial guess $E V P_{i}$ of evaporation loss is first made. The total carryover storage, including evaporation loss, is:

$$
q_{\text {itotal }}=\left(q_{i S(\text { active })}-q_{i S(\text { flood })}\right)
$$

2.. The current estimate of actual end-of-period storage is

$$
S_{\text {ifinal }}=q_{\text {itotal }}-E V P_{i}
$$

3. Compute the average surface area $A_{\text {iave }}$ over the period for each reservoir $i$ :

$$
A_{\text {iave }}=0.5 \cdot\left[A_{i}\left(S_{i}\right)+A_{i}\left(S_{i f i n a l}\right)\right]
$$

and update the evaporation estimate $E V P_{i}$ as

$$
E V P_{i}=e_{i} \cdot A_{\text {iave }}
$$

4. Return to Step 2 and repeat until successive evaporation estimates converge within a predefined error tolerance.

Evaporation loss is not directly calculated for other water bodies such as streams in MODSIM. For streams, however, channel loss coefficients may be appropriately increased to account evaporation losses, or properly adjusted to consider a net loss term which includes rainfall. Since channel loss coefficients are allowed to vary seasonally (e.g., monthly), adjustments for evaporation and rainfall can also be made seasonally.

\subsection{Hydropower Calculations}

MODSIM accepts a variable number of elevation-area-capacity data points for any reservoir. Elevations need only be input if hydropower is generated at a storage node. Setting them to zero indicates that there is no hydropower at that node. Tailwater effects on net head are not directly considered, but can be indirectly incorporated through adjustments to the turbine efficiency tables or addition of block loading estimates to the power plant elevation levels.

MODSIM computes both power capacity and energy production in a hydroelectric system. The basic power equation used in MODSIM is:

$$
P=K \cdot Q \cdot H \cdot e(Q, H)
$$

where $P$ is mean power output in kilowatts; $Q$ is reservoir release (volume/period); $H$ is mean effective head (i.e., (mean gross head on turbines) - (mean tailwater elevation) - (head loss)); $e$ is overall plant efficiency, which can be entered as a table of values as a function of discrete release rates $Q$ and heads $H$ (note: these tables can include consideration of hydraulic losses and tailwater affects during high flow periods); and $K$ is a constant based on selected units, which equals $1.403 \mathrm{x}$ $10^{-1}$ for $Q$ in AF/month and head in $\mathrm{ft} ; 6.1006 \times 10^{-3}$ for $Q$ in AF/wk; 3.729 for $Q$ in $10^{6} \mathrm{~m}^{3} / \mathrm{mo}$ and head in $\mathrm{m} ; 16.214$ for $Q$ in $10^{6} \mathrm{~m}^{3} / \mathrm{wk}$; etc.

P'umped storage projects can be indirectly considered by simply increasing the operating hours per period, or load factor. All hydropower plants are assumed to be downstream of storage projects. 
The user can enter the average number of on-peak hours in each selected period in order to calculate energy production during the period. If on-peak hours are entered which are less than total hours in the period, it can be assumed that there is downstream reregulation capability. In this case, it is assumed that water is released through the turbines during on-peak hours only, as reflected in a higher rate of release during the shorter period, but the same total volume of release during the period. Otherwise, the model assumes that releases can be made during off-peak periods.

\subsection{Consumptive Demands and Instream Flow Requirements}

Consider the example network shown in Figure 3.5, where the two demand nodes 3 and 4 are isolated. Though not considered in this example, nodes 1 and 2 could be specified as demand nodes, since a storage node can also be a demand node, as well as an inflow node. The model automatically creates accounting links which originate at each demand node and accumulate at a single accounting demand node $\mathbf{D}$. The link parameters are shown, with demands $D_{3}$ and $D_{4}$ specified for each node.

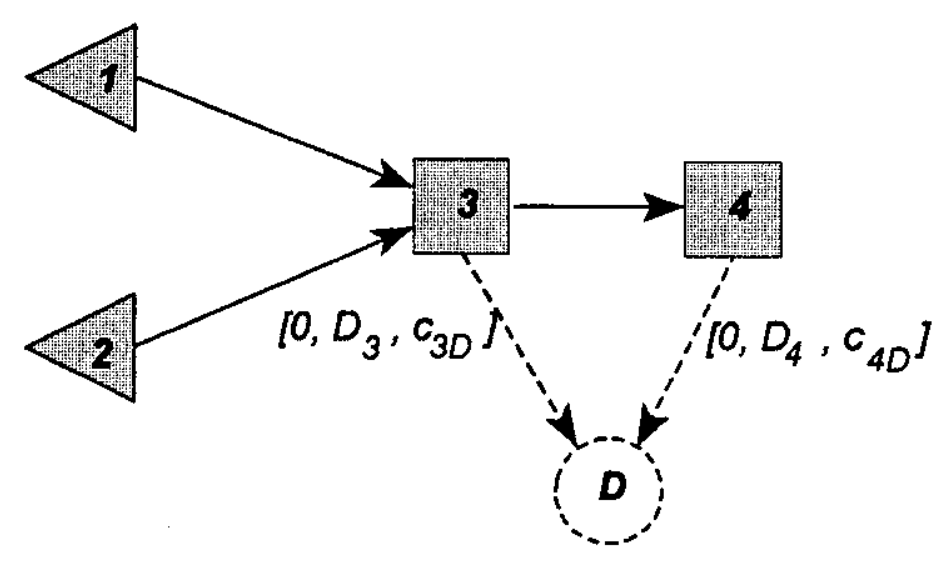

Figure 3.5. Accounting Demand Links and Node

Demands may be defined as:

- historical diversions

- decreed water right amounts

- predicted agricultural demands based on consumptive use calculations (performed outside the model)

- projected municipal and industrial demands:

The link costs on the accounting demand links are calculated as follows:

$$
c_{i D}=-\left(1000-10 \cdot D E M R_{i}\right)
$$

As with reservoir priorities $O P R R_{i}$, the user must select priorities $D E M R_{i}$ for demands between -999 and +999 . These priorities must be selected in relation to reservoir storage priorities. 
If shortages must occur, then demands with lower priority (i.e., junior water rights) are denied flow first. For inefficient water application, MODSIM is capable of calculating return flows via groundwater or surface water. Calculation of return flows is described in more detail in a subsequent section.

Figure 3.6 illustrates a situation where a particular demand may own several direct diversion rights on natural flow in the river. In this case, the user may specify several links as shown, with the capacity of each link corresponding to the decreed amount for each water right. Time variable decrees may be specified through use of variable capacity links. The user must directly assign the (negative) link costs $c_{i}, c_{j}$, and $c_{k}$ to these links that will provide the proper ranking for the water rights in relation to other specifications of $D E M R_{i}$ and $O P R R_{i}$ in the basin.

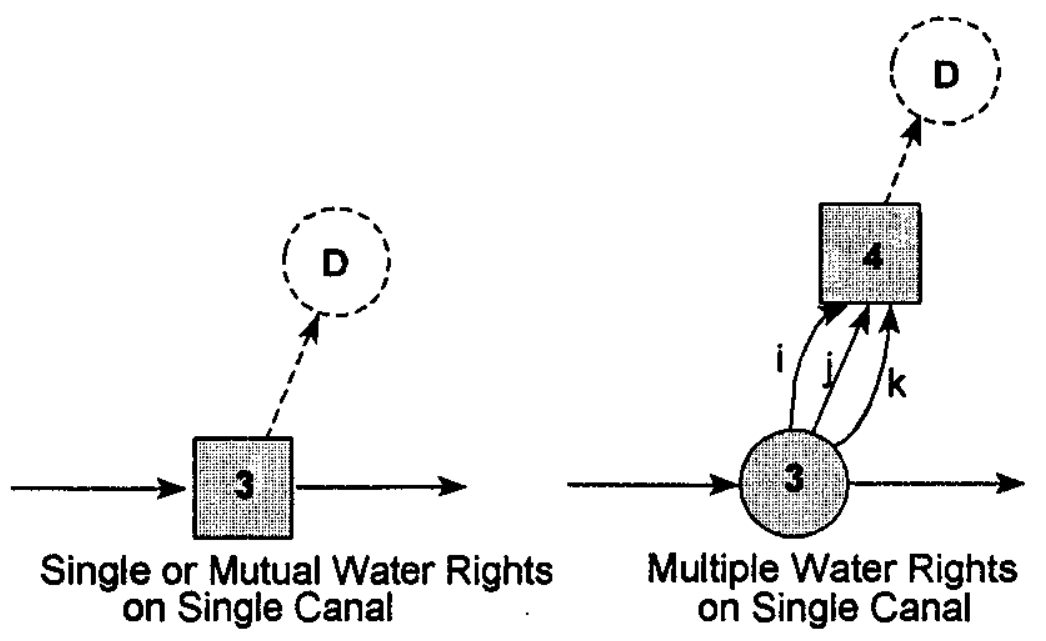

Figure 3.6. Use of Several Links for Multiple Water Rights

It should be noted that in this case, the user should assign a priority to the demand at node 4 equal to +100 , since this corresponds to assigning a zero cost to the accounting demand link connecting node 4 with the accounting demand node $\mathbf{D}$. Otherwise, a double counting of demand priority will occur, since it is assumed that the direct (negative) link costs assigned to links $i, j$, and $k$ correctly specify the water right priorities. The demand assigned to node 4 may correspond to consumptive use or other estimates of actual demand. In this way, the maximum possible total delivery will be dictated by the lower of the sum of the decreed water rights and the demand assigned to node 4 . The demand amount specified may be further limited by the capacity of the diversion structure or structures delivering the flow.

As illustrated in Figure 3.7, MODSIM also provides for demands for water which are not terminal; i.e., instream flow demands which flow through the demand node and remain in the network for possible downstream diversion. In effect, this would correspond to demands with $100 \%$ return flow which is unlagged. This includes demands for instream flow uses for navigation, water pollution control, fish and wildlife maintenance and recreation. Flow-through demands are also useful for augmentation plans, exchanges between basin water users, and development of reservoir release operating rules. 


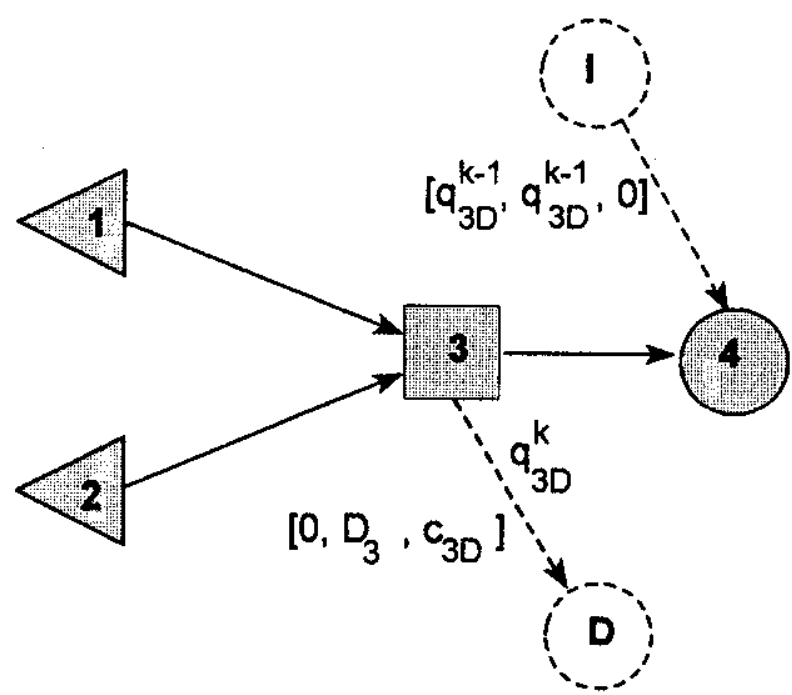

Figure 3.7. Illustration of Flow-Through Demands

In effect, the flow-through demand operates by iteratively removing flow as a demand from the network, but then replacing the flow at one or more specified (usually the next downstream) node(s), with any fractional division of flow to downstream nodes specified by the user. For purposes of instream flow requirements, usually only one downstream accrual node is specified. It should be emphasized that, in effect, it is as if the flow never actually left link [3,4]. Reference to link $[i, j]$ indicates a link originating at node $i$ and terminating at node $j$. This notation is only possible if there is one unique link connecting node $j$ from node $i$. The flow diverted into link $[3, D]$ is replaced by adding it as an inflow to the designated accrual node 4 via the accounting arc connected to the accounting initial storage and inflow node $\mathbf{I}$.

The superscript $\mathrm{k}$ in Figure 3.7 represent an iteration counter, since flow-through demand returns must be calculated iteratively. In the first iteration, the demand is treated as a consumptive demand and flow is delivered according to priority through solution of the network algorithm. At the next iteration, the flow $q_{3 D}$ actually observed to have been delivered in link $[3, D]$ is then added to the accounting inflow link returning flow to the accrual node 4 , and the network is solved once again. This solution process continues until successive estimates of returns to node 4 agree. Note that the flow in link $[3,4]$ does not actually represent the total instream flow. Flows leaving node 4 would better represent the actual flows in link [3,4], assuming there are no other demands or inflows at node 4 . The output report for demand node 3 will properly consider the actual flow in link $[3,4]$ as related to the instream flow requirement.

An option is available in MODSIM for specifying a bypass credit link as a means of improving convergence of the flow-through demand iterative process. In Figure 3.7, the bypass credit link would be specified as link $[3,4]$. Figure 3.8 illustrates the iterative process where, for iteration $k=1$, flow $q_{34}$ is initialized to demand $D_{3}$; i.e., the demand at node 3 is temporarily turned off and the network is solved. At the next iteration, the actual flow observed in link [3,4] from the current network solution is then subtracted from $D_{3}$ and the net flow becomes the new upper bound for link $[3, D]$. This represents the additional flow required to satisfy the flow-through demand. This additional flow, however, will be supplied only if there is sufficient flow available and the priority is 


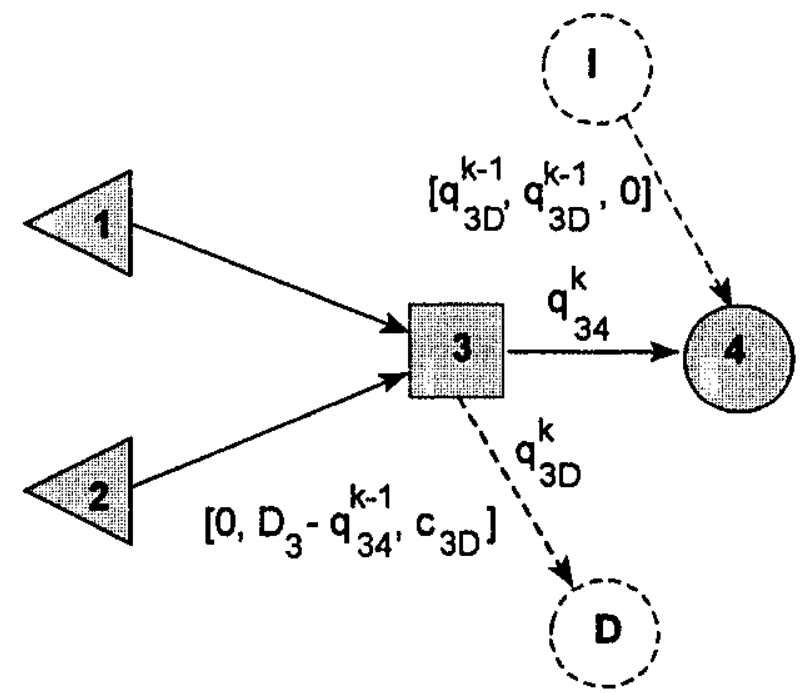

Figure 3.8. Flow-Through Demands with Bypass Credit Link

senior enough to meet the instream flow demand. With use of the bypass credit link, if there is already sufficient flow in the link to satisfy the instream flow demand, then no iterations are required and the demand is considered to be satisfied.

The use of a flow-through demand for minimum streamflow requirements has two primary advantages: (i) the flow-through demand can be assigned a priority similar to any other demand in the basin, and (ii) simply setting a fixed lower bound on the link corresponding to a minimum streamflow requirement can result in the network algorithm converging to an infeasible solution if there is insufficient flow available to meet the demand. The flow-through demand can receive a shortage similar to any other demand, depending on the relative ranking of the water right priority. An additional advantage of the flow-through demand is that it may be used to divide flow according a predetermined fractional distribution.

The terminal downstream node in a river basin system should always be specified as a demand node. If there are senior downstream water rights, then two terminal demand nodes are necessary. One specifies the senior downstream water right and its associated priority. The other is set to a very high value, but given a priority value $D E M R$ of 100 , which corresponds to a zero cost. This demand receives all excess flows that cannot be captured or used upstream. Note that if the priority of the terminal demand is set to 99 , then reservoirs will be drained to their target storage levels, since a zero value is always assigned to storage in a reservoir above the target level. The user can therefore specify whether flood pool waters should always be released, or if they should be stored temporarily.

\subsection{Water Exchanges and Credits}

The ability for water users to formulate exchange agreements and plans for augmentation have become an important part of water administration in many highly appropriated river basins. For example, a water user may own storage rights in a reservoir from which it is physically impossible for the owner to directly receive releases. In this case, the owner may enter into an exchange agreement 
whereby direct river flow is diverted out of priority by the storage right owner, with an equal amount of flow released from the reservoir to satisfy senior water right holders that would be otherwise injured. MODSIM provides a variation on the flow-through demand concept to allows users to define exchange demands and exchange links.

As illustrated in Figure 3.9, an exchange demand is defined based on flow occurring in a another link in the basin. The demand in this case is conditioned solely on the amount of flow in the link being watched by the demand. A credit demand is established based on flow in the watch link. Again, an iterative structure is required where, initially, the demand is set to zero. Upon solution of the network flow algorithm, whatever flow was observed in the watch link is then assigned as a demand in the exchange demand, and the network solution is repeated. Since it is important that the flow in the watch link agrees with the flow diverted to the demand, iterations proceed until the flows are equalized.

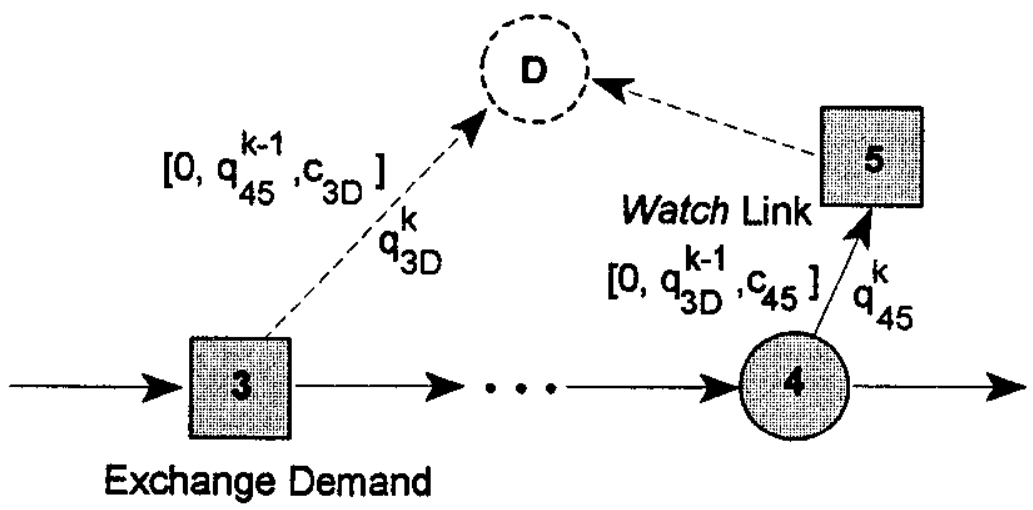

Figure 3.9. Illustration of Exchange Demand and Watch Link

An exchange link operates in much the same way as an exchange demand, except that the upper bound on the exchange link is set based on the flow observed in the watch link. Again, (negative) costs assigned to the exchange link must insure that senior water right holders are not injured as a result of the exchange. A similar iterative process occurs with the exchange link as with the exchange demand, until flows in the watch link agree with flows diverted in the exchange link.

\subsection{Link Capacities and Losses}

All physical links in the network must be bounded from above and below. MODSIM includes the capability of allowing the user to input a constant bound for each link, or varying daily, weekly or monthly maximum flow limits for certain specified variable capacity links. The latter are useful for considering seasonal influences in canal capacities and maintenance schedules. In addition, to variable capacity links, MODSIM allows specification of seasonal capacity links, whereby a total seasonal maximum flow through a particular link may be specified. Once the seasonal maximum is exceeded, the link is effectively turned off, and no further flows can be made through the current season. For monthly time steps, for example, a season would be considered as one year in length. The initial month 
or time period (i.e., time $t=I$ ) results in seasonal flow capacities being reinitialized to the specified maximum capacity as input by the user.

Minimum flow capacities may also be assigned to any link in the network, but care must be taken to avoid infeasible solutions. Improperty assigned minimum and maximum flow capacities on links are the major reasons for network solutions terminating in infeasibility errors.

For certain problems where it would be desirable to include pumping costs, MODSIM provides the option of user input of costs for any linkage in the network. Negative costs can be entered to represent benefits, such as from low head hydropower production. Costs (positive or negative) can be assigned to any link by the user to discourage or encourage, respectively, flow in that particular link according to predefined operational criteria. It must be remembered, however, water rights are included, then any link costs introduced by the user must set at small relative values that will not disrupt the distribution of flows according to the water right priorities.

MODSIM includes the capability of removing channel losses directly. A loss coefficient $c l_{i j}$ for any link $[i, j]$ can be defined in the input data. This coefficient represents the fraction of flow at the head of the link that is lost during transition through the link. An iterative procedure is employed in MODSIM for calculating channel losses, as illustrated in Figure 3.10. First, network flows are initially solved via the Lagrangian relaxation algorithm with no losses assumed. The losses in each link are computed by multiplying the loss coefficient by the calculated flows from the initial solution. This loss is removed during the next iteration by an accounting link to the accounting groundwater GW node with both lower and upper bounds equal to the amount of loss. The network flow algorithm is then solved again. If current flows in the reach agree with those found in the previous iteration, then convergence has occurred. Otherwise, the procedure is repeated with channel losses defined on the bounds of the accounting link updated to reflect current flows in the real link This process continues until successive link loss estimates agree within a specified error tolerance. Currently, the error tolerance is based on aggregate losses over the entire network, rather than each individual loss term. Channel losses may also reappear as lagged return flows to any user specified downstream nodes.

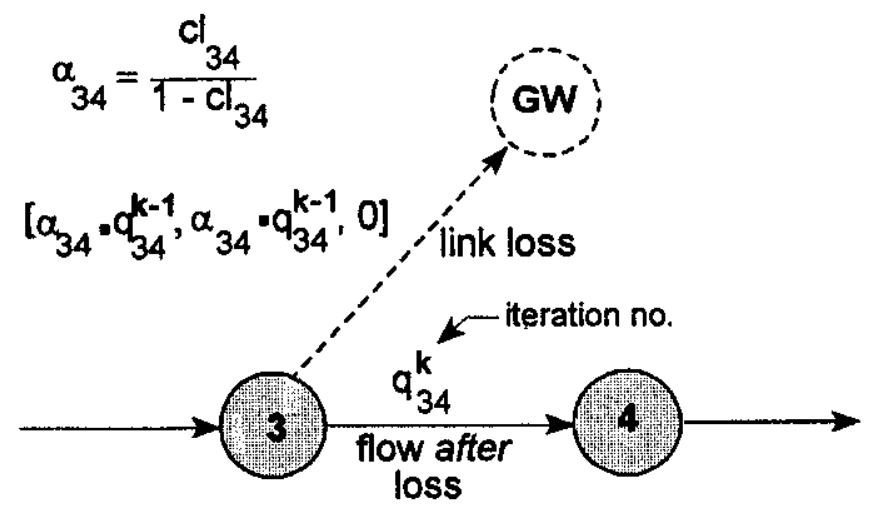

Figure 3.10. Iterative Procedure for Link Loss Calculations 


\subsection{Streamflow Routing}

For simulation of daily stream flow, it may be necessary to consider channel routing. This is accomplished in MODSIM by designating a network link as a routing link. Inflow to this link is distributed over time in accordance with routing coefficients calculated by MODSIM using the Muskingum formula. Alternatively, the user may directly input any desired routing coefficients and lagging factors. The MODSIM routing module assumes that outflow from a routing reach is a linear function of inflow to the reach, where the basic routing equation is:

$$
O_{n}=C_{1} I_{n}+C_{2} I_{n-1}+C_{3} I_{n-2}+\cdots
$$

where $O_{n}$ is the ordinate of the outflow hydrograph at time $n ; h$ is the ordinate of the inflow hydrograph at time $n$; and $C_{1}, C_{2} \ldots$ are routing coefficients.

The coefficients $C_{l}, C_{2}, \ldots$ are determined internally by MODSIM using the following Muskingum routing equations:

$$
\begin{aligned}
& C_{1}=(\Delta t-2 X X) /(2 K(1-X)+\Delta t) \\
& C C=((2 K(1-X)+\Delta t)-2 \Delta t) /(2 K(1-X)+\Delta t) \\
& C_{2}=C_{1} \cdot C C+(\Delta t+2 K X) /(2 K(1-X)+\Delta t) \\
& C_{i}=C_{i-1} \cdot C C \quad \text { for } i>2
\end{aligned}
$$

where $\Delta t$ is the routing time element; $K$ is the Muskingum routing parameter having units of time; and $X$ is the Muskingum dimensionless routing parameter between 0 and 0.5 .

It is important to note that the downstream node for a routing reach should not be assigned as a demand node because it will interfere with the routing calculation. To avoid negative coefficients the Muskingum $K$ should be greater than or equal to $\Delta t /[2 \cdot(1-X)]$ and less than or equal to $\Delta t / 2 X$. The user must input flood wave travel time $K$, routing time $\Delta t$, and the Muskingum routing parameter $X$. The actual Muskingum coefficients are calculated by MODSIM and stored in an ASCII output file for review by the user.

\subsection{Reservoir Storage Rights and Accounts}

For reservoirs with storage right accounts, it is necessary to treat them as offstream reservoirs, even if they are actually on-stream reservoirs. As shown in Figure 3.11, the reservoir is represented as off-stream storage, with an accrual link and a release link returning to the river. Each storage account in the reservoir must be treated as a separate account reservoir. The account reservoir should not be confused with the terms accounting nodes and links, since the former is a real node which is supplied by the user. Notice that flow must be allowed to bypass the reservoir, which, for an onstream reservoir, represents flow passing through the reservoir and being called to meet senior demands downstream. In effect, nodes 2,3 , and 4 all represent a single reservoir containing two storage accounts. 


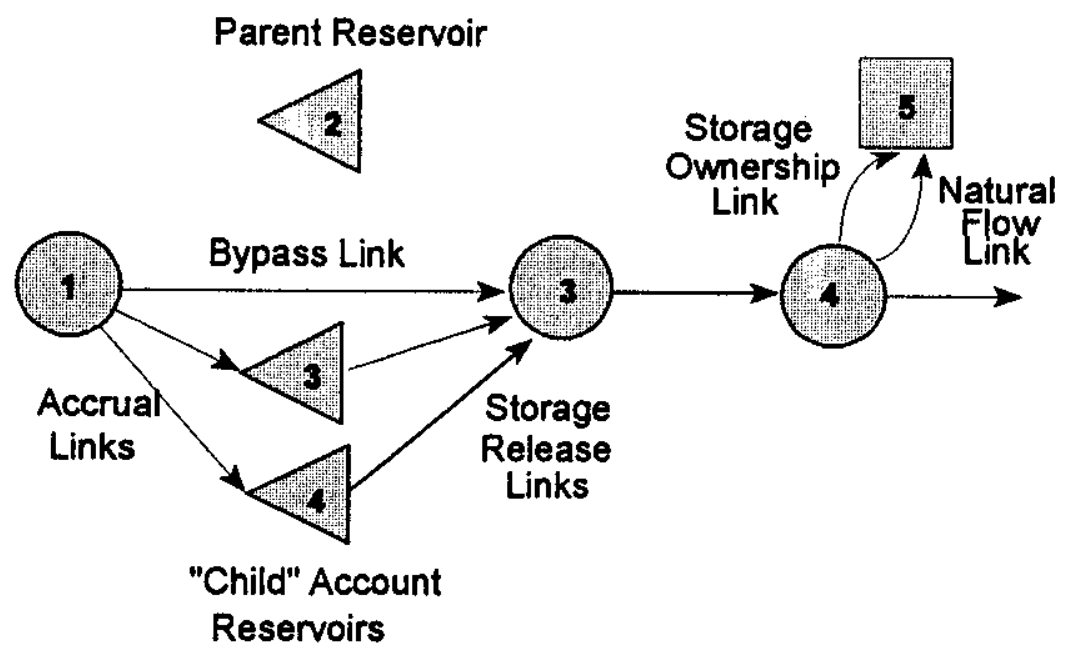

Figure 3.11. Storage Accounts and Storage Ownership

The accrual links can be assigned negative costs as related to a fill decree priorities. They can also be specified as a variable capacity links if the there are time limitations on the fill period. Zero capacities can be set for those periods where the reservoir is not allowed to fill. In addition, the accrual link can be specified as a seasonal capacity link, with the seasonal capacity corresponding to the amount of the fill decree.

Inflows and outflows based on water right allocation can be directed to and from a water right account reservoir. Because account storage volume generally depends on reservoir evaporation, this account reservoir can be associated with a parent reservoir that will adjust water right account storage volumes for total reservoir evaporation. Evaporation data are read in for the parent reservoir, as well as the area-capacity-elevation tables. Total volume is determined from the volumes of the water right reservoirs attached to the parent reservoir. It is not necessary to provide formal links connecting the parent reservoir to the system network or to its associated water right reservoirs. Inflow and outflow should not be directed to the parent reservoir. All network linkages should be directed to the child or water right account reservoirs. For the latter, evaporation data and area-capacity tables need not be defined. Total evaporation loss calculated for the parent reservoir is allocated to each storage account according to the fraction of contents in each account in relation to total contents in the reservoir at the beginning of the period.

It is not unusual for reservoir decreed water rights to be specified as a total annual volume. A provision has been added to MODSIM that allows a storage account to annually impound only the decreed amount each year. The model maintains a running total of the stored amounts in each water year and allows storage to occur when the rumning total is less than the decreed storage capacity. This is done by assigning a maximum accumulated amount equal to the storage decree to the reservoir inflow accrual link. Once this maximum value is reached, the maximum link capacity is set to zero and no flow is allowed through the link. The accumulated flow volume through the link is set back 
to zero, or the carryover storage in that account from the previous season, at the start of each accrual season. The desired starting month for the accrual season is specified by the user.

Although accrual to the storage accounts via the accrual links in Figure 3.11 are governed by the normal, priority based allocation process of MODSIM, once water is available in a storage account, it must be released to the owner as needed to meet demands. This implies a process which is not governed by a priority-based network flow allocation process. The storage ownership link shown in Figure 3.11 is related to one of the accrual links to the child account reservoirs. This guarantees that the owner of the storage right will receive water from the correct account.

In order to allow for allocation of releases from storage accounts to the owners of those accounts, MODSIM includes an additional iterative step which is performed after allocation of all natural flows or direct diversions according to water right priority. The storage allocation step follows the natural flow allocation step in MODSIM. During the natural flow allocation step, releases are not allowed from the storage accounts, and diversions to the storage ownership links are also temporarily turned off. The storage allocation step is only performed in MODSIM if storage ownerships exist in the network.

The storage allocation step proceeds as follows:

1. After all natural flows and direct diversions have been allocated in the natural flow allocation step, demands with storage ownerships are evaluated as to any shortages which have been incurred. It is important to note that demands with storage ownerships must be introduced as off-line demand nodes (as in Figure 3.11) in the network structure, with separate links to the demand designated as either storage ownership links or direct diversion right links. Demands may of course have several storage ownerships as well as several natural flow rights.

2. MODSIM evaluates the volume available in the storage account, and releases via the outflow links an amount which is the lower of the volume available versus the shortage incurred by the storage account owner. This is accomplished by executing the network flow algorithm with storage account outflow link bounds fixed to assure release of the correct amount of water.

3. During the storage allocation step, all direct flow diversions allocated during the natural flow allocation step are frozen to these values by assigning the lower bounds on these natural flow links equal to the amount of flow allocated. MODSIM automatically assigns much larger negative costs to the storage ownership links than the natural flow links during the storage allocation step, which assures that storage owners receive the releases from their accounts that they are entitled to.

4. MODSIM maintains a separate accounting of each storage ownership which keeps track of accruals to the account, releases, and other debits such as allocation of evaporation loss. Again, once an account has received its designated seasonal accrual, then no additional accrual is allowed to take place until the next accrual season.

In some cases, owners of storage accounts may not be able to physically receive reservoir releases from their accounts. In this case, MODSIM allows exchange mechanisms to take place whereby releases are made to downstream senior water right holders, and in return, the storage right owner is allowed to divert water out of priority. Since all natural flow links are frozen to allocations obtained during the natural flow allocation step, there is no danger of senior water right holders being injured by this procedure. However, it is possible, in certain situations, that although a storage owner 
has a certain amount of water available for release for exchange purpose, there may be insufficient flow available for upstream diversion to the storage right owner. In this case, MODSIM monitors how much flow the storage owner was actually able to divert, and then reduces the amount available to be released from the storage account during the next cycle of iterations. 


\section{CHAPTER 4}

\section{STREAM-AQUIFER MODELING COMPONENTS}

\subsection{Introduction}

The stream-aquifer module within MODSIM allows consideration of reservoir seepage, irrigation infiltration, pumping, channel losses, return flows, river depletion due to pumping, and aquifer storage. Other features modeled include: overbank storage, channel routing, and divided flows. Stream-aquifer return/depletion flows can be simulated using response coefficients calculated using the one dimensional equations developed by Maasland (1959), Glover (1960), and McWhorter (1972). Alternatively, groundwater response coefficients estimated from other methods such as the stream depletion factor (SDF) method (Jenkins, 1968), the three-dimensional finite difference groundwater model MODRSP/MODFLOW (Maddock and Lacher, 1991a), or the discrete kernel generator GENSAM (Morel-Seytoux and Restrepo, 1987), can be read into MODSIM from external data files.

\subsection{Groundwater Flow Equations}

The mathematical flow equation for general two dimensional flow in an unconfined groundwater aquifer can be derived from Darcy's Law and the principle of mass continuity. The resultant equation is a nonlinear, second-order pjartial differential equation known as the Boussinesq equation (Willis and Yeh, 1987):

$$
\frac{\partial}{\partial x}\left(K_{x} b \frac{\partial h}{\partial x}\right)+\frac{\partial}{\partial y}\left(K_{y} b \frac{\partial h}{\partial y}\right)+Q=S \frac{\partial h}{\partial t}
$$

where $K_{\triangleright} K_{y}$ is hydraulic conductivity along the $x, y$ axes $\left(\mathrm{Lt}^{-1}\right) ; h$ is potentiometric head $(\mathrm{L}) ; Q$ is net groundwater withdrawal per unit area $\left(\mathrm{Lt}^{-1}\right) ; S$ is storage coefficient $\left(\mathrm{L}^{-1}\right)$; and $t$ is time $(\mathrm{t})$.

Where variation in saturated thickness is small and the specific yield/storage coefficient is assumed constant, the governing groundwater equation can be written as a linear form of the Boussinesq equation:

$$
T\left(\frac{\partial^{2} h}{\partial x^{2}}+\frac{\partial^{2} h}{\partial y^{2}}\right)+Q=S \frac{\partial h}{\partial t}
$$

where $T$ is transmissivity $\left(\mathrm{L}^{2} \mathrm{t}^{-1}\right)=K b, K$ is hydraulic conductivity ( $\left.\mathrm{L}^{\mathrm{t}}\right)$, and $b$ is saturated thickness (L).

Maddock (1974) showed that if the ratio of drawdown to saturated thickness is less than 20 percent, then for a nonlinear free-surface model (i.e., the Boussinesq equation), the linear contribution is between 75 to 100 percent of drawdown due to pumping. Accuracy of the linear model increases as the drawdown to saturated thickness ratio decreases. If the ratios are large, the Dupuit assumptions and the nonlinear flow equations are invalid.

Since the governing groundwater equation is linear and time invariant, linear system theory can be applied via the principle of superposition (Bear, 1979). This principle states that the presence 
of one boundary condition does not effect the response produced by the presence of other boundary conditions and that there are no interactions among the responses produced by the various boundary conditions. It is then possible to analyze the effect of individual events and then linearly combine the results.

Glover and Balmer (1954) and Glover (1968) presented an analytical procedure for determining depletion of flow in a nearby stream caused by pumping a well. Depletion flows were calculated using the distance of the well from the river, the properties of the aquifer (i.e., storage coefficient and transmissivity), time of pumping and time from start of pumping. The following assumptions apply:

1. aquifer is unconfined, homogeneous, isotropic, and of infinite extent

2. river is straight, fully penetrates the aquifer and is a constant head source.

3. water table is initially horizontal and water is released instantaneously from storage.

4. well fully penetrates the aquifer.

5. pumping is steady and drawdown is small compared to aquifer thickness.

6. residual effects of previous pumping are negligible.

According to Glover (1968), the ratio of the rate of stream depletion to the rate of well discharge is:

$$
\frac{Q_{s}}{Q_{w}}=1-e r f\left(\frac{a}{\sqrt{4 t T / S}}\right)
$$

where $Q_{s}$ is rate of stream depletion; $Q_{w}$ is rate of well discharge; $a$ is perpendicular distance from well; $t$ is pumping time; $T$ is transmissivity; $S$ is specific yield; and $\operatorname{erf}(z)$ is the error function.

Glover (1977) extended the analytical approach to include bank storage, line source, return flows from irrigation, and intermittent well operation. Willis and Yeh (1987) presented a list of fifteen analytical response equations. Warner et al (1989) reviewed various analytical solutions to the artificial recharge problem, including Glover (1960), Hantush (1967), Rao and Sarma (1981), and Hunt (1971). The Hantush and Glover solutions were shown to be identical and were highly recommended for rectangular basins. It was also suggested that solutions for circular basins may be replaced by solutions for square basins with equivalent area. Madsen (1988) concluded that analytical models are not ideal for verifying the influence of existing wells on stream depletion, but are suitable as a tool for estimating impacts of new wells on streamflow depletion. Madsen (1988) also showed that analytical methods often overestimate stream depletion by failing to account for resistance near the stream.

The major disadvantage of the analytical method is that nonpoint sources of flow are often approximated as point sources (Wamer et al., 1986). Other limitations of analytical methods such as Glover's method include (Morel-Seytoux and Zhang, 1990):

\footnotetext{
- method of averaging transmissivities over a heterogeneous aquifer is arbitrary - procedure for calculating depletion from a certain reach (not the entire river) is inconvenient, involving numerical integration, or inaccurate because of steady state assumptions

- In most cases, the river is not straight
} 
Qazi and Danielson (1974) used a computer program based on the Glover equations to evaluate augmentation plans for wells, recharge lines, and pit operations in an alluvial aquifer. Contributory effects of only those pumped wells or recharge sources requiring evaluation are determined, which are independent of other interactions already in process such as: effects of precipitation, surface water application, evapotranspiration, or other wells, reservoirs, and ditches. Labadie, et al. (1983) used analytical solutions embedded in a conjunctive use model to consider groundwater pumping (Glover, 1977), reservoir seepage (Glover, 1977), canal seepage (McWhorter, 1972), irrigation recharge (Maasland, 1959) and bank storage (Glover, 1977). Hantush and Marino (1989) developed a chance constrained stream-aquifer management model based on the Hantush (1959) analytical solution. Male and Mueller (1992) used the equations of Jenkins (1968) to develop a groundwater management model for prescribing groundwater use permits in Massachusetts.

\subsection{Discrete Kernel/Response Functions}

Most groundwater management scenarios require information only on select events in an aquifer. Extraneous information on drawdown and flow rates at noncritical locations is not only unnecessary but computationally prohibitive. Applying linear system theory to the groundwater equation allows the use of Green's function to solve the resulting non-homogeneous boundary value problem (Maddock, 1972). Response of the groundwater system due to external excitations such as pumping, recharge, or infiltration at any point in space and time can be expressed as a set of unit coefficients independent of the magnitude of the excitation. Integrated with a finite difference groundwater model, resultant flows can be superimposed to determine net effects at a single location due to a series of excitations or at a series of locations due to a single excitation.

It is convenient to express the Boussinesq equation in terms of water table drawdown:

$$
S \frac{\partial s}{\partial t}-\frac{\partial}{\partial x}\left(T \frac{\partial s}{\partial x}\right)-\frac{\partial}{\partial y}\left(T \frac{\partial s}{\partial y}\right)=Q_{p}
$$

where $T$ aquifer transmissivity; $s$ is water table drawdown; $Q_{p}$ is groundwater withdrawal rate at well $p ; S$ is storage coefficient; $t$ is time $(t)$; and $x, y$ are horizontal coordinates.

This equation can be solved using Green's function (Maddock, 1972):

$$
s_{w}(t)=\int_{0}^{t} k_{w p}(t-\tau) Q_{p}(\tau)
$$

where $s_{w}(t)$ is drawdown at aquifer point $w$ due to a single well pumping $Q_{p}$ at point $p$; and $k_{w p}$ is the kemel function (Green's function) of aquifer drawdown at $w$ due to a unit impulse excitation at $p$. The discrete form of the convolution equation for a heterogeneous aquifer with finite boundaries is (Maddock, 1972; Morel-Seytoux and Daly, 1975):

$$
s_{w}(n)=\sum_{p=1}^{P} \sum_{v=1}^{n} \delta_{w p}(n-v+1) Q_{p}(v)
$$

where $s_{w}(n)$ is drawdown from an initially horizontal (or initially steady) water table at any aquifer point $w$ at the end of the $n^{\text {th }}$ period; $Q_{p}(v)$ is the mean pumping rate from well $p$ during the period $v$ (pumped volume for the period); $P$ is the total number of excitation points or wells; $\delta_{w p}$ is the 
discrete kernel coefficient; and $\delta_{\text {wp }}(n)$ represents the drawdown at the end of period $n$ if a unit volume of water was withdrawn during the first week from well $p$ and well pumping terminated indefinitely thereafter.

Maddock (1974), Morel-Seytoux and Daly (1975), and Illangasekare and Morel-Seytoux (1982) extended the Green's function or discrete kernel approach to the case of stream aquifer interactions by treating the stream as an imposed boundary condition:

$$
s_{w}(n)=\sum_{p=1}^{P} \sum_{v=1}^{n} \delta_{w p}(n-v+1) Q_{p}(v)+\sum_{r=1}^{R} \sum_{v=1}^{n} \delta_{w r}(n-v+1) Q_{r}(v)
$$

where $Q_{r}(v)$ is the mean pumping rate from the $r^{\text {th }}$ reach of the river during the $v^{\text {th }}$ period; and $R$ is the number of reaches. It can be shown that the flow between a stream and an aquifer is proportional to a difference in the drawdowns to the stream surface level and to the aquifer water table. The coefficient of proportionality or streambed conductance depends on the streambed characteristics and shape of the stream cross section (Bouwer, 1978; McDonald and Harbaugh, 1988):

$$
Q_{r}=C_{r}\left(r_{r}-s_{r}\right)
$$

where $C_{r}$ is streambed conductance; $r_{r}$ is stream surface drawdown; and $s_{r}$ is aquifer water table drawdown.

Through substitution and use of linear system theory, Morel-Seytoux and Daly (1975) and Maddock and Lacher (1991a) show that assuming: (i) a head gradient between the river and the aquifer; (ii) the head gradient is in the vertical direction; (iii) water flows only through the streambed; (iv) the streambed has vertical conductivity and no storage; (v) the river stage remains unchanged by any flow between the river and the aquifer; (iv) the flow between the river and aquifer is linear; and (v) the stream water level does not fall below the bottom of the streambed, then for a discrete number of river reaches and pulse pumping:

$$
Q_{r}(n)=\sum_{p=1}^{P} \sum_{v=1}^{n} \delta_{r p}^{n}(v) Q_{p}(v)
$$

where $Q_{r}(n)$ is return volume to reach $r$ during the $n_{\text {th }}$ period; $Q_{p}(v)$ is volume pumped at well $p$ during the $v^{\text {th }}$ period; $P$ is total number of pumping wells; and $\delta_{p m m}(v)$ is the stream capture response function and represents the quantity of flow captured through the $r^{\text {th }}$ river reach in the $n^{\text {th }}$ stress period due to unit pumping from the $p^{\text {th }}$ well during the $v^{\text {th }}$ stress period when linearity is maintained.

Maddock (1972) first introduced the concept of a response function for a groundwater system, with drawdown in response to pumping stress modeled by a two-dimensional linear partial differential equation. This allowed an explicit coupling of a groundwater simulation model with a quadratic programming management model to optimize an economic objective of minimizing pumping costs subject to satisfying specified demands. Maddock (1974) used Green's function to extend this approach to the case of stream-aquifer interactions.

Again, based on linear system theory and the Green's function, Morel-Seytoux and Daly (1975) developed a finite difference model to generate any aquifer response as an explicit function of pumping rates, which they referred to as a discrete kernel generator. The discrete kernel method has been utilized extensively as a tool for solving complex groundwater management problems (Morel- 
Seytoux, et al., Illangasekare, 1987; Illangasekare and Morel-Seytoux, 1982; Illangasekare and Brannon, 1987; and Illangasekare and Morel-Seytoux, 1986).

\subsection{Parallel Drain Analogy for Stream-Aquifer Systems}

The interaction of a water table aquifer receiving recharge from irrigation and precipitation, and an interconnected stream, can be modeled utilizing the method developed by Maasland (1959). This method was developed for a parallel drain system and can be applied to a stream-aquifer system as well. The idealized parallel drain system is shown in Figure 4.1.

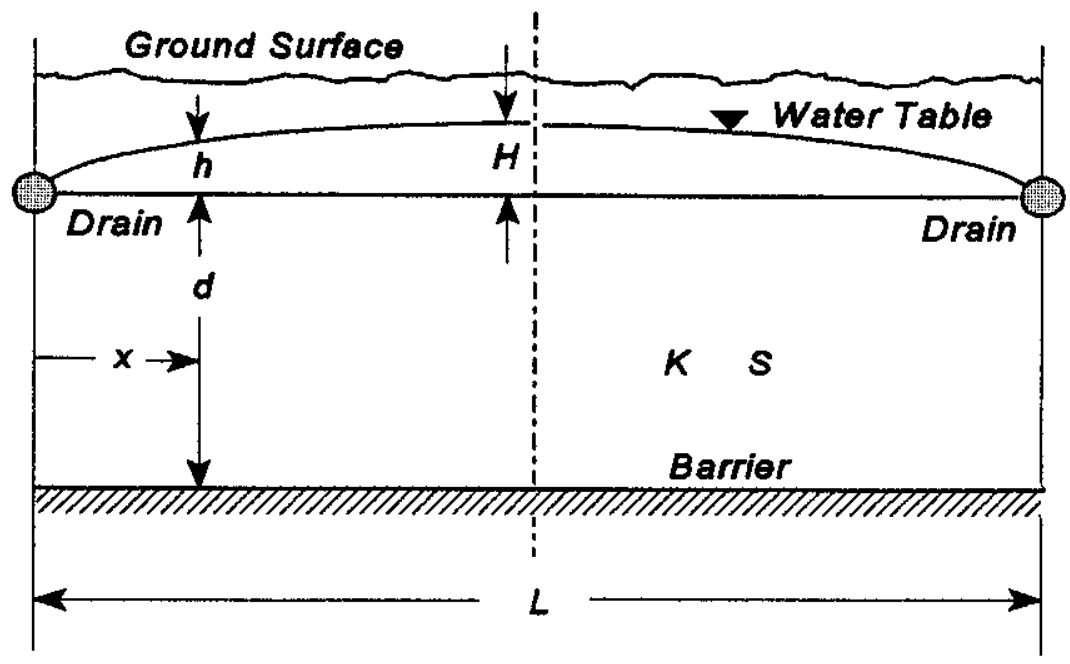

Figure 4.1. Parallel Drain Analogy for Stream-Aquifer Systems

The nonlinear partial differential equation for one-dimensional groundwater flow is

$$
K \frac{\partial}{\partial x}(d+h) \frac{\partial h}{\partial x}=S \frac{\partial h}{\partial t}
$$

where $K$ is permeability of the aquifer; $d$ is original saturated thickness; $S$ is specific yield; $h$ is height of the water table measured from the assumed original stable water table level; $x$ is distance measured along the path of flow; and $t$ is time.

By assuming $h$ is small compared to $d$, the linearized form of equation 4.10 is:

$$
\alpha \frac{\partial^{2} h}{\partial x^{2}}=\frac{\partial h}{\partial t}
$$

where $\alpha=T / S ; T$ is transmissivity, which is equal to $K \cdot d$; and the boundary conditions are:

$h=0$ when $x=0$ for $t>0$

$h=0$ when $x=L$ for $t>0$

$h=H$ when $t=0$ for $0<x<L$ 
Maasland (1959) obtained the solution as

$$
h=\frac{4 H}{\pi} \sum_{n=1,3,5 \ldots}^{\infty} \frac{1}{n} \exp \left(\frac{-n^{2} \pi^{2} \alpha t}{L^{2}}\right) \sin \left(\frac{n \pi x}{L}\right)
$$

where $H$ is initial uniform height of recharge water and $L$ is spacing of the parallel drains.

The volume of water remaining to be drained is

$$
V_{d}=S \int_{0}^{L} h d x
$$

and the fraction remaining to be drained is

$$
F=\frac{V_{d}}{V}
$$

where initial drainable volume is

$$
V=S \cdot H \cdot L
$$

Therefore

$$
F=\frac{0}{S \int_{0}^{L} h d x}
$$

Substitution of $h$ from equation 4.12 and integration results in:

$$
F=\frac{8}{\pi^{2}} \sum_{n=1,3,5 \ldots}^{\infty} \frac{1}{n^{2}} \exp \left(-n^{2} \pi^{2} \frac{\alpha t}{L^{2}}\right)
$$

This represents the fraction of the total initially drainable volume in the aquifer at the end of time $t$ that is available for flow to the drains. For any time $t$ from the beginning of recharge, $F$ can be predetermined. The difference of successive $F$ values over two adjacent time periods represents the flow fraction to the drains during that time interval.

\subsection{Return Flow Calculations}

Consider the idealized stream-aquifer system as shown in Figure 4.2. The river is assumed to be located at the center of the valley. The solution described above can be applied directly with $L$ equal to the valley width. The analogy is applicable since the middle section of the parallel drains is a no-flow boundary and is analogous to either the left boundary or the right boundary of the streamaquifer system. If the parallel drain system is divided in half at the no flow boundary and rearranged to bring the drains into coincidence, the direct analogy with the stream-aquifer system is evident. The drains are replaced by the river and the flow to the drains represents return flow to the river. 


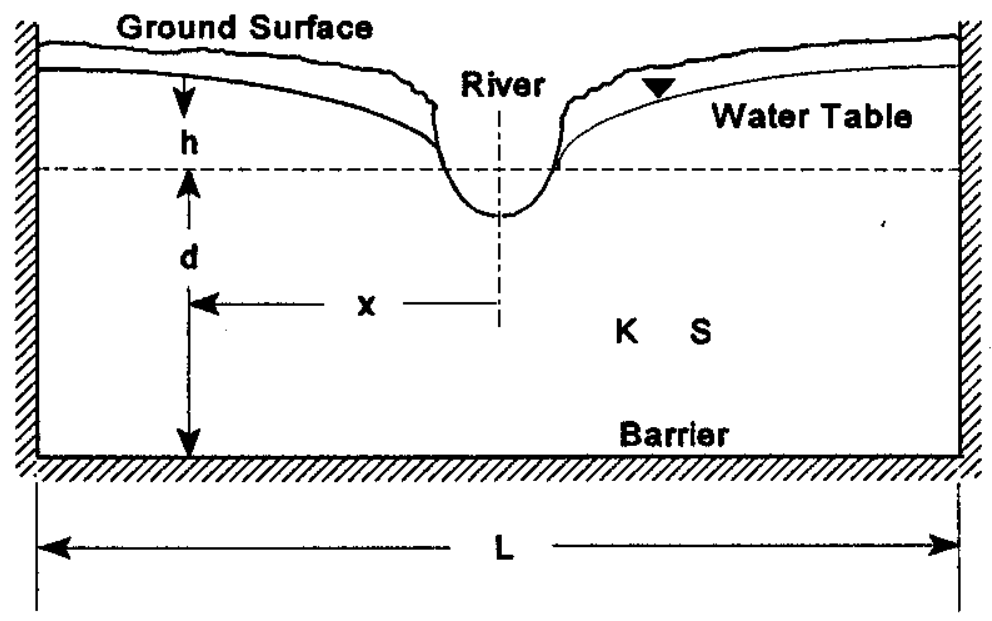

Figure 4.2. Idealization of Stream-Aquifer System

(Glover, 1977)

When the river is not located at the center of the valley, the above solution (equation 4.17) is still applicable with $L$ equal to twice the width $W$ of either side of the valley (i.e., $L^{2}=4 W^{2}$ ). Fraction $F$ can be determined for each side of the valley and return flows computed separately.

Let $N$ be the total number of time intervals of length $\Delta t$ and $I_{k}$ the recharge rate during the $k$-th time interval, where $k<N$, as shown in Figure 4.3.

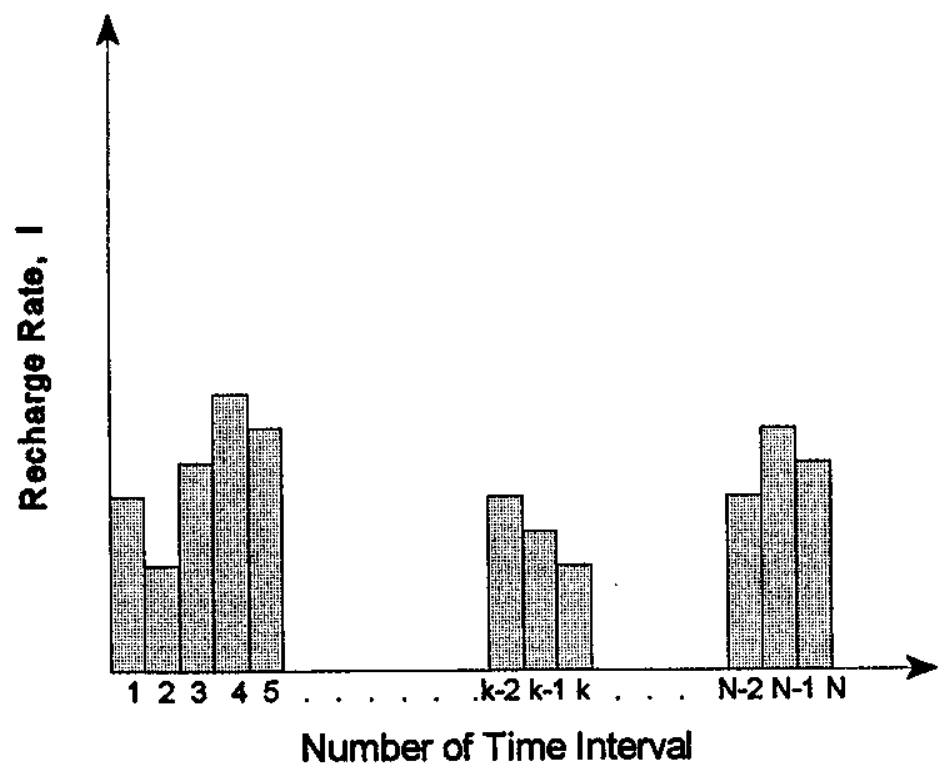

Figure 4.3. Series of Recharge Events 
The fraction of retum flow to the river during time interval $k$ is

$$
\begin{aligned}
F_{k-1}-F_{k} & =\frac{8}{\pi^{2}}\left[\sum_{n=1,3,5 \ldots}^{\infty} \frac{1}{n^{2}} \exp \left(-n^{2} \pi^{2} \frac{\alpha(k-1) \Delta t}{L^{2}}\right)\right. \\
& \left.-\sum_{n=1,3,5 \ldots}^{\infty} \frac{1}{n^{2}} \exp \left(-n^{2} \pi^{2} \frac{\alpha k \Delta t}{L^{2}}\right)\right]
\end{aligned}
$$

Define

$$
\delta_{k}=F_{k-1}-F_{k}
$$

where $\delta_{k}$ is a unit response or discrete kernelfor a recharge rate $I$ of unity. Therefore, for demand node $i$ and any current time period considered, the total return flow $I R F_{i k}$ from previous and current time periods due to groundwater recharge is

$$
I R F_{i k}=\sum_{\tau=1}^{k} I_{i \tau} \cdot \delta_{i, k-\tau+1} ; \quad \delta_{i, k-\tau+1}=0 \text { for } k-\tau+1>N
$$

where response $\delta_{i, k-\tau+1}$ is the discrete kernel coefficient defined for node $i$, period $k-\tau+1$.

In MODSIM, upper bounds on return flow links (Figure 3.1) are adjusted iteratively. The iteration procedure is as follows:

1. In the first iteration, all upper bounds are set equal to return flows computed from previous development activities, which can be read in as input data. The return flow from current activities are yet unknown. The total return flow from all links is computed.

2. MODSM is now nun for the current period using these bounds. Retum flows from all sources are recomputed using available link flows obtained from this solution. The total return flow is computed and compared to the previous estimate. If the difference of the total return flow is within specified tolerance limits, the solution is assumed to have been found; otherwise step two is repeated until convergence is achieved.

\subsection{Stream Depletion from Pumping}

The same approach used for calculating return flows is also applied to calculation of stream depletion due to pumping $P S D_{i k}$, where

$$
P S D_{i k}=\sum_{\tau=1}^{k} P_{i \tau} \cdot \alpha_{i, k-\tau+1} ; \quad \alpha_{i, k-\tau+1}=0 \text { for } k-\tau+1>N
$$

In the case of groundwater withdrawal $P_{i r}$, the same principles described above is applicable to determining response coefficent kemels $\alpha_{i, k-\tau+1}$. Here, it is river depletion that is considered rather than return flows to the river. Since the computation is sequentially carried out period by period in MODSIM, the current period stream-aquifer interactions are contingent upon stresses during previous periods. Therefore, it is recommended to run MODSIM for an initial $N$ periods for start-up or 


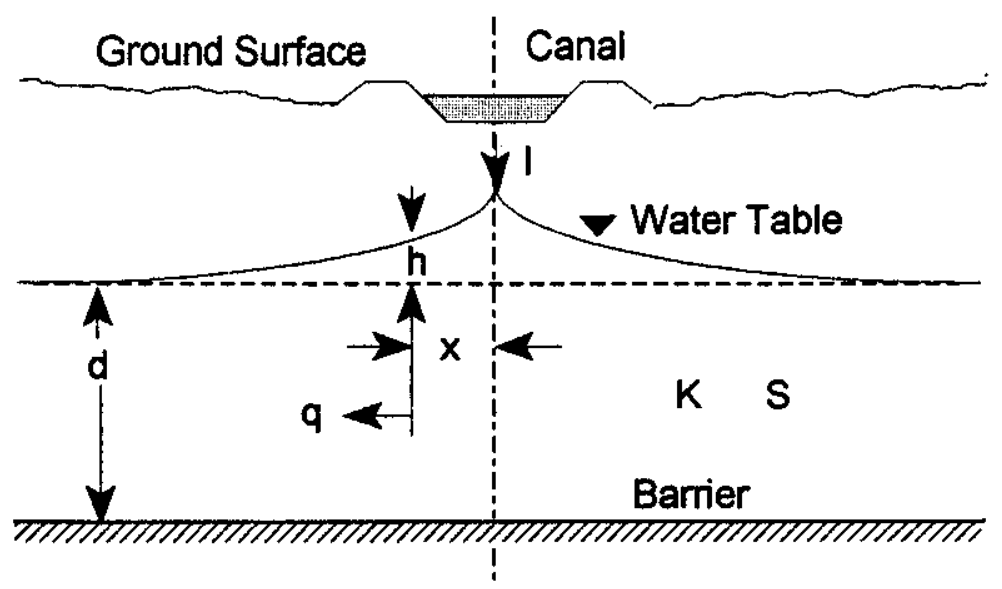

Figure 4.3. Ilustration of Line Source for Canal Seepage

initialization purposes, such that after $N$ periods, the model output can be trusted to properly account for past history. Specification of $N$ is left up to the user.

\subsection{Canal Seepage}

Seepage from a canal or a stream is assumed to correspond to a line source of recharge water. For a one-dimensional line source in an infinite aquifer, as shown in Figure 4.3, the governing flow equation is (McWhorter, 1972)

$$
\alpha \frac{\partial^{2} q}{\partial x^{2}}=\frac{\partial q}{\partial t}
$$

where $x$ is the Cartesian coordinate in the horizontal plane and $q$ is the flow rate or Darcy velocity, calculated as:

$$
q=-K \frac{\partial h}{\partial x}
$$

The solution is (McWhorter, 1972):

$$
q=\frac{I}{2} \operatorname{erfc}\left(\frac{x}{\sqrt{4 \alpha t}}\right)
$$

where $I$ is the one dimensional magnitude of the source in units of length per unit time, with $\operatorname{erfc}(z)$ representing the complementary error function:

$$
\operatorname{erfc}(z)=\frac{2}{\sqrt{\pi}} \int_{z}^{\infty} e^{-u^{2}} d u
$$

assuming the following boundary and initial conditions: 


$$
\begin{gathered}
q=\frac{I}{2} \text { at } x=0 \\
q=0 \text { as } x-\rightarrow \infty \\
q=0 \text { at } t=0 ; \text { for all } x
\end{gathered}
$$

Now define $q_{0}=I / 2$ as the applied line source flow rate in the aquifer at the line source location. Note that the denominator of two is necessary since $q$ can flow in two horizontal directions. Integrating equation 4.23 from zero to $t$ results in the ratio of the volume of flow applied up to time $t$ :

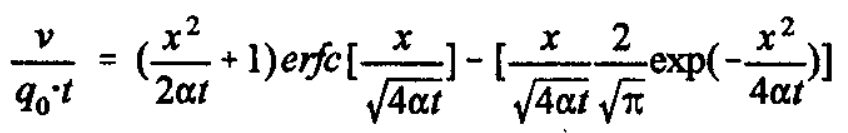

This solution is for a continuous application of a line source. After termination of the source, the residual effect still contributes flow to the stream. The residual is taken into account by assuming an imaginary pumping source at the same location and initiating pumpage at the same rate as the recharge source from the time recharge terminates. The volume ratio at any time after recharge ceases is the difference between the volume ratio obtained if recharge had continued and the volume ratio obtained from pumping of the imaginary pumping source. For a discrete time interval, if the applied line source volume equals one, the volume ratio is in essence the unit response of line source or canal seepage.

Let $\phi$ represent the unit response of canal seepage. Then for canal link $\ell$, the total return flow $C R F_{\ell k}$ from canal seepage $C_{\ell 1}, C_{\ell 2}, \ldots, C_{\ell k}$ during each time interval $k$ is

$$
C R F_{\ell k}=\sum_{\tau=1}^{k} C_{\ell \tau} \cdot \phi_{\ell, k-\tau+1} ; \phi_{\ell, k-\tau+1}=0 \text { for } k-\tau+1>N
$$

\subsection{Point Source Water Application}

Reservoir seepage $R S_{i k}$ is defined as a point source application for storage node $i$, time period $k$. The effect on the stream corresponds to the effect of a recharge well, which in turn has the same absolute flow magnitude as a pumping well, with the flow direction reversed. This solution tums out to be exactly the same as that for the line source solution (Glover, 1977). Therefore, $C_{\ell \tau}$ is replaced with $R S_{i \tau}$ in equation 4.28, with the resulting return flow defined as $R R F_{i k}$. Again, there is little error in assuming reservoir seepage as a point source, as long as the reservoir surface area is small in comparison with the area of the subsystem containing it.

For reservoir $i$ during time period $k$, the total return flow $R R F_{i k}$ from reservoir seepage, based on current and previous period seepage, is

$$
R R F_{i k}=\sum_{\tau=1}^{k} R S_{i \tau} \cdot \phi_{i, k-\tau+1} ; \phi_{i, k-\tau+1}=0 \text { for } k-\tau+1>N
$$




\subsection{Stream Depletion Factor Method (SDF)}

Jenkins (1968) solved the Glover equation graphically by developing dimensionless curves and tables to compute the rate and volume of stream depletion by wells. The stream depletion factor (SDF) was arbitrarily chosen as the time in days where the volume of stream depletion is $28 \%$ of the net volume pumped during time $t$, and can be expressed as:

$$
S D F=a^{2} S / T
$$

where $a$ is perpendicular distance from the pumped well to the stream $(\mathrm{L}) ; S$ is specific yield of the aquifer (dimensionless); and $T$ is transmissivity $\left(\mathrm{L}^{2} / \mathrm{T}\right)$.

In a complex system, the value of SDF at any location depends on the integrated effects of irregular impermeable boundaries, stream meanders, aquifer properties, areal variation, distance from the stream, and hydraulic connection between stream and aquifer. The basic assumptions are similar to those associated with the Glover equation:

1. transmissivity does not change with time, and drawdown is negligible when compared to saturated thickness

2. temperature of the stream is assumed to be constant and the same as the temperature of water in the aquifer

3. the aquifer is isotropic, homogeneous, and semi-infinite in areal extent

4. the stream forming the boundary is straight and fully penetrates the aquifer

5. water is released instantaneously from storage

6. the well is open to the full saturated thickness of the aquifer

7. pumping rate is steady during any period of pumping.

Moulder and Jenkins (1969) introduced the SDF concept to a digital model and the USGS used it to generate groundwater response coefficients for developing regional models (Taylor and Luckey, 1972; Hurr, 1974; Hurr and Burns, 1980; and Warner et al., 1986) and groundwater SDF contour maps (Hurr, et al., 1972).

\subsection{Finite Difference Groundwater Models}

The partial differential equation for groundwater movement in a heterogeneous and anisotropic medium can be solved using finite difference or finite element numerical methods (Willis and Yeh, 1987). The finite difference method uses a finite set of discrete points or grids to represent the system and replaces the partial differential equations with terms calculated from differences in potentiometric head at these grid points. The result is a system of simultaneous linear difference equations. Figure 4.5 compares a network formulation and a finite difference grid structure for a river basin system.

The finite element method is generally formulated using the method of weighted residuals, with co-location and Galerkin the most popular solution techniques. The finite elementmethod also requires discretization of the groundwater system, making it is less amenable to efficient solution strategies than the classical finite difference approach. The finite element procedure must generate a more accurate solution for a given number of equations, which can only be achieved by proper choice of nodal locations or through use of higher order accurate approximations (Pinder, 1988). Output from finite 
element numerical models includes drawdown and flow at each grid for each time period. For regional aquifer models, computational time can be quite extensive.

Lee, et al. (1980) used a digital finite difference model to determine the feasibility of a demonstration recharge project located in the South Platte River basin in northeastern Colorado. Maurer (1986) used the USGS finite difference model MODFLOW (McDonald and Harbough, 1988) to simulate the effects of groundwater development in the Carson Valley, Nevada on the Carson River. Hartwell (1987) compared results from a model based on the Glover solution, the SDF method, and a finite difference model for a recharge site along the along the South Platte River, Colorado. The use of the finite difference model was recommended in this study, which can be run with relatively few idealizing assumptions and can easily be calibrated to produce more accurate return flow values than the other methods. Stoertz and Bradbury (1989) used MODFLOW to map regional recharge areas.

The data requirements for the USGS Modular Three-Dimensional Finite-Difference Groundwater Flow Model MODFLOW are shown in Table 4.1, along with indications as to which input data types can be prepared with the aid of geographic information systems (GIS). Application of GIS to preparation of input data files for MODFLOW is detailed in the following chapter. 


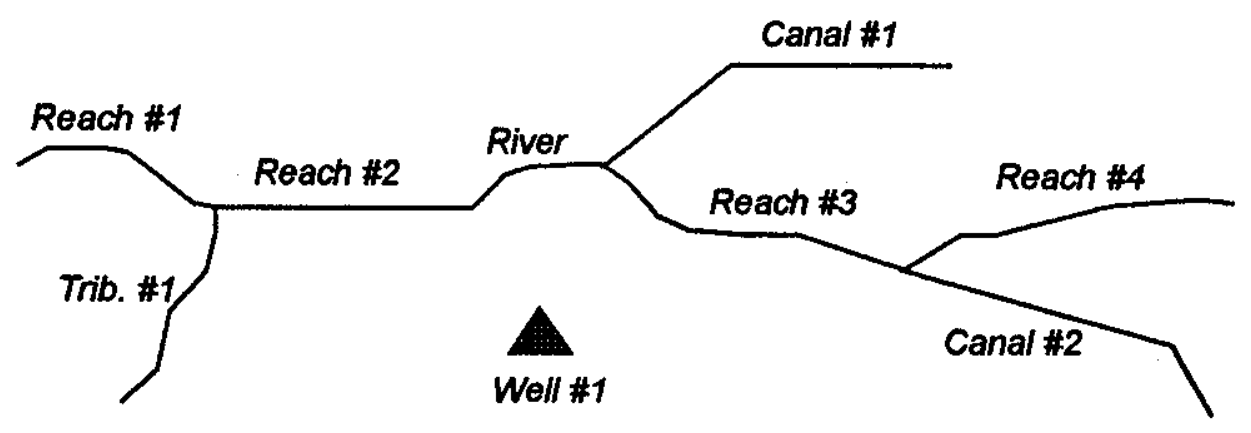

PHYSICAL CONCEPTUAL MODEL

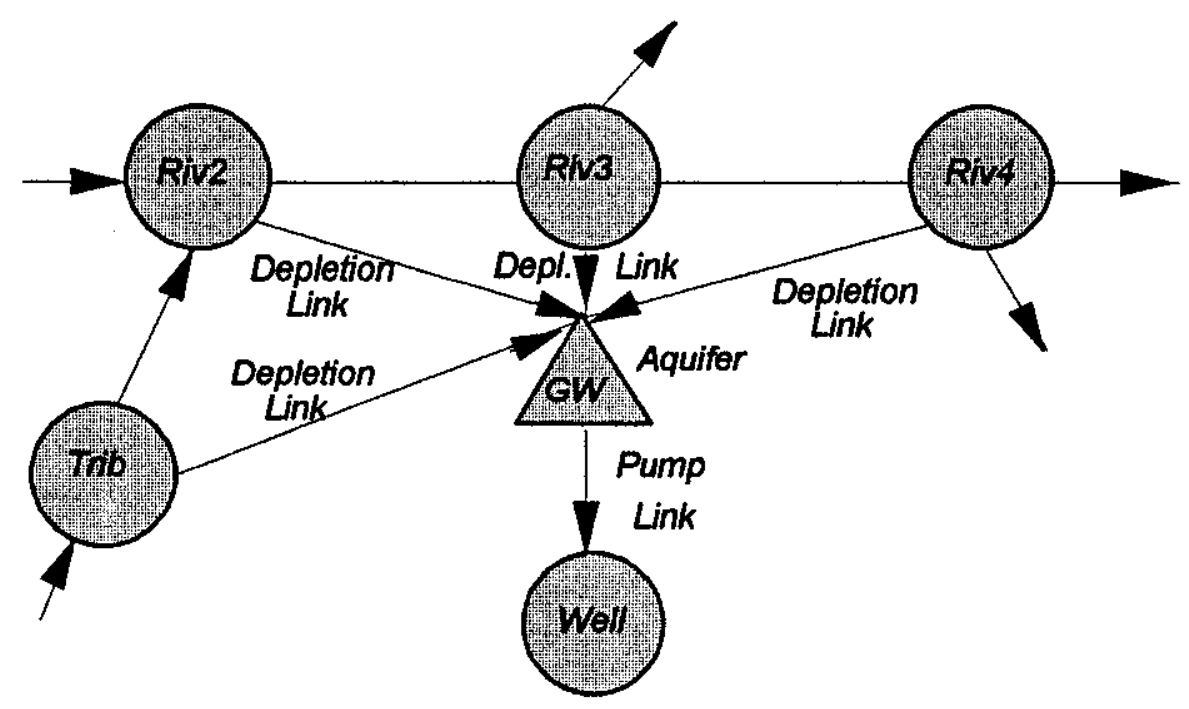

NETWORK MODEL

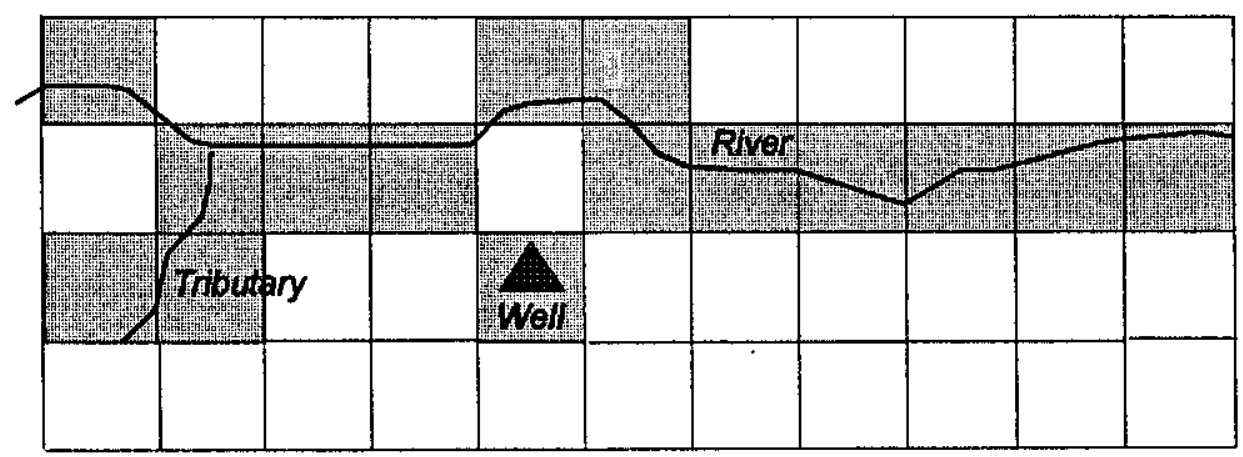

FINITE DIFFERENCE MODEL

Figure 4.5. Comparison Between Network Model and Finite Difference Grid Structure for River Basin 
The file input structure for MODFLOW allows input to be collected as needed from a number of different files. The user assigns unit file names to those options to be included in the running of the program. Each unit file name refers to an actual input data file. Most of the data submitted by the user will be made up of one or two dimensional data arrays. The program allows the user to define the structure of the input data arrays and the file locations. For example, transmissivity data for an aquifer can be read in from the Block Centered Flow File, along with other miscellaneous data, or it can be read in separately from a user assigned file. The data can also be read in any format defined by the user. MODFLOW output can be manipulated in the same manner.

Maddock and Lacher (1991a) have developed MODRSP, a modified version of MODFLOW, to calculate the volume of water captured, volume of storage loss, drawdown, and velocities from pumping stresses at specified locations and times in multiple aquifer systems. The concept of MODRSP is expanded to cover response functions for stream-aquifer leakage, reduction of evapotranspiration, flows to and from constant head boundaries, and increases or decreases in natural recharge or discharge from head dependent boundaries. MODRSP was selected as the most appropriate numerical model for determining response function coefficients for several reasons. MODRSP allows the modeling of a multi-aquifer groundwater flow system as a linear system with irregularly shaped areal boundaries and non-homogeneous transmissivity and storativity qualities. The aquifer must first be defined in terms of boundary conditions and the aquifer parameters of transmissivity and specific yield. The model initializes all heads to zero. Since MODRSP is a linear model, transmissivity and storage coefficients are considered constant. The user selects the grid location of the well and the type and location of the response for which the response coefficients are to be calculated.

If spatially distributed stream-aquifer response coefficients have been generated using MODRSP they can be used to allocate groundwater return/depletion flows to multiple return/depletion flow node locations any where in the river basin network system as shown in Figure 4.5.

MODRSP calculates responses for one well at a time over the total simulation period assuming a unit stress has been applied during the first period and discontinued for the remainder of the simulation. MODRSP assumes that stream-aquifer interaction is independent of the location of the stream reach within the grid cell, the level of water in the stream is uniform over the reach, and constant over each stress period. This implies that conditions of flow in the stream do not vary significantly during stress periods. If streams go dry or overflow their banks during a stress period, it is assumed such events are of short duration and have negligible effect on stream-aquifer interaction. Because of this it is not necessary to read in the river stage height and the head at the bottom of the streambed in defining river reach data. Output for the response coefficient data generated by the model can be output formatted or unformatted and includes well grid location, response grid location, stress period, and calculated response coefficient for that period.

Because MODRSP is a modification of the USGS MODFLOW finite difference groundwater model, it uses many of the same input data and file structures as MODFLOW. However, there are several major differences between the two programs. For example all starting heads are set to zero in MODRSP so a starting head input file is not required. Because MODRSP is a linear model, transmissivity and storage coefficient are considered constant and must be entered as input data. For the MODRSP well package, it is not necessary to read in pumping values. The MODRSP river package does not require data on river stage height and the head at 
Table 4.1 Use of GIS for MODFLOW Input Data Requirements

\begin{tabular}{|c|c|c|c|c|c|c|}
\hline \multicolumn{3}{|r|}{ D.TAR } & \multirow{3}{*}{$\begin{array}{l}\text { GIS? } \\
\text { YES }\end{array}$} & \multicolumn{2}{|r|}{ B.4.8 } & \multirow{3}{*}{$\begin{array}{l}\text { GIS? } \\
\text { YES }\end{array}$} \\
\hline 1. & \multicolumn{2}{|c|}{ Basic Data } & & 5. & River Package & \\
\hline & - & Boundary Conditions & & & Number of Reaches & \\
\hline & - & Starting Years & YES & & Location & YES \\
\hline & - & Simulation Period & No & & Head & YES \\
\hline 2. & \multicolumn{2}{|c|}{ Block-Flow Centered } & & & Hydraulic Conductivity & YES \\
\hline & - & Type of Aquifer & No & & Bed Elevation & YES \\
\hline & - & Anistropy & YES & 6. & $\begin{array}{l}\text { Evapotranspiration } \\
\text { Package }\end{array}$ & \\
\hline & • & Grid Size (row x col) & YES & & Location & YES \\
\hline & - & Specific Yield & YES & & $\begin{array}{l}\text { Elevation of ET } \\
\text { Surface }\end{array}$ & YES \\
\hline & - & Transmissivity & YES & & Max. ET Rate & YES \\
\hline & • & Hydraulic Conductivity & YES & & ET Extent Depth & YES \\
\hline & - & Bottom of Aquifer & YES & 7. & Recharge Package & \\
\hline 3. & \multicolumn{2}{|c|}{ Well Package } & & & Location & YES \\
\hline & - & Number & YES & & Recharge Amount & YES \\
\hline & $\bullet$ & Location & YES & 8. & Solution Procedure & No \\
\hline & - & Discharge & YES & & & \\
\hline & - & Period & YES & & & \\
\hline 4. & \multicolumn{2}{|c|}{ Drainage Package } & & & & \\
\hline & - & Number & YES & & & \\
\hline & - & Location & YES & & & \\
\hline & - & Drain Elevation & YES & & & \\
\hline & - & Hydraulic Conductivity & YES & & & \\
\hline
\end{tabular}


the bottom of the streambed. Output for the response coefficient data generated by MODRSP can be printed to a file as formatted or unformatted data. Typical database structure for response coefficient output data is presented in Table 4.2 .

Table 4.2. MODRSP Response Coeficient Database Output File

RIVER CAPTURE RESPONSE FUNCTIONS

\begin{tabular}{|c|c|c|c|c|c|c|c|c|c|}
\hline RIVER & & & & PUMP & & & & & \\
\hline REACH & & & & WELL & & & & TIME & \\
\hline$\#$ & K & $I$ & $\mathrm{~J}$ & \# & K & I & $\mathrm{J}$ & PER & $R F[0]$ \\
\hline
\end{tabular}

The following modifications were made to MODRSP:

- The program was compiled to run under Microsoft WINDOWS using Microsoft FORTRAN 5.1. This allows resizing of the array dimension variable LENX up to the limits allowed by extended memory. On an IBM-compatible personal computer using a DOS operating system with $8 \mathrm{MB}$ memory, the program MODRSP was successfully run with LENX set at 7.5 million.

- The modules RRIV.FOR and RPGM.FOR source code were modified to reduce unnecessary output to a river response file. In line 1 of the RRIV input file, field 41 to 50 , a decimal value for the variable, RDROP, can be input. Response coefficients lower than this value will not be printed to the river response output file. This reduces the size of river response output file by eliminating zero value response functions.

- The modules RRIV.FOR and RPGM.FOR code were modified to terminate a computer processing loop for a specific well when the calculated response coefficient values fall below a specified lower limit.

- The modules RRIV.FOR and RPGM.FOR were modified to read in a river reach file that assigns a specific river reach value to each river reach grid cell and then sums the response coefficients by river reach.

- The module RPGM.FOR was modified to read in a recharge site file that assigns a recharge site number to each well grid cell number.

\subsection{Simulation of Stream Boundaries}

Finite difference numerical solution of the groundwater flow equations requires the assignment of boundary conditions, which generally correspond to hydrologic boundaries. Boundary conditions used in groundwater flow models include (Willis and Yeh,1987): 


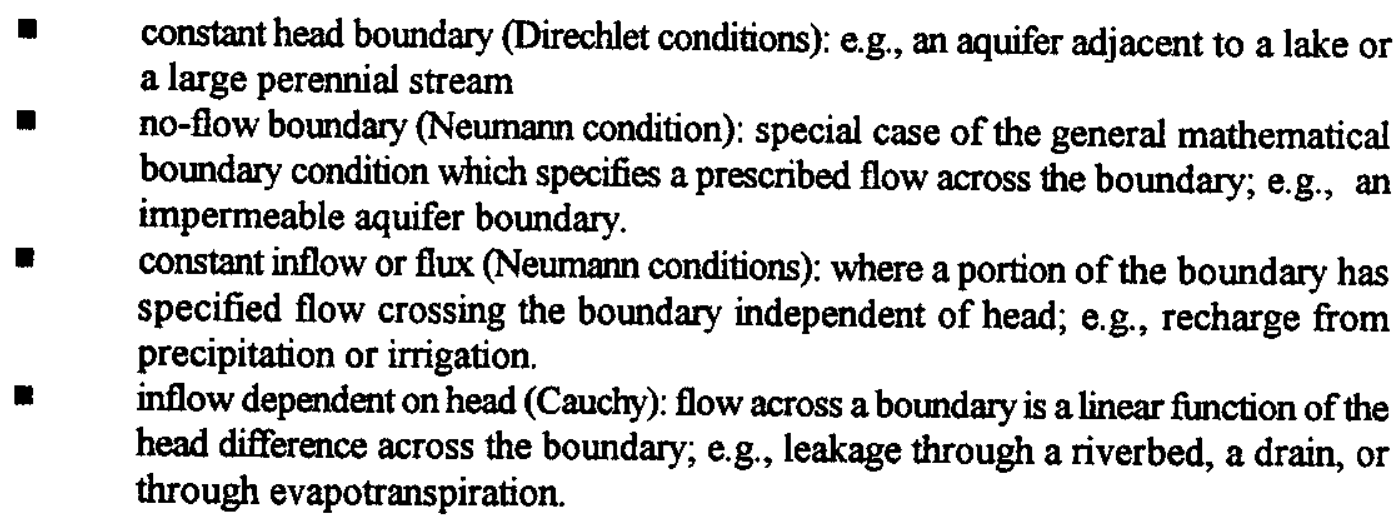

Since analytical solutions assume an aquifer of infinite areal extent, analytical equations generally do not directly simulate streams or other bodies of surface water adjacent to an aquifer (Kraeger-Rovey ,1990). Using the principle of superposition, a line along which the head is constant can be defined within the idealized, infinite aquifer. The aforementioned Glover equation for determining stream depletion due to pumping of a well in an adjacent aquifer uses this procedure (Glover, 1977). The linear constant head representation may be acceptable for simulating a stream boundary in cases where a large, perennial stream flows in a reasonably straight line past an aquifer and the natural or induced seepage from the stream into the aquifer is considerably less than the streamflow (Kraeger-Rovey, 1990).

Earlier numerical models represented a stream or body of surface water as one or more constant head grid cells or nodes at the proper location within the groundwater model grid or mesh (Trescott, et al.,1976pl; Morel-Seytoux and Restrepo, 1987). This procedure provided greater flexibility in locating stream reaches within the model domain than the straight line representation required for analytical models. It also offered the advantage that each stream or water body cell could be assigned its own head value (Kraeger-Rovey, 1990).

Most numerical groundwater models now offer the capability of computing seepage across the stream-aquifer interface through a series of production terms. These terms can be assigned to each grid cell or node adjacent to a stream reach. The stream reach is assumed to have a constant water surface elevation during the simulation time step, but can vary period by period and reach to reach (McDonald and Harbaugh, 1988; Zhang, 1990; Maddock and Lacher, 1991a).

This procedure offers two advantages over the use of constant head cells (Kraeger-Rovey, 1990). Instead of replacing an entire grid or node of the aquifer with a cell or node that represents a body of surface water, grid cells or nodes in which stream reaches are located are realistically modeled as part of the aquifer, and the head in these cells can vary. The capability exists to simulate the effect on seepage of a restricting streambed layer having lower hydraulic conductivity than the underlying aquifer material. This capability allows the head in the aquifer to fall below the level of the streambed.

The major disadvantage of this procedure is that a continuity check on streamflow is required. An adjustment of stream depth and seepage conditions caused by gains and losses in streamflow due to seepage interactions with the adjacent aquifer may be required. These considerations are important when the rate of seepage between the aquifer and the stream is a significant fraction of total streamflow. Results of using fixed-head stream representations in systems that include groundwater 
dependent streams is over-prediction of seepage from the stream, under-prediction of water level declines in the aquifer, and inaccurate prediction of the actual effect of system stresses on streamflow (Kraeger-Rovey, 1990). Stream-aquifer modification packages (Miller, 1988; Schenk, et al., 1990) to the MODFLOW groundwater program are now available which include continuity and river stage estimates for calculating variable stream head values.

\subsection{Streambed Conductance}

The general equation for hydraulic conductance between a stream and an underlying aquifer can be expressed as (McDonald and Harbaugh, 1988):

$$
\text { Conductance }=\frac{K \cdot L \cdot W}{M}
$$

where $K$ is hydraulic conductivity of streambed material; $W$ is stream width; $M$ is distance of flow taken as thickness of streambed layer; and $L$ is length of stream as it crosses a node or grid.

McDonald and Harbaugh (1988) advise that if reliable field measurements of stream seepage and associated head difference are available, they should be used to estimate streambed conductance. Otherwise, a conductance value must be arbitrarily chosen more adjusted during model calibration. Equivalent conductances can be developed to simulate calibrated seepage flows.

Kraeger-Rovey (1990) cautions against misapplication of the conductance factor due to a lack of understanding and consensus among hydrologists and modelers on the behavior and nature of the seepage-restricting streambed and limitations on the use of the equations for seepage through it.

Maurer (1986), in modeling the Carson Valley, Nevada, identified several factors that presented complications in estimating hydraulic conductivity of a streambed for use in MODFLOW, such as variation in streambed areas due to changes in flow or dredging and cleaning of drains. Instead of attempting to account for these factors, conductances were assumed to be similar over major parts of the system. Streambed area was assumed to represent the total flooded area of each cell, including streams, ditches, and flooded fields. The thickness was assumed to one foot, due to frequent dredging of ditches and the practice of flood irrigation, the thickness was assumed to be one foot.

Schenk, et al. (1990) suggest that the hydraulic conductivity of the grid cell be used in calculation of conductance if a silt layer does not exist on the stream bottom. If a silt layer is present, and there is a hydraulic connection between the river and the grid cell, an equivalent hydraulic conductivity should be calculated:

$$
\text { Equivalent } K=\frac{d}{\left(\frac{d_{1}}{K_{1}}+\frac{d_{2}}{K_{2}}\right)}
$$

where $d$ is total thickness of silt layer and underlying grid cell; $d_{l}$ is thickness of silt layer; $K_{l}$ is hydraulic conductivity of silt layer; $d_{2}$ is thickness of grid cell below stream bottom; and $K_{2}$ is hydraulic conductivity of the grid cell. The hydraulic conductivity $K$ and thickness $M$ of the silt layer should be used in the calculation of the streambed conductance if head in the grid cell is below the river bottom and the flow is unsaturated. 
Peters (1978), Illangasekare (1978), Morel-Seytoux and Restrepo (1987), and Zhang (1990) suggest the following equation based on the method of flow nets:

$$
\text { Conductance }=\frac{T}{e} L\left(\frac{W_{p}+2 e}{e+10 W_{p}}\right)
$$

where $T$ is transmissivity of the aquifer undertying the reach; $e$ is average saturated thickness of the aquifer along the reach; $L$ is length of reach; and $W_{p}$ is wetted perimeter of stream equal to width of the reach.

In cases where the streambed is clogged, the following formula is proposed (Morel-Seytoux and Restrepo,1987; Zhang,1990):

$$
\Gamma_{c}=\Gamma \frac{1}{1+\frac{z_{c} \Gamma}{W_{p} L K_{c}}}
$$

where $\Gamma_{c}$ is streambed conductance adjusted for clogging; $\Gamma$ is streambed conductance; $z_{c}$ is thickness of clogging layer; $K_{c}$ is hydraulic conductivity of clogging layer, $L$ is length of reach; and $W_{p}$ is wetted perimeter of stream equal to width of reach.

Restrepo (1988) in a first step calibration of the SAMSON model for the South Platte River adjusted clogging factors to balance return flows calculations.

\subsection{Calibration of Stream-Aquifer Models}

It is possible to estimate reach gains and losses along the various reaches of a river system where adequate streamflow and diversion records are available. Estimates of historical river return/depletion flows on a reach by reach basis can be useful in the development and calibration of stream-aquifer models. For most conjunctive use models, it is the river return/depletion flows which are the dependent variables. Knowing actual historical values allows the user to calibrate various parameters and coefficients to reproduce the historical return/depletion flow values.

The program PTFLOW (USBR, 1989) is a useful tool for calculating historic return/depletion flows along a river system. 'The PTFLOW program performs several computations:

- calculates reach gains and losses between stream gages

- prorates reach gains and losses between diversions and inflow points.

- calculates point flow upstream and downstream of diversions.

- calculates point flow upstream and downstream of inflow locations and tributaries.

- calculates point flow at gage locations for years with missing gage records.

Reach gains and losses are defined as the cumulative impacts on streamflow due to unmeasured tributary and overland inflows, irrigation return flows, ground water discharge, channel infiltration, evapotranspiration due to riparian vegetation, precipitation over the channel, stream evaporation, and unmeasured diversions.

The PTFLOW computer program is general in nature and can be used on any river. The model uses traditional FORTRAN read and write card formats for data input and output. The input 
data requirements for the USBR South Platte River Point Flow Study Computer Model (PTFLOW) are shown in Table 4.3. Although data input to the PTFLOW model is read from a single file, a user can collect data from various external databases and consolidate the data into a single file using a standard ASCII file text editor. The proposed external database structure for two of the input data groups are shown in Table 4.4.

The PTFLOW program was modified to allow output as an ASCII database text file using the following structure:

$\begin{array}{cclcc}\text { Field } & \text { Field Name } & \text { Type } & \text { Width } & \text { Decimal } \\ 1 & \text { MILEAGE } & \text { Numeric } & 5 & 1 \\ 2 & \text { YEAR } & \text { Numeric } & 4 & \\ 3 & \text { MONTH } & \text { Numeric } & 2 & \\ 4 & \text { TYPE } & \text { Character } & 4 & \\ 5 & \text { FLOW } & \text { Numeric } & 6 & 1\end{array}$

where MILEAGE is CDATA or river station mileage number.; YEAR is flow year, MONTH is flow month; GAGE is gage flow; GAIN is reach tributary inflow; DIVR is reach diversion flow; PTBL is flow below the gage, tributary inflow, or diversion point; PTAB is flow above the gage, tributary inflow, or diversion point; and FLOW is flow value. 
Table 4.3. USBR PTFLOW Model Input Requirements

\begin{tabular}{|c|c|c|}
\hline ISTUDY & : & STUDY NUMBER \\
\hline ISTART & : & EIRST CALENDAR YEAR OF STUDY \\
\hline IEND & : & IAST CALENDAR YEAR OF THE STUDY \\
\hline NG & : & NUMBER OF IINE GROUP HEADINGS \\
\hline NL & : & NUMBER OE IINE HEADINGS \\
\hline NC & : & NUMBER OF CONSTANT 'CDATA' VALUES (MILE LOCATIONS) \\
\hline NA. & : & NUMBER OF AVERAGE MONTHLY 'ADATA' CONSTANTS \\
\hline NH & : & NUMBER OF MONTHLY INPUT 'HDATA' TO BE READ \\
\hline IERST & : & FIRST CALENDAR YEAR OF INPUT DATA \\
\hline NYI & : & NUMBER OE YEARS OE 'HDATA' TO BE READ \\
\hline NCI & : & NUMBER OF COMMENT IINES TO BE READ \\
\hline NPT & : & FLAG TO READ 'HDATA' ONE YEAR AT A TIME. \\
\hline IUNIT & : & OUTPUT IN CFS OR AF (O-AF/1-CES) \\
\hline NTAB & : & NUMBER OE SUMMARY TABLES \\
\hline IRTAB & : & NUMBER OF REACH BALANCE TABLES \\
\hline TBMIL & : & MILE MARKER FOR GENERATING SUMMARY TABLE \\
\hline IRBEG & : & MILE MARKER TO BEGIN REACH BALANCE TABLE \\
\hline IREND & : & MILE MARKER TO END REACH BAIAANCE TABLE \\
\hline \multirow[t]{7}{*}{ ITBEI } & : & ELEMENT CODE FOR GENERATING SUMMARY TABLE \\
\hline & & GAGE FLOW $\quad: 1$ \\
\hline & & POINT ELOW AB TRIB OR DIVERSION : 2 \\
\hline & & TRIBUTARY INELOW $: 3$ \\
\hline & & DIVERSION \\
\hline & & REACH GAIN \\
\hline & & POINT FLOW BI TRIB OR DIVERSION : 6 \\
\hline IGROUP & : & $\begin{array}{l}\text { NUMBER LINES TO BE PRINTED AFTER EACH IINE GROUP } \\
\text { HEADING }\end{array}$ \\
\hline TITLE & : & TITLE CARDS (2 LINES) \\
\hline COMMENT & & COMMENT CARDS (NUMBER SPECIFIED BY NCL) \\
\hline CDATA & : & CONSTANT MILE LOCATIONS \\
\hline OP & : & $\begin{array}{l}\text { AIPHA CODE FOR TYPE OF HDATA THAT WILI BE INPUT AT EACH } \\
\text { LOCATION }\end{array}$ \\
\hline CNAME & : & CDATA DESCRIPTION \\
\hline
\end{tabular}


1. Constant Mile Data Location:

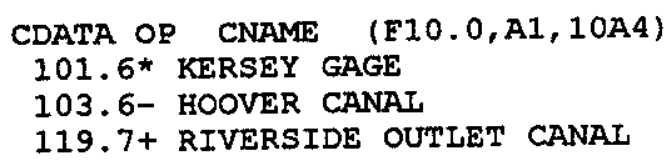

2. Monthly Input Flow data:

\begin{tabular}{|c|c|c|c|c|c|c|c|c|c|c|c|c|}
\hline & $\begin{array}{l}2 \pi 1 \\
8.5\end{array}$ & on & $\begin{array}{l}\text { Mon3 } \\
28.1\end{array}$ & $\begin{array}{l}\text { Mon4 } \\
23.0\end{array}$ & & & $\begin{array}{r}\text { Mon } 7 \\
7.2\end{array}$ & $\begin{array}{r}\text { Mon8 } \\
8.2\end{array}$ & $\begin{array}{r}\text { Mon } 9 \\
8.2\end{array}$ & $\begin{array}{r}\text { Mon1.0 } \\
12.7\end{array}$ & $\begin{array}{r}\text { Mon11 } \\
24.8\end{array}$ & $\begin{array}{r}\text { Mon12 } \\
33.4\end{array}$ \\
\hline & & & . & & & & & & .1 & .6 & .4 & 0 \\
\hline & & 1 & 7. & 2. & & & & & & 0 & & \\
\hline & 29.6 & 8. & 6. & 5. & 6. & 1. & 1. & & & & & \\
\hline & & 4.8 & 2.0 & 6.8 & 10.0 & 11.9 & 7.2 & 7. & 7.0 & 12.0 & & \\
\hline
\end{tabular}




\section{CHAPTER 5}

\section{DATA BASE MANAGEMENT AND GIS}

\subsection{Role of GIS in SAMDSS}

Geographic information systems (GIS) provide a number of concepts and tools which have become essential in the implementation of an effective water management decision support system. A few of the characteristics often attributed to GIS (Loucks, et al., 1985b; Goulter and Forest, 1987) include: the ability to display and graphically summarize data input and output, improve data input and editing, provide an effective interface between models, modelers and data bases, and improve comprehension of spatial and time varying information.

GIS software can be classified as vector based or raster based. Vector based software describes all entities as points, lines, or polygons which can be specified by geographical coordinates. Associated data located in a separate data base can be linked to each entity. Raster based software uses a grid system, with each cell assigned a single representative attribute. Vector based software is attractive for plotting maps and presentation of data base attributes. The raster format is useful for combining and analyzing different categories of information. Both formats are required for proper GIS management. SAMDSS integrates several GIS and spatial analysis tools and software packages such as AUTOCAD (CAD/CAM, vector), IDRISI (raster), and SURFER (surface modeling). A number of support utilities were written to convert USGS DLG, USGS DEM, and TIGER files into AUTOCAD DXF and IDRISI file format. The USGS General Cartographic Transformation Package (GCTP) was modified to support AUTOCAD DXF file format.

GIS procedures and techniques are used to:

- transform coordinates between geometric (latitude-longitude), Universal Transmercator, and Albert systems for use in AUTOCAD; the USGS Coordinate Transformation Package was modified for use with DXF file format for this purpose.

- read and process commercially available digitized map files; the WRTIGER, DLG, and CONVERT programs were written for this purpose.

- transfer GIS related data between various software packages; ACDTOIDR.Isp, VECDIST.lsp, VECWIDTH.lsp, IDRSS.exe, SURF.exe, and MODCOEF.exe were written for this purpose.

- digitize, edit, present, analyze, and geocode vector data using AUTOCAD.

- convert vector files to raster images using. IDRISI.

- convert contour data to digital elevation grid format using IDRISI and SURFER.

- convert point data to digital elevation grid model format using kriging or distance weighted averaging using IDRISI or SURFER.

- map algebra through overlays, reclassification, summary, group selection, and data manipulation using IDRISI, AUTOCAD, DBASEIV, and QUATTRO PRO.

a prepare input files for use in the finite difference groundwater flow models MODFLOW and MODRSP using IDRISI and DBASEIV.

- estimate actual grid cell river reach lengths using AUTOCAD.

m assign attribute data to vector based points, lines, or polygons using AUTOCAD. 


\subsection{Data Sources}

One of the aims in the design of SAMDSS is to create the ability to link with external computerized data bases developed by local, state and federal government agencies involved in data collection and distribution of water related information. The USGS and the Census Bureau are the primary government agencies involved in digitizing maps and preparation of coordinate linked geographical data bases. The USGS and EOSAT (1990), a private government contractor, are responsible for LANDSAT maps. The USGS and the USEPA have formal water related data bases such as WATSTOR and STORET. The U.S. Soil Conservation Service maintains maps and digitized data records on soil classification, land cover, drainage and runoff potential. Most states have a department of water resources, a division of natural resources, or a department of agriculture which

maintains irrigation and water related data records. Most irrigation and water conservancy districts, cities, and ditch companies also support computerized data bases.

A large amount of digital data are available for most locations throughout the United States, and these data can be used directly in the SAMDSS:

\subsubsection{Digital Elevation Model (DEM): USGS}

USGS DEM data consist of arrays of regularly spaced elevations:

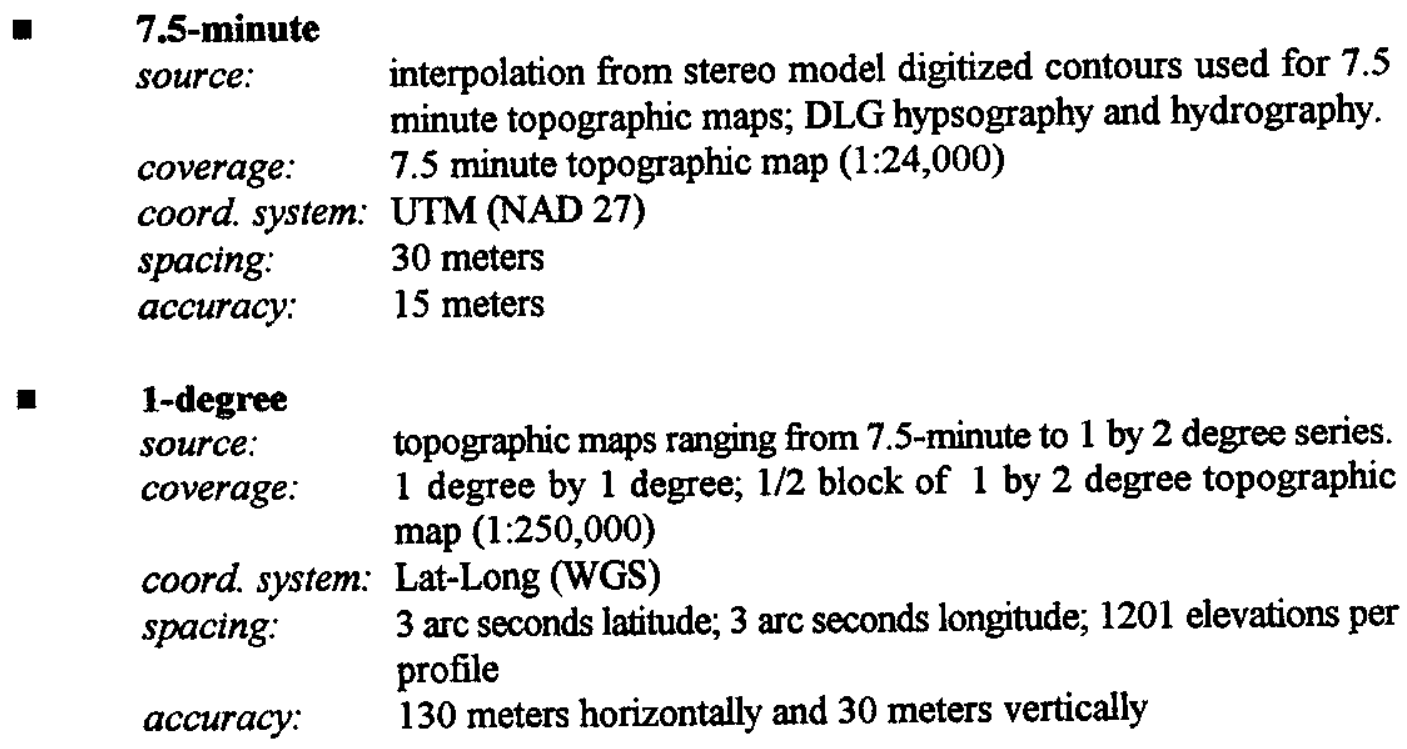

\subsubsection{Digital Line Graphs (DLG): USGS}

USGS DLG data are digital representations of cartographic information, with options of 80 byte record lengths and UTM coordinate system:

- large-scale source: coverage:

7.5 minute topographic maps $(1: 24,000)$

7.5 minute topographic map; 60 square miles; $6-1 / 2$ miles wide by 9 miles high; 1 inch $=2000 \mathrm{ft}$ 
content: nine categories: hypsography (contours), hydrography (water), vegetative surface cover, non-vegetative, boundaries, survey control markers, transportation, manmade features, and U.S. Public Land Survey System (township, range, section).

structure: vector format: points, lines, and areas with associated attribute codes

intermediate-scale

source: $\quad 30$ by 60 minute topographic maps $(1: 100,000)$

coverage: $\quad 30$ by 30 minute; $1 / 2$ block of 30 by 60 minute topographic map; distributed as four 15 by 15 minute cells or $16,7.5$ by 7.5 minute cells; 789-1083 square miles

content: nine categories: hypsography (contours), hydrography (water), vegetative surface cover, non-vegetative, boundaries, survey control markers, transportation, manmade features, and U.S. Public Land Survey System (township, range, section).

structure: vector format: points, lines, and areas with associated attribute codes

small-scale

source:

National Atlas maps (1:2,000,000)

coverage:

$1: 2,000,000$ map; sold in multi-state units.

content: three categories: hydrography, boundaries, and transportation.

structure: $\quad$ vector format: points, lines, and areas with associated attribute codes

\subsubsection{Land Use and Land Cover (LULC): USGS}

The USGS LULC data base provides information on urban or developed land, agricultural land, range land, forest land, water, and wetlands.

scales: $\quad 1: 250,000$ or $1: 100,000$

content: nine major classes: urban, agricultural land, rangeland, forest land, water areas, wetland, barren land, tundra, perennial snow; each major class composed of several minor classes (i.e., streams, canals, lakes, reservoirs, bays, and estuaries); associated map data consist of separate files on political units, census tracts, hydrologic units, and federal land ownership.

structure: $\quad$ vector (GIRAS) or composite theme grid cell polygon (CTGC) format with associated attribute codes, with the latter divided into four hectare (10 acre) cells.

\subsubsection{Geographic Names Information System (GNIS): USGS}

The USGS GNIS automated data system standardizes and disseminates information on geographic names: 
- National Geographic Names Data Base (State):

State files on towns, schools, reservoirs, etc., found on USGS topographic maps; 15 descriptive elements, including geographic coordinates.

- $\quad$ National Atlas Data Base (Concise):

Contains information on geographic names in the National Atlas of the U.S., including geographical coordinates.

\subsubsection{LANDSAT: USGSEOSAT}

The USGS/EOSAT LANDSAT data are Multispectral Scanner (MSS) satellite photos:

coverage: $\quad 185 \times 170 \mathrm{~km}$ for full scene; 3484 pixels by 2983 lines for each quadrant; 80 meter interval.

options: $\quad$ available as LTWG CCT BSQ, BIL, or Band Interleaved by Pixel-Pair (BIP2); 4 bands

\subsubsection{Topographically Integrated Geographic Encoding and Referencing System (TIGER): Census Bureau}

The Census Bureau TIGER line files are a compilation of digital maps of the entire U.S., with an accompanying data base that integrates accurate map data with related geographic information and population statistics.

application: for use with general geographic planning and demographic studies, rather than detailed engineering studies.

source: urban areas: Census Bureau Dime files, which compile information from city and county maps.

rural areas: USGS 1:100,000 maps, which are more accurate than Dime files.

coverage: by county

content: five feature categories: roads, railroads, pipelines, hydrography, and political boundaries; types of associated data include feature names, political boundaries, Census geography, address range, zip codes.

\subsection{Data Conversion}

Since most software packages have there own own unique data input file formats, use of data compiled or developed in another software format normally requires some type of data transformation. The better commercial software packages generally contain data export and import modules for enhancing compatibility. AUTOCAD requires a DXF file format, whereas IDRISI provides a number of modules for converting various data types such as DLG, CTGC, AUTOCAD, ARCINFO, and LANDSAT.

The U.S. Bureau of Census TIGER files (Bureau of the Census, 1989) provide invaluable data for use in the Stream-Aquifer Management Decision Support System (SAMDSS). Figure 5.1 shows steps used to extract digital map data from TIGER files for import into AUTOCAD. TIGER files are 
available on CDROM for the entire United States. Each CDROM holds a single state, with data listed by county. Of the six files or Record Types, only the first two are necessary to develop digital maps:

- basic data records (individual feature segment records)

- shape coordinate points (feature shape records)

Each segment record contains a unique 10-digit record number, a feature class code, and beginning and ending latitude/longitude coordinates. The feature shape records contain the unique 10digit record number and the intermediate latitude/longitude coordinate values that describe the shape of those feature segments that are not straight. Two files must be linked and written to a DXF file for use with AUTOCAD, with each segment coded as an AUTOCAD polyline and associated with an AUTOCAD layer corresponding to the feature class code. This is the purpose of the WRTIGER program. WRTIGER requires that the record 1 file be named TIGER1 and the record 2 file be named TIGER2. Output is to a file called TIGOUT.dxf. Because of the original format for the TIGER files found on the CDROM they must be converted from files with record length of 228 byte to record lengths of 80 byte. The CONVERT.exe program does this. It is important to sort both of the TIGER record files before rumning WRTIGER exe. Each file should be sorted on the 10-digit record number, which was accomplished using DBASEIV for this study. Once the DXF file has been prepared it can be imported directly into AUTOCAD for viewing.

A conversion program DLG.exe was written to transfer USGS optional format DLG files to AUTOCAD DXF format files. Use of DLG.exe requires the input file be named DLGl and have a record length size of 80 bytes, with output going to a file called DLG.dxf. The Program CONVERT can be used to assign variable length records to the 80 byte record length format required by DLG.exe. Details on digital line graph types and file structure can be found in the USGS National Mapping Technical Instructions Data Users Guide 1-3 (USGS, 1990a,b,c). 

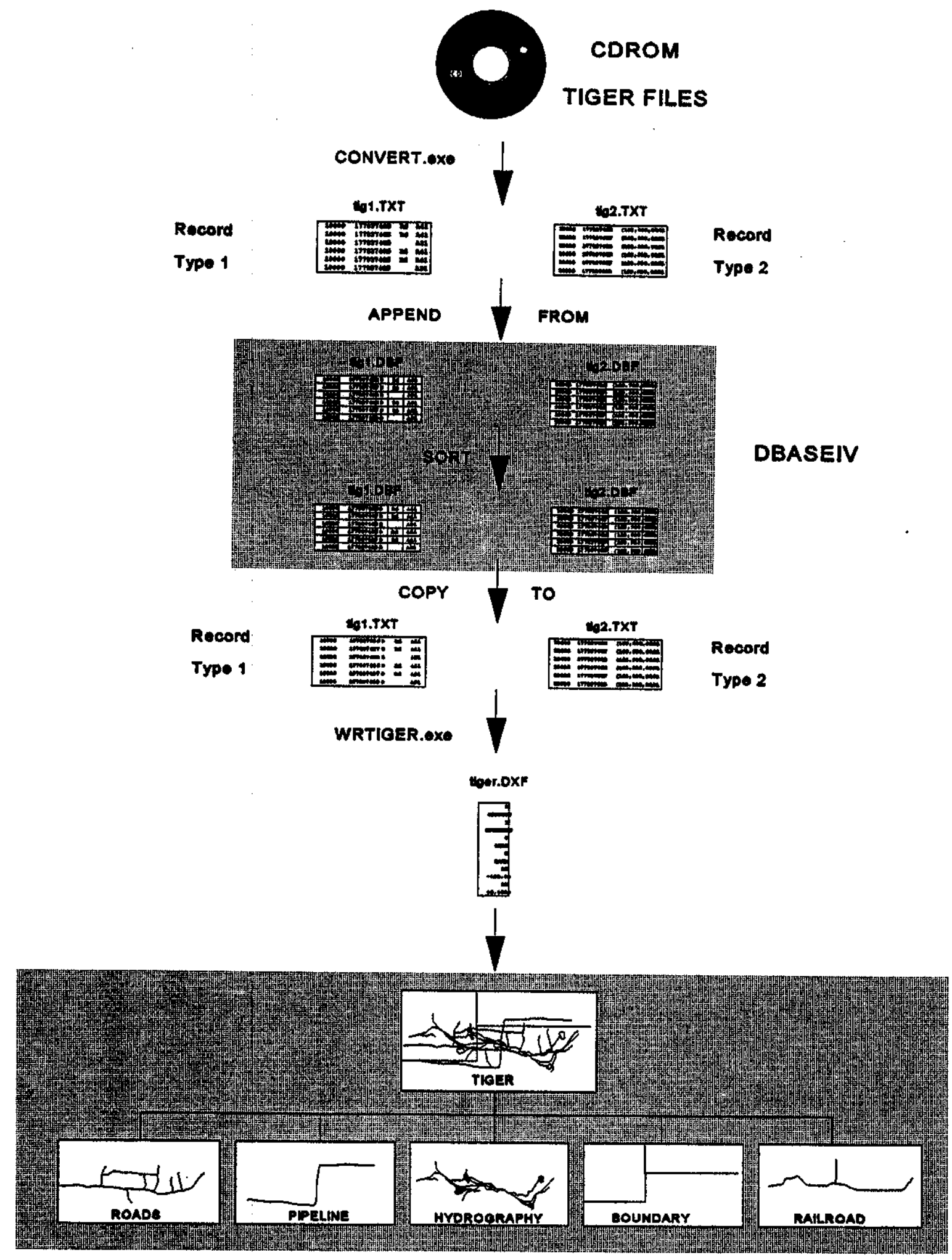

\section{AUTOCAD}

Figure 5.1. Procedures for Converting TIGER Files into AUTOCAD DXF Format 


\subsection{Using GIS to Prepare Data for MODFLOW/MODRSP}

One useful application of GIS is in the preparation and processing of data for input into MODFLOW, the USGS Modular Three-Dimensional Finite Difference Grjoundwater Flow Model. Table 4.1 listed MODFLOW data requirements and indicated the types of data that can be generated through GIS. Specific details on how GIS can be used for preparation and presentation of data for use in a finite difference groundwater model are given in Appendix B.

Well data represent an important data type stored in public domain databases, as shown in Figure 5.2. Examples of public domain databases are the USGS Ground Water Site Survey Database (GWSD) or the Colorado State Engineer Office Well File. Typical data available from these databases are: depth of well, ground surface elevation at well, specific capacity, transmissivity, well location, pumping capacity, seasonal water levels, and well use.

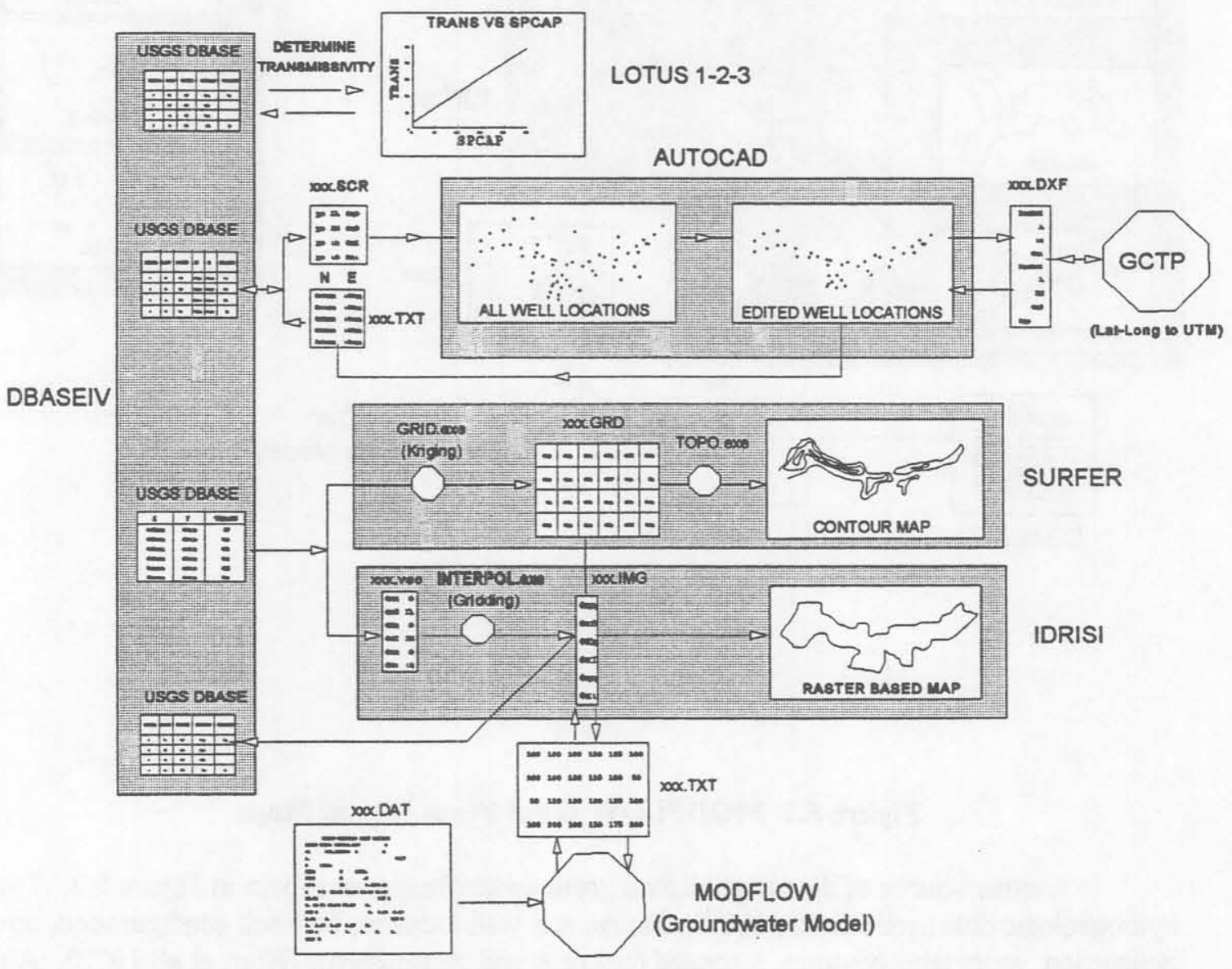

Figure 5.2. MODFLOW Input from Database 


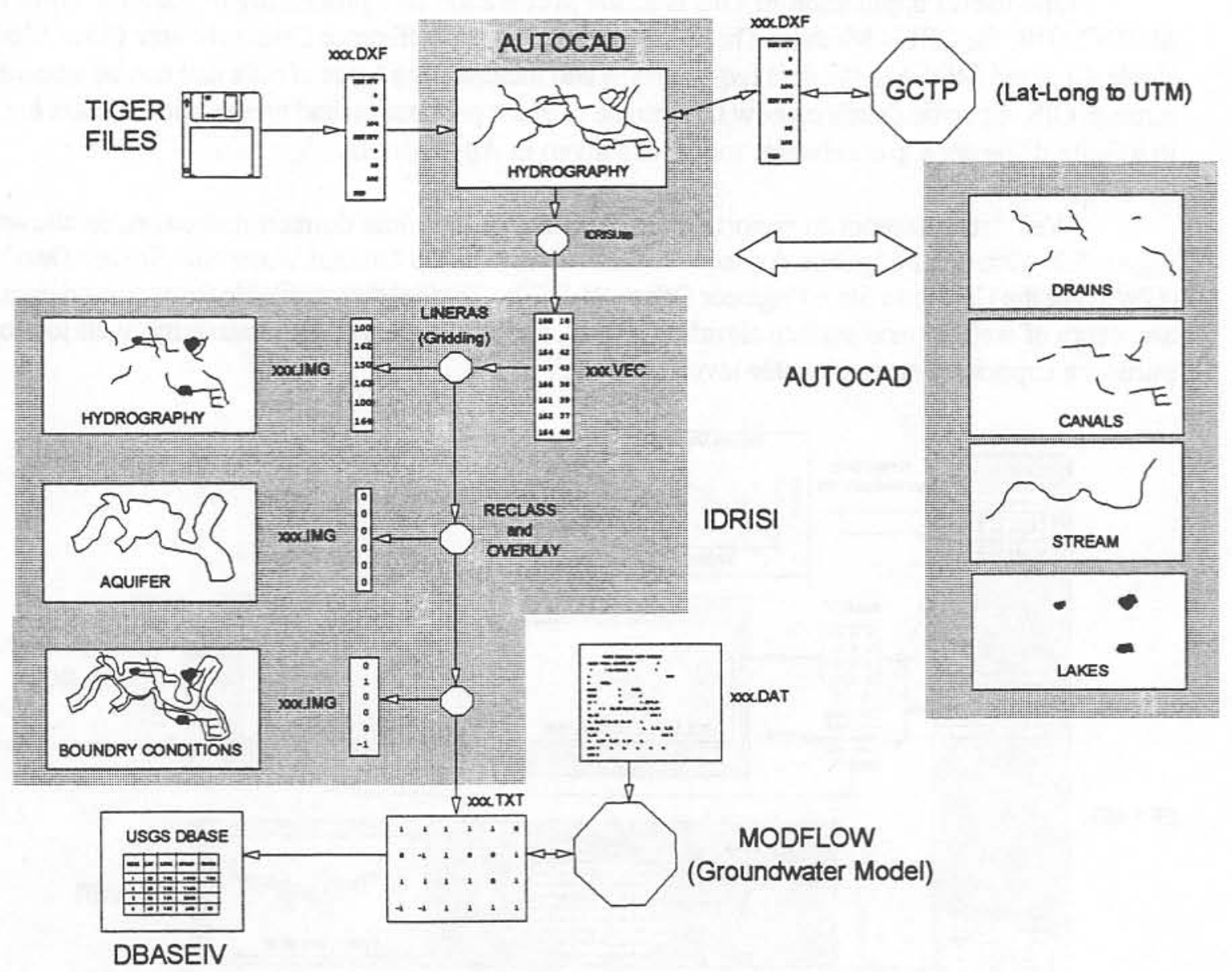

Figure 5.3 MODFLOW Input From Digital Maps

Another source of data is published groundwater maps, as shown in Figure 5.3. Typical hydrogeologic data available as published maps are: well location, bedrock configuration, aquifer delineation, water table contours, saturated thickness, and transmissivity (Hurr, et al.,1972). A third source of data is digital maps and related data, as presented in Figure 5.4. Examples of these types of data are Department of Census Topographically Integrated Geographic Encoding and Referencing System (TIGER) for hydrography, roads, and political boundaries; USGS Digital Elevation Model (DEM) for ground surface elevations; USGS Digital Line Graphs (DLG) for hydrography, roads, public land survey, and contours; USGS Land Use and Land Cover (LULC) for nine major land classes such as urban, agricultural, etc.; USGS LANDSAT data, USGS AVHRR Vegetative Index data; and SCS soil classification maps. 


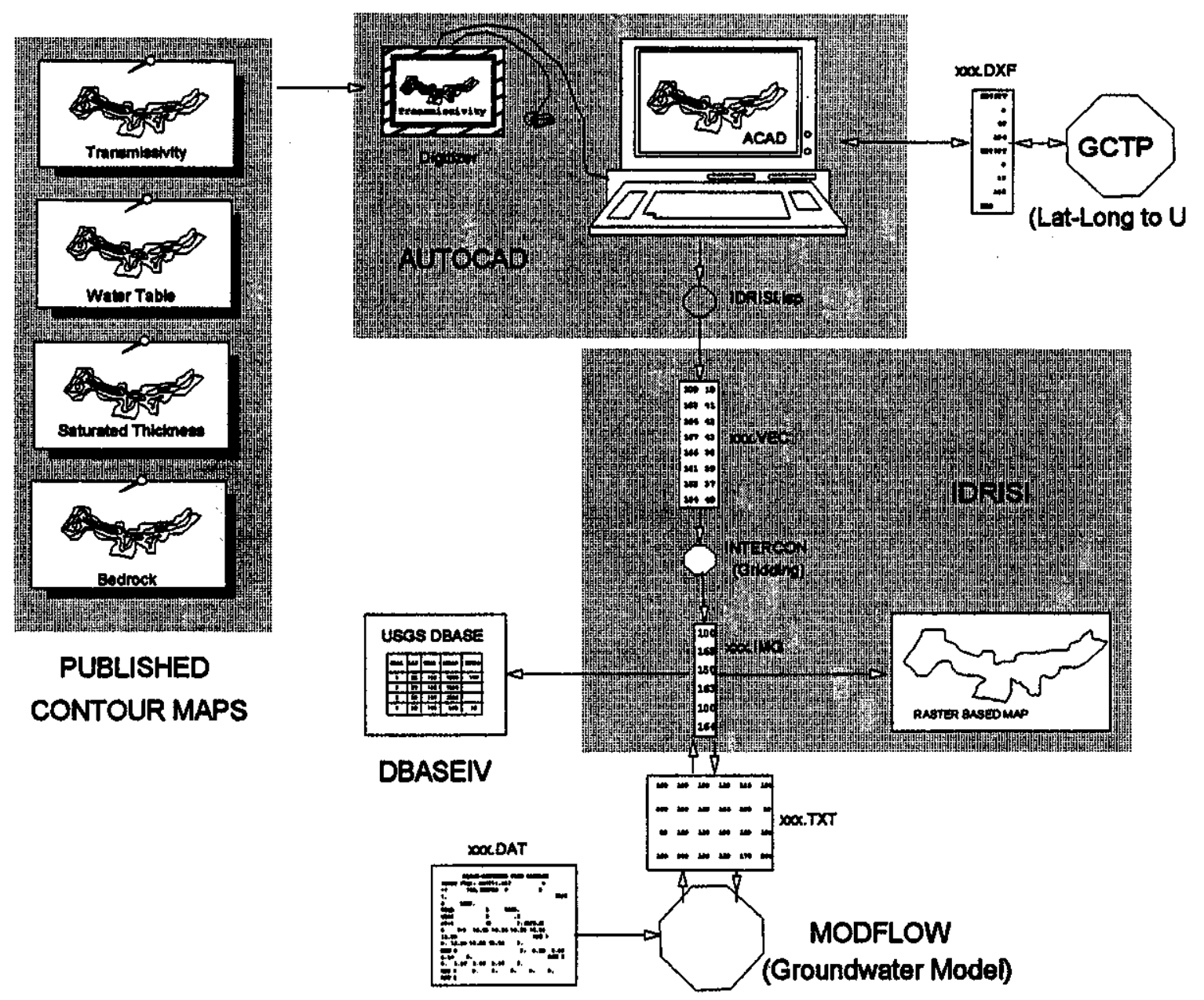

Figure 5.4 MODFLOW Input From Published Maps

\subsection{Generating Stream-Aquifer Response Coefficients Using MODRSP}

SAMDSS uses MODRSP (Maddock and Lacher,1991a) to generate stream-aquifer response coefficients based on a finite difference numerical solution to the groundwater flow problem. The general procedures required to generate spatially distributed stream-aquifer response coefficients for use in a stream-aquifer management model are shown in Figure 5.5. Detailed procedures can be found in Appendix C.

GIS and DBMS procedures are powerful tools that are well suited for preprocessing data for use with MODRSP. Aquifer transmissivity, boundary, well, and river input data files used by MODRSP can all be prepared using GIS and DBMS procedures. 


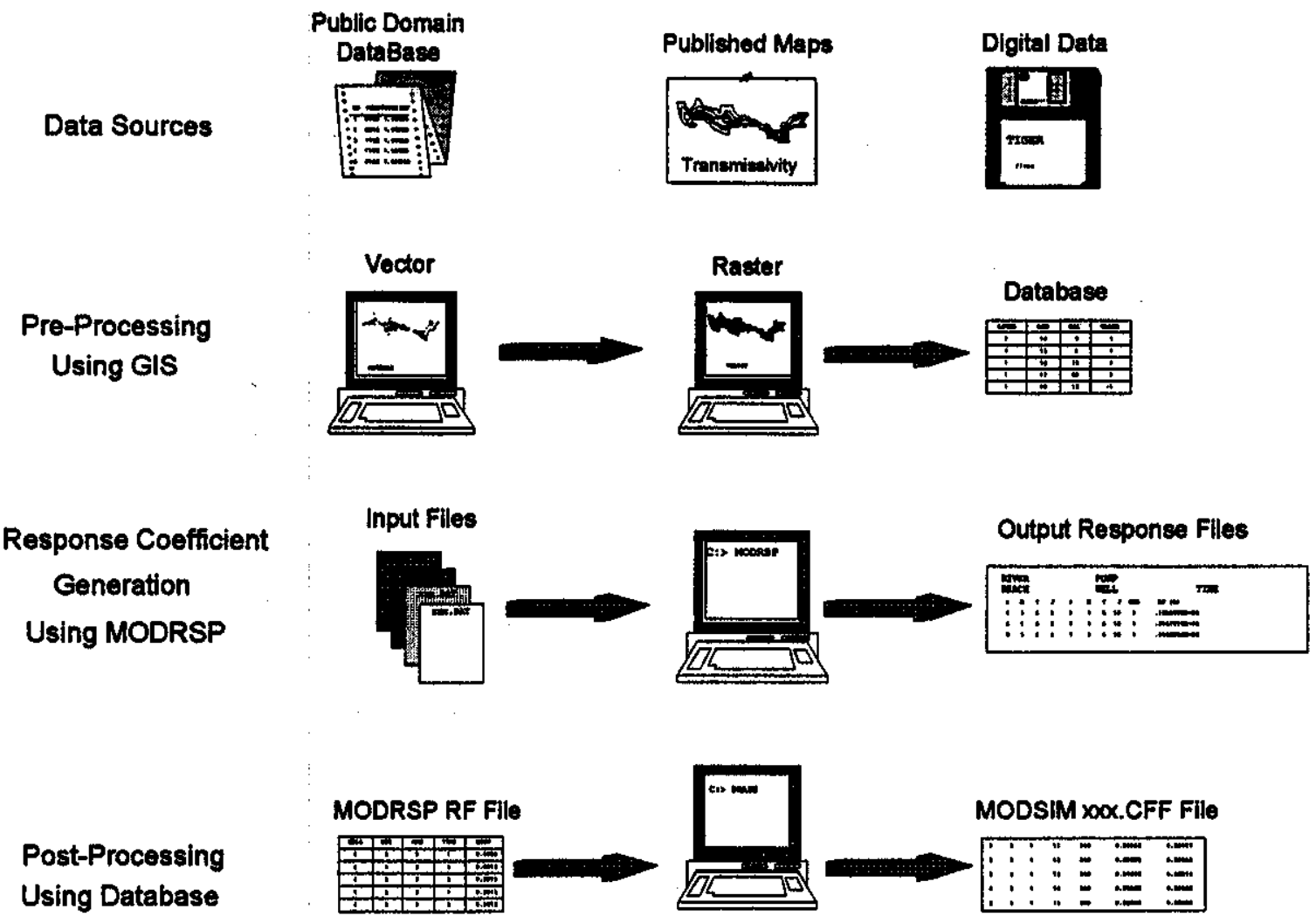

Figure 5.5 Using MODRSP to Create Response Coefficients

The procedures for preparing an aquifer transmissivity file are shown in Figure 5.6. Assuming that transmissivity contour maps are available, SAMDSS uses AUTOCAD software to digitize these data. The data are then written as IDRISI vector files and converted to IDRISI raster format. IDRISI commands can then be used to interpolate between the contour line values and assign transmissivity values to each grid cell. The IDRISI output file can be read directly into MODSRP.

The groundwater system boundary data used by MODRSP requires that each finite grid be assigned a boundary value:

$\begin{array}{ll}\text { No flow: } & 0 \\ \text { Constant head: }<= & -1 \\ \text { Underflow: }>= & +1\end{array}$




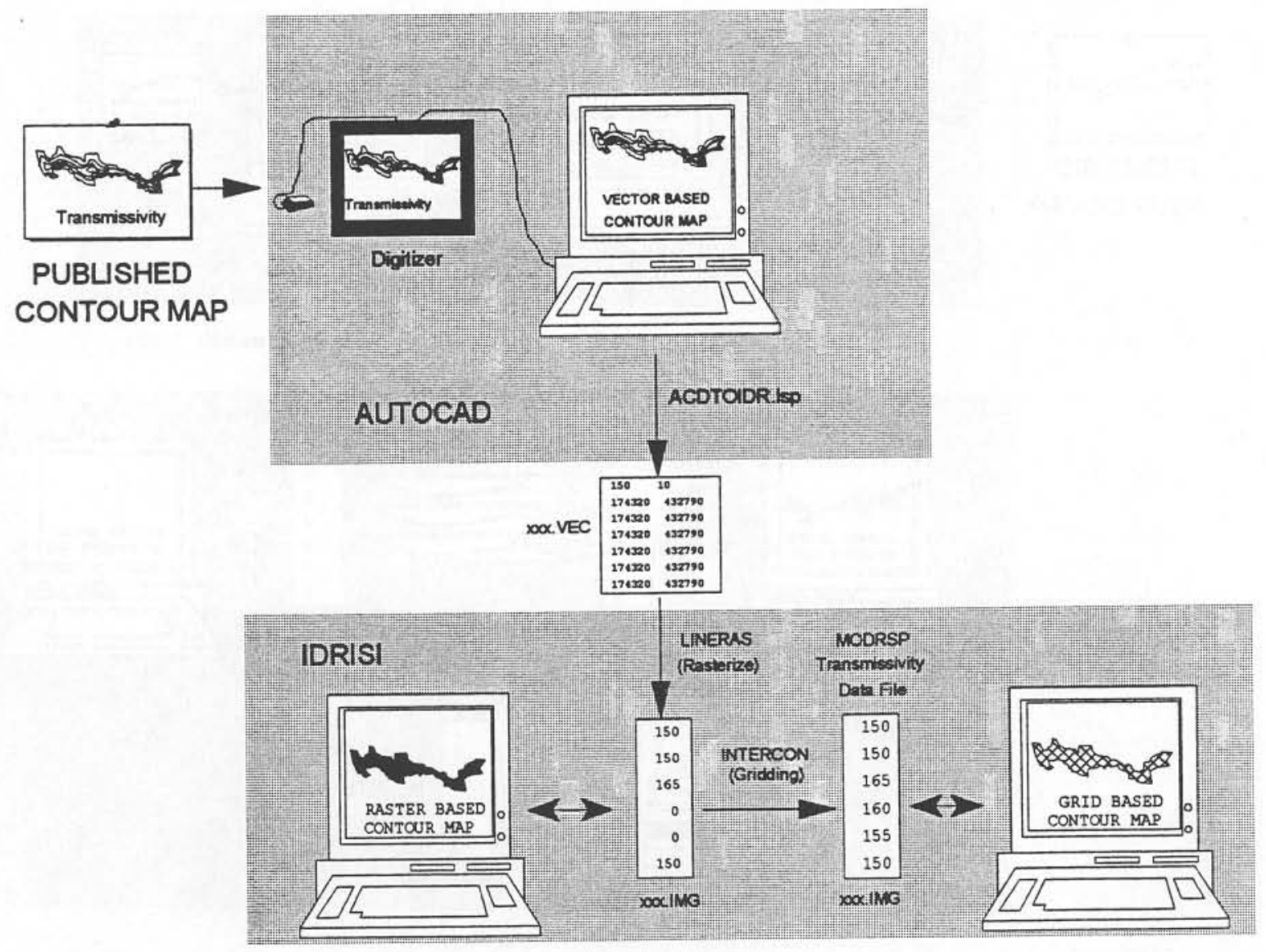

\section{Figure 5.6 MODRSP Transmissivity File}

A raster based aquifer file must first be developed designating those cells inside the aquifer $(+1)$ and those outside $(0)$. This file is then combined with a separate raster file identifying the aquifer cells that are reservoirs, ponds, or perennial streams. For the example shown in Figure 5.7, it is assumed that aquifer boundary data are available from a published map which can be digitized into AUTOCAD. The hydrography data are read into AUTOCAD from TIGER files. Two separate IDRISI vector files are first created from the AUTOCAD data, then processed into raster format, and finally overlain using IDRISI software. The IDRISI output raster file is in a format that can be read directly by MODRSP.

MODRSP requires a well file to identify the location of each cell in the finite difference model for which response coefficients are to be generated. In a groundwatermanagement model, these grid related response coefficients can represent a single well, several wells located within a grid, or be combined with response coefficients developed for other grids to model return flows from groundwater recharge, reservoir seepage, or channel loss. 


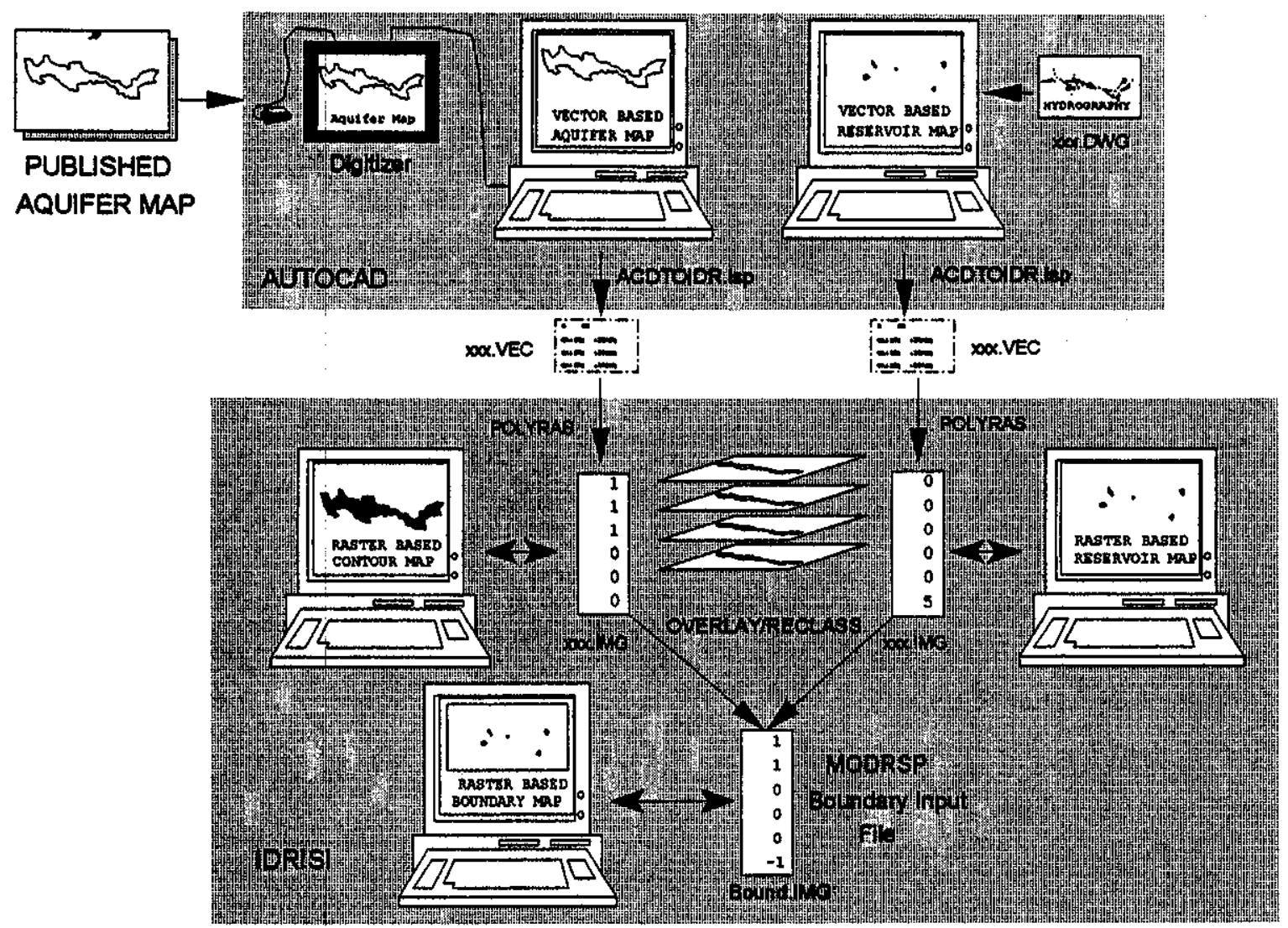

Figure 5.7. MODRSP Boundary File

The steps required to develop a MODRSP well file are shown in Figure 5.8. The example assumes that well or recharge locations are available from published maps and non-geographical related data are available from a separate computer database. The well file used by MODRSP requires the number of wells and their row/column locations. The process of identification of row/column grid locations for a single well is different than for a reservoir or a channel. Well data are treated as point data, and can be associated with a single grid cell. In situations where more than one well is located in the same grid cell, the response coefficients can be generated for the grid cell and assigned to all wells in the grid. Channels or drains are treated as line data, and must generally be represented by more than one grid cell. Response coefficients are generated for each grid cell occupied by the channel. The results are added together to form one set of response coefficients. Reservoirs and ponds are treated as polygons. They also usually cover more than a single grid cell, and the response coefficients generated for a single cell must be combined into a single set. In all cases, it is important that each well, channel, or reservoir be assigned a unit number and that response coefficients generated for a grid cell can be identified with this unit number using DBMS procedures. 


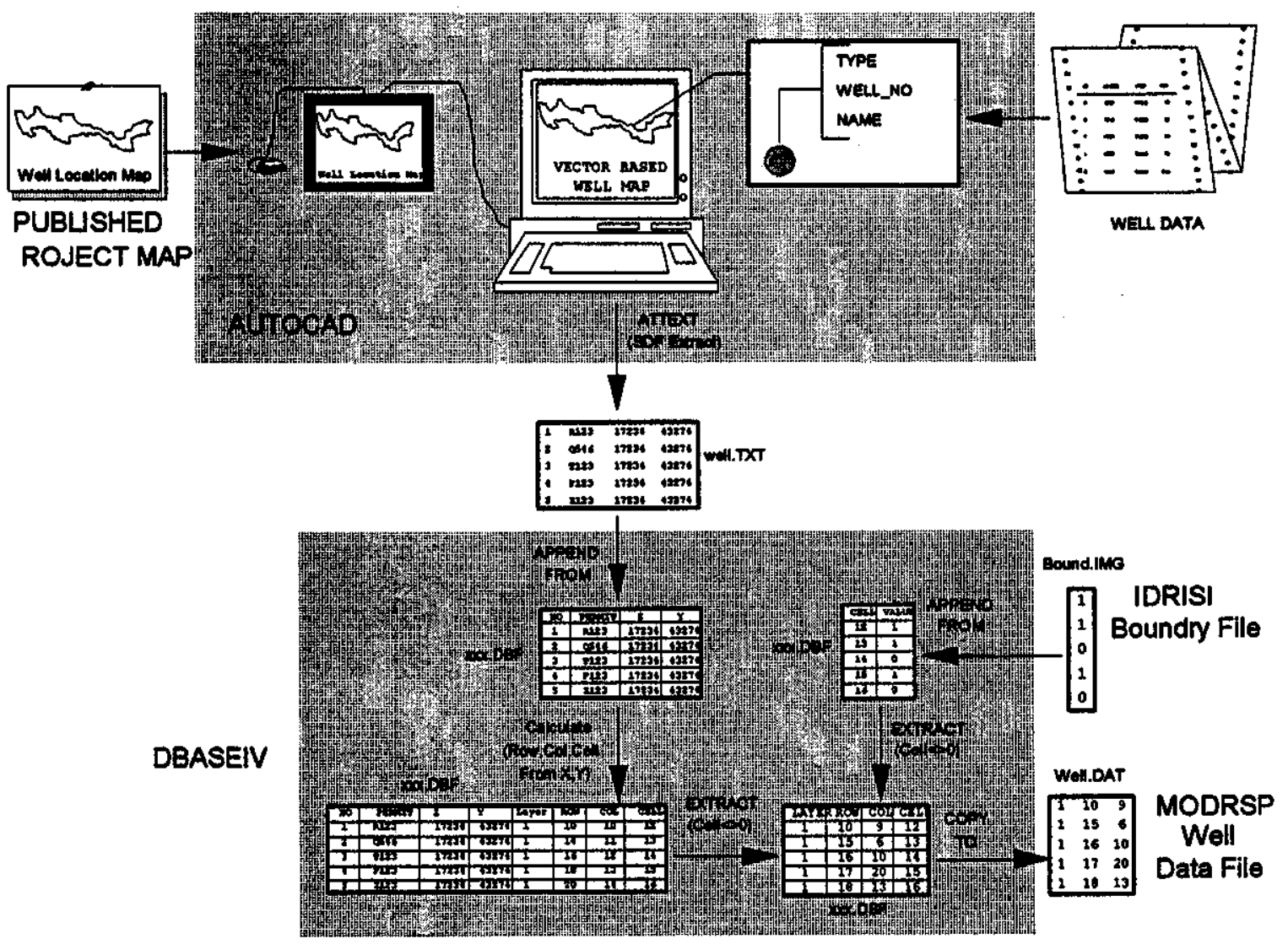

Figure 5.8. MODRSP Well File

To determine return/depletion flow effects on a stream, MODRSP requires a river input file. Procedures for preparing a MODRSP river input file are shown in Figure 5.9. The river data file provides the number and location of river segments in the finite difference model. Each grid containing a river cell must be labeled in the river file by layer, row, and column. A streambed conductance must also be assigned to each river cell. MODRSP calculates a series of time based response coefficients at each river cell location as a result of unit pumping in each cell listed in the well file.

Since a river reach may be represented by more than one grid cell, it is generally necessary to combine response coefficients from several grid cells into a single set for use in a groundwater management model. For this reason, it is important to record which grid cells are associated with which river reaches. Streambed conductance must be calculated outside of MODRSP. GIS and DBMS techniques are useful for generating and managing this type of information. 


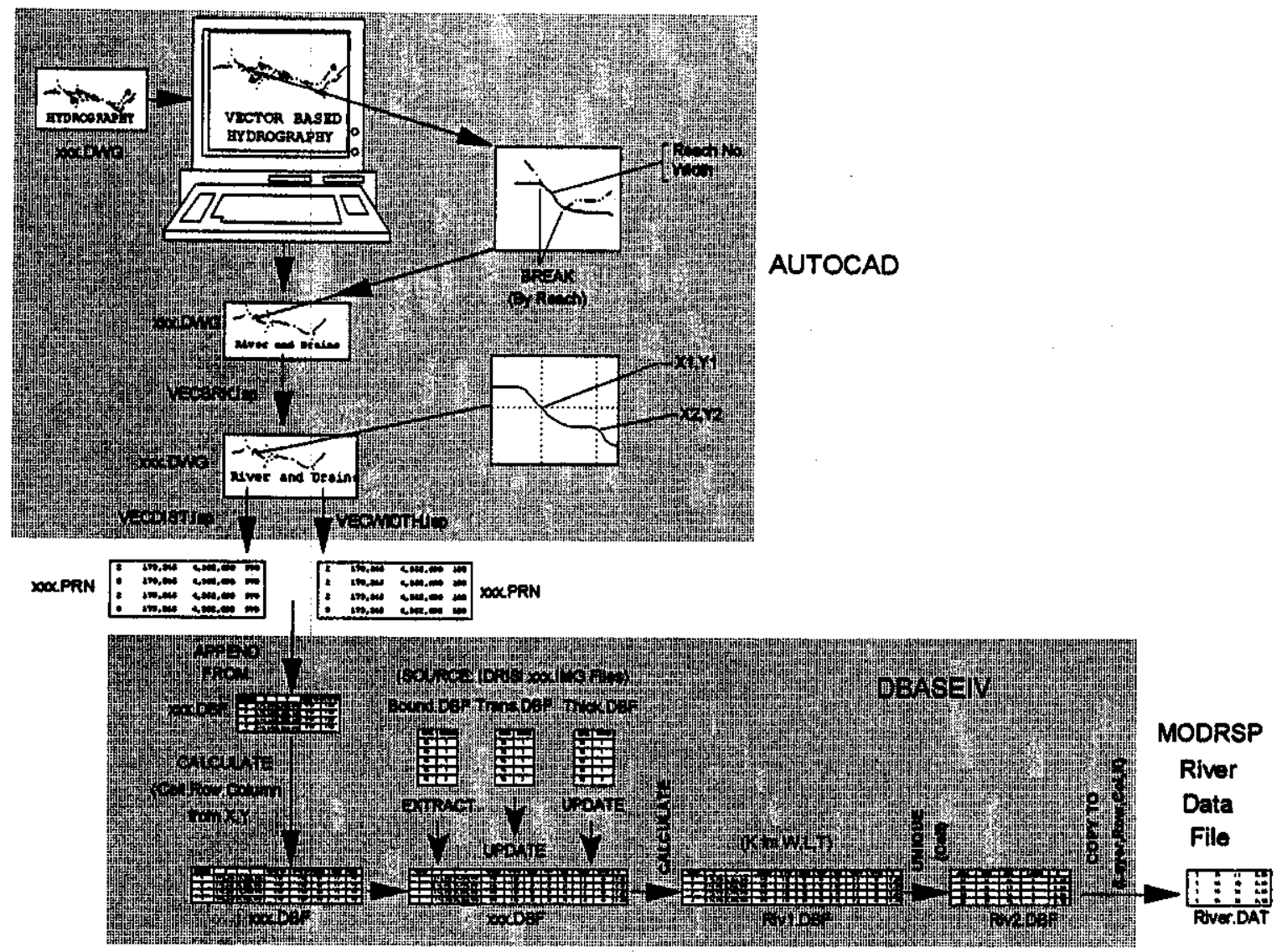

Figure 5.9. MODRSP River File

In this exampleit is assumed that river and stream hydrography data can be read from TIGER files, River conductance can be expressed as a function of stream width, aquifer saturated thickness, grid reach length, and aquifer transmissivity. Stream width data are available from cross-section surveys, and saturated thickness and transmissivity contour maps are also available.

Figure 5.10 shows the input and output files used by MODRSP for generating stream-aquifer response coefficients. Input and output requirements are described in a well documented MODRSP user manual (Maddock and Lacher,1991b).

To execute the program, the user simply types MODRSP at the DOS prompt. The screen clears, the title MODRSP appears, and the user is prompted to supply the names of the various modules input and output file names, as shown in Figure 5.11. 

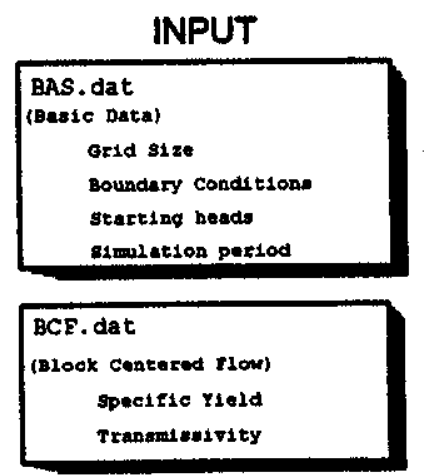

WEL. dat

(Well package)

Numbor

Location

RIV. dat

(R1 ver Packegu)

Number of Renches

Location

Hydraulie conductivity

OPC.dat

Output sormut

PCG. dat

Solution Proceduce

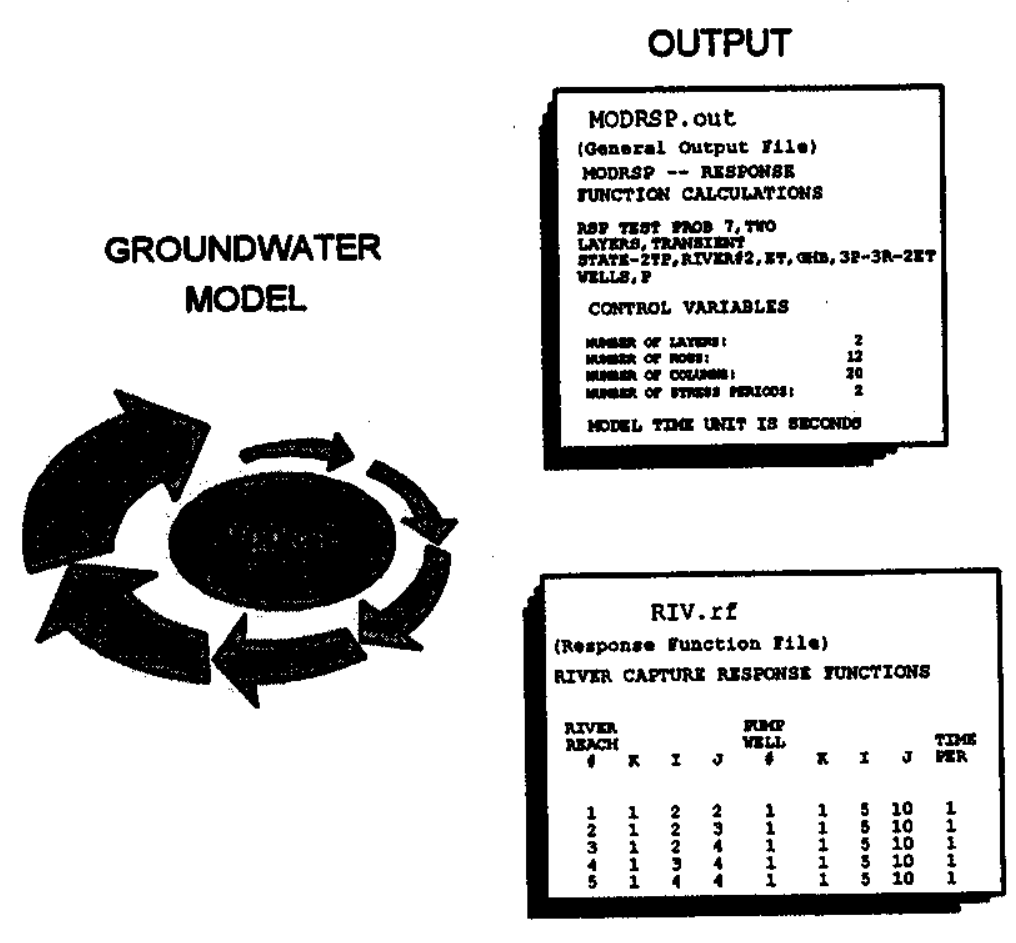

Figure 5.10. Executing MODRSP

MODRSP

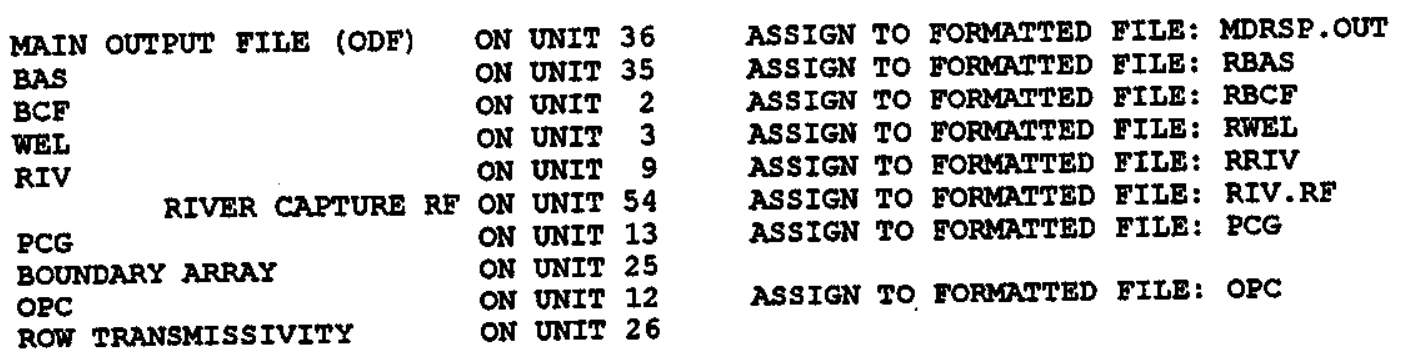

Figure 5.11. MODRSP Input Screen 
The number of output files created by MODRSP depends on the packages being used. For stream-aquifer functions where only river response is being calculated, only two output files are created: the main output file (MDRSP.OUT) and the river response file (RIV.RF), which is the river response file containing the groundwater response coefficients.

The procedures used to post-process MODRSP response file data for use in MODSIM are summarized in Figure 5.12. The coefficients output from MODRSP represent groundwater flow responses over a user defined time period at a single river grid due to the pumping of a unit discharge for a single period at a single well. These results must be summarized by river reach and by source before they can be used in a stream-aquifer management model. This can be a one, two, or three step process depending on whether each record in the well data file represents a single well a segment of channel reach or reservoir, or if more than one well is located in a grid cell. MODRSP determines the effects of well pumping on individual river reach grid cells. Usually most river reaches will be made up of a number of grid cells. Data base concepts can be used to summarize MODRSP response coefficients by river reach.

For reservoirs or channels where more than one cell grid is used to represent the reservoir or channel system, the response coefficients of several grids can be superimposed. Input of the response coefficients generated by MODRSP into a MODSMM river basin network requires preparation of a node source file and a node river reach reference file. These files should each have two fields: one with a MODRSP well or reach number and the other with the corresponding MODSIM node number. Using database techniques, the well and reach numbers assigned by MODRSP in the response output files can be linked with the node reference files and the MODRSP unit numbers can be replaced with the proper MODSIM node values.

The groundwater response coefficient file required by MODSIM can be created by running the Program MODCOEFF.exe using the well response file created from MODRSP as input, which produces a MODSIM response coefficient file. 


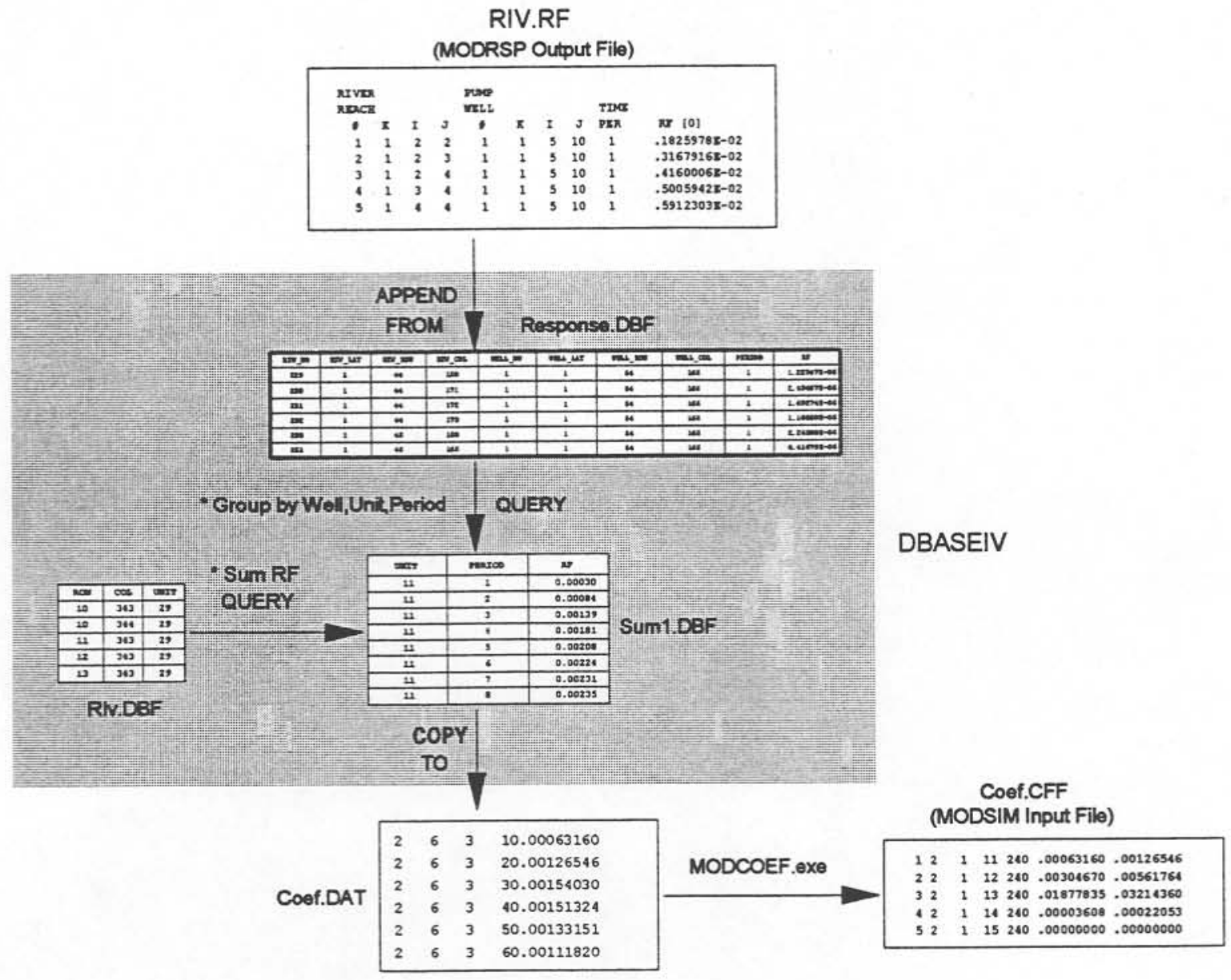

Figure 5.12. MODSIM Coefficient File 


\section{CHAPTER 6}

\section{CASE STUDY: LOWER SOUTH PLATTE RIVER BASIN}

\subsection{Purpose}

A case study is presented for a portion of the Lower South Platte River Basin, Colorado, in order to demonstrate the capabilities of the Stream Aquifer Management Decision Support System (SAMDSS). The case study was carried out with the following purposes:

- conduct a resource inventory to determine sources and types of data available for a conjunctive use decision support system

- develop stream-aquifer response coefficients for the study area using GIS and a finite difference groundwater flow model

- simulate the water right return/depletion flow accounts for a groundwater augmentation plan

- simulate daily administration of a river regulated under prior appropriation water right laws

- $\quad$ present procedures for integrating a groundwater augmentation plan with daily administration of water rights

\subsection{Study Area Description}

The South Platte River begins in the Rocky Mountains of central Colorado and flows northeast across the Great Plains, joining the north branch of the Platte River in Nebraska and eventually draining into the Missouri River. The total drainage area of the basin is 24,000 square miles with $80 \%$ located within the State of Colorado. The Lower South Platte basin represents the section of the river from the Denver gaging station to the Julesburg gaging station at the ColoradoNebraska border (Figure 6.1).

The Lower South Platte basin has a semi-arid climate with an average annual precipitation of 16 inches, with $70-80 \%$ occurring as summer rainfall. Other features include warm summers, cold winters, low humidity, abundant sunshine, considerable wind, frequent tornadoes and hailstorms. The average July temperature is about $74^{\circ} \mathrm{F}$ and the average January temperature is $25^{\circ} \mathrm{F}$ with temperatures ranging from 108 to $-33^{\circ} \mathrm{F}$.

The Lower South Platte basin consists of rolling hills and valleys. The study area is underlain by unconsolidated fill deposits from the Pleistocene and recent age consisting of mixtures of clay, silt, sand, and gravel. The alluvium has been deposited in a broad channel eroded into a bedrock formation of sedimentary rocks ranging in age from Cretaceous to Pliocene. The formations inciude Pierre shale, Fox Hills sandstone, and Laramie, Chadron, Brule, and Ogallala formations.

Since the bedrock formations are relatively impermeable, the valley fill alluvium contains an unconfined aquifer with a water table sloping toward the South Platte River from both sides of the valley. The alluvial aquifer ranges from one to nine miles in width, with aquifer water depths from 10 to 100 feet, saturated thickness depths up to 240 feet, aquifer transmissivity 


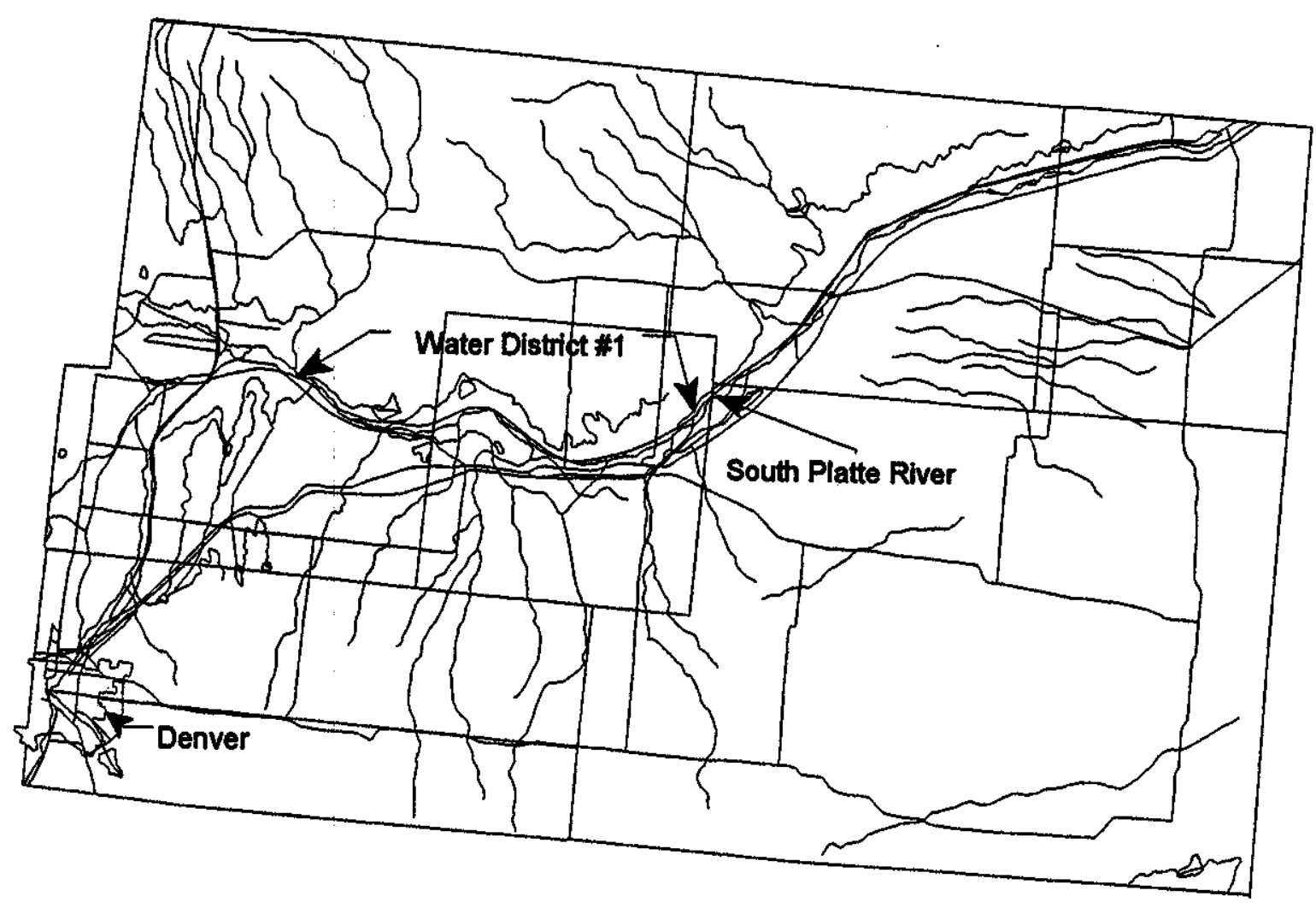

Figure 6.1. Map of Lower South Platte River Basin, Colorado; Source: USGS 1:2,000,000 DLG Data

up to $1,200,000 \mathrm{gal} / \mathrm{day} / \mathrm{fh}$, average specific yield of 0.16 , and an aquifer storage capacity estimated at 3.5 million ac-ft (Hurr et al., 1975).

The primary source of natural streamflow in the basin is from snowmelt, with $70-80 \%$ occurring during the months of April through July. South Platte flow data for the period 1931 through 1983 are available as part of the South Platte Point Flow Study (USBR, 1989). Annual flows in the Lower South Platte at the Denver gaging station averaged 230,000 acre-feet per year for the 53 years of data. The average annual outflow at the Nebraska-Colorado border was 360,000 acre-feet per year. Annual river diversions for the Lower South Platte were 1,150,000 acre-feet per year, with tributary inflows estimated at 480,000 acre-feet per year. Return flows, primarily due to irrigation recharge to the aquifer, are estimated at 750,000 acre-feet per year (USBR, 1989). Although streamflow in the South Platte is variable seasonally, annually, and spatially, it is generally an effluent or gaining stream.

Irrigation is the primary consumptive use of water in the Lower South Platte River basin. Typical irrigated crops include com, sugar beets, beans, and alfalfa, with the growing season generally from April to October. Recharge to the aquifer has been estimated at $50 \%$ of applied water on irrigated land (Hurr et al., 1975). A number of off-stream reservoirs have been 
constructed to store irrigation water, although it is estimated that $25-65 \%$ of reservoir water is lost to seepage and evaporation.

The Lower South Platte River basin currently lacks a significant on-stream storage project, although several projects have been proposed. The lack of in-stream storage has reinforced the need for development of integrated conjunctive use schemes in the basin for surface water and groundwater.

\subsection{Water Rights Administration}

Allocation of water in the study area is subject to the Doctrine of Prior Appropriation. The Office of the Colorado State Engineer (SEO) has the responsibility of administering all water in the State. The State is divided into water divisions, with each water division subdivided into water districts. The Lower South Platte River is in Division \#1 and includes three water districts (1,2, and 64), not including tributaries. Each water district is under supervision of a Water Commissioner. The main branch of the Lower South Platte River from Denver to the Nebraska border extends for 260 miles, has 64 points of diversion and 138 major surface water rights (SPBWMC, 1989).

Division \#1, Water District \#1 covers a 70 mile stretch of the South Platte River from Kersey to Balzac (Figure 6.1). There are five reservoirs, 15 major river diversions, 35 major water right decrees, 11 major tributary inflows, and three active gage stations. Table 6.1 shows the distribution of water rights for District \#1.

Since wells are included in the priority system, pumping is not allowed when a senior water right places a call on the river. To protect senior surface water rights and prevent the interruption of well pumping during the irrigation season, well owners are allowed to implement a groundwater augmentation plan. This allows replacement of well depletion flows through groundwater recharge, water exchanges, and water trades. Water District \#1 has over 5000 decreed wells, 27 conditional or approved augmentation plans, and 32 monitored groundwater recharge sites (SEO database).

\subsection{Bijou Irrigation System}

Bijou Irrigation Company operates one of the major irrigation systems in District \#1. Complete details on the Bijou Irrigation System are available from the Bijou Irrigation System Plan of Augmentation Engineering Report (HRS, 1983). The Bijou system diverts irrigation water 
from the South Platte River into the Bijou Canal. The offtake is located 13 miles downstream of the Kersey gage station and just east of the town of Hardin. Surface water is delivered to laterals at various points along the main canal for irrigation and groundwater recharge. The Bijou Canal has a capacity of $600 \mathrm{cfs}$ at the headgate and is $\mathbf{4 0}$ miles in length. The canal also carries releases from Empire Reservoir, exchange water, and inflow to Bijou \#2 Reservoir. The Bijou system has an irrigated command area of 24,000 acres with 2,000 acres irrigated solely from surface diversions.

The average annual surface water supply to the Bijou Canal is 69,380 acre-feet (19601980). Water delivered into Bijou \#2 Reservoir cannot be returned to the canal for irrigation purposes; however, it can be delivered to Bijou Creek for augmentation purposes. Remaining water in the reservoir is lost through evaporation and recharge to groundwater through seepage. Bijou Canal has up to $43 \%$ main canal conveyance losses and an estimated $35 \%$ loss below the headgate laterals. The average annual crop irrigation requirement for the system is 39,793 acrefeet (1960-1980). Ditch water supplies an annual average of 25,850 acre-feet, with the remaining water supply from pumping groundwater.

A groundwater augmentation plan for the Bijou Irrigation Company was prepared by HRS (1983) to replace depletions that would otherwise accrue to the South Platte River as a result of well pumping used to meet irrigation demands. A map showing the location of the various components of the augmentation plan is presented in Figure 6.2.

The Bijou Irrigation Company Augmentation Plan has an original appropriation date of 1972 , which was updated in 1986 . The plan involves 196 individual wells and a groundwater recharge program that includes recharge from Bijou Canal, Bijou Reservoir \#2, several creeks, and a number of small recharge ponds. Effects on the South Platte River from pumping and recharge are determined for the augmentation plan using stream depletion factor (SDF) values taken from USGS SDF hydrogeologic maps (Hurr et al., 1972). The canal and creeks are divided into reaches based on average SDF values. The original augmentation plan used the USGS computer program SDFDEP (Hartwell, 1987) to determine stream accretion and depletion. The SDFDEP computer program uses the Glover analytical method (Glover,1977) to generate groundwater response coefficients. The original augmentation plan was prepared using historical data, with groundwater pumping estimated as that portion of calculated historical crop water requirement that could not be met through surface diversions. It was anticipated that records of measured recharge supplied to each site would be maintained on a regular basis and that well use would be estimated from crop water requirement calculations.

At the present time, a water right augmentation account is prepared for the Bijou system on a monthly basis by the Northern Colorado Conservancy Water District (NCCWD) and is submitted to the Office of the State Engineer (SEO) for use in administering water in the South Platte River. The current calculation procedure for preparing the water right account balance uses SDF recharge site values, measured channel inflow and outflow, and estimates of surface area evaporation to calculate monthly recharge credits. Account debits due to well pumping are estimated based on calculated irrigation crop demands minus irrigation water supplied through measured surface diversions. Irrigation demands are determined for each of the 200 wells. BlaneyCriddle evapotranspiration values are calculated from actual climatological data. Irrigated area, crop distribution, and cropping patterns are provided by the Bijou Irrigation Company members. 


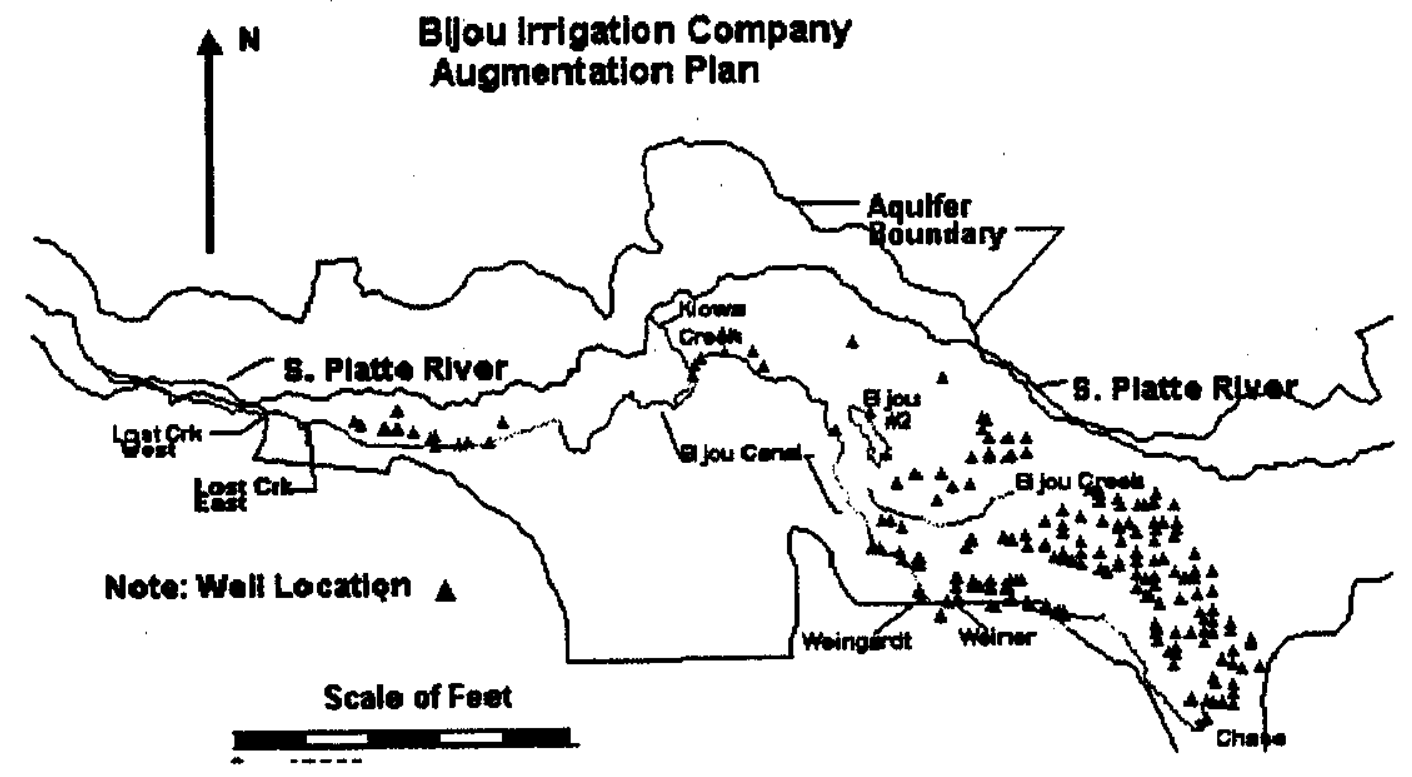

Figure 6.2. Bijou Irrigation Company Augmentation Plan

If during the irrigation season there is a call for water by a senior water right owner and the Bijou Augmentation account for the month shows a negative balance, then the Bijou Irrigation Company must provide supplemental water to the SEO to offset the negative balance, or face the possibility have having its member wells temporarily shut down. Supplemental water can come from exchanges, trades, and upstream reservoir releases.

\subsection{Groundwater Management Issues}

Important issues related to groundwater management in the basin include: stream depletion caused by wells operating under an augmentation plan; stream accretion resulting from recharge under augmentation plans; and the net effect on the river and its tributaries resulting from operation of wells and recharge projects. Because of lags in the response time between pumping and the resultant river depletion, pumping at a well site during the irrigation season may have minor affects on a river source during the irrigation months. It is possible that the major affects of well pumping during the irrigation season may not impact the river source until the off-season winter months when there is no irrigation call on the river by senior water right owners and therefore no legal consequences resulting from the pumping.

Well locations, recharge sites, aquifer boundary conditions, and aquifer characteristics impact the net balance of depletion and accretion spatially along the river system. It is important that the degree of injury to senior water rights over time and the location of those water rights injured be identified. Effective river administration requires a daily accounting of the affects of an augmentation plan. The management of a groundwater augmentation program requires an understanding of the consequences of various recharge projects. 


\subsection{Inventory of Data Resources}

An inventory of data resources was carried out as part of the SAMDSS implementation process. Although a number of the data sets reviewed are unique to Colorado, most of the data required to support SAMDSS are available from local, state, or federal agencies involved in collecting and monitoring water resource data in other States.

The type and amount of data available from the U.S. Geological Survey (USGS) is quite extensive. The USGS Ground Water Site Survey Database (GWSI) includes data on depth of well, ground surface elevation at a well, specific capacity, transmissivity, well location, pumping capacity, seasonal water levels, and well use. Published groundwater maps showing hydrogeology characteristics such as well location, bedrock configuration, aquifer delineation, water table contours, saturated thickness, and transmissivity are available for most major aquifers (Hurr, et al., 1972). Digital Line Graphs (DLG) provide digital representation of cartographic information such as hypsography (contours), hydrography (water), vegetative surface cover, boundaries, survey control markers, transportation, man made features, and U.S. Public Land Survey System (township, range, section).

Land Use and Land Cover (LULC) data provide information on nine major land classes such as urban or built-up land, agricultural land, range land, forest land, water, and wetlands. The Geographic Names Information System (GNIS) is an automated database system on geographic names. The Digital Elevation Model (DEM) provides elevation data interpolated from USGS maps. LANDSAT provides satellite photos and the Northem Great Plains AVHRR Data Set includes NOAA-9 Advanced Very High Resolution Radiometer (AVHRR) data at one kilometer grids for bands 1-5 afternoon satellite coverage with normalized difference vegetative index images.

Another important source of data is the Colorado Division of Water Resources. Typical databases include: the Water Rights Database which contains data on structure type, source, location, use, appropriation date, and decreed amount; Diversion and Reservoir Database, which provides information on daily diversion and reservoir levels; Well File which includes information on location, well number, uses, well permit number, owner, yield, depth, well elevation, appropriation date, and pumping data where available; Aquifer Water Levels, an annual publication of water levels in various aquifers; Water Talk, a telephone hookup to satellite water monitoring system that provides on-line access to streamflow at important stream gage locations; Streamflow Database which contains data collected from stream gage network monitoring stations; and Daily Report of River Flows and Ditch Diversions prepared by the Water Commissioners.

Cross section data for tributaries and streams at road crossings are available from the Bridge Division of the Colorado Department of Transportation. The U.S. Soil Conservation Service has prepared State-County Soil Digital Data (STATSCO) which contains information on soil type, vegetative cover, drainage potential, etc. The Colorado State Climatologist maintains a Climatology Data Base which contains daily data on precipitation, evaporation, temperature, and solar radiation.

A number of publications are available from the National Oceanic and Atmospheric Administration. These include: Climatological Data of Colorado, a monthly publication of 
Colorado climatology data; Evaporation Atlas for Contiguous 48 United States, a published estimate of average and seasonal evaporation for free water surface; and Mean Monthly, Seasonal, and Annual Pan Evaporation for The United States, which provides estimated pan evaporations based on observations from Class A pans and meteorological measurements that can be used to develop free water surface maps.

The Bureau of the Census is the source for the Topographically Integrated Geographic Encoding and Referencing System (TIGER files). These files are a compilation of digital maps of the entire U.S. and an accompanying data base that integrates map data with related geographic information and population statistics. The TIGER files include digitized data on hydrography, roads, and political boundaries.

The U.S. Bureau of Reclamation has conducted many river basin hydrologic studies. The South Platte River Point Flow Study is an historic accounting of monthly streamflows for the period 1931-1983 at defined locations along the South Platte River, taking into consideration diversions, tributary inflows, and reach gains and losses.

The Bijou Irrigation Company maintains their own detailed records. The Augmentation Report (HRS, 1983) provides the engineering data used to develop a plan for augmentation for 196 wells operating under the Bijou Irrigation System. The Well Consumptive Use Data Base contains data on well owner, well permit number, and net consumptive use demand for 1985-1991. The Well Decree Data Base contains information on well owner, well permit number, location, decreed pumping rate, and SDF. The Recharge Accounting Forms are monthly accounting forms on recharge amounts for the Bijou Irrigation Company. Well and recharge maps are available for the project area.

\subsection{Generating Response Coefficients Using MODRSP}

MODRSP was used to generate stream-aquifer response coefficients for each of the 196 wells and 32 recharge sites identified in the Bijou Augmentation Plan (Figure 6.2). The alluvial aquifer is unconfined but water table fluctuation compared with depth of saturated thickness is sufficiently small so that transmissivity can be treated as independent of head (Romero, 1990). Sets of coefficients for each well and recharge site were developed to simulate the effects of groundwater pumping and recharge on the South Platte River and its major tributaries. The Lower South Platte River was divided into 29 reaches with 11 separate tributaries (Figure 6.3).

\subsubsection{Groundwater Network}

The network for the finite difference groundwater model was constructed to cover all of Water District \#1 located within the South Platte alluvial aquifer. The aquifer boundary was taken from USGS maps prepared by Hurr, et al. (1972). A 370 by 140 groundwater grid network with each cell having dimensions of $1000 \mathrm{ft} \times 1000 \mathrm{ft}$., as shown in Figure 6.4, was developed using GIS techniques. MODRSP transmissivity, boundary condition, river, and well data input files were also developed using the GIS and database procedures. 


\section{Lower South Platte River \\ Water District $\#$}

River Reach and Tributarles

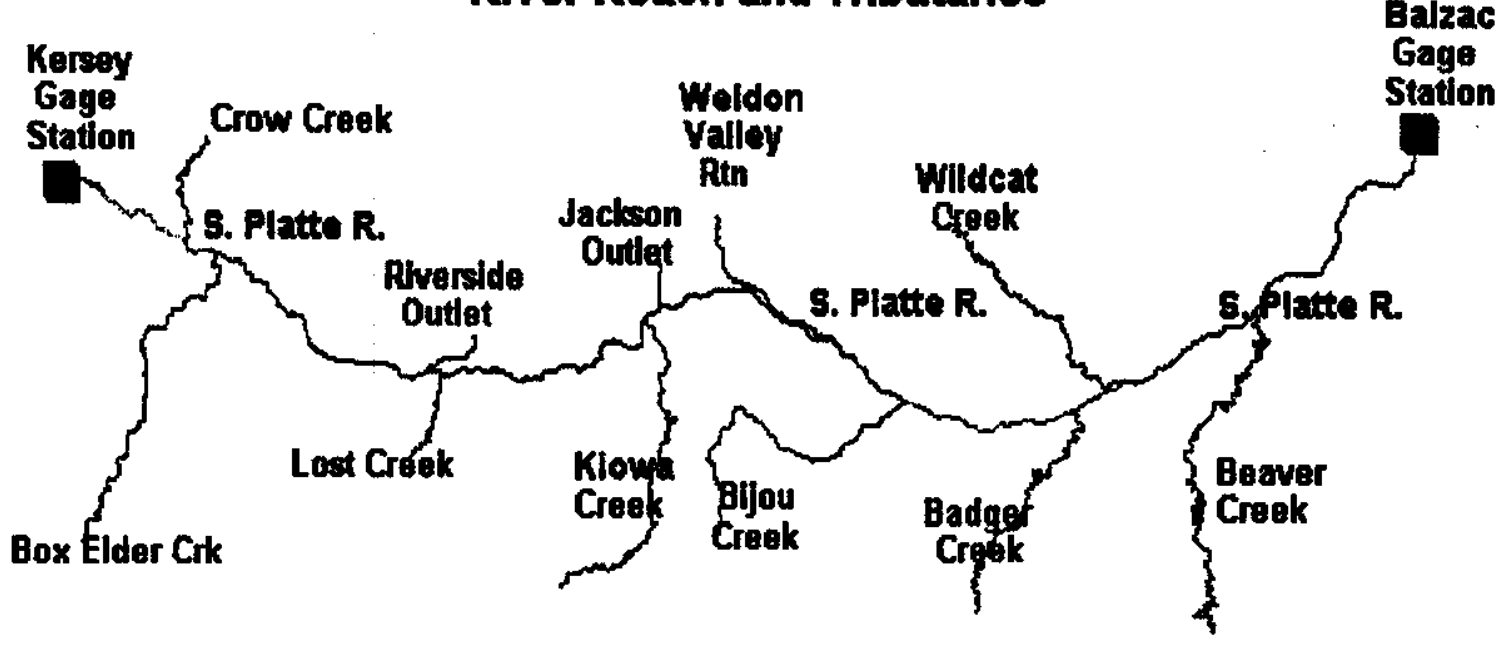

Figure 6.3. Water District \#1, Lower South Platte River System

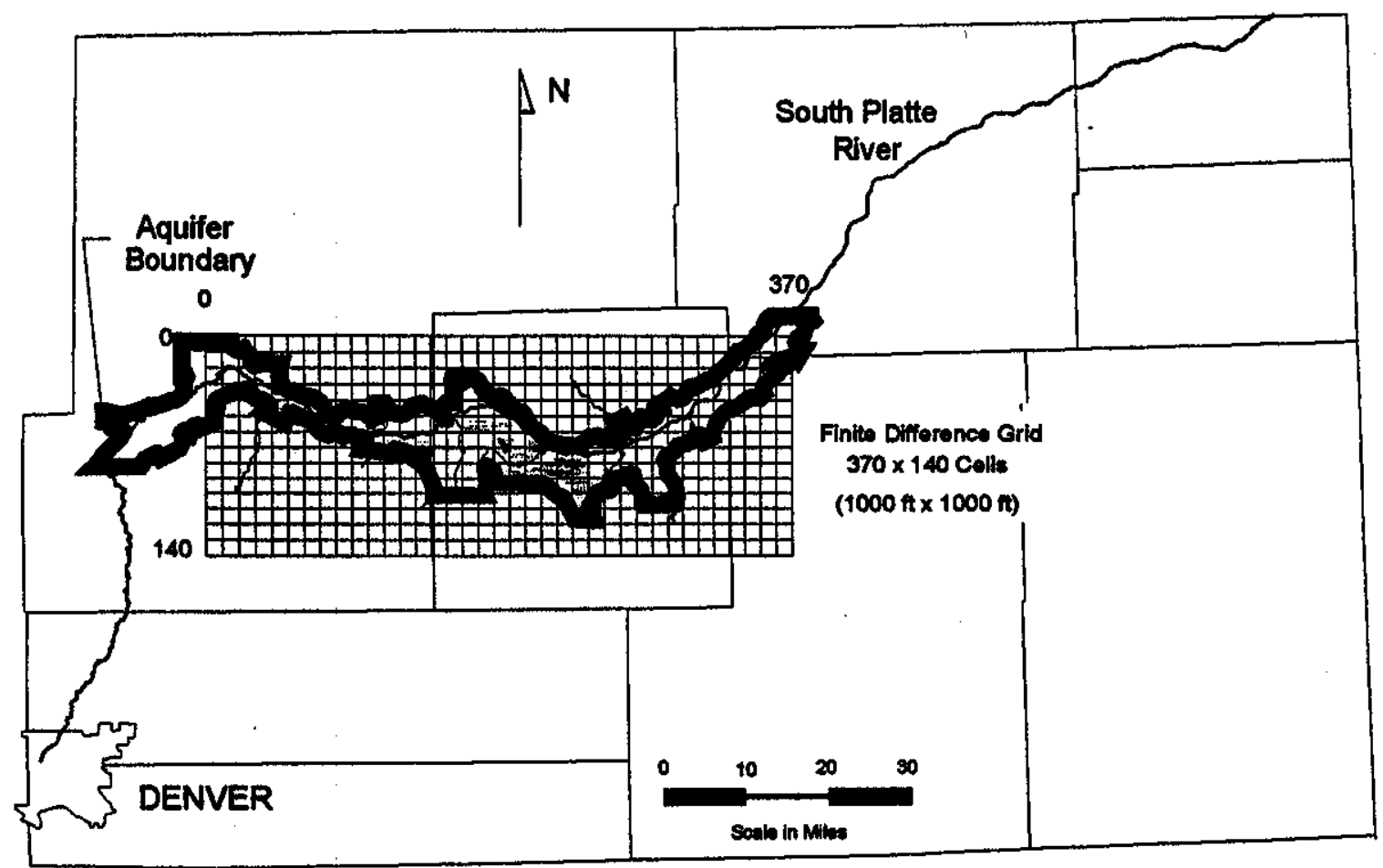

Figure 6.4. Groundwater Model Finite Difference Grid 


\subsubsection{Hydrography Data}

Hydrography for the study area was read into AUTOCAD from Bureau of Census TIGER Files, The data were edited into single AUTOCAD polylines as shown in Figure 6.5. The USBR Point Flow Study schematic (USBR, 1989), USGS 1:100,000 County maps, the State Engineer Diversion Structure computer database for District No. 1, and South Platte Straight Line Diagram for Irrigation Division No. 1, Water District \#1 (Wheeler, 1985) were used to identify individual river reaches, drains, canals, and reservoirs.

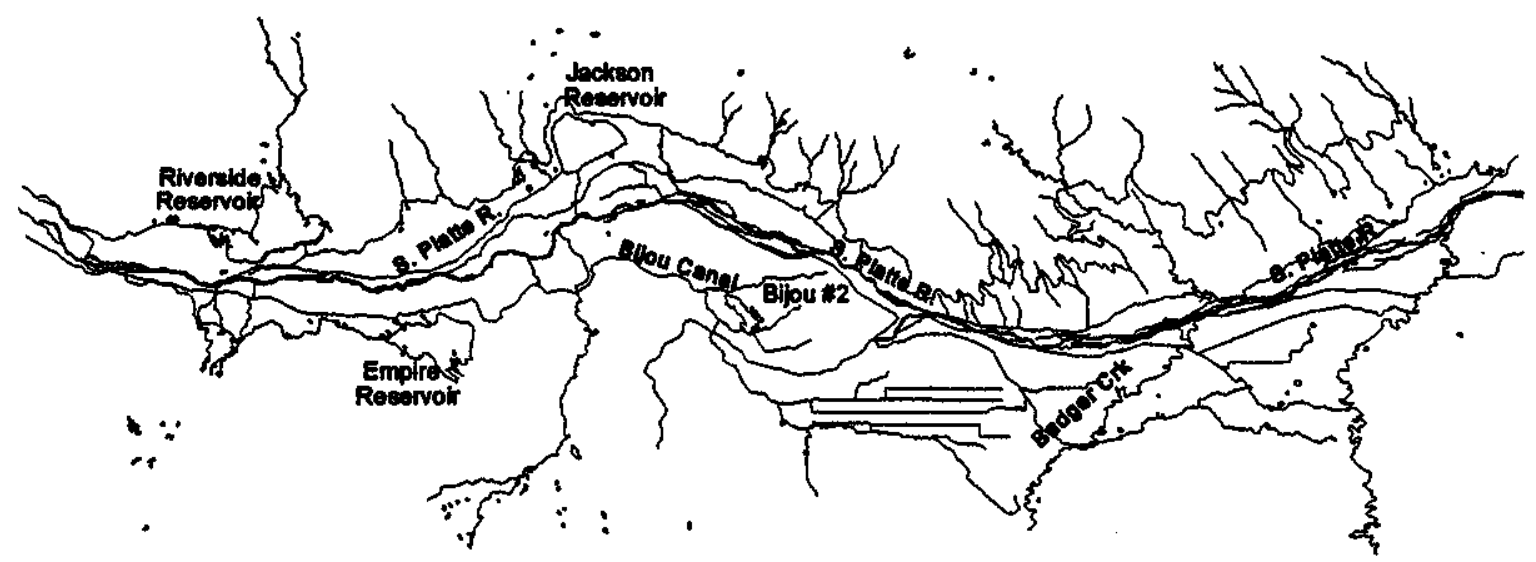

Figure 6.5. Lower South Platte Basin Hydrography; Source: TIGER Files

\subsubsection{Transmisstivity Data File}

Aquifer transmissivity data were digitized from transmissivity maps in Hurr et al. (1972) for the Greeley, Weldonna, and Brush reaches of the South Platte River (Figure 6.6). IDRISI was used to develop a raster grid file from the contour data. Cells outside the aquifer were assigned a transmissivity value of zero. The data in $1000 \mathrm{gal} /$ day/ft was converted to $\mathrm{ft}^{2} / \mathrm{sec}$ for input into MODRSP. 


\section{Lower South Platte River Basin}

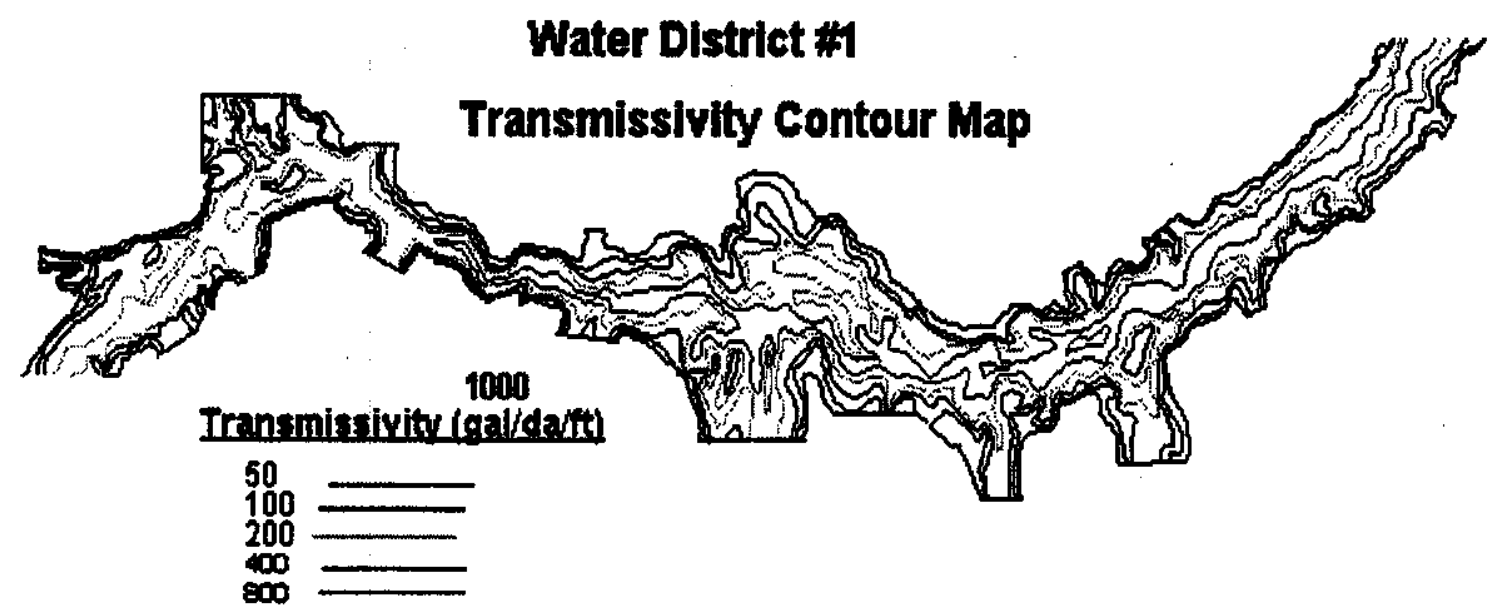

Figure 6.6. Lower South Platte Transmissivity Map

\subsubsection{Boundary Data File}

The boundary file was developed using IDRISI. All cells located within the aquifer were assigned a value of one, with cells outside the aquifer assigned a value of zero to represent no flow. The east and west boundaries of the aquifer were also assigned as no flow boundaries. Simulation of groundwater flow across these boundaries requires assigning appropriate recharge and discharge wells to these cells. This step is not required, however, for developing response coefficients. Reservoirs were assigned as constant head boundaries and given a value of -1 .

\subsubsection{Well Data Files}

Three separate MODRSP well files were prepared. These files represent the Bijou irrigation wells, the Bijou recharge canals and drains, and the Bijou recharge ponds and reservoirs. Well data were digitized into AUTOCAD using the Bijou Irrigation Company Plan for Augmentation Irrigation Well Location Map (HRS, 1983). The associated grid cell, along with the groundwater grid row and column number for each well, was directly calculated from the well x,y locations provided in AUTOCAD. Although the Augmentation Plan covers 196 wells, the MODRSP well file created coefficients for only 176 wells. The calculation process was not duplicated for those wells located in common grid cells, and several wells are actually located outside the defined aquifer boundaries.

For implementation of the Bijou Augmentation Plan, the Bijou Canal, Kiowa Creek, and Bijou Creek recharge sites were subdivided into 26 separate recharge sites. Locations of the Bijou augmentation plan recharge drains and canals are available from the TIGER hydrography data. For, demarcation of individual reaches, however, it was necessary to digitize this information into 
the computer using the Bijou Irrigation Company Plan for Augmentation Recharge Site StreamDepletion Factor Contour Map (HRS,1983). This reach information was then overlain on the hydrography data. Since IDRISI apparently omits several grid cells when converting from vector format to raster format, AUTOLISP (VECBRK.lsp and VECWIDTH.Isp) was used to output data for these polylines into a format that could be read by QUATTRO PRO (ACDPRNIN.wq1). QUATTRO PRO was used to calculate the finite difference groundwater model grid cell row and column locations for each site. The 26 recharge sites were defined by 246 grid cells.

Locations of four of the seven reservoir and pond recharge sites were input from the TIGER hydrography data. For the Weimer and Lost Creek East pond sites, it was necessary to digitize their locations into AUTOCAD from the Bijou Irrigation Company Plan for Augmentation Recharge Site Stream-Depletion Factor Contour Map (HRS,1983). IDRISI was used to convert the vector polygons into raster grids. IDRISI requires a vector polygon with a coverage area greater than $50 \%$ to be recognized and converted to a raster cell. The IDRISI reservoir/pond file was read into DBASEIV to separate out the reservoir and pond grid cells. The DBASE file was retrieved into a QUATTRO PRO spreadsheet to calculate the finite difference model row and column values from the grid cell values. The seven recharge reservoirs and ponds of the Bijou Augmentation Plan were covered by 25 finite difference model grid cells, with the Weimer and Lost Creek West recharge ponds falling outside the aquifer boundary.

\subsubsection{River Data File}

The process of identifying grid locations of the river and tributary cells is similar to that used for the recharge channel and drain well file, although more complicaterd. TIGER hydrography data were imported into AUTOCAD as polylines, edited, and then separated into river reaches and tributaries, with each river reach and tributary assigned a unit number. Since it was assumed the South Platte river acts as an hydraulic barrier, tributaries on the north side of the Platte River were not included in the analysis. AUTOLISP (VECBRK.Isp and VECWIDTH.lsp) was used to place the polylines in a format that could be read by QUATTRO PRO (ACDPRNIN.wq1). The finite difference groundwater model grid cell row and column locations for each site were then calculated. At river and tributary confluence locations, the finite difference grid cell was assigned the unit value of the river reach.

Preparation of the river file also requires a calculated river-bed material conductance value. This value was estimated from the method of flow nets (Peters, 1978; Illangasekare, 1978; Restrepo, 1988; Zhang, 1990), where:

$$
\text { Conductance }=\frac{T}{e} L\left(\frac{W_{p}+2 e}{e+10 W_{p}}\right)
$$

where $T$ is transmissivity of the aquifer underlying the reach; $e$ is average saturated thickness of the aquifer along the reach; $L$ is length of reach; and $W_{p}$ is wetted perimeter of the stream, which is assumed to equal the width of reach with negligible error.

With transmissivitiues already available for each grid cell (Figure 6.6) as an IDRISI raster file (Figure 6.6), saturated thickness data (Figure 6.7) were digitized into AUTOCAD from USGS saturated thickness maps (Hurr, et al., 1972) for the Greeley, Weldonna, and Brush reaches of the South Platte River. The resulting contour map was transferred to IDRISI vector file format, from 


\section{Lower South Platte River Basin}

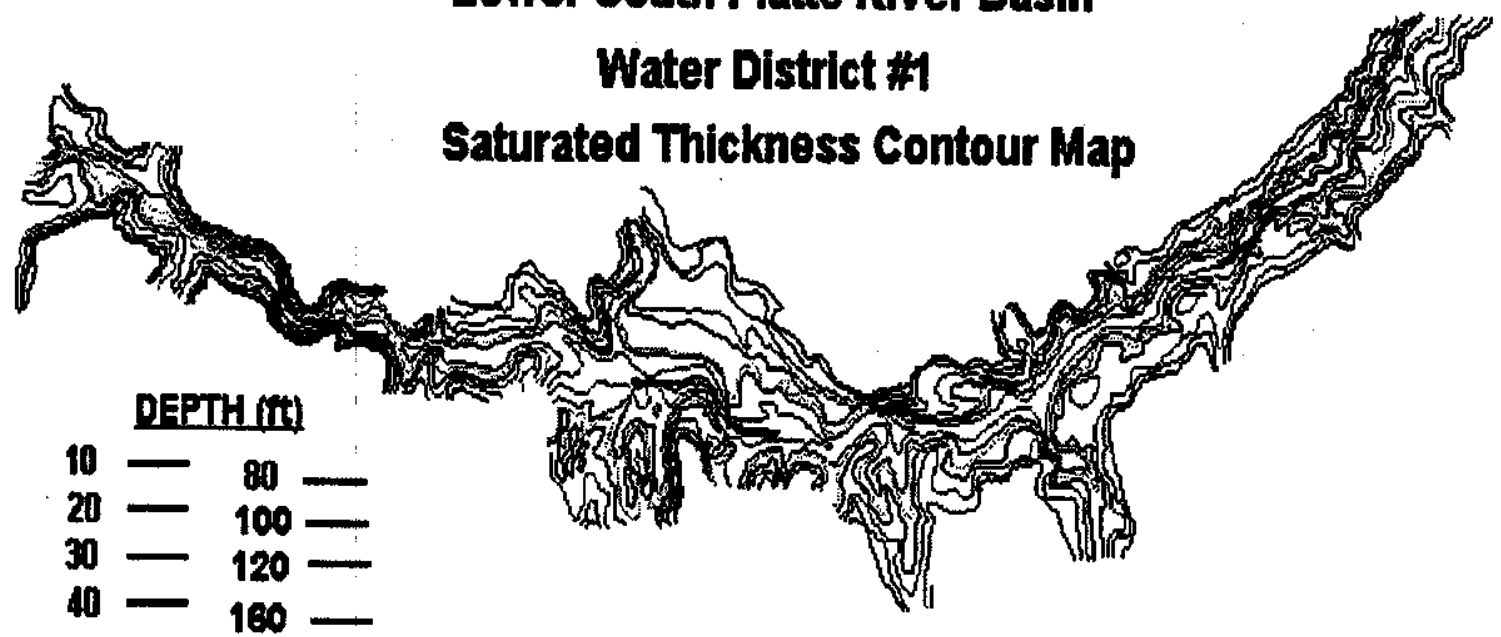

Figure 6.7. Lower South Platte Saturated Thicloness Map

which IDRISI was then used to develop a raster grid file from the saturated thickness contour data. Cells outside the aquifer were assigned a saturated thickness value of zero. The IDRISI transmissivity and saturated thickness files were imported into DBASEIV and the data required for river and tributary grid cells extracted. Reach width data were assigned as a polyline width to each river reach and tributary in AUTOCAD and extracted as grid cell data using the aforementioned AUTOLISP and QUATTRO PRO files. Width data were then linked by cell to the river and tributary cell data in DBASEIV. Tributary width was derived with data from the Colorado Highway Department Bridge Division database. The South Platte River width was set at $150 \mathrm{ft}$. $(50 \mathrm{~m}$ ) based on previous South Platte River Studies (Peters, 1978; Zhang, 1990). A separate AUTOLISP program (VECDIST.lsp) was written to determine the river reach length in each grid cell. QUATTRO PRO (ADPRNIN.wq1) was used to assign a cell location to each grid and its attribute width. This information was then linked with the river and tributary data in DBASEIV. The river conductance value was calculated and the final results output from DBASEIV to an ASCII text file for use by MODRSP. The 29 river reaches and six tributaries were represented by a total of 889 grid cells.

\subsubsection{Executing MODRSP}

MODRSP was set up to generate response coefficients for 120 monthly periods. or ten years. Specific yield was set at a constant value of 0.16 . MODRSP was run with the following input files: basic package input file, block-centered flow package input file, well package input file, preconditioned conjugate gradient file, a transmissivity data file, and a boundary condition data file. The program was run using three different well package files: a well file, a recharge file for channels and drains, and a recharge file for ponds and reservoirs. The MODRSP input and output files are listed in Appendix D. Because of the number of wells, recharge sites, and river reaches it was considered more efficient to run the program on the Colorado State University IBM RISC 6000 computer. Rumning on a $50 \mathrm{Mhz} 80486$ PC under Windows required about 20 minutes per well, and a DEC 5000 workstation under UNDX requiring about 10 minutes per well. 


\subsubsection{Post-Processing MODRSP Response Data Fules}

The response data file output from MODRSP was processed using DBASEIV, with cells summed by recharge and well site. Well, recharge, river reaches, and tributary site numbers were assigned actual MODSIM node values. The results were exported to an ASCII text file and run through the Program MODCOEFF.EXE. The final result was a MODSIM groundwater response coefficient file with 1079 sets of coefficient data representing monthly response data for a ten year period for 193 wells, 30 recharge sites, 13 river reaches and four tributaries. Again, several of the wells positioned outside the aquifer boundary were deleted from the analysis.

\subsection{Augmentation Water Right Account Using MODSIM}

\subsubsection{Introduction}

The Bijou Augmentation Plan (HRS,1983) was selected as the case study example. The return/depletion flow account was prepared from recharge and groundwater well data provided by The Northem Colorado Water Conservation District (NCWCD) using a monthly time step. One reason for selecting the Bijou Augmentation Plan was because of the role of the NCWCD as a consultant for the Bijou Irrigation Company. NCWCD prepares a monthly augmentation account balance which is submitted to the Office of the State Engineer, where it is used to determine potential injury to senior water rights during river administration. Due to this reporting activity, excellent records are available for the Bijou Augmentation Plan.

The present calculation procedure for the Bijou Augmentation Plan account uses calibrated SDF values (Hurr, et al., 1972; Hartwell, 1987) with the Glover analytical method (Glover, 1977). The limitations of this method have been previously documented in this report, including: lack of consideration of spatial variation in depletion and accretion; incomplete consideration of the major tributaries; and utilization of an inaccurate lumped parameter approach to consider the influence of aquifer characteristics and boundary conditions on groundwater flow responses. An improved alternative is to use response coefficients generated from a finite difference groundwater model such as MODFLOW. This case study analyzes the Bijou Augmentation Plan using both methods and compares results.

\subsubsection{MODSIM Augmentation Network}

The monthly water account for the Bijou Irrigation Augmentation Plan was simulated using MODSIM for a period of seven years from 1985 to 1991. The MODSIM network for the system is presented in Figure 6.8. The network was constructed with 281 nodes, 8 reservoirs, 232 demands and 81 links. Detailed input data files are listed in Appendix E. 


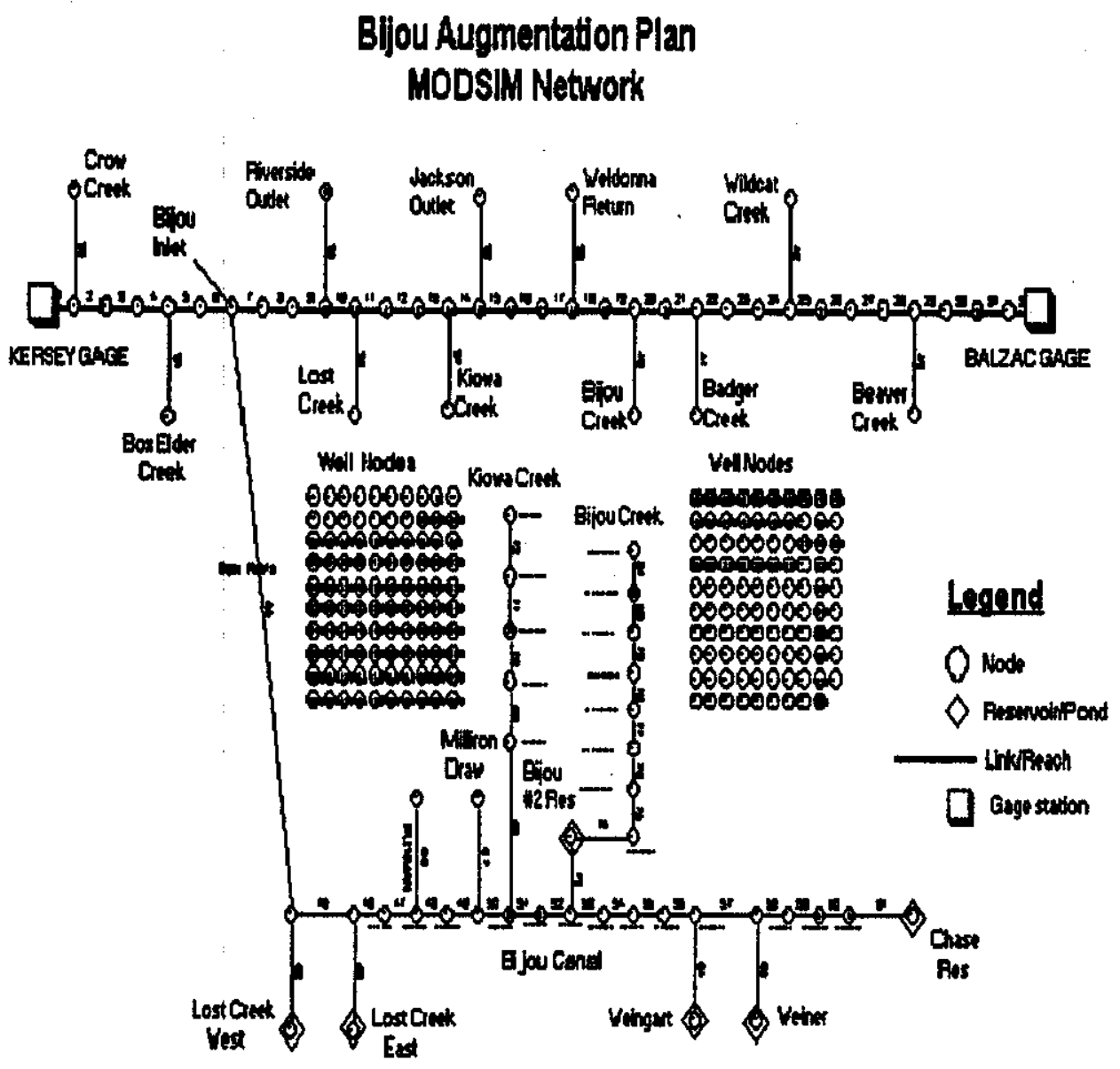

Figure 6.8. MODSIM Network for Bijou Augmentation Plan

A list of the 196 member wells covered in the Bijou Plan is presented in Appendix F. The recharge sites included in the plan are Bijou Canal, Bijou Creek, Kiowa Creek, Bijou \#2 Reservoir, Milliron Draw, Chase Pond, Weingarde Pond, Kiowa Creek, Lost Creek East Pond, Lost Creek West Pond, and Weimer Pond (Table 6.2). The groundwater pumping and the monthly recharge credit data for each well and recharge site were read in as demand data. Well nodes were only allowed to meet demands through groundwater pumping, whereas recharge nodes were restricted to satisfying demands through surface diversions only. The infiltration rate was set at 0.5 for the recharge demand nodes to insure that infiltration return flow would equal the recharge demand. 
Table 6.2. Bijou Augmentation Plan Recharge Sites

\begin{tabular}{|c|c|c|c|c|c|c|c|c|}
\hline & Node & & ite Name & & & $\begin{array}{c}\text { SDF } \\
\text { (days) }\end{array}$ & $\begin{array}{l}\text { Percent } \\
\text { Credit }\end{array}$ & Location \\
\hline $\begin{array}{r}1 \\
2 \\
3 \\
4 \\
5 \\
6 \\
7 \\
8 \\
9 \\
10 \\
11 \\
12 \\
13 \\
14 \\
15 \\
16 \\
17 \\
18 \\
19 \\
20 \\
21 \\
22 \\
23 \\
24 \\
25 \\
26 \\
27 \\
28 \\
29 \\
30 \\
31 \\
32 \\
33\end{array}$ & $\begin{array}{l}47 \\
48 \\
49 \\
51 \\
52 \\
53 \\
54 \\
55 \\
56 \\
57 \\
59 \\
60 \\
61 \\
62 \\
63 \\
64 \\
65 \\
66 \\
68 \\
69 \\
70 \\
71 \\
72 \\
73 \\
74 \\
75 \\
76 \\
77 \\
78 \\
79 \\
80 \\
81 \\
82\end{array}$ & $\begin{array}{l}\text { BIJOU } \\
\text { BIJOU } \\
\text { BIJOU } \\
\text { BIJOU } \\
\text { BIJOU } \\
\text { BIJOU } \\
\text { BIJOU } \\
\text { BIJOU } \\
\text { BIJOU } \\
\text { BIJOU } \\
\text { BIJOU } \\
\text { BIJOU } \\
\text { BIJOU } \\
\text { CIIASE } \\
\text { IOST C } \\
\text { LOST C } \\
\text { WIEINGA } \\
\text { WIINER } \\
\text { MIILIR } \\
\text { RIOWA } \\
\text { RIOWA } \\
\text { KIOWA } \\
\text { KIOWA } \\
\text { KIOWA } \\
\text { BIJOU } \\
\text { BIJOU } \\
\text { BIJOU } \\
\text { BIJOU } \\
\text { BIJOU } \\
\text { BIJOU } \\
\text { BIJOU } \\
\text { BIJOU } \\
\text { BIJOU }\end{array}$ & $\begin{array}{l}\text { CANAL: } \\
\text { CANAL: } \\
\text { CANAL: } \\
\text { CANAI: } \\
\text { CANAL: } \\
\text { CANAL: } \\
\text { CANAL: } \\
\text { CANAI: } \\
\text { CANAI: } \\
\text { CANRAI: } \\
\text { CANAI: } \\
\text { CANAI: } \\
\text { CANAI: } \\
\text { RES } \\
\text { CRK WEST } \\
\text { CRK EEAST } \\
\text { ART } \\
\text { R } \\
\text { RON DRAW } \\
\text { CREEK: } \\
\text { CREEK: } \\
\text { CREEK: } \\
\text { CREEK: } \\
\text { CREEK: } \\
\text { \#2 RES } \\
\text { CRK RCH } \\
\text { CRK RCH } \\
\text { CRK RCH } \\
\text { CRK RCH } \\
\text { CRK RCH } \\
\text { CRK RCH } \\
\text { CRK RCH } \\
\text { CRK RCH }\end{array}$ & $\begin{array}{l}\text { RCH } \\
\text { RCH } \\
\text { RCH } \\
\text { RCH } \\
\text { RCH } \\
\text { RCH } \\
\text { RCH } \\
\text { RCH } \\
\text { RCH } \\
\text { RCH } \\
\text { RCH } \\
\text { RCH } \\
\text { RCH } \\
\\
\mathbf{T}\end{array}$ & $\begin{array}{l}\# 1 \\
\# 2 \\
\# 3 \\
\# 4 \\
\# 5 \\
\# 6 \\
\# 7 \\
\# 8 \\
\# 9 \\
\# 10 \\
\# 11 \\
\# 12 \\
\# 13\end{array}$ & $\begin{array}{r}125 \\
350 \\
270 \\
750 \\
677 \\
1590 \\
3310 \\
4875 \\
5550 \\
5800 \\
5225 \\
4915 \\
7100 \\
7825 \\
30 \\
100 \\
5880\end{array}$ & $\begin{array}{r}34 \\
12 \\
5 \\
11 \\
5 \\
14 \\
2 \\
4 \\
4 \\
2 \\
2 \\
1 \\
4 \\
100 \\
100 \\
100 \\
100 \\
100 \\
100 \\
36 \\
14 \\
14 \\
22 \\
14 \\
100 \\
35 \\
17 \\
12 \\
6 \\
8 \\
6 \\
10 \\
6\end{array}$ & $\begin{array}{l}\text { To Putnam } \\
\text { To Putnam } \\
\text { To Kiowa } \\
\text { To Kiowa } \\
\text { To Bijou\#2 Inlet } \\
\text { To Bijou\#2 Inlet } \\
\text { To weingardt } \\
\text { To Weingardt } \\
\text { To woingardt } \\
\text { To Weingardt } \\
\text { To Chase } \\
\text { To Chase } \\
\text { To Chase } \\
6-2 \mathrm{~N}-57 \mathrm{~W} \\
23-4 \mathrm{~N}-62 \mathrm{~W} \\
24-4 \mathrm{~N}-62 \mathrm{~W} \\
23-3 \mathrm{~N}-59 \mathrm{~W} \\
24-3 \mathrm{~N}-59 \mathrm{~W}\end{array}$ \\
\hline
\end{tabular}

\subsubsection{Simulation Using SDF Values}

The first simulation run used SDF well and recharge site values given in the Bijou Augmentation Plan Report. Groundwater response coefficients were generated using the Glover module within MODSIM. Results of the recharge and depletion calculations and their effects on the South Platte River for the seven years of study are shown in Figure 6.9. Actual result tables are listed in Appendix $\mathbf{G}$.

Figure 6.9. Bijou Augmentation Plan Using SDF Values

Bijou Augmentation Plan Net Accretion to South Platte River

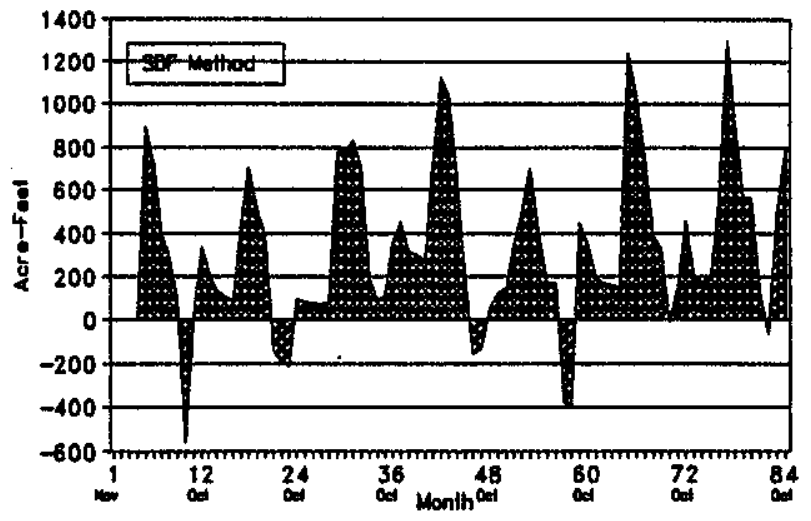
It can be seen from these results 
that no deficit accounts occur for this case during the entire 84 month period.

\subsubsection{Simulation Using MODRSP Values}

The second simulation run used the response coefficient file from MODRSP. The following sites are located outside the aquifer boundary and were not included in the network calculations: Lost Creek West, Weimer Pond, Well 0400F, Well 14336F, Well 1941, Well 1942, Well 6481, Well 8209, and Well 8210. All other data remained the same. Figure 6.10 shows a plot of the monthly recharge and depletion

Figure 6.10. Bijou Augmentation Plan Using MODRSP Response Coefficients calculations over the seven year study period. Actual result tables are given in Appendix G. In contrast with the previous run using SDF values, deficit accounts occur in seven out of the 84 months: September 1989, October 1989, November 1988, December 1988, January 1989, March 1990, and April 1991.

\subsubsection{Comparison of Simulation Results}

A comparison of the two simulation runs shows is presented in Figure 6.11. The finite difference method using MODRSP resulted in the larger credit account. Total net account for the seven years for the SDF method was 18,900 ac-ft and 44,200 ac-ft for the finite difference method. Average monthly return flow rate for the seven years was $225 \mathrm{ac}-\mathrm{ft} /$ month for the SDF method and $525 \mathrm{ac}-\mathrm{ft} / \mathrm{month}$ for the finite difference method. During the critical irrigation months of July, August, September the SDF method resulted in an average of $235 \mathrm{ac}-\mathrm{ft} / \mathrm{month}$ (July: $250 \mathrm{ac}-\mathrm{ft}$; August:200 ac-ft; September:250 ac-ft) and the finite difference method resulted in an average of 762 ac-ft/month (July:984 ac-ft; August: 858 ac-ft; September: 444 ac-ft).

\subsubsection{Comparison of Response Coefficients}

Comparison of response coefficients generated by the numerical finite difference method using MODRSP and using the SDF values calculated from the analytical Glover equation for a single well located within the study area are shown in Figure 6.12. 


\section{Bijou Augmentation Plan \\ Not River Rotum Flow Due to Rocharge}

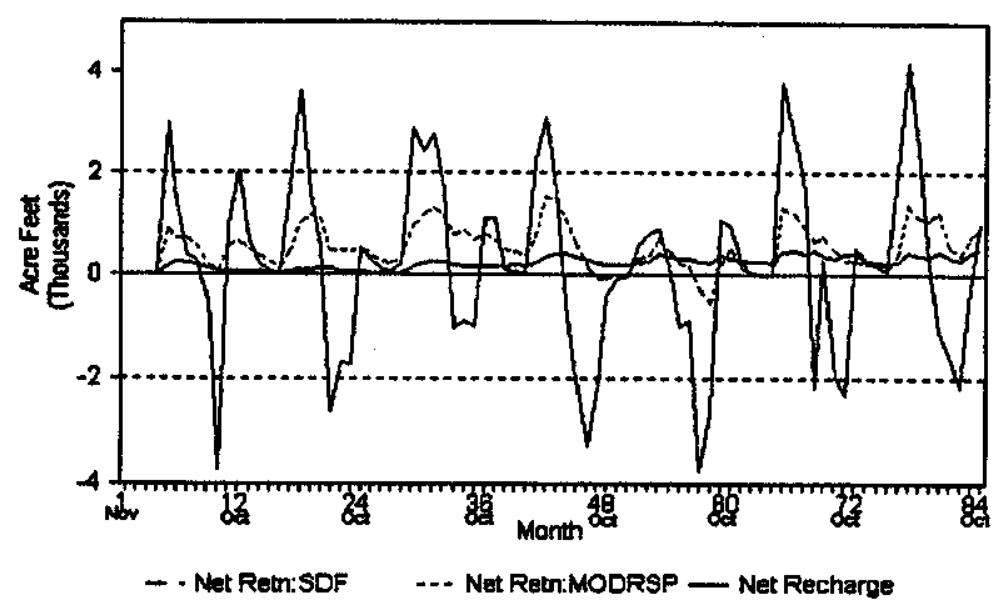

Figure 6.11. Comparison of Augmentation Plan Results (SDF vs. MODRSP)

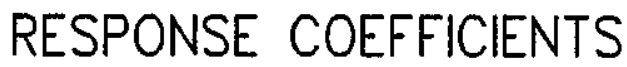

WELL R68 1

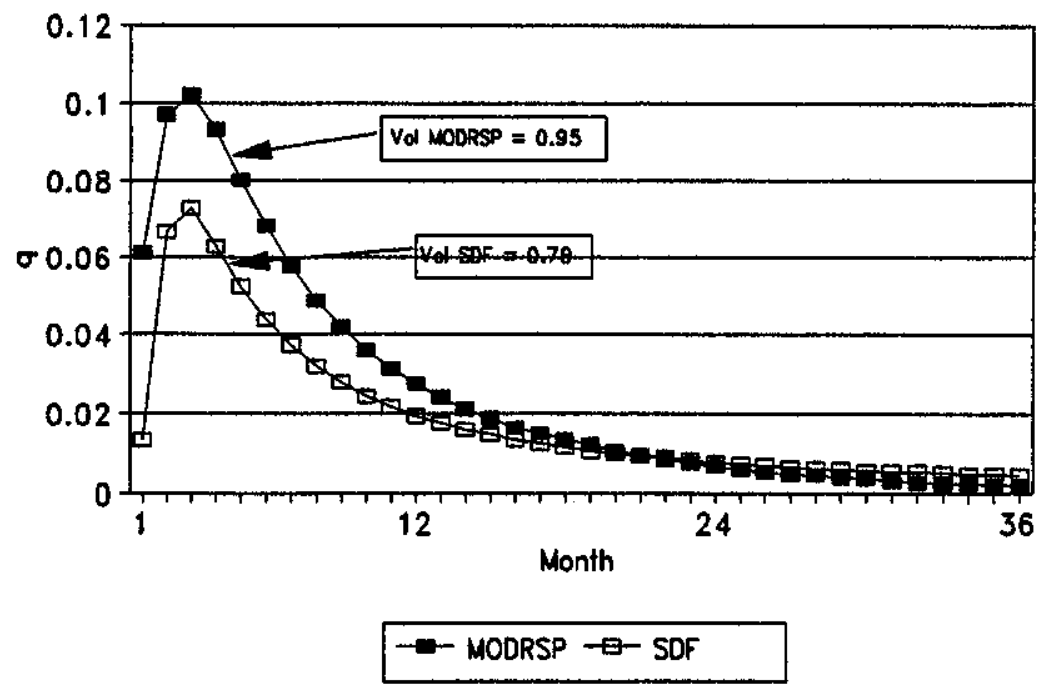

Figure 6.12. Single Well Comparison of Response Coefficients (SDF vs MODRSP)

The finite difference model produced coefficients for Well R681 that resulted in 95\% of depletion flows to the well being drawn from the river and its tributaries over a seven year (84 month) period, while the SDF method accounted for only $79 \%$ of depletion flows during the same period. For the well Well R681 represented in this example, 53\% of depletion flow determined using the finite difference method was drawn from tributary sources, as shown in Figure 6.13. 


\section{RESPONSE COEFFICIENTS}

\section{WELL R681}

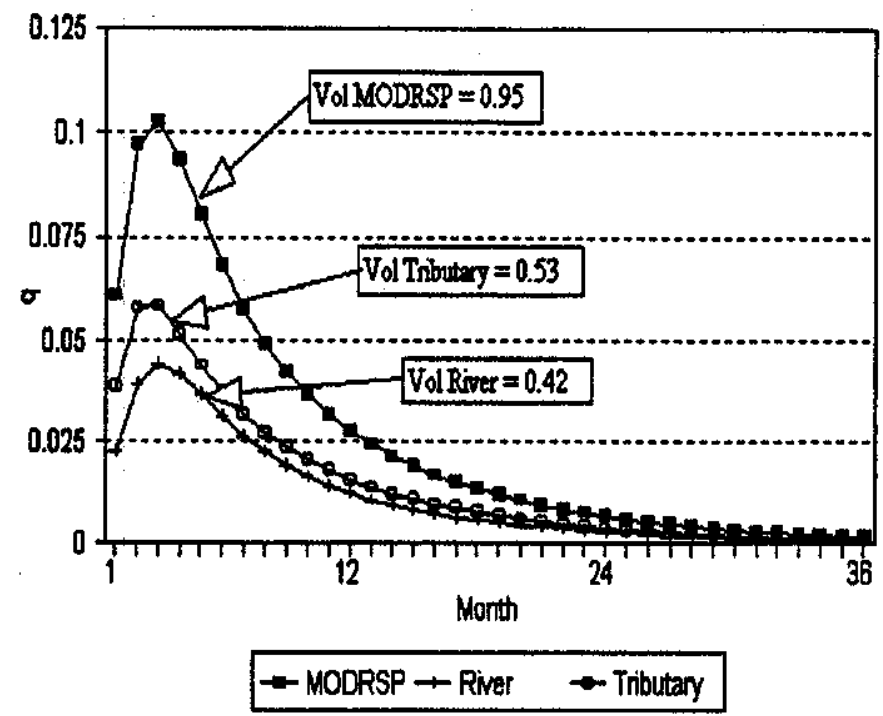

Figure 6.13. Single Well Comparison of MODRSP Tributary and River Response Coemients

A more general review of the response coefficient data shows that for the SDF method, an average of $51 \%$ (standard deviation: $4 \%$ ) of the unit response volume is returned/depleted within a seven year period. For the response coefficients derived from the finite difference method, an average of $92 \%$ (standard deviation: $4 \%$ ) of the unit response volume is returned/depleted within a seven year period. A comparison between the spatial variation of the finite difference based response coefficients showed that $30 \%$ of the return/depletion flow effects directly impact flows in the river, with $70 \%$ influencing the tributaries.

\subsection{Augmentation Plan DSS}

An interactive format was prepared in MAPINFO to demonstrate procedures for displaying spatial data output using DSS techniques. Figure 6.14 shows the general MAPINFO screen display for the Bijou Irrigation Company Augmentation Plan physical network. Three types of output display have been used: interactive maps, graphs, and data tables. Figure 6.15 shows output display capabilities for the Augmentation Plan DSS. 


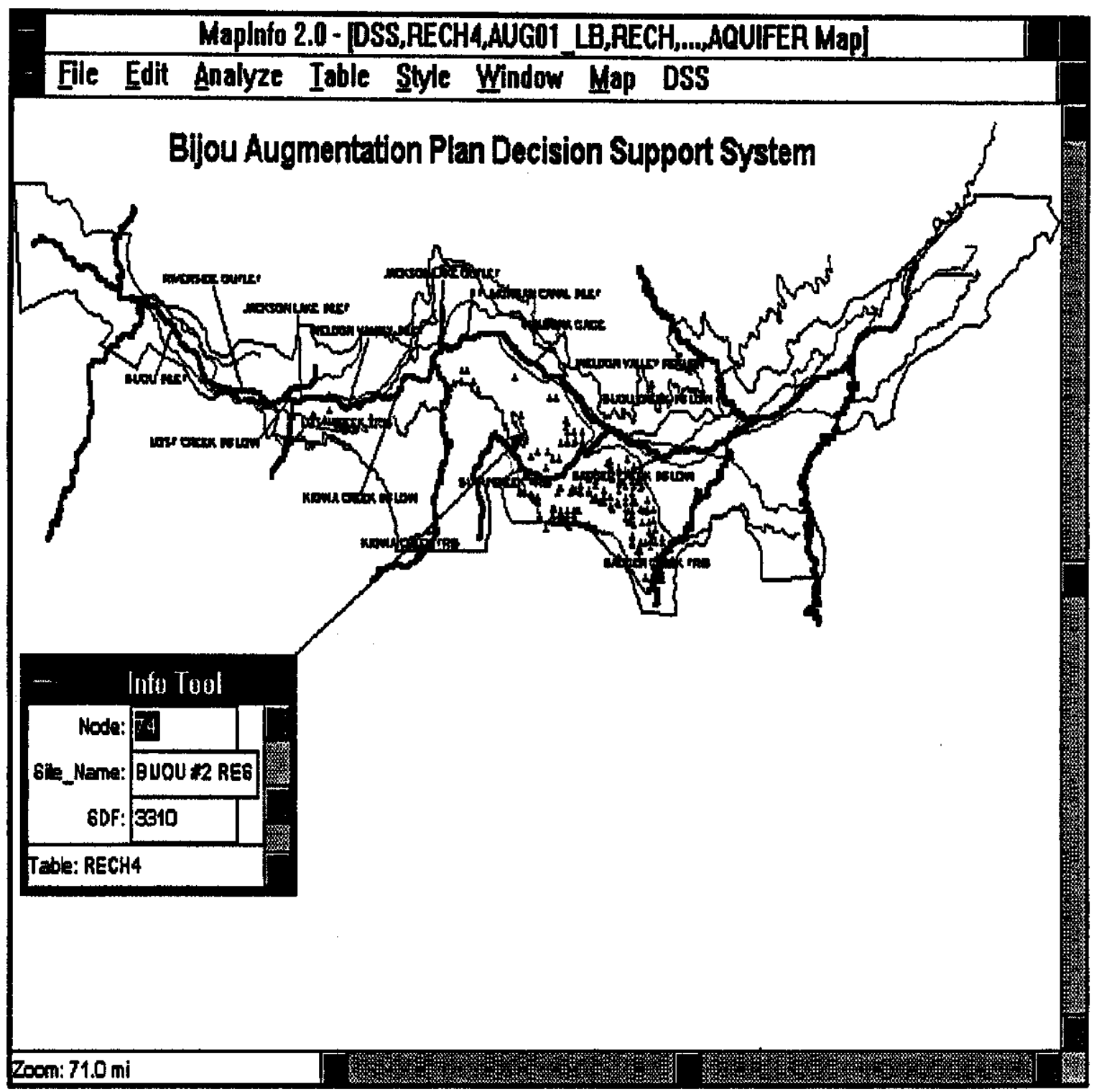

Figure 6.14. Bijou Irrigation Company Augmentation Plan Network 


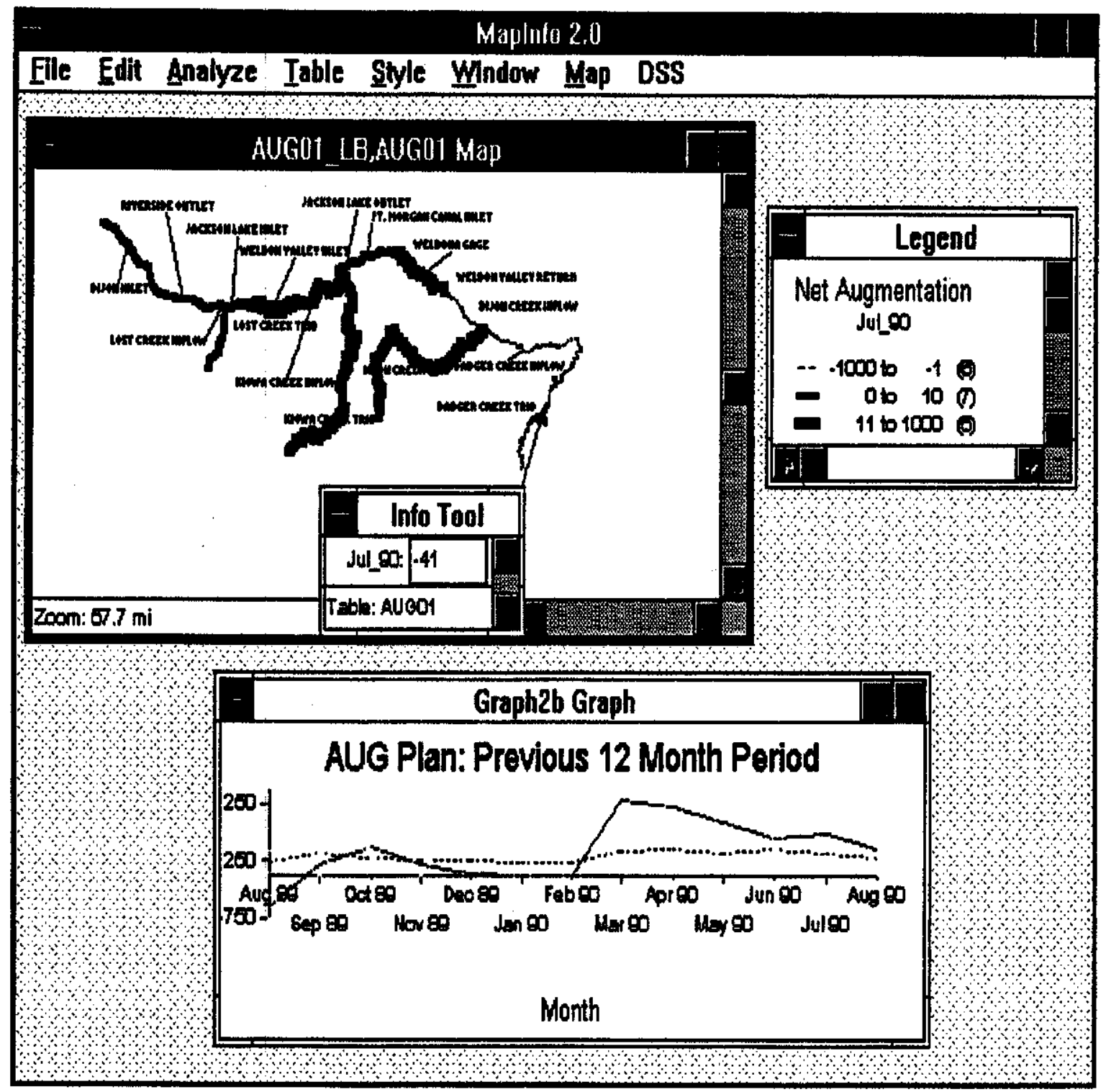

Figure 6.15. Augmentation Plan DSS Output Options

Figure 6.16 shows a layout map of the South Platte River and components of the augmentation plan. Red (depletion), green (accretion), and yellow (border line accretion) colors have been used to group data values that reflect the net affects of the augmentation plan on various river reaches and tributaries. 


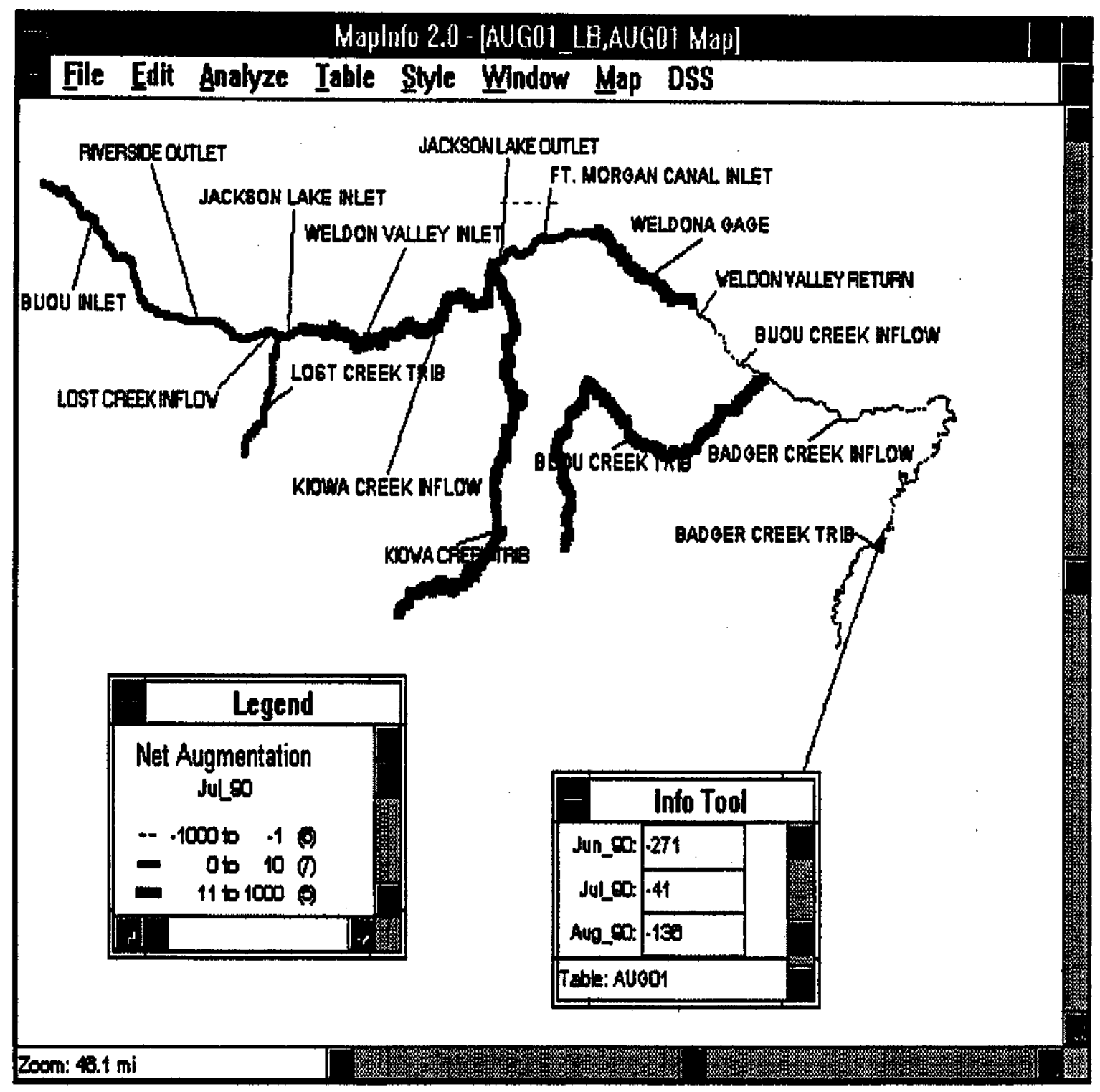

Figure 6.16. Bijou Augmentation Plan Net Streamflow Affects

\subsection{Daily River Administration Using MODSIM}

\subsubsection{Introduction}

This portion of the case study demonstrates how to integrate an augmentation plan directly into daily administration of a river regulated under prior appropriation water right laws. The MODSIM model was used to simulate daily operations of a section of the Lower South Platte River, Colorado, between the Kersey and Balzac river gage stations under administrative control of Colorado State Engineer's Water District \#1. Procedures on preparing a daily administration 
MODSIM network are presented that allow consideration of individual water rights, river diversions, river calls, tributary inflows, and augmentation plans.

The case study is based on data used for daily administration of the South Platte for August 15, 1990. Table 6.3 presents data taken from the August 1990 daily water reports prepared by the District No. 1 Water Commissioner. These reports provide information on river calls, historic river discharges and tributary inflows. Historical diversion data taken from the State Engineer Office (SEO) diversion database are shown in Table 6.4. A summary of the historical data used to simulate daily administration is presented in Table 6.5. Augmentation data were taken from the Bijou Augmentation Plan case study results for August 1990. The augmentation summary table is presented as Table 6.6 .

\subsubsection{MODSIM Dally Administration Network}

The daily administration network was prepared using data from the SEO water rights database. The MODSIM network prepared for the river system is shown in Figure 6.17. The network has 158 nodes and 157 links, and includes 27 reservoirs, 18 diversion points, 25 direct decree diversions, 10 storage decree diversions, and 75 separate water rights. The network is structured to guarantee water allocation in accordance with administrative water right decrees. The network is organized so that flow accounts and operational control can be maintained at several levels, as shown in Figure 6.18.

Each water right decree is assigned as a demand node, with the demand set equal to the decreed water right and the priority equal to the State Engineer's administrative number. Since each decreed water right is usually associated with a diversion point or structure ID number, a node and corresponding structure $\mathrm{ID}$ link is provided upstream of each decreed water right. A structure ID can be associated with more than one decree and is the same number used by the State Engineer's Office to record actual structure diversions. Another set of nodes with a connecting link are placed upstream of the Structure ID node. This link is included to represent the actual diversion offtake canal and its headgate.

Kersey gaging station on the main stem of the South Platte River is assigned as the first upstream node, with the Balzac gaging station assigned as the terminal downstream node. Both gaging station nodes are represented as dummy storage nodes for several reasons. Assigning the upstream Kersey gage node as a storage node provides a reservoir source for all unmeasured or unknown excess inflows to the system required to balance the MODSIM network. Assigning the downstream Balzac gage node as a storage node provides flexibility in testing the network system by forcing unaccounted excess flows through the network system. It also allows the accounting for all downstream gage flows and downstream river calls to be maintained at the same node. The Weldona gage, located on the South Platte between the Kersey and Balzac stations, is assigned as a flow-through demand node. Tributaries are represented as links with an upstream node. 
Water District 1 Selected Dally Inflows: Source: Water Commissioner's Daily Report Discharge in CES August 1990

Jackson Weldon Bifou

Junior Priortty w.D. 64 Upper

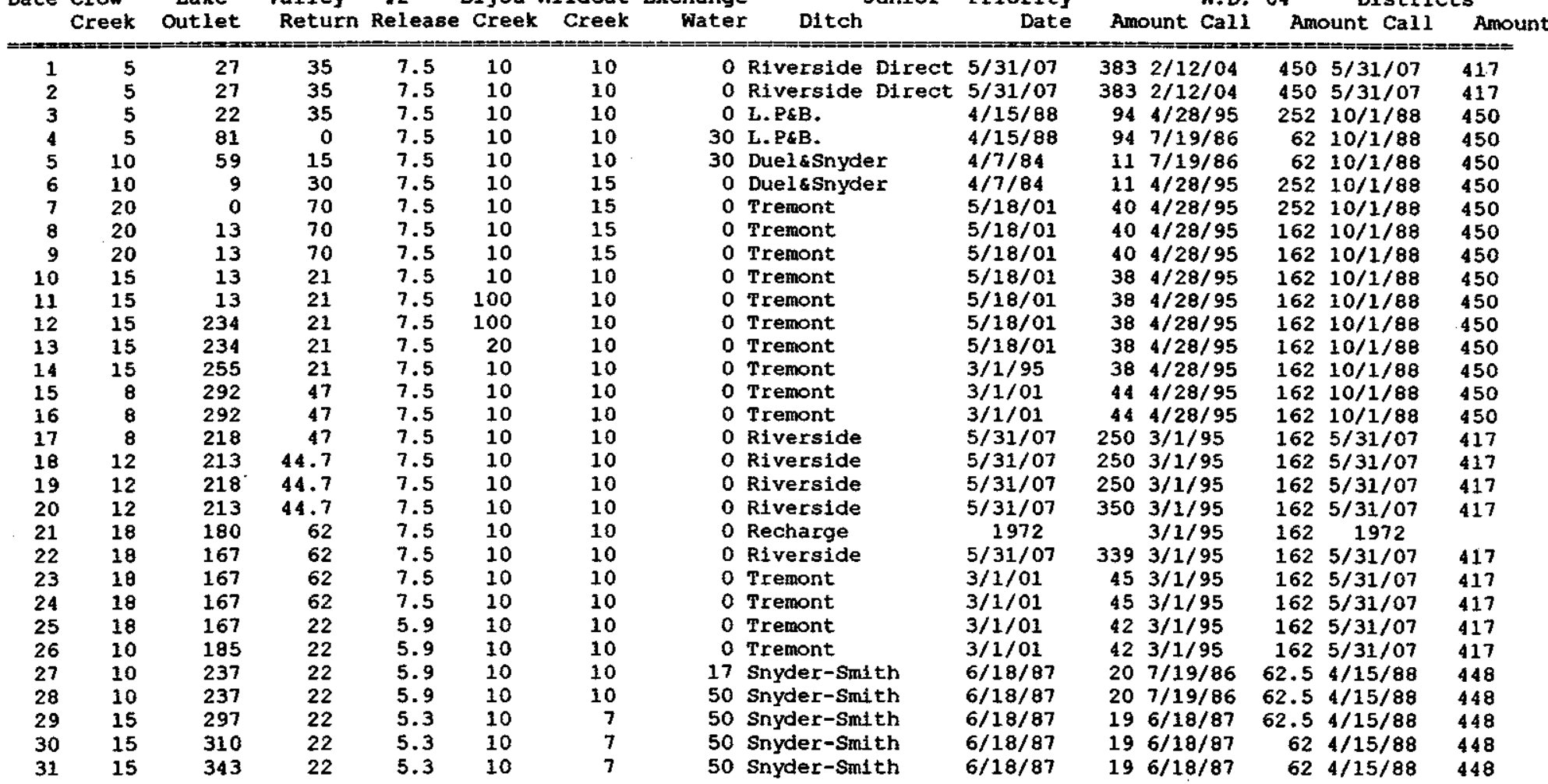


Table 6.4. SEO Diversion Database Data

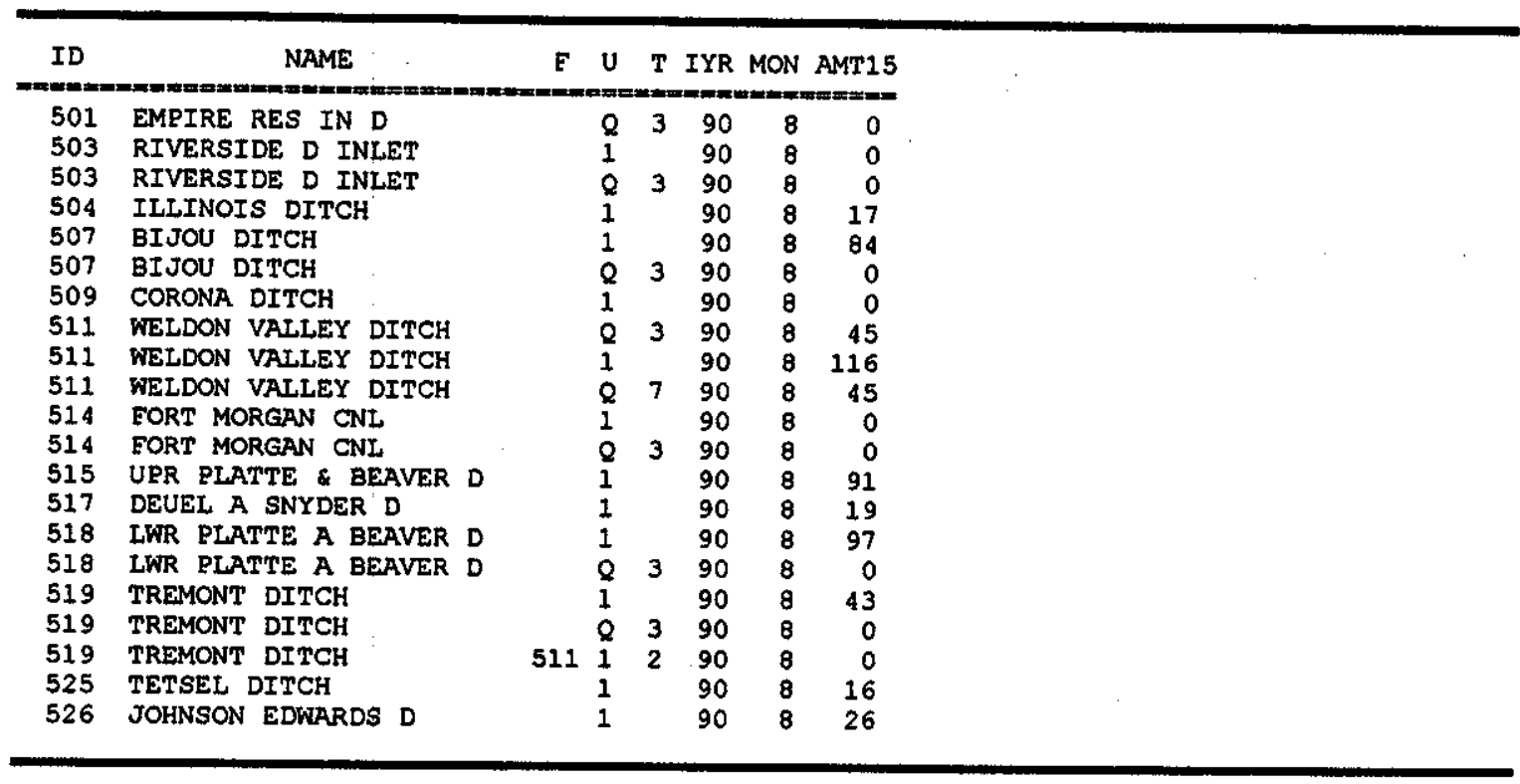

Table 6.5. Summary of Fistorical Daily Data

\begin{tabular}{|c|c|c|c|c|c|}
\hline 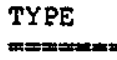 & NAME & IYR & MON & DAY & 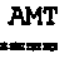 \\
\hline DIVERT & EMPIRE RES IN D & 90 & 8 & 15 & 0 \\
\hline DIVERT & RIVERSIDE D INIET & 90 & 8 & 15 & 0 \\
\hline DIVERT & ILLINOIS DITCH & 90 & 8 & 15 & 17 \\
\hline DIVERT & BIJOU DITCH & 90 & 8 & 15 & 84 \\
\hline DIVERT & CORONA DITCH & 90 & 8 & 15 & 0 \\
\hline DIVERT & WELDON VALLEY DITCH & 90 & 8 & 15 & 161 \\
\hline DIVERT & FORT MORGAN CNL & 90 & 8 & 15 & 0 \\
\hline DIVERT & UPR PLATTE \& BEAVER D & 90 & 8 & 15 & 91 \\
\hline DIVERT & DEUEL A SNYDER D & 90 & 8 & 15 & 19 \\
\hline DIVERT & LWR PLATTE A BEAVER D & 90 & 8 & 15 & 97 \\
\hline IVERT & TREMONT DITCH & 90 & 8 & 15 & 43 \\
\hline DIVERT & TETSEL DITCH & 90 & 8 & 15 & 16 \\
\hline DIVERT & JOHNSON EDWARDS D & 90 & 8 & 15 & 26 \\
\hline GAGE & BALZAC & 90 & 8 & 15 & 389 \\
\hline GAGE & KERSEY & 90 & 8 & 15 & 525 \\
\hline GAGE & WELDONNA & 90 & 8 & 15 & 449 \\
\hline INELOW & CROW_CREEK & 90 & 8 & 15 & 8 \\
\hline INELOW & JACKSON_OT & 90 & 8 & 15 & 292 \\
\hline INELOW & WELDON_RTN & 90 & 8 & 15 & 47 \\
\hline NELOW & BIJOU\# 2 & 90 & 8 & 15 & 8 \\
\hline INELOW & BIJOU_CRK & 90 & 8 & 15 & 10 \\
\hline INELOW & WILDCĀT & 90 & 8 & 15 & 10 \\
\hline INELOW & EXCHANGE & 90 & 8 & 15 & 0 \\
\hline
\end{tabular}


Table 6.6. Augmentation Summary Table

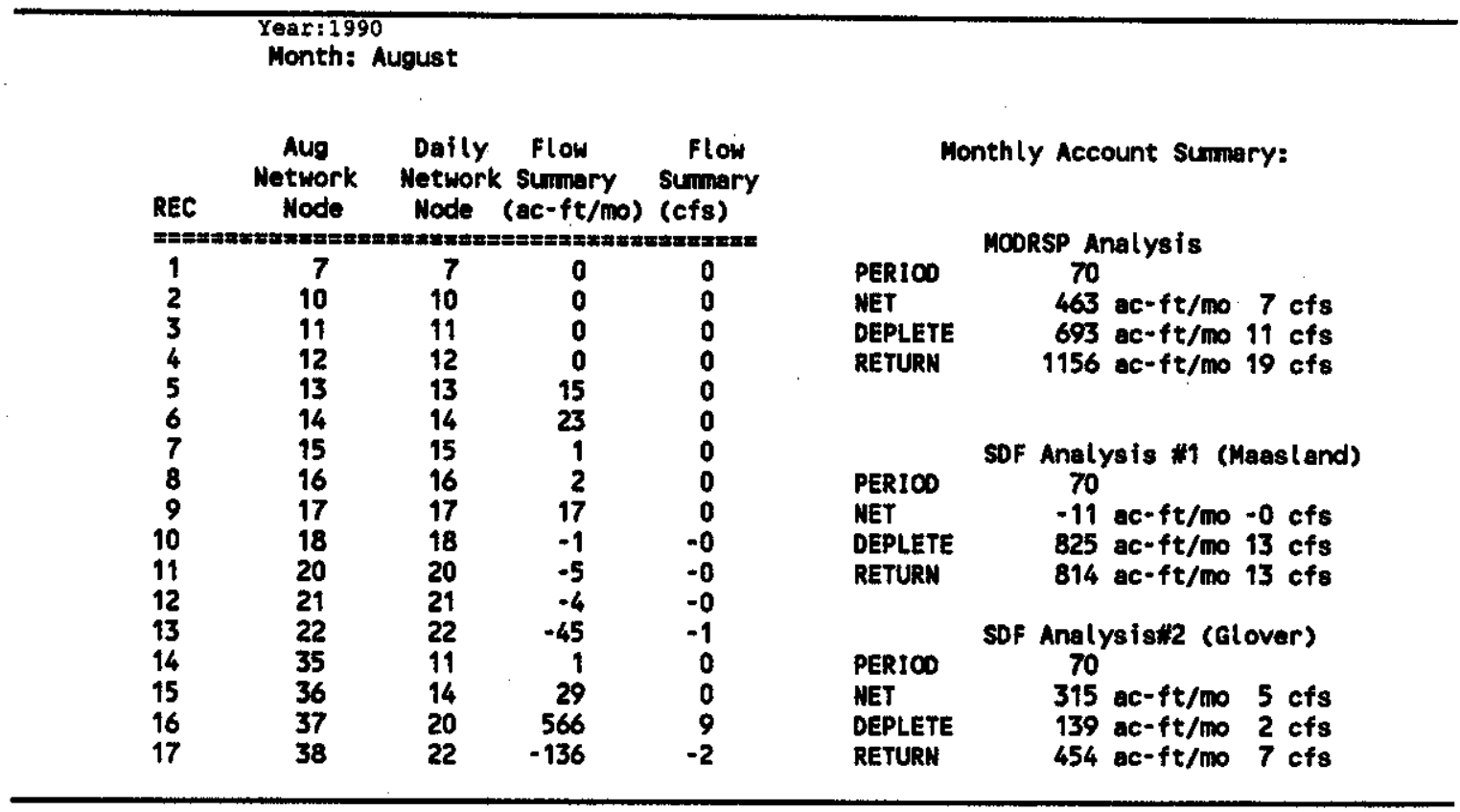

This framework allows considerable flexibility in the simulation of the daily administration of the network. A call placed on the river by a senior water right located in a downstream water district can be simulated by assigning the sum of all senior downstream water right flow requirements as a demand at the Balzac gaging station. The priority can be set equal to the downstream senior water right administrative number. If for some reason a user within the water district does not require or is not authorized to take water, the associated water right can be deactivated by setting the capacity of the water right link equal to zero. Otherwise, the water right link upstream of the decree node can be assigned a link capacity equal to the water right decree amount. To simulate the operation of a headgate with a measured or regulated diversion rate, the flow rate can be assigned as the link capacity on the ID structure link or as a prioritized flowthrough demand.

The network model can be used for daily operation as a planning or evaluation tool. In the planning mode, it is expected that the water commissioner would know river inflow at the upstream Kersey Gage station, the downstream flow-through requirements, the senior downstream river call below the Balzac gage station, tributary inflows, and a list of users requesting water. Given this information, available water supply can be allocated by MODSIM in accordance with water right priorities. This is done by running the model without placing capacity restrictions on the various diversion and structure $\mathrm{ID}$ links and allowing the model to directly allocate flows according to priority. 


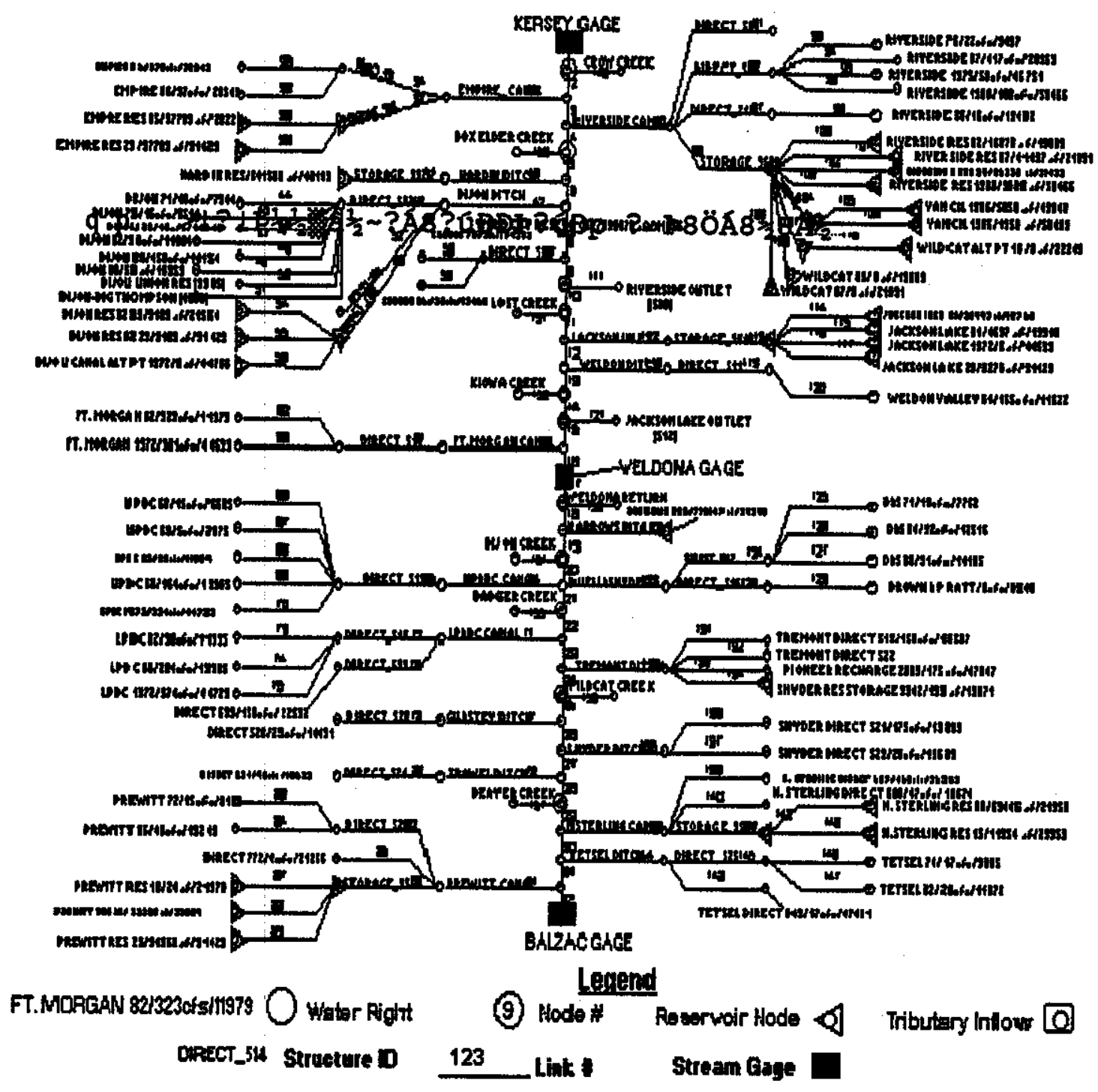

Figure 6.17. Daily Administration MODSIM Network

Once a decision has been made on how to allocate water within the water district, it is usually desirable to evaluate the consequences of the allocation and the overall response of the river system. This information can be used to better understand system performance and aid in future administrative decisions. For evaluation purposes, actual diversion amounts can be assigned to the structure ID and diversion links. Net river gains and/or lojsses can be calculated by using the model to perform a water balance based on known river inflows and outflows. This information can then be used to estimate surface flow routing coefficients or to evaluate groundwater return flow conditions. 


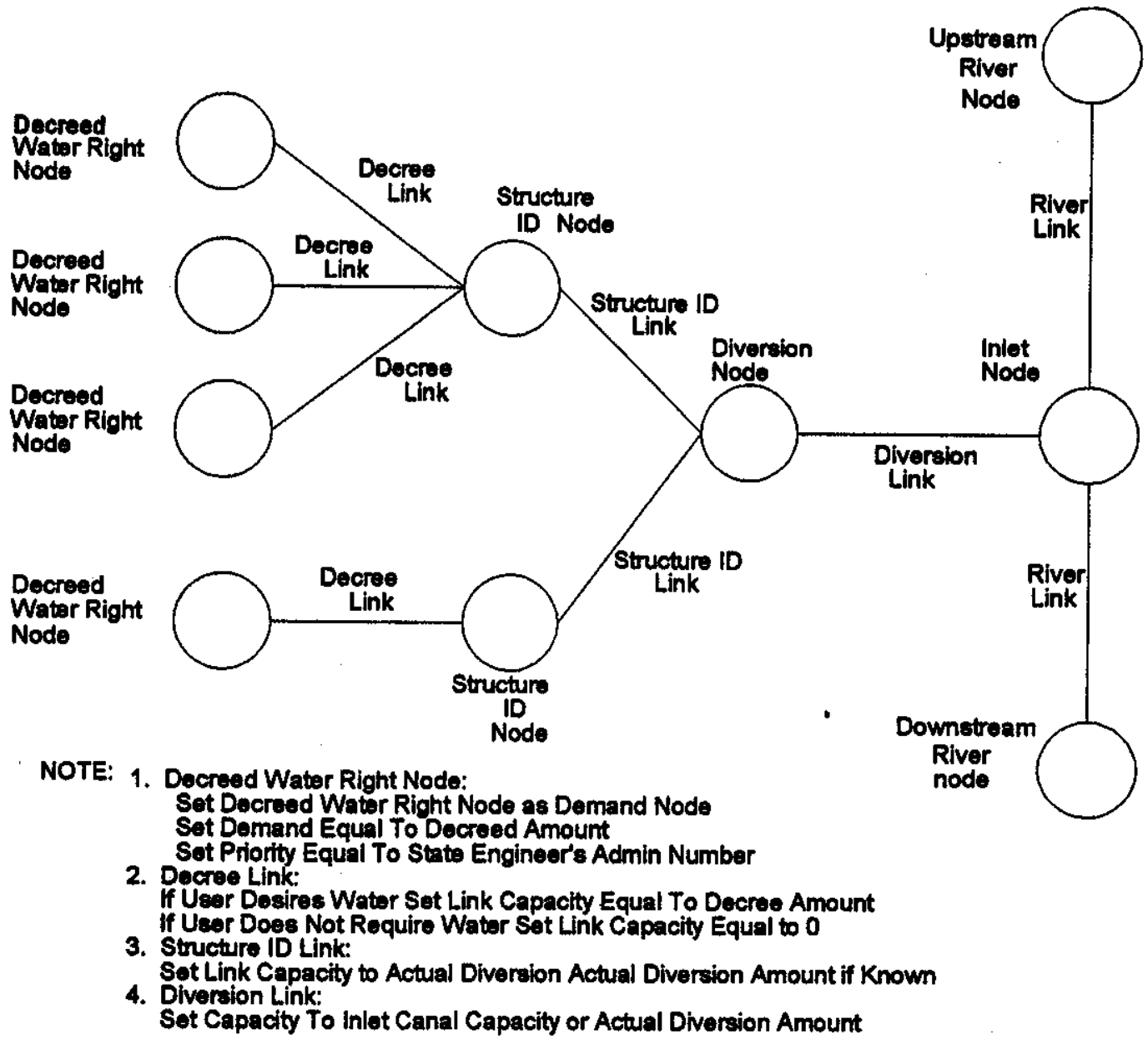

Figure 6.18. Network Structure for Daily Administration

\subsubsection{Integration of Augmentation and Daily Administration}

To integrate the Bijou Augmentation Plan into the South Platte Water District No. 1 daily administration model, MODSIM was run in evaluation mode. Two separate simulation runs were carried out. The purpose of Run \#1 is to determine the amount of system flow resulting from unmeasured river losses and gains such as groundwater return flows, tributary inflows, and diversions. All gage, tributary, and diversion flows are set to historical values by assigning node inflows, demands, and variable link capacities in MODSIM. Bijou Augmentation Plan depletion and accretion flows based on the MODRSP finite difference model response coefficients are 
converted from acre-feet per month to average daily cubic feet per second (cfs). Augmentation flows are assigned by node inflows (i.e., accretions) or demands (i.e., depletion)s. High demand priorities for the augmentation flow depletion demands are assigned in MODSIM to insure that these depletions are met. The Kersey gage storage node is given a reservoir beginning storage component equal to $1000 \mathrm{cfs}$ and a target priority that results in releases only to meet the most junior historic water right receiving water on 15 August 1990. This results in releases to balance all historic SEO diversion demands not satisfied by river, tributary inflows, and the Bijou Augmentation Plan net return flows.

For the second simulation run, the affects of the Bijou Augmentation Plan are removed. The Kersey storage node starting capacity is set to the net water balance value determined in Run \#1. A target value for the reservoir is set to insure full release of the stored flow. To determine differences in the availability of water to satisfy system demands as a result of the Bijou Augmentation Plan, the demand shortages for Run \#1 with the augmentation plan and Run \#2 without augmentation plan are compared. The water balance to account for unmeasured net river gains/losses from Run \#1 with the augmentation plan included required a net inflow of $36 \mathrm{cfs}$. The Bijou Augmentation Plan account provided a net of $7 \mathrm{cfs}$ return flow. The net effect of the Bijou Augmentation Plan on system administration was to make an additional 7 cfs available for diversion to Tremont ditch to satisfy the Tremont direct water right decree dated 1901, as shown in Table 6.7.

\section{Table 6.7. Daily Admin Diversion Allocation-With/Without Bijou Augmentation Plan}

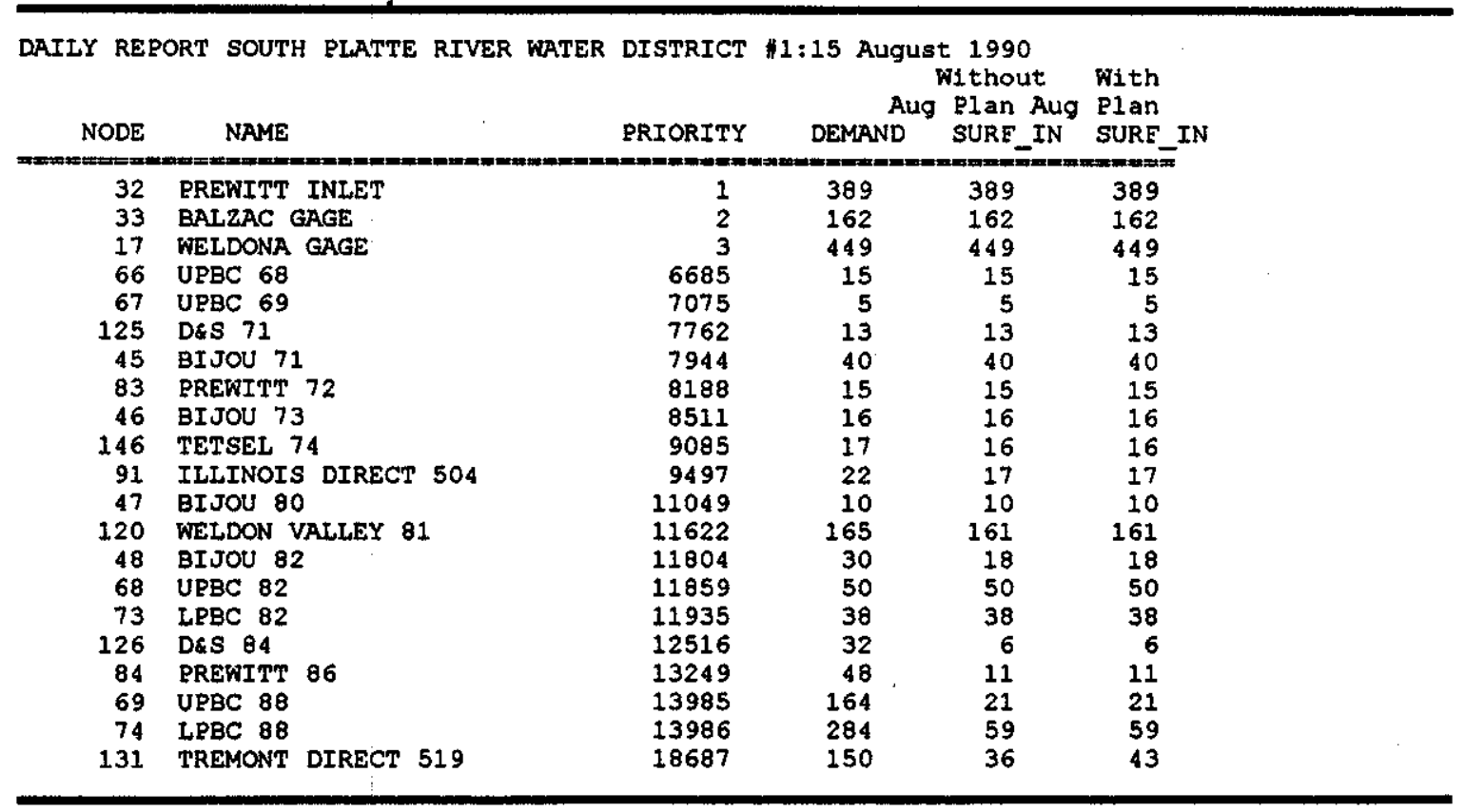




\subsubsection{Daily Administration DSS}

A prototype daily administration DSS was prepared using QUATTRO PRO, MAPINFO, and MODSIM software to demonstrate procedures for managing the interface between the user and the modeling system. The DSS was designed to assist in the daily administration for Water District \#1 and to consider the effects of the Bijou Augmentation Plan on daily administration. QUATTRO PRO serves as the central shell for the DSS from which MODSIM can be executed. MAPINFO software is used to display output results. Figure 6.19 shows the main menu for the daily administration DSS with options included to simplify data entry and provide graphical output display.

The input dialog menu for setting diversion flows is shown in Figure 6.20. Input and output files used by MODSIM, QUATTRO PRO and MAPINFO are prepared internally by the DSS. Output can be displayed in map, graph, or tabular format. Example output display types available in the DSS are shown in Figure 6.21.

Figure 6.22 shows how the user is able to interactively view daily administration diversion results on a river diversion map of the Lower South Platte River Basin. The canals and ditches diverting surface flows are automatically highlighted in one color and the most junior canal or ditch receiving water is shaded in another color.

Figure 6.23 shows how the user is able to interactively view daily administration on the Water District \#1 MODSIM daily administration network drawing. The links and nodes carrying flows are automatically highlighted. The node for the most junior water right receiving water is automatically labeled.

Augmentation data are automatically selected and filtered based on the user entered simulation date. Input to the DSS can be done interactively or by accessing external data bases. MODSIM data are entered in spreadsheet format within the DSS. The DSS automatically creates the ASCII text files necessary to execute MODSIM. The DSS has been structured to run the case study example, but can be easily modified to run other scenarios.

After entering the required data, the DSS can be executed by selecting the MODSIM menu control button. The DSS first executes MODSIM without consideration of the effects of the Bijou Augmentation Plan and performs the network water balance. Next, output results from MODSIM are imported back into the DSS. These files are used by the DSS to set up new MODSIM input files and the DSS then reruns the daily MODSIM model to account for the Bijou Augmentation Plan effects.

The DSS converts MODSIM output files into a database format that can be read directly by MAPINFO for displaying results. MAPINFO is accessible from within the DSS using the main menu control buttons. 


\section{Quattro Pro for Windows - INPUT1.WB1}

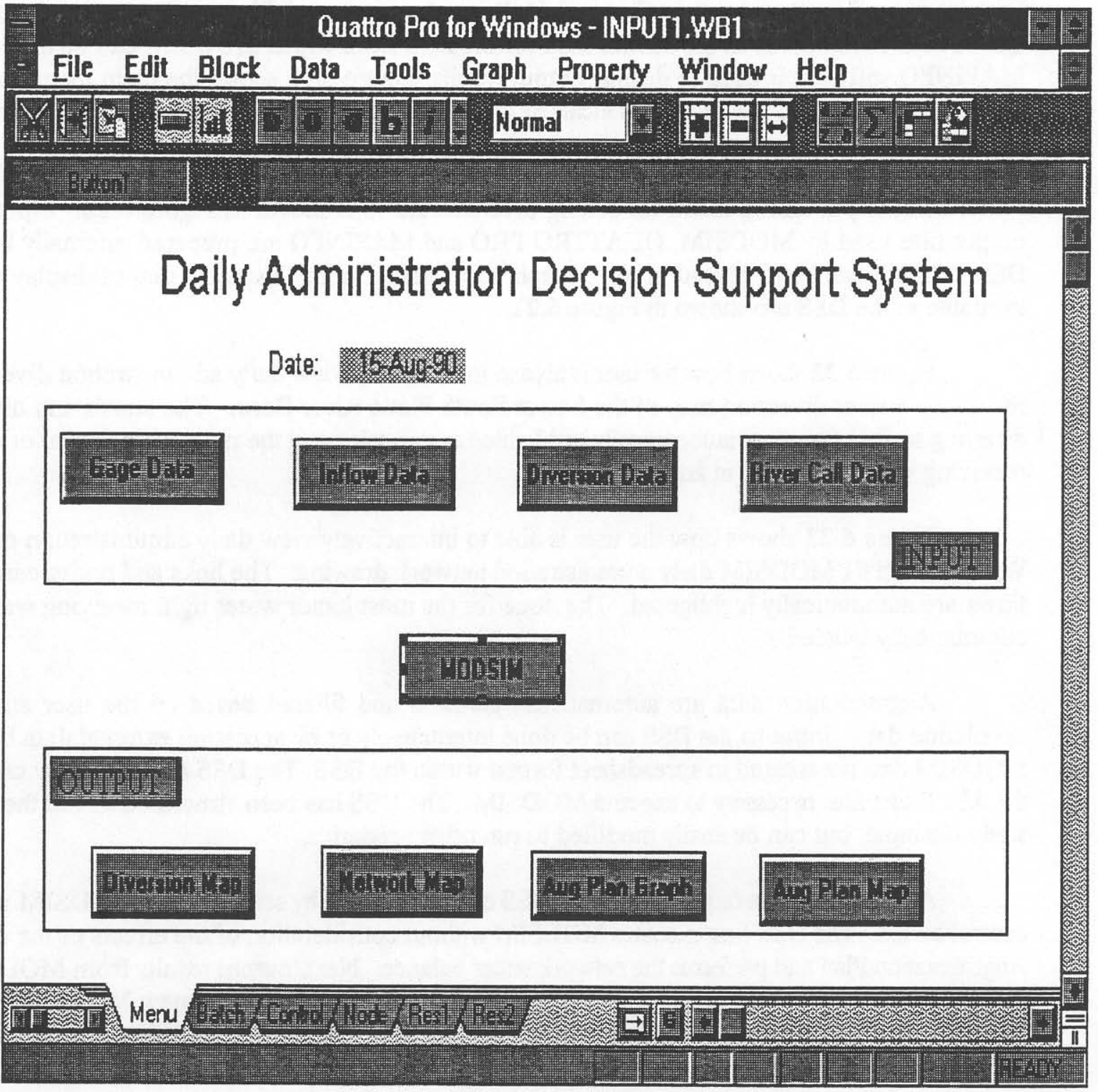

Figure 6.19. Daily Administration DSS Main Menu 


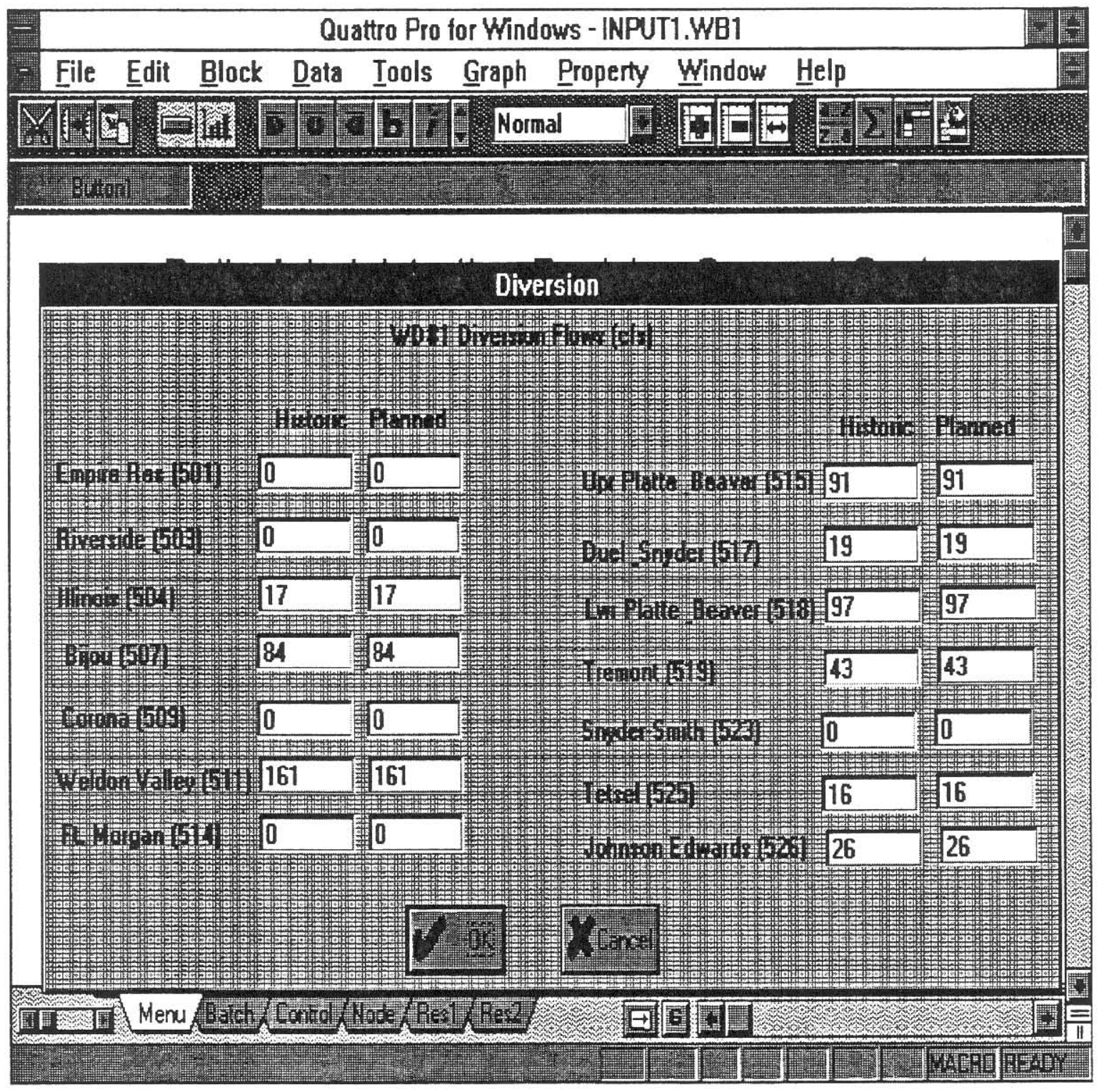

Figure 6.20. Daily Administration DSS Diversion Input Menu 


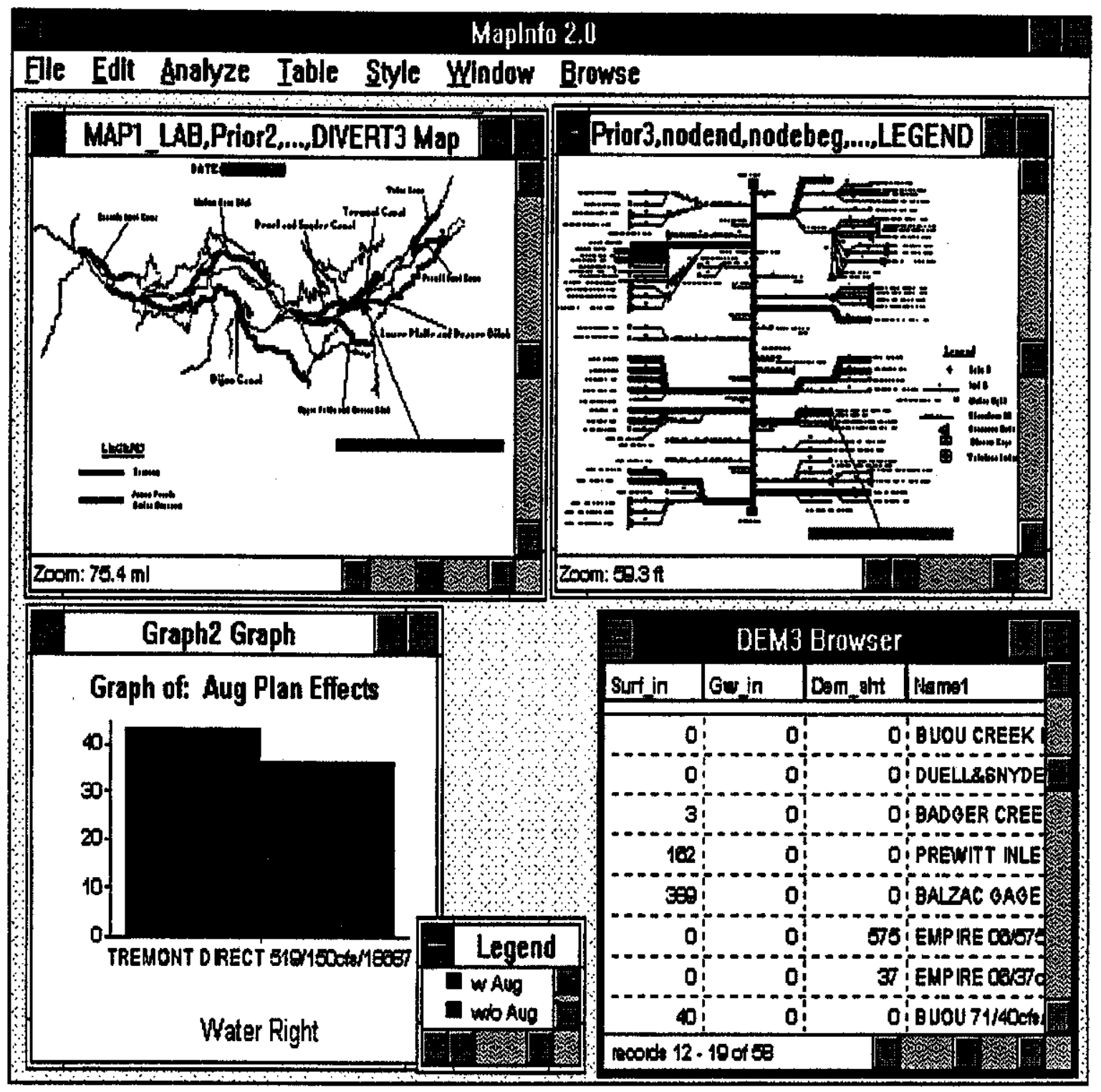

Figure 6.21. Daily Administration DSS Example Output 


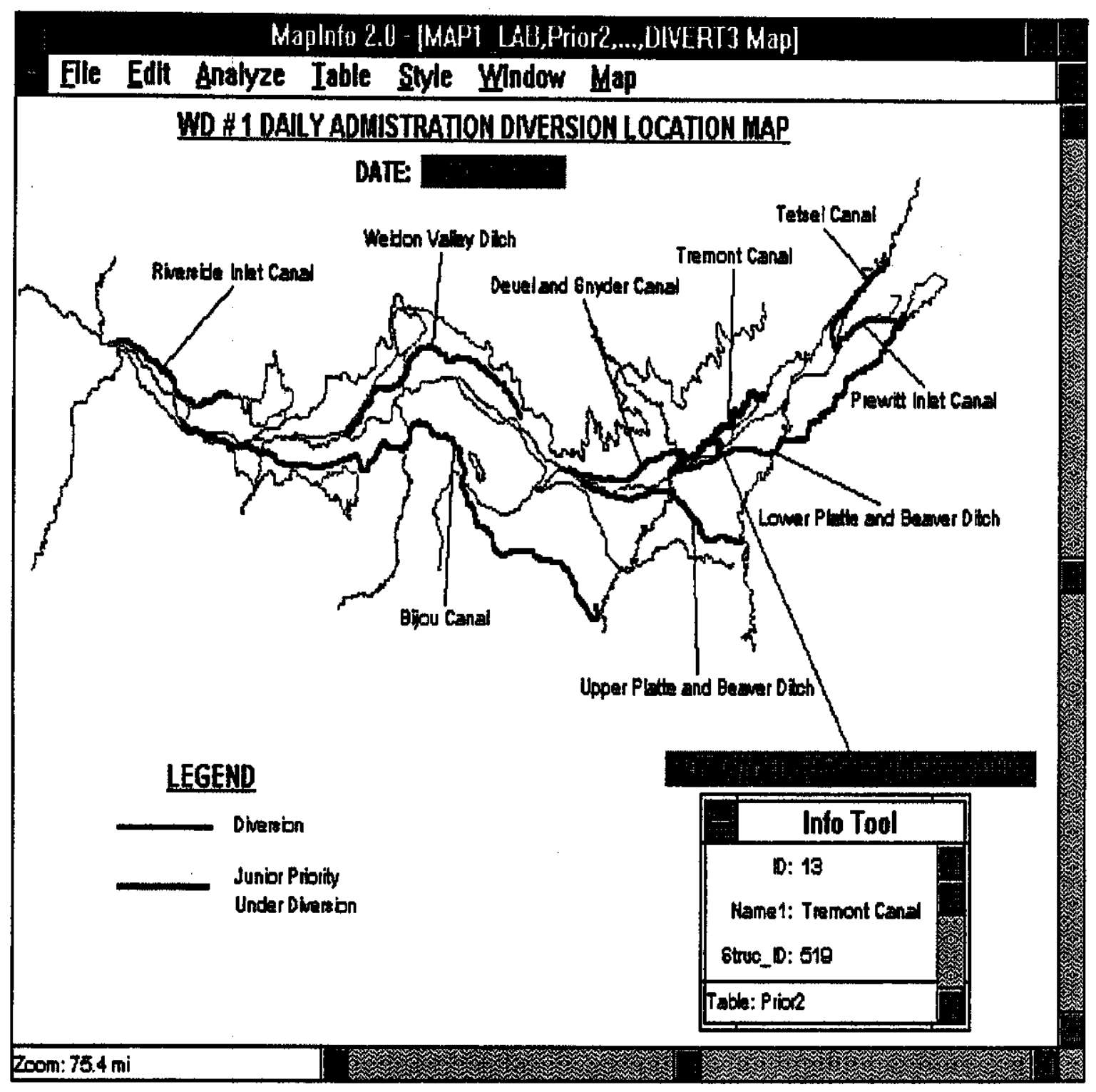

Figure 6.22. Daily Administration DSS Diversion Map 


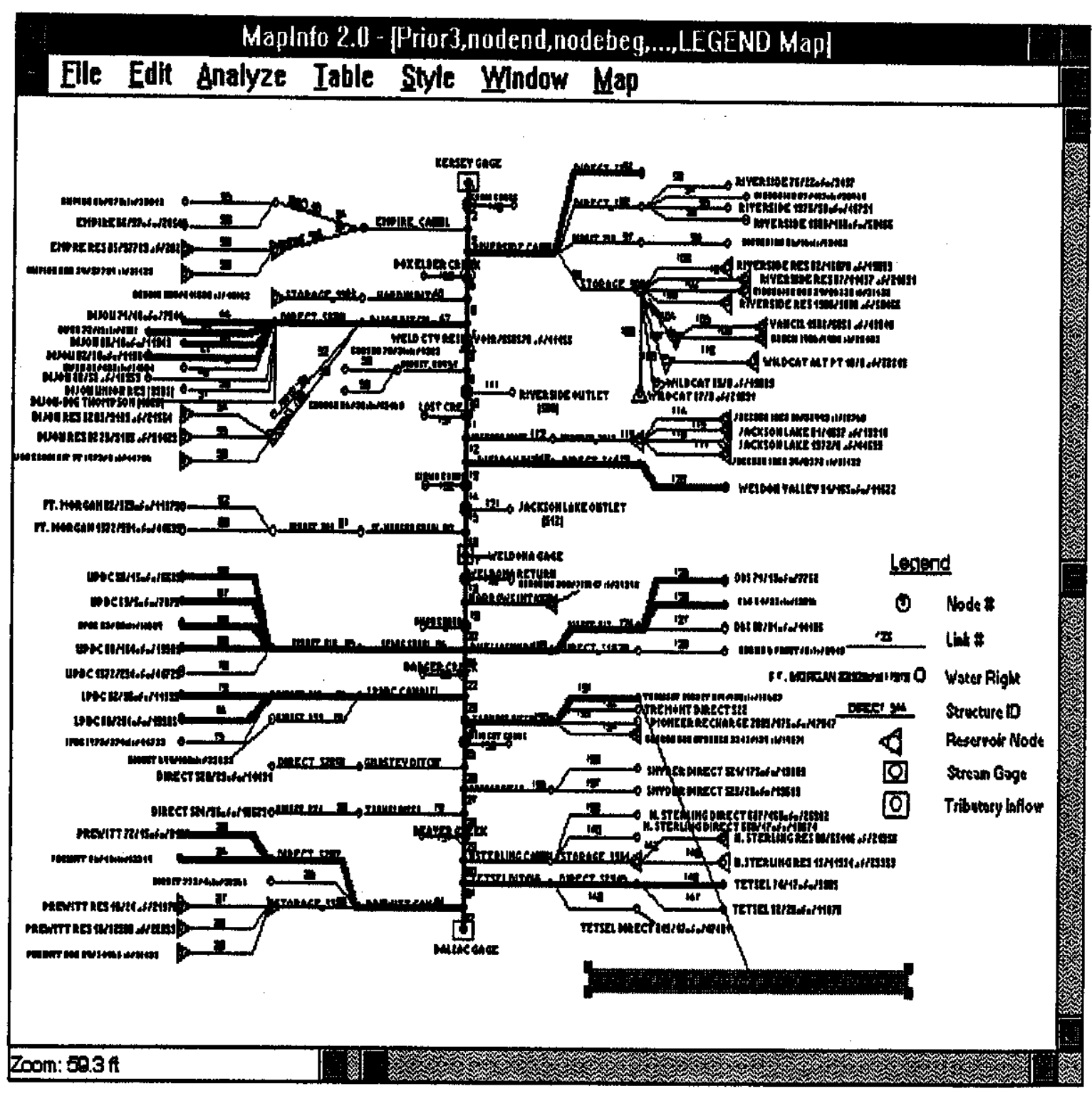

Figure 6.23. Daily Administration DSS Network Map 


\subsection{Discussion of Results}

The case study demonstrates how decision support system concepts and techniques can successfully be applied to a conjunctive use management problem for a large regional river basin with complex water rights. The resource inventory indicates that a large amount of water resource data, sufficient to model a large river basin, are available from several sources. Unfortunately, no central resource center is in place for distributing or locating the data. To collect information and data, it is necessary to contact each agency and often different persons within the same agency. Most data are available in digital format; however, lack of compatibility in data formats complicates the transfer of files between computers. It was found that most PC based commercial software packages are able to import or export DBF (dBASE III/IV) files and system data format (ASCII text) files structured in database format. These formats were adopted for use in the DSS. Most interface software requirements needed to link DSS components can be written using the internal macro languages found in the various commercial software packages used by the DSS.

The introduction of GIS and database technology to preprocess input data and postprocess output data greatly expands the potential of groundwater models as a management tool for regional basin studies. For example, the Lower South Platte River summary data on basin diversions, tributary inflow, gage flow, and reach gain and loss were calculated by importing USBR PTFLOW model output results into DBASEIV and using the sum and group by functions. All of the major files required for executing the USGS finite groundwater model MODFLOW can be prepared using GIS and database techniques. The abilities to transfer vector based hydrography data from USGS digital databases, rasterize or grid the data using GIS software, and overlay the results with other aquifer data to prepare a file directly readable by a finite difference groundwater model as a boundary file, provides powerful computational tools It is no longer necessary to aggregate or lump physical components because of computer or data processing limitations. Individual response units, such as single wells, river reaches, tributaries, recharge sites, and recharge ponds, can be included in the modeling process as easily as aggregated data.

The case study demonstrates in detail the actual steps required to develop groundwater response coefficients for use in any river basin simulation model that has a groundwater component. Groundwater response coefficients for individual wells, canals, drains, ditches, reservoirs and pond recharge sites; and their effects on a major river and its tributaries, can be calculated. Because of the GIS and database procedures, separate sets of coefficients for individual river, canal, and drain sub-reaches can also be generated. These response coefficients, once determined, can be used repeatedly in different river basin simulations.

A $1000 \mathrm{ft} \times 1000 \mathrm{ft}$ groundwater grid size for the finite difference model was selected to test the computational limits of using a small grid size in a regional model. It is common for regional studies not using GIS procedures to restrict grid size to 1 mile by 1 mile in order to simplify data entry (Maurer, 1986; Morel-Seytoux and Restrepo, 1987). Although the grid size used in the finite difference model has a major effect on computation time, the case study showed that developing a data set and executing a large groundwater model of 370 x 140 cells is manageable. One parameter in the groundwater model that needs additional attention is river bed conductance, as used in the MODRSP/MODFLOW River input data file. The technical literature provides little consensus on the physical basis for determining this important parameter. 
The results of the case study have shown that groundwater response coefficients derived from a finite difference groundwater model can be integrated into a full scale river basin simulation model by using MODSIM to simulate a groundwater augmentation plan. The Bijou Augmentation Plan was selected because it is a complex system that includes 193 wells, 30 recharge sites, four tributaries, and 13 river reaches. Seven years of monthly data recharge and well pump data are also available (1984-1991). Although these hydrologic data were input from data records provided by the NCWCD, it is possible to expand the network to make these calculations within MODSIM.

MODSIM was run using two different sets of response coefficients: the numerical coefficients calculated using the MODRSP finite difference groundwater model and analytical coefficients calculated with the Glover equation using predefined SDF values. Use of the analytically based SDF coefficients produces significantly lower net river return flow values when compared with results from the numerically based finite difference coefficients (i.e., 18,900 ac-ft vs $44,200 \mathrm{ac}-\mathrm{ft}$ ). This difference can be attributed to the inclusion of tributary flows in the simulation using the MODRSP finite difference coefficients.

The MODRSP finite difference coefficients generate net river return responses that follow a pattern similar to the net sum of the augmentation plan recharge and pumping flows. The distribution pattem for the SDF based net river return responses show a positive net gain in return flows over time which are substantially less dependent on the recharge/pumping flow trends. Deficits appear in 7 out of 84 months with use of the MODRSP finite difference coefficients, with deficits distributed over seven different months. On the other hand, the Glover based SDF method spawns no deficits in any of the 84 months.

The SDF coefficients produce unit response hydrographs with longer durations and lower peaks than the MODRSP coefficients. Time to peak for both methods generally occurrs in the first few periods. Because of differences in the shapes of the unit response hydrographs, the GloverSDF derived coefficients yield results that eliminate net river depletions, while the MODRSP finite difference response coefficients only reduce and redistribute the effects on net river depletions.

The case study identifies several of the basic differences between the two methods of generating response coefficients. Although the SDF method requires less computation time than the finite difference method (i.e., 232 Glover-SDF derived unit response curves vs. 1079 MODRSP derived unit response curves), the theoretical and spatial capabilities of the response coefficients derived from a finite difference groundwater model make this methodology a more powerful tool in stream-aquifer modeling. The Glover method uses only three variables to represent aquifer characteristics: average distance from the return flow source to the well site or channel reach, an average aquifer transmissivity, and an average aquifer specific yield: The stream depletion factor (SDF) combines all these variables into a single lumped parameter. The finite difference groundwater model considers spatial variation in aquifer characteristics and the effects of complex boundary conditions. The case study demonstrates that once the MODRSP finite difference response coefficients have been prepared, they can be used in MODSIM as easily as the Glover based SDF coefficients to model stream-aquifer interaction.

The river basin simulation model MODSIM was also applied as a daily administrative model. The daily model can be used to simulate river administration regulated under prior appropriation water right laws. Procedures are presented for determining the effects of a 
groundwater augmentation plan on daily river administration. The MODSIM network structure proposed for the case study allows water right priorities and flow diversions by structure to be linked together in a single model. The same network can be used for daily river planning, management, and evaluation.

The use of commercial software packages to develop a prototype DSS was accomplished by integrating QUATTRO PRO, MAPINFO and MODSIM software. QUATTRO PRO serves as the shell. Output from the Bijou Augmentation Plan MODSIM study is used as input to the daily administration model. The daily administration DSS is able to run MODSIM with and without considering the effects of the Bijou Augmentation Plan. The results of the first simulation are used as input to the second simulation and MODSIM is then rerun. This is all done automatically from within QUATTRO PRO.

Results for the daily administration example showed that the influence of the augmentation plan on Water District \#1 water rights administration was not significant (7 cfs), even though the Bijou Augmentation return flow did constitute up $20 \%$ of the unmeasured inflow to the river. The daily administration case study did demonstrate that the affects of an augmentation plan can be accurately quantified spatially and in time, and integrated into a river basin simulation model. 


\section{CHAPTER 7}

\section{SUMMARY AND CONCLUSIONS}

\subsection{Summary}

A prototype microcomputer based Stream-Aquifer Management Decision Support System (SAMDSS) has been presented with three components: database management system, model management system, and user management system or user interface. SAMDSS includes the capability of utilizing groundwater response coefficients generated from a groundwater flow model and a management capability for analysis of various conjunctive use scenarios. SAMDSS includes use available and widely accepted water resource models. Procedures and guidelines for linking and using various predictive models are included in SAMDSS. Data files and model input and output routines are structured around database concepts. Commercial software packages such as Lotus 1-2-3 and dBASEIV are used for interfacing, presenting, summarizing, and analyzing model results. GIS and database management tools are applied to preprocessing and postprocessing data.

A number of activities were carried out to develop the working SAMDSS. The first step was preparation of the conceptual model for a conjunctive stream-aquifer management decision support system. Next, the software components and software to be used were identified. MODSIM was selected as the river basin water rights and network flow model. The USGS finite difference model MODFLOW was selected as the groundwater flow model. MODRSP, a modified version of MODFLOW, was chosen as the numerical groundwater model for generating response coefficients. The USBR program PTFLOW was identified as a model that could be used to calibrate aquifer return flows. AUTOCAD (vector) and IDRISI (raster) were selected as the GIS software packages, along with DBASEIV as the database package. LOTUS 1-2-3 and QUATTRO PRO were used for spreadsheet calculations. MAPINFO and Microsoft Windows were used in developing the prototype user interface. The DSS was structured for use in a DOS/Windows-based microcomputer environment.

SAMDSS uses stream-aquifer response coefficients to model return flow, stream depletion flow, and stream aquifer responses over time due to reservoir seepage, irrigation and precipitation infiltration, well pumping, channel conveyance losses, artificial recharge from ponds, reservoirs, channels, and wells. Response coefficients can be generated from three sources: (i) a numerical finite difference model using a discrete kernel/response function approach; (ii) analytical methods using one-dimensional groundwater equations, or (iii) using predefined SDF values. Details and provisions have been included in SAMDSS for using GIS tools and techniques for preparing and processing data for input into the various models. A source list for digital data and public domain databases was prepared. Special utility programs were written to convert data to common formats for use in SAMDSS. Where possible, input and output data files for the various models selected for use in SAMDSS were structured as ASCII database text files.

To demonstrate the capabilities of the SAMDSS, a case study was carried out on a portion of the Lower South Platte River Basin, Colorado. The case study uses actual data to develop stream-aquifer response coefficients using GIS, database technology, and the groundwater finite difference model MODRSP. The water right retur/depletion flow account for the Bijou Irrigation Company groundwater augmentation plan was simulated using MODSIM. The plan involves 
approximately 200 wells and 30 recharge areas with data for a seven year period from 1985 to 1991. Two simulations studies were conducted:: one with stream-aquifer coefficients generated from MODRSP, and the second with groundwater response coefficients generated by MODSIM using predefined SDF values. A separate MODSIM network was constructed for the Lower South Platte River Colorado State Engineer Water District \#1 to simulate daily administration of a river regulated under prior appropriation water right laws. Data provided by the State Engineer were used to demonstrate the use of MODSIM to simulate an actual river call. The simulation was carried out with and without considering the effects of the Bijou augmentation plan to show the effects of a groundwater augmentation plan on daily administration of water rights. Two separate prototype user interfaces, one using the Bijou augmentation plan flow account network and the other using the daily administration example, were constructed using MAPINFO to demonstrate some of the capabilities inherent in a successful decision support system.

\subsection{Conclusions}

It has long been recognized in the Western United States that maximum water development can only be met through conjunctive use of surface and groundwater. Although considerable progress has been made in the development of regional groundwater models and river basin simulation models, previous attempts at linking these two types of models into a workable conjunctive use model for comprehensive river basin planning, management, and administration have not been completely successful. With recent advances in computer hardware and software technology such as geographic information systems (GIS) and data base management system technology (DBMS), it is now possible to develop a computer based river basin decision support system for improved conjunctive use management of groundwater and surface water by linking a finite difference groundwater flow model with a river basin network model.

Although most water managers and water resource planners appreciate that computerbased decision support tools are needed to assist in developing and administering alternative water resource planning and management strategies, many of the important agencies and organizations directly responsible for water planning, management, and administration are not making effective use of these models. Computer modeling structured around decision support theory can help bridge the gap between model development and model use.

Because each river system and model user has individual requirements that many times can not be met from an off-the-shelf commercial package, research efforts are best directed towards development of a collection of tools with guidelines and procedures that can be effectively applied to any river basin, instead of towards the development of a single large, general, and comprehensive model.

The key to the development of computer-based decision support tools is through a synthesis of existing technology rather than development of new models. A decision support system framework can be used to develop interfaces to link various modeling and database components. The modeling component should allow the user the option of problem solving using already familiar and recognized analytical procedures or using more theoretically based techniques that take advantage of computer technology advances such as geographic information systems. The data base component should be able to interact directly with existing data bases. 
Although GIS has been used extensively in a variety of water resource projects over the past 20 years, it is receiving renewed attention by many in the water resources field. One reason may be that only now are GIS systems, such as IDRISI, becoming usable in a computational environment that is affordable and generally available to researchers and practitioners. As a result, the state-of-the-art in interactive and integrated regional river basin planning and management can be implemented at a working level. Without the use of GIS and database technology, it would not be practical or cost-effective to develop groundwater response coefficients from a finite difference flow model and use these stream-aquifer response functions in a full scale river basin simulation model.

The use of a quasi-simulation model which combines simulation and optimization offers distinct advantages over a standard river basin simulation models, particularly for use in allocating water according to demands and targets based on priorities established by water rights. As compared with many of the more common river basin simulation models such as HEC5, SSARR, IRIS, HYDROSS, MODSIM is most effective for modeling complex water rights and conjunctiveuse groundwater events.

One limitation in the implementation of decision support system technology has been in the time and cost required to develop a proper user interface. Modestly priced desktop mapping software packages such as MAPINFO allow users and developers to take advantage of extended memory, Windows environment, and computational speed now available on DOS based microcomputers. These packages also make it possible for non-programmers and users to tailor input and output procedures to meet individual requirements.

The use of groundwater response coefficients generated from a numerical finite difference model versus an analytical model offers the advantage of incorporating spatially distributed information in predicting groundwater flow responses. The user is able to consider the influence of distributed aquifer characteristics, aquifer boundaries, tributaries, variable stream levels, constant head reservoirs and ponds, and most importantly, the spatial distribution and location over time of depletion and return flows resulting from well pumping and groundwater recharge.

Model input and output subroutines should be programmed to read and write data in database format as ASCII text files. This makes it convenient to use readily available database or spreadsheet software to preprocess and postprocess data. Study-specific front ends and graphical user interfaces can be developed without having to access and modify original model source code. Data from existing databases or data output from other computer models can be read directly into models as an input data file. This allows users and developers to employ standard and commercial software for preprocessing and postprocessing data without having to modify or even access model source code. It also makes it easier to read data directly from existing databases or output data for use by another model. Finally it encourages the development of a centralized database that can be accessed by more than a single user working with a single model. 


\section{REFERENCES}

Andrews, A. S., "Status of Water Rights Engineering, "Proceedings of the Colorado Water Engineering and Management Conference, Colorado Water Resources Research Institute, Colorado State University, Ft. Collins, Colorado, 1987.

Arnold, U. and G. T. Orlob, "Decision Support for Estuarine Water Quality Management," Journal of Water Resources Planning and Management, ASCE, Vol. 115, No. 6, pp. 775-792, 1989.

Ashton-Tate, Inc., dBASE IV, Version 4.01, Torrance, California, 1990.

Autodesk, Inc., AutoCAD, Release 11, Sausalito, Califormia, 1990.

Bear, J. , Hydraulics of Groundwater, McGraw Hill, NewYork, 1979.

Berthouex, P. M., W. Lai, and A. Darjatmoko, "Statistics-Based Approach to Wastewater Treatment Plant Operations," Journal of Environmental Engineering, ASCE, Vol. 115, No. 2, pp. 650-671, 1989.

Bertsekas, D. P., Linear Network Optimization, The MIT Press, Cambridge, Massachusetts, 1991.

Bertsekas, D. P. and P.Tseng, "Relaxation Methods for Minimum Cost Ordinary and Generalized Network Flow Problems," Operations Research, Vol 36, No. 1, pp. 93-114, 1988.

Bethel, R., Description of River Basin Simulation Model (RIBSIM), Leonard Rice Consulting Water Engineers, Inc., Denver, Colorado, 1986.

Boudon, J. P. and B. M. Saunier, "Computerized Operation of Water and Urban Networks: From Digital Mapping to Integrated Information Systems," in Computerized Decision Support Systems for Water Managers, J. Labadie, et al. (eds.) ASCE, New York, pp. 822-828, 1989.

Bouwer, H., Groundwater Hydrology, McGraw-Hill, New York, 1978.

Bridgeman, S. G., D. J. W. Norrie, J. J. Cook, and B. Kitchen, "Computerized Decision-Guidance System for Management of the Trent River Multireservoir System," in Computerized Decision Support Systems for Water Managers, J. Labadie, et al. (eds.) ASCE, New York, pp. 280-290, 1989.

Bradley, A. A., L. A. Anich, and N. H. Crawford, "Streamflow Forecasting for Hydropower Operations Using Interactive Modeling Systems," in Computerized Decision Support Systems for Water Managers, J. Labadie, et al. (eds.) ASCE, New York, pp. 280-290, 1989.

Brendecke, C. M, W. B. DeOreo, E. A. Payton, and L. T. Rozaklis, "Network Models of Water Rights and System Operations," Journal of Water Resources Planning and Management, ASCE, Vol. 115, No. 5, pp. 684-696, 1989. 
Camara, A. S., M. C. da Silva, A. C. C. Rodrigues, J. M. Remedio, P. P. Casto, M. J. Soares de Oliveira, and T. F. Femandes, "Decision Support System for Estuarine Water-Quality Management," Journal of the Water Resources Planning and Management, ASCE, Vol. 116, No. 3, pp. 417-432, May/June, 1990.

Chung, F. I., S. K. Aurora, and M. C. Archer, "Stochastic Evaluation of Reservoir Operation Rules," in Computerized Decision Support Systems for Water Managers, J. Labadie, et al. (eds.) ASCE, New York, pp. 131-140, 1989.

Clausen, R. J., The Numerical Solution of Network Problems Using the Out-of-Kilter Algorithm, Report No. RM-5456-PR, The Rand Corporation, Santa Monica, Califormia, 1968.

Colorado Division of Water Resources, Water Commissioner Manual, Denver, Colorado, 1989.

Courtney, B.M. and A.W. Whitlock, "Computer Support for TVA's Reservoir System Operations: Software," in Computerized Decision Support Systems for Water Managers, J. Labadie, et al. (eds.) ASCE, New York, pp. 51-56, 1989.

EOSAT, LANDSAT Products and Services Catalog, Lanham, Maryland, 1990.

Eastman, J. R, IDRISI: A Grid-Based Geographical Analysis System Version 3.22, Graduate School of Geography, Clark University, Worcester, Massachusetts, 1990.

El-Kadi, A. I , "Watershed Models and Their Applicability to Conjunctive Use-Management", Water Resources Bulletin, Vol. 25, No. 1, pp. 125-137, 1989.

Farley, D. W., M. Sydor, and G. E. Brown, "Heuristics and Network Flow Algorithms for Multireservoir System Regulation," in Computerized Decision Support Systems for Water Managers, J. Labadie, et al. (eds.) ASCE, New York, pp. 607-620, 1989.

Fedra, K, "Model-Based Education Support Systems: Application to Large Lakes and Hazardous Waste, " in Toxic Contamination in Large Lakes, Volume IV: Prevention of Toxic Contamination in Large Lakes: Managing a Large Ecosystem for Sustainable Development, Lewis Publishers, Chelsea, Michigan, pp. 77-103, 1988.

Fedra, K, "From Useful to Really Usable: Software for Water Resources Planning and Management," in Transferring Models to Users, E. B. Janes and W. R. Hotchkiss (eds.) American Water Resources Association, Bethesda, Maryland, pp. 73-86, 1990.

Frevert, D. K., J. W. Labadie, R. K. Larson, and N. L. Parker, "Integration of Water Rights and Network Flow Modeling in the Upper Snake River Basin," Proceedings of the 21st Annual Conference, Water Resources Planning and Management Division, D. G. Fontane and H. N. Tuvel (eds.) ASCE, Denver, Colorado, p. 157, 1994.

Glover, R. E. and G. G. Balmer, "River Depletion Resulting from Pumping a Well Near a River," Transactions of the American Geophysical Union, Vol. 35, No. 3, pp. 468-470, 1954. 
Glover, R. E., Mathematical Derivations as Pertaining to Groundwater Recharge, Agricultural Research Service, USDA, Ft. Collins, Colorado, 1960.

Glover, R.E., The Pumped Well, Technical Bulletin No. 100, Colorado State University Experiment Station, Ft. Collins, Colorado, 1968.

Glover, R.E., Transient Groundwater Hydraulics. Water Resources Publications, Fort Collins, Colorado, 1977.

Golden Software, Inc., SURFER, Golden, Colorado, 1987.

Goutler, I. C. and D. Forest, "Use of Geographical Information Systems (GIS) in River Basin Management," Water Science Technology, Vol. 19, No.9, pp. 81-86, 1987.

Graham, L.P., J. W. Labadie, I. P. G. Hutchison, and K A. Ferguson, "Allocation of Augmented Water Supply Under a Priority Water Rights System," Water Resources Research, Vol. 22, No. 7, pp. 1083-1094, 1986.

Grobler, D. C., J. N. Rossouw, P. van Eeden, and M. Oliveira, "Decision Support System for Selecting Eutrophication Control Strategies," in Systems Analysis in Water Quality Management, Pergamon Press, New York, pp 219-230, 1987.

Guymon, G. L, A. C. Bagtzoglou, and M. R. Welch, "A Lumped Stream-Aquifer Model to Assess Reclaimed Water Impacts," Water Resources Bulletin, Vol. 28, No. 2, pp. 361-370, 1992.

Hantush, M.D., "Growth and Decay of Groundwater-Mounds in Response to Uniform Percolation," Water Resources Research, Vol, 3, pp. 227-234, 1967.

Hantush, M. S. and M. A. Marino, "Chance-Constrained Model for Management of StreamAquifer System," Journal of Water Resources Planning and Management, ASCE, Vol. 115 , No. 3, pp. 259-277, 1989.

Hartwell, A., Artificial Recharge in the South Platte River Basin, Colorado: A Comparison of Four Models, M. S. Thesis, Department of Civil Engineeringt, Colorado State University, Ft. Collins, Colorado, 1987.

HRS Water Consultants, Inc., Bijou Irrigation Company Plan for Augmentation Engineering Report, Lakewood, Colorado, 1983.

Hunt, B. W., "Vertical Recharge of Unconfined Aquifers," Journal of the Hydraulics Division, ASCE, Vol. 97, No. HY7, ASCE, pp. 1017-1030, 1971.

Hurr, R. T., P. A. Schneider, et al., Hydrogeologic Characteristics of the Valley Fill Aquifer in the Brighton, Greeley, Weldona, Brush, Sterling, and Julesberg Reaches of the South Platte River Valley, Colorado. U.S. Geologic Survey Open File Report, prepared in cooperation with the Colorado Water Conservation Board, Water Resources Division, Colorado District, Lakewood, Colorado, 1972. 
Hurr, R. T., P. A. Schneider, and D. R. Minges, Hydrology of the South Platte River Valley, Northeastern Colorado, Colorado Water Resources Circular Number 28, U.S. Geological Survey Open File Report, Lakewood, Colorado, 1975.

Hurr, R T. and A W. Burns, Stream-Aquifer Management Model of the South Platte River Valley, Northeastern Colorado, Preliminary Report, U.S. Geological Survey, Lakewood, Colorado, 1980.

Hydrologic Engineering Center, HEC-5: Simulation of Flood Control and Conservation Systems, User's Manual, U.S. Army Corps of Engineers, Davis, California, 1991.

Illangasekare, T. H., Influence Coefficients Generator Suitable for Stream-Aquifer Management, Ph.D Dissertation, Department of Civil Engineering, Colorado State University, Ft. Collins, Colorado, 1978.

Illangasekare, T. H. and H. J. Morel-Seytoux, "Stream-Aquifer Influence Coefficients as Tools for Simulation and Management," Water Resources Research, Vol. 18, No. 1, pp. 168-176, 1982.

Illangasekare, T. H. and H. J. Morel-Seytoux, "Algorithm for Surface/Ground-Water Allocation Under Prior Appropriation Doctrine," Ground Water, Vol. 24, No. 2, pp. 199-206, 1986.

nlangasekare, T. H. anc J. H. Brannon, "Microcomputer Based Interactive Simulator," Journal of Hydraulic Engineering, ASCE, Vol. 113, No. 5, ASCE, pp. 573-582, 1987.

Illangasekare, T. H., "Distributed Parameter Models for Decision-Making in the Management of Surface-Groundwater Systems," Proceedings of the Colorado Water Engineering and Management Conference, Colorado State University, Ft. Collins, Colorado, 1987.

Jenkins, C. T., "Computation of Rate and Volume of Stream Depletion by Wells: Hydrologic Analysis and Interpretation," in Techniques of Water-Resources Investigations of the U.S. Geological Survey, Book 4, Chapter D1 U.S. Printing Office, Washington D.C, 1968.

Johnson, L. E., "Water Resource Management Decision Support Systems," Journal of Water Resources Planning and Management, ASCE, Vol. 112, No. 3, pp. 308-325, 1985.

Johnson, L. E, "Computer-Aided Planning for Muitiple-Purpose Reservoir Operating Policies," Water Resources Bulletin, Vol. 26, No. 2, pp. 299-311, 1990.

Kemodle, J. M. and R. D. Philip, "Using a Geographic Information System to Develop a GroundWater Flow Model," in Regional Aquifer Systems of the United States: Aquifers of the Western Mountain Area, J. S. McLean and A. I. Johnson (eds.) AWRA Monograph Series No. 14, AWRA, Bethesda, Maryland, pp. 191-202, 1988.

Kilborn, K, H. S. Rifai, and P. B. Bedient, "The Integration of Ground Water Models with Geographical Information Systems (GIS)," Proceedings of the ACSM/ASPRS/AutoCarto 10 National Convention and Exposition, Baltimore, Maryland, March 23-29, 1991. 
Kraeger-Rovey, C., "Simulation of Stream Boundaries in Groundwater Models: An Historical Overview," Proceedings Groundwater Engineering and Management Conference, Colorado State University, Ft. Collins, Colorado, February 28-March 1,1990.

Labadie, J. W., S. Phamwon, and R. Lazaro, Model for Conjunctive Use of Surface and Groundwater: Program CONSIM, Completion Report No. 125. Colorado Water Resources Research Institute, Colorado State University, Ft. Collins, Colorado, 1983.

Labadie, J. W. , D. Bode and A. Pineda, "Network Model for Decision-Support in Municipal Raw Water Supply," Water Resources Bulletin, Vol 22, No. 6, pp. 927-940, 1986a.

Labadie, J. W. and C. Sullivan, "Computerized Decision Support Systems for Water Managers," Journal of Water Resources Planning and Management, ASCE, Vol. 112, No. 3, pp. 299$307,1986 \mathrm{~b}$.

Labadie, J. W., Program MODSIM: River Basin Network Flow Model for the Microcomputer, Program Documentation, Department of Civil Engineering, Colorado State University, Ft. Collins, Colorado, 1988.

Labadie, J. W., L. E. Brazil, I. Corbu, L. E. Johnson (eds.) Computerized Decision Support Systems for Water Managers, American Society of Civil Engineers, New York, 1989.

Lanfear, K.J., "Water Resource Applications of Geographic Information systems by the U.S. Geological Survey," Update Water Resources, No. 87, Universities Council on Water Resources, pp. 12-16, 1992.

Law, J. and M. Brown,"Development of a Large Network Model to Evaluate Yield of a Proposed Reservoir," in Computerized Decision Support Systems for Water Managers, J. Labadie, et al. (eds.), ASCE, New York, pp. 621-631, 1989.

Lee, C.Y., A. R. Qazi, and J. A. Danielson, "A Digital Model Applied to Groundwater Recharge and Management," Water Resources Bulletin, Vol. 16, No. 3, pp. 514-521, 1980.

Lotus Development Corporation, LOTUS 1-2-3, Release 2.2, Cambridge, Massachusetts, 1989.

Loucks, D. P and K. A. Salewicz, IRIS: An Interactive River Simulation System Program: General Introduction and Description, School of Civil and Environmental Engineering, Cornell University, Ithaca, New York, 1989

Luecke, D. F., "Groundwater as an Environmental Issue," Proceedings of the Groundwater Engineering and Management Conference, Colorado Water Resources Research Institute, Colorado State University, Ft. Collins, Colorado, 1990.

Maasland, M., "Water Table Fluctuations Induced by Intermittent Recharge," Journal of Geophysical Research, Vol. 64, No. 5, pp. 549-559, 1959. 
MacDonnell, L. J, Integrating Tributary Groundwater Development into the Prior Appropriation System: The South Platte Experience, Completion Report No. 148, Colorado Water Resources Research Institute, Colorado State University, Ft. Collins, CO, 1988.

Maddock III, T., "Algebraic Technological Functions from a Simulation Model," Water Resources Research, Vol 8, No. 1, pp 129-134, 1972.

Maddock III, T., "The Operation of Stream-Aquifer System Under Stocastic Demands," Water Resources Research, Vol. 10, No. 1, pp. 1-10, 1974.

Maddock III, T. and L. Lacher, "Drawdown, Velocity, Storage and Capture Response Functions for Multiaquifer Systems," Water Resources Research, Vol. 27, No. 11, pp. 2885-2898, 1991a.

Maddock III, T. and L. Lacher, MODRSP: A Program to Calculate Drawdown, Velocity, Storage and Capture Response Functions for Multi-Aquifer Systems, HWR Report No. 91-020, Department of Hydrology and Water Resources, University of Arizona, Tucson, Arizona, $1991 b$.

Madsen, H., "Irrigation, Groundwater Abstraction and Stream Flow Depletion," Agricultural Water Management, Vol. 14, Elsevier Science Publishers, pp. 345-354, 1988.

Male, J. W. and F. Mueller, "Model for Prescribing Ground-Water Use Permits," Journal of Water Resources Planning and Management, ASCE, Vol. 118, No. 5, pp. 543-561, 1992.

MapInfo Corp., MAPINFO for WINDOWS, Troy, New York, 1992.

Mauer, D. K., Geohydrology and Simulation Response to Ground-Water Pumpage in Carson Valley, a River-Dominated Basin in Douglas County, Nevada, and Alpine County, California. Water-Resources Investigations Report 86-4328, U.S. Geological Survey, Carson City, Nevada, 1986.

McDonald, M. G. and A. W. Harbaugh, A Modular Three-Dimensional Finite Difference GroundWater Flow Model, in Techniques of Water-Resources Investigations of the U.S. Geological Survey, Book 6, Chapter A1, U.S. Printing Office, Washington D.C, 1988.

McWhorter, D. B. et al., Analytical Model of Stream-Aquifer Systems with Pumping and Recharge, Completion Report. Colorado State University, Ft. Collins, Colorado, 1972.

Miller, R. S., User's Guide for RIV2: A Package for Routing and Accounting of River Discharge for a Modular Three-Dimensional Finite-Difference Ground-Water Model, U.S. Geological Survey Open-File Report 88-345, Albuquerque, New Mexico, 1988.

Morel-Seytoux, H. J. and C. J. Daly, "A Discrete Kernel Generator for Stream-Aquifer Studies," Water Resources Research, Vol. 11, No. 2, pp. 253-260, 1975. 
Morel-Seytoux, H. J. , C. J. Daly, T. llangasekare, and A. Bazaraa, "Design and Merit of a RiverAquifer Model for Optimal Use of Agricultural Water," Journal of Hydrology, Vol. 51, No. 17-21, pp. 17-27, 1981.

Morel-Seytoux, H. J. and J. I. Restrepo, SAMSON User's Manual, Vol. I, Colorado Water Resources Research Institute, Colorado State University, Ft. Collins, Colorado, 1987.

Morel-Seytoux, H. J. and C. M. Zhang, "Anticipation of Augmentation Needs for Allocation Operations," Proceedings Groundwater Engineering and Management Conference, Colorado Water Resources Research Institute, Colorado State University, Ft. Collins, CO, February 28-March 1, 1990.

Moulder, J. E. and C.T. Jenkins, "Analog-Digital Models of Stream Aquifer Systems," Ground Water, Vol. 7, No. 5, pp. 19-24, 1969.

Office of Technology Assessment, Use of Models for Water Resources Management, Planning, and Policy, GPO Stock 052003-00880-7, U.S. Congress, U.S. Printing Office, Washington D.C, 1982.

Orzol, L. L. and T. S. McGrath, Modifications of the U.S. Geological Survey Modular FiniteDifference Ground-Water Flow Model to Read and Write Geographic Information System Files. Open File Report 92-50, U.S. Geological Survey, Portland, Oregon, 1992.

Ozbilgin, M. M., S. H. Chieh, W. R Swanson, K. A. Shutter, W. W. Hoye, and M.L. Blevins, "Management of a Groundwater Basin Using an Integrated Numerical Model and a Geographic Information System," J. L Anderson (ed.), Water Resources Planning and Management and Urban Water Resources, pp. 80-85, 1991.

Palmer, R N. and K. J. Holmes, "Operational Guidance During Droughts: Expert System Approach," Journal of Water Resources Planning and Management, ASCE, Vol. 114, No. 6, ASCE, pp. 647-666, 1988.

Peters, G., Modeling Aquifer Return Flows and Non-Equilibrium Initial Conditions, M.S. Thesis, Department of Civil engineering, Colorado State University, Ft. Collins, CO, 1978.

Pike, E. , J. Fuerst, and H. Horsey , Logical Groundwater Workstation: Design Foundation and Initial Design, Draft Report, CADWES, University of Colorado, Boulder, Colorado, 1990.

Pinay G., K. A. Salewicz, and G. Kovacs, "An Attempt to Facilitate water Management Issues in the Zamberi River Basin Using Decision Support Systems," Regulated Rivers: Research and Management, Vol. 2, pp. 559-563, 1988.

Pinder, G. F., "An Overview of Groundwater Modelling," in Groundwater Flow and Quality Modeling, E. Custodio, et al. (eds). D. Reidel Publishing Company, pp. 119-134, 1988. 
Pingry, D. E., T. L. Shaftel, and K. E. Boles, "Role for Decision-Support Systems in WaterDelivery Design," Journal of the Water Resources Planning and Management, ASCE, Vol. 117, No. 6, pp. 629-644, November/December, 1991.

Qazi, R. and J. Danielson, "Analytical Model for Management of Alluvial Aquifers," Journal of the Irrigation and Drainage Division, ASCE, Vol. 100, No. IR2., pp. 143-152, 1974.

Rau, D. M., "Water Rights Accounting Program," Proceedings of the Colorado Water Engineering and Management Conference, Colorado State University, Ft. Collins, Colorado, 1987.

Rau, N. H. and P. B. S. Sharma, "Groundwater Recharge from Rectangular Areas," Ground Water, Vol. 19, No. 3, pp. 270-274, 1981.

Restrepo, J. I., SAMPSON Stream-Aquifer Model for Management by Simulation, Vol II: Calibration to the South Platte River Basin, Colorado Water Resource Research Institute, Colorado State University, Ft. Collins, Colorado, 1988.

Romero, J. C., Water Levels in the Alluvial Aquifers of the Lower South Platte River Basin, Colorado, Office of the State Engineer, Division of Water Resources, Denver, CO, 1987.

Rogers, P. P. and M. B. Fiering, "Use of System Analysis in Water Management," Water Resources Research, Vol. 22, No. 9, pp. 146S-158S, 1986.

Schenk, J., E. Poeter, and C. Kraeger-Rovey, "Improved Code for Simulating Surface and Groundwater Interactions with MODFLOW," Proceedings of the Groundwater Engineering and Management Conference, Colorado Water Resources Research Institute, Colorado State University, Ft. Collins, Colorado, February 28-March 1, 1990.

Shafer, J. M., An Interactive River Basin Water Management Model: Synthesis and Application, Technical Report No. 18, Colorado Water Resources Research Institute, Colorado State University, Ft. Collins, Colorado, 1979.

Sigvaldason, O., "A Simulation Model for Operating a Multipurpose Multireservoir System," Water Resources Research, Vol. 12, No. 2, pp. 263-278, 1976

Sprague, R. H., "A Framework for the Development of Decision Support Systems," MIS Quarterly, Vol. 4, No.4, pp. 1-26, 1980.

Sprague, R. H. and E. D. Carlson, Building Effective Decision Support Systems. Prentice Hall Inc, 1982.

Stoertz, M. W. and K. R. Bradbury, "Mapping Recharge Areas Using a Ground-Water Flow Model-A Case Study," Ground Water, Vol. 27, No. 2, pp. 220-228, 1989.

South Platte Basin Water Management Committee, South Platte Basin Management Study, Draft Report, R. Weidelman (ed.), U.S. Bureau of Reclamation, Loveland, Colorado, 1989. 
Stover, C. M., "Development of the Hydro Optimization Management System at Alabama Power Company," Proceedings of Conference on Water Resources Planning and Management and Urban Water Resources, J. L. Anderson (ed.), ASCE, pp. 57-65, 1991.

Taylor, O. J. and R. R. Luckeyk, "A New Technique for Estimating Recharge Using a Digital," Groundwater,Vol. 10, No. 6, pp. 22-26, 1972.

Texas Water Development Board, Economic Optimization and Simulation Techniques for Management of Regional Systems: River Basin Simulation Model SIMYLD-II, Program Description, Systems Engineering Division, Austin Texas, 1972.

Trescott, P. C., G. F. Pinder, and S. P. Larson, "Finite-Difference Model for Aquifer Simulation in Two-Dimensions with Results of Numerical Experiments," in U.S Geological Survey Techniques in Water Resource Investigations, Book 7, U.S. Printing Office, Washington D.C., 1976.

U.S. Army Corps of Engineers, SSARR Model Streamflow Synthesis and Reservoir Regulation: User Manual, North Pacific Division, Portland, Oregon, 1986.

U.S. Bureau of the Census, TIGER/Line Precensus Files, 1990, Technical Documentation. U.S. Department of Commerce, Washington D.C, 1989.

U.S. Bureau of Reclamation, South Platte River, Colorado, Point Flow Study 1931-1983., Denver, Colorado, 1989.

U.S. Bureau of Reclamation, HYDROSS Version 4.3, Information Resources Division, Billings, Montana, 1991.

U.S. Geological Survey, GCTP General Cartographic Transformation Package: Software Documentation, National Mapping Division, U.S. Department of the Interior, Reston, Virginia, 1990.

U.S. Geological Survey, Digital Line Graphs from 1:1:24,00-Scale Maps: Data Users Guide: USGeoData, National Mapping Program, Technical Instructions Data Users Guide 1, U.S. Department of the Interior, Reston, Virginia, 1990a.

U.S. Geological Survey, Digital Line Graphs from 1:1:100,000-Scale Maps:Data Users Guide. USGeoData, National Mapping Program, Technical Instructions Data Users Guide 2, U.S. Department of the Interior, Reston, Virginia, 1990b.

U.S. Geological Survey, Digital Line Graphs from 1:1:2,000,000-Scale Maps: Data Users Guide. USGeoData, National Mapping Program, Technical Instructions Data Users Guide 3, U.S. Department of the Interior, Reston, Virginia, 1990c.

U.S. Geological Survey, Land Use and Land Cover Digital Data from 1:250,000- and 1:100,000Scale Maps: Data Users Guide. USGeoData, National Mapping Program, Technical Instructions Data Users Guide 4, U.S. Department of the Interior, Reston, Virginia, 1990d. 
U.S. Geological Survey, Digital Elevation Models: Data Users Guide. USGeoData, National Mapping Program, Technical Instructions Data Users Guide 5, U.S. Department of the Interior, Reston, Virginia, 1990e.

U.S. Geological Survey, Geographic Names Information System: Data Users Guide.USGeoData, National Mapping Program Technical Instructions Data Users Guide 6, U.S. Department of the Interior, Reston, Virginia, 1990f.

Van der Heijde, P., Y. Bachmat, J. Braedehoeft, B. Andrews, D. Holtz, and S. Sebastian, Groundwater Management: The Use of Numerical Models, Water Resources Monograph Series, American Geophysical Union, Washington D.C, 1985.

Vassilev, P., D. Martin, M. Tremblay, and C. Marche, "Brief Description of CASTOR Software for Management of Reservoir Systems," in Computerized Decision Support Systems for Water Managers, J. Labadie, et al. (eds.), ASCE, New York, pp. 593-606, 1989

Warner, J. W., D. K Sunada, and A. Hartwell, Recharge as Augmentation in the South Platte River Basin, Technical Report No. 13, Colorado Water Resources Research Institute, Ft. Collins, Colorado, 1986.

Warner, J. W. ,D. Moulden, M. Chehata, and D. K. Sunada,"Mathematical Analysis of Artificial Recharge from Basins," Water Resources Bulletin, Vol. 25, No. 2, pp. 401-411, 1989.

Wheeler, W. W. and Associates, Inc., Straight Line Diagram for The South Platte River Irrigation Division No. 1.,Englewood, Colorado, 1985.

Willis, R. and W. Yeh, Groundwater Systems Planning and Management, Prentice-Hall, Englewood Cliffs, New Jersey, 1987

Willeke, G. E., "Geographic Information Systems and Water Resources," Update Water Resources, No. 87, Universities Council on Water Resources, pp. 17-20, 1992.

Woodward-Clyde Consultants, South Platte River Basin Assessment Report, Englewood, Colorado, 1982.

Wurbs, R. A. and W. B. Walls, "Water Rights Modeling and Analysis," Journal of Water Resources Planning and Management, ASCE, Vol. 115, No. 4, pp. 416-430, 1989.

Yeh, W., "Reservoir Management and Operations Models: A State-of-the-Art Review," Water Resources Research, Vol. 21, No. 12, pp 1797-1818, 1985.

Zhang, C. M., Modeling a Groundwater System Under Complex Boundary Conditions by Discrete Kernel Approach. Ph.D. Dissertation, Department of Civil Engineering, Colorado State University, Ft. Collins, Colorado, 1990. 


\section{APPENDIX A \\ LAGRANGIAN RELAXATION ALGORITHM FOR SOLVING \\ MINIMUM COST NETWORKS}

\section{A.1 Problem Formulation}

The minimum cost network flow problem solved in MODSIM is formulated as follows, where link $[i, j]$ is designated by the node pair $[i, j]$ representing the beginning and ending nodes of the link, respectively. This notation implies one unique node pair for each link, and is used for convenience in the following development only. The algorithm is actually capable of considering multiple links for the same node pair. The objective function is :

$$
\min \sum_{(i, j) \in A} c_{i j} \bar{x}_{i j}
$$

subject to:

$$
\begin{aligned}
& \sum_{U(i, N) \in A\}} \bar{x}_{i j}-\sum_{U(V, n) \in A\}} \bar{x}_{j i}=0 \quad \forall i \in N \\
& \bar{l}_{i j} \leq \bar{x}_{i j} \leq \bar{u}_{i j} \quad \forall(i, j) \in A
\end{aligned}
$$

where $\bar{x}_{i j}$ represents the flow rate in link $[i, j]$, with link parameters $\left[\bar{l}_{i j}, \bar{u}_{i j}, c_{i j}\right]$. A transformation can be performed to remove the lower bounds from this problem. Let

$$
\begin{gathered}
x_{i j}=\bar{x}_{i j}-\bar{l}_{i j} \text { or } \bar{x}_{i j}=x_{i j}+\bar{l}_{i j} \\
u_{i j}=\bar{u}_{i j}-\bar{l}_{i j} \forall(i, j) \in A
\end{gathered}
$$

The transformed objective function is now formulated as:

$$
\min \sum_{(i, j) \in A} c_{i j}\left[x_{i j}+\bar{l}_{i j}\right] .
$$

Since the constant term can be removed, the objective is:

$$
\min \sum_{(i, j) \in A} c_{i j} x_{i j}
$$


subject to:

$$
\begin{gathered}
\sum_{\forall \mid(i, j) \in A\}}\left[x_{i j}+\bar{l}_{i j}\right]-\sum_{(j \mid(j, n) \in A\}}\left[x_{j i}+\bar{l}_{j i}\right]=0 \quad \forall i \in N \\
0 \leq x_{i j} \leq u_{i j}=\bar{u}_{i j}-\bar{l}_{i j} \quad \forall(i, j) \in A
\end{gathered}
$$

or

$$
\sum_{(j(i, j) \in A\}} x_{i j}-\sum_{U \mid(j, i) \in A\}} x_{j i}=s_{i} \forall i \in N
$$

where

$$
s_{i}=\sum_{U \mid(j, i) \in A\}} \bar{l}_{j i}-\sum_{U \mid(i, N) \in A\}} \bar{l}_{l j} \forall i \in N
$$

In this formulation, all link parameter data $\left[u_{i j}, c_{i j}\right]$ and $s_{i}$ are assumed to be integer.

\section{A.2 Lagrangian Relaxation Algorithm}

The solution to this problem is based on a Lagrangian relaxation algorithm developed by Bertsekas (1991). Introducing Lagrange multipliers or dual prices $p_{i}$, the Lagrangian function is defined as:

$$
L(x, p)=\sum_{(i, j) \in A} c_{i j} x_{i j}+\sum_{i \in N} p_{i}\left[s_{i}-\sum_{\ell \mid(i, \lambda) \in A\}} x_{i j}+\sum_{(j \mid(j, i) \in A\}} x_{j i}\right]
$$

Note that:

$$
\sum_{(j, i) \in A} p_{i} x_{j i}=\sum_{(i, j) \in A} p_{j} x_{i j}
$$

Therefore:

$$
L(x, p)=\sum_{(i, j) \in A}\left[c_{i j}+p_{j}-p_{i}\right] x_{i j}+\sum_{i \in N} s_{i} p_{i}
$$

Instead of attempting to directly solve the original minimum cost network flow problem, the goal is to successively obtain updated dual price vectors $p$ that solve the following dual problem:

$$
\max \phi(p)
$$


where

$$
\phi(p)=\sum_{(i, \sqrt{ }) \in A} \phi_{i j}\left(p_{i}-p_{j}\right)+\sum_{i \in N} s_{i} p_{i}
$$

with

$$
\begin{gathered}
\phi_{i j}\left(p_{i}-p_{j}\right)=\min _{0 \leq x_{i j} \leq u_{i j}}\left(c_{i j}+p_{j}-p_{i}\right) x_{i j} \\
=\left[\begin{array}{cr}
\left(c_{i j}+p_{j}-p_{i}\right) u_{i j} & \text { if } p_{i}>c_{i j}+p_{j} \\
0 & \text { if } p_{i} \leq c_{i j}+p_{j}
\end{array}\right.
\end{gathered}
$$

Solution of the dual problem results in solution of the original minimum cost network flow problem. Notice that in the dual problem, the node mass balance constraints are temporarily relaxed since they are placed in the objective function via the Lagrangian function; hence, the term relaxation algorithm. The link capacity constraints remain explicitly accounted for. The objective is to

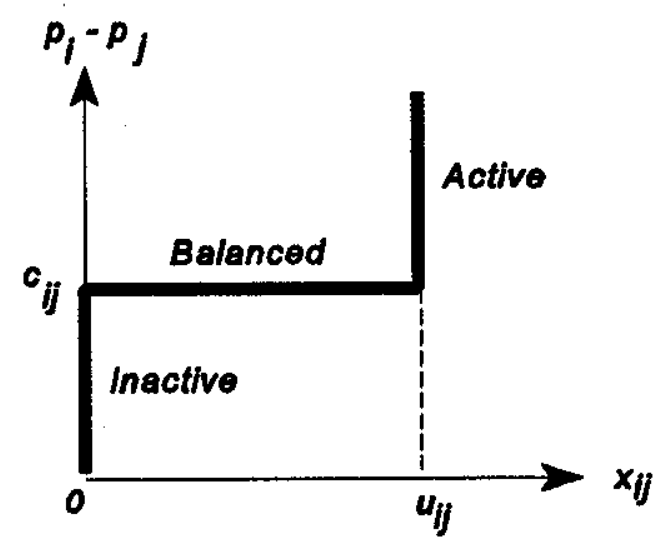
find the optimal dual price vector $p$ that will result in a solution that will fully satisfy the node mass balance constraints. The advantage of this approach is that the inner minimization problem as defined by $\phi_{i}\left(p_{i}-p_{j}\right)$ is extremely easy to solve. The following complementary slackness conditions are optimality conditions associated with flow in link $[i, j]$ for a given dual price vector $p$ :

$$
\begin{aligned}
& \text { inactive } \operatorname{arc}\left[x_{i j}=0\right] \text { if. } \quad p_{i}<c_{i j}+p_{j} \\
& \text { balanced } \operatorname{arc}\left[0 \leq x_{i j} \leq u_{i j}\right] \text { if. } p_{i}=c_{i j}+p_{j} \\
& \text { active arc }\left[x_{i j}=u_{i j}\right] \text { if. } \quad p_{i}>c_{i j}+p_{j}
\end{aligned}
$$

The basic duality result of linear programming states that: If a feasible flow vector $x *$ and a price vector $p^{*}$ sastisfy the complementary slackness conditions, then $x^{*}$ is an optimal solution of the minimum cost flow problem and $p^{*}$ is an optimal solution of the dual problem. The optimal solution of the dual problem is found using a coordinate-wise dual ascent algorithm.

Define the surplus $g_{i}$ of node $i$ as the difference between the total inflow into node $i$, less the total outflow from node $i$ : 


$$
g_{i}=\sum_{U(j, i) \in A\}} x_{j i}-\sum_{U j(i, j) \in A\}} x_{i j}
$$

At the start of an iteration, an integer flow-node price pair $(x, p)$ is assumed to be available which satisfy complementary slackness. The current iteration will indicate: (i) if the primal problem is infeasible (i.e., node surplus $g_{i}<0$ for some $i$ ); (ii) if $(x, p)$ is optimal (i.e., $g=0$ for all $i$, implying that $x$ is feasible and, since complementary slackness is satisfied, is also optimal); or (iii) if a new pair can be found improves the dual objective function (i.e., $g_{i}>0$ for at least one node $i$ ). For the latter case, the iteration begins by selecting node $k$ such that $g_{k}>0$. The iteration maintains the two sets: $S$ and $L$; where $S \subset L$. At the initial iteration, set $S=\{0\}$ and $L=\{k\}$. A label is also maintained for all nodes $\epsilon L$ which is an incoming arc to that arc.

The goal is to maximize the dual objective function, which will result in solution to the original minimum cost network flow problem. A dual ascent direction is defined using the nodes contained in set $S$. Since set $S$ usually contains a single node, the search procedure generally proceeds in one coordinate direction at a time. Dual prices are changed in the dual ascent direction so as to increase the dual objective function. Since the goal is to eventually achieve a solution where all $g_{i}=0$, a flow augmentation step occurs in the algorithm where a path through the network is defined from a node $\mathrm{k}$ where $g_{k}>0$ to a node $j$, where $g<0$. This means that flow can be increased along that path, resulting in improved node surplus conditions for both nodes.

\section{A.3 Typical Relaxation Iteration}

\section{o. INITIALIZATION}

Select a node $k$ with node surplus $g_{k}>0$ [if no such node can be found, then the solution is optimal or infeasible]

$$
g_{k}=\sum_{(j, k) e A} x_{j k}-\sum_{(k, j) e A} x_{k j}+s_{k}
$$

- Let the set of labels $L=\{k\}$

- Let the direction vector set $S=\{\theta\}$

\section{CHOOSE A NODE TO SCAN}

- IF $S=L$ [i.e., we are sure of ascent direction]

\section{ELSE}

GOTO Step 4 and perform price change

select node $i$ which is contained in the current set of labels, but not in the current direction vector set; i.e., select $i \in L-S$

$S:=S \cup\{i\}$

GOTO Step 2 


\section{LABEL NEIGHBORING NODES OF i}

- Check the directional derivative of the dual objective:

$$
y^{\prime}\left(p ; d_{S}\right)=\sum_{(j, i): \text { active, j\&S, } i \in S} u_{j i}-\sum_{(i, j): a c t \text { tive or balanced, }, \in S, j \in S} u_{i j}+\sum_{i \in S_{i}} s_{i}
$$

where direction vector $d_{S}=\left(d_{1}, \ldots, d_{N}\right)$, with

$$
d_{i}=\left[\begin{array}{ll}
1 & \text { if } i \in S \\
0 & \text { if } i \notin S
\end{array}\right.
$$

- If $y^{\prime}>0$, then current direction $d_{s}$ is an ascent direction GOTO price change [Step 4]

ELSE add to labeled set of neighboring nodes that can eventually result in identification of a flow augmentation path from node $k$ to node $j$ : $L=L+\{j\}$ for all nodes $j$ such that:

- $\quad \operatorname{link}(j, t)$ is balanced and $x_{j i}>0$ [assign label $(j, i]$ ], or

- $\quad$ link $(i, j)$ is balanced and $x_{i j}<u_{i j}$ [assign label $(i, j)$ ]

IF for every node $j$ added to $L$, we have $g_{j}>0$, then we have not yet found a flow augmentation path: RETURN to Step 1

ELSE: Select one of the nodes $j$ with: $g_{j}<0$; GOTO Step 3

\section{FLOW AUGMENTATION}

A flow augmentation path $P$ has been found starting at node $k$ and ending at the node $j$ found in Step 2. Since $g_{k}>0$ and $g_{j}<0$, then flow can be increased along the path such that $g_{k}$ will decrease towards zero, and $g_{j}$ will increase towards zero, subject to limitations.

Path $P$ is constructed by tracing labels backward starting from $j$, where $P^{+}$is the set of all forward arcs and $P^{-}$is the set of backward arcs:

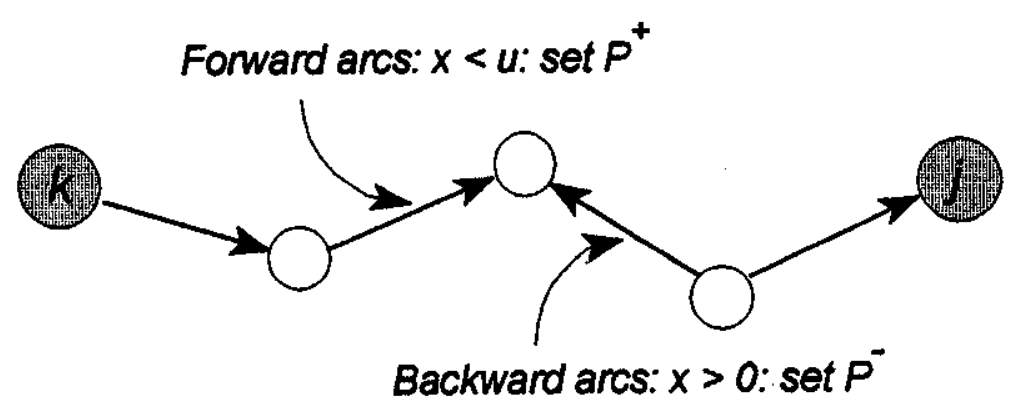


Calculate:

- For all links in $P^{+}$, ADD $\delta$ to the current flows.

- $\quad$ For all links in $P^{-}$, SUBTRACT $\delta$ from the current flows.

- GOTO NEXT ITERATION.

\section{PRICE CHANGE}

$$
\delta=\min \left\{\begin{array}{c}
g_{k} \\
-g_{j} \\
\left(u_{m n}-x_{m n}\right) \quad \forall(m, n) \in P^{+} \\
\left(x_{m n}\right) \forall(m, n) \in P^{-}
\end{array}\right.
$$

Set

$$
\begin{array}{ll}
x_{i j}=u_{i j} & \forall \text { balanced links }(i, j) \text { with } i \in S, j \notin S \\
x_{j i}=0 & \forall \text { balanced links }(j, i) \text { with } i \in S, j \notin S
\end{array}
$$

Let

$$
\gamma=\min \left\{\begin{array}{l}
\left\{c_{i j}-\left(p_{i}-p_{j}\right)\right\} \mid x_{i j}<u_{i j}, i \in S, j \notin S \\
\left\{-c_{j i}-\left(p_{i}-p_{j}\right)\right\} \mid x_{j i}>0, i \in S, j \notin S
\end{array}\right.
$$

Set

$$
p_{i}=\left\{\begin{array}{l}
p_{i}+\gamma \text { IF iES } \\
p_{i} \text { OTHERWSE }
\end{array}\right.
$$

\section{GOTO NEXT ITERATION}

\section{A.4 Example Problem}

Consider the example network below, where exogenous flows are shown as supply and demand entering and leaving (respectively) each node. The link parameters are shown on each link, with all lower bounds set to zero. The objective is to find the minimum cost flow through the network that satisfies mass balance and all link flow upper bounds. 


\section{We begin}

with an initial solution for the integer flow vector, dual price vector pair as $(x, p)=$ $(0,0)$. Notice that this solution satisfies the complementary s 1 a c k n e s conditions, but violates feasibility since node surpluses

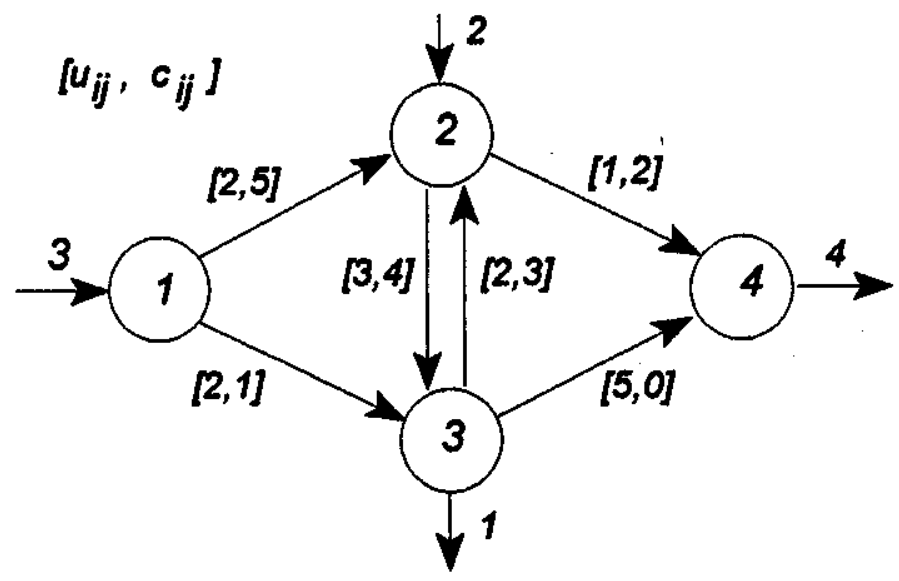
$g_{i} \neq 0$.

\section{ITERATION \#1}

\begin{tabular}{ccccccccccc} 
ARC & $\mathbf{x}_{\mathrm{ij}}$ & $\mathbf{u}_{\mathrm{ij}}$ & $\mathrm{s}_{\mathrm{i}}$ & $\mathrm{s}_{\mathrm{j}}$ & $\mathrm{c}_{\mathrm{ij}}$ & $\mathrm{p}_{\mathrm{i}}$ & $\mathrm{p}_{\mathrm{j}}$ & $\mathrm{g}_{\mathrm{i}}$ & $\mathrm{g}_{\mathrm{j}}$ & STATE \\
\hline$(1,2)$ & 0 & 2 & 3 & 2 & 5 & 0 & 0 & 3 & 2 & NACT \\
$(1,3)$ & 0 & 2 & 3 & -1 & 1 & 0 & 0 & 3 & -1 & INACT \\
$(2,3)$ & 0 & 3 & 2 & -1 & 4 & 0 & 0 & 2 & -1 & NACT \\
$(2,4)$ & 0 & 1 & 2 & -4 & 2 & 0 & 0 & 2 & -4 & INACT \\
$(3,2)$ & 0 & 2 & -1 & 2 & 3 & 0 & 0 & -1 & 2 & INACT \\
$(3,4)$ & 0 & 5 & -1 & -4 & 0 & 0 & 0 & -1 & -4 & BAL
\end{tabular}

Dual Objective Function $=0+0=0$

\section{Step}

0. $\mathrm{L}=\{1\} ; \mathrm{S}=\{0\}$

1. Select $i \in L-S ; S=S \cup\{i\}$

2. $y^{\prime}=\sum_{\text {active }} u_{j i}-\sum_{\text {active or balanced }} u_{i j}+\sum_{i \in S} s_{i}$

$$
=0-0+3>0
$$

4. No $x_{i j}$ adjustment is made at this iteration, since this is only done for balanced arcs; calculate:

$$
\gamma=\min \left\{\begin{array}{l}
0-0+5 \\
0-0+1
\end{array}=1 \quad[\text { for } \operatorname{arc}(1,3)]\right.
$$




\section{ITERATION \#2}

\begin{tabular}{lccrrrrrrrl} 
ARC & $x_{i j}$ & $u_{i j}$ & $s_{i}$ & $s_{j}$ & $c_{i j}$ & $p_{i}$ & $p_{j}$ & $g_{i}$ & $g_{j}$ & STATE \\
\hline$(1,2)$ & 0 & 2 & 3 & 2 & 5 & 1 & 0 & 3 & 2 & INACT \\
$(1,3)$ & 0 & 2 & 3 & -1 & 1 & 1 & 0 & 3 & -1 & BAL \\
$(2,3)$ & 0 & 3 & 2 & -1 & 4 & 0 & 0 & 2 & -1 & INACT \\
$(2,4)$ & 0 & 1 & 2 & -4 & 2 & 0 & 0 & 2 & -4 & INACT \\
$(3,2)$ & 0 & 2 & -1 & 2 & 3 & 0 & 0 & -1 & 2 & INACT \\
$(3,4)$ & 0 & 5 & -1 & -4 & 0 & 0 & 0 & -1 & -4 & BAL
\end{tabular}

Dual Objective Function $=0+3=3$

\section{Step}

0. $\mathrm{L}=\{1\} ; \mathrm{S}=\{\phi\}$

1. Select $i \in L-S ; S=\{1\}$

2. $y^{\prime}=-2+3=1>0$

4. Link $[1,3]$ is balanced-set $x_{13}=2$ $\gamma=0-1+5=4$ (for link [1,2] ); therefore, $p_{1}=1+4=5$

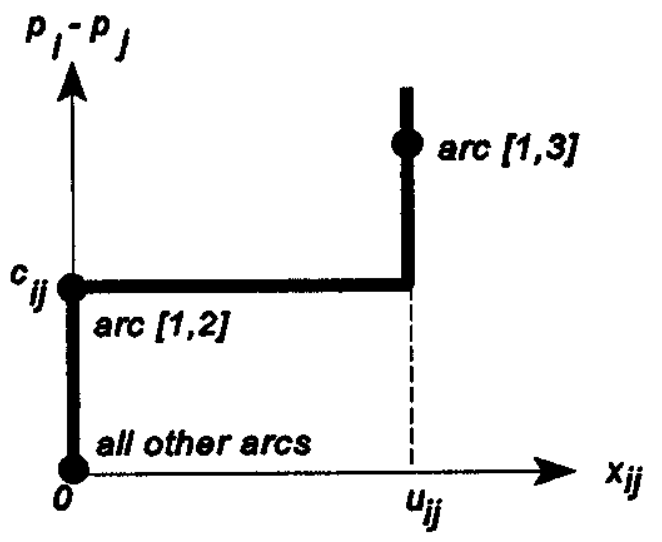

\section{ITERATION \#3}

\begin{tabular}{lllllllllll} 
ARC & $\mathbf{x}_{\mathrm{ij}}$ & $\mathbf{u}_{\mathrm{ij}}$ & $\mathrm{s}_{\mathrm{i}}$ & $\mathrm{s}_{\mathrm{j}}$ & $\mathrm{c}_{\mathrm{ij}}$ & $\mathrm{p}_{\mathrm{i}}$ & $\mathrm{p}_{\mathrm{j}}$ & $\mathbf{g}_{\mathrm{i}}$ & $\mathbf{g}_{\mathrm{j}}$ & STATE \\
\hline$(1,2)$ & 0 & 2 & 3 & 2 & 5 & 5 & 0 & 1 & 2 & BAL \\
$(1,3)$ & 2 & 2 & 3 & -1 & 1 & 5 & 0 & 1 & 1 & ACT \\
$(2,3)$ & 0 & 3 & 2 & -1 & 4 & 0 & 0 & 2 & 1 & INACT \\
$(2,4)$ & 0 & 1 & 2 & -4 & 2 & 0 & 0 & 2 & -4 & INACT \\
$(3,2)$ & 0 & 2 & -1 & 2 & 3 & 0 & 0 & 1 & 2 & INACT \\
$(3,4)$ & 0 & 5 & -1 & 0 & 0 & 0 & 0 & 1 & -4 & BAL
\end{tabular}

Dual Objective Function $=2+5=7$ 


\section{Step}

0. $\quad \mathrm{L}=\{1\} ; \mathrm{g}_{1}>0$

[Note: node 1 is still selected, even though $\mathrm{g}_{2}$ is a greater value]

1. $S=\{1\}$

2. $y^{\prime}=-\sum_{\text {active or bal }} u_{i j}+\sum_{i \in S} s_{i}=-4+3<0$

$\mathrm{L}=\mathrm{L}+\{\mathrm{j}\}$

$\mathrm{L}=\{1,2\}$ : outflow link and balanced and $\mathrm{x}_{\mathrm{ij}}<\mathrm{u}_{\mathrm{ij}}$

Check if $\mathrm{g}_{2} \geq 0$ [yes!]

RETURN TO Step 1:

1. $\mathrm{S}=\{1\} ; \mathrm{L}=\{1,2\}$

Select $i \in L-S ; i=2$;

$S=\{1,2\}$

2. $y^{\prime}=\sum_{i \in S} s_{i}=5>0$

4. $\quad \gamma=\min \left\{\left[\mathrm{p}_{\mathrm{j}}+\mathrm{c}_{\mathrm{ij}} \mathrm{p}_{\mathrm{j}}\right]\right.$ for arcs $\left.[2,3],[2,4]\right\}$

$=\min \{4,2\}=2$

Therefore, $p_{1}=5+2=7 ; p_{2}=0+2=2$

\section{ITERATION \#4}

\begin{tabular}{llllrllllll} 
ARC & $\mathbf{x}_{\mathrm{ij}}$ & $\mathrm{u}_{\mathrm{ij}}$ & $\mathbf{s}_{\mathrm{i}}$ & $\mathrm{s}_{\mathrm{j}}$ & $\mathrm{c}_{\mathrm{ij}}$ & $\mathrm{p}_{\mathrm{i}}$ & $\mathrm{p}_{\mathrm{j}}$ & $\mathrm{g}_{\mathrm{i}}$ & $\mathrm{g}_{\mathrm{j}}$ & STATE \\
\hline$(1,2)$ & 0 & 2 & 3 & 2 & 5 & 7 & 2 & 1 & 2 & BAL \\
$(1,3)$ & 2 & 2 & 3 & -1 & 1 & 7 & 0 & 1 & 1 & ACT \\
$(2,3)$ & 0 & 3 & 2 & -1 & 4 & 2 & 0 & 2 & 1 & INACT \\
$(2,4)$ & 0 & 1 & 2 & -4 & 2 & 2 & 0 & 2 & -4 & BAL \\
$(3,2)$ & 0 & 2 & -1 & 2 & 3 & 0 & 2 & 1 & 2 & INACT \\
$(3,4)$ & 0 & 5 & -1 & -4 & 0 & 0 & 0 & 1 & -4 & BAL
\end{tabular}

Dual Objective Function $=2+7+4=13$ 
Step

0. $L=\{1\} ;$ keep selecting node 1 since $\mathrm{g}_{1}>0$

1. $S=\{1\}$

2. $y^{\prime}=(-2-2)+3=-1<0$

$\mathrm{L}=\mathrm{L}+\{\mathrm{j}\}$

$\mathrm{L}=\{1,2\}$

Check if $g_{j} \geq 0$ [Yes!] RETURN to Step 1

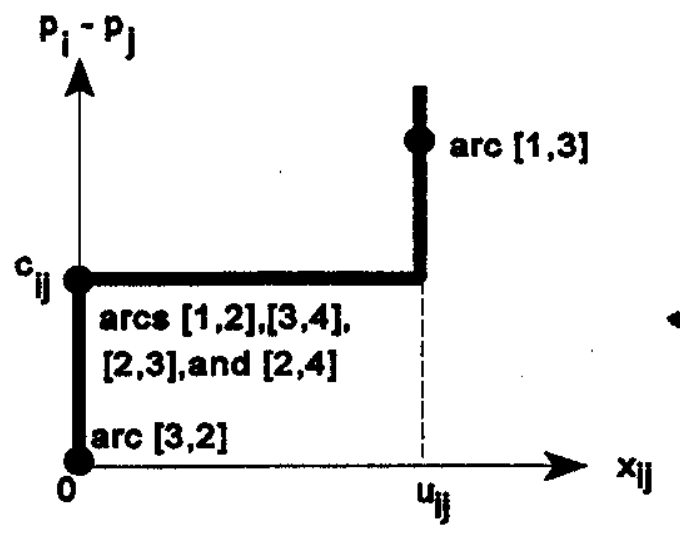

1. $\mathrm{S}=\{1,2\} ; \mathrm{L}=\{1,2\}$

2. $y^{\prime}=-2-1+5=2>0$

4. Does $\mathrm{x}_{\mathrm{ij}}=\mathrm{u}_{\mathrm{ij}}$ for all balanced arcs OUT? Yes!--arc $[2,4]$

Therefore, set $x_{24}=1$

$\gamma=\min \left\{\left[p_{j}+c_{i j}-p_{i}\right]\right.$

for $\operatorname{arc}[2,3]\}=2$

Therefore $\mathrm{p}_{1}=7+2=9 ; \mathrm{p}_{2}=2+2=4$

\section{ITERATION \#5}

\begin{tabular}{lllllllllll} 
ARC & $\mathbf{x}_{\mathrm{ij}}$ & $\mathrm{u}_{\mathrm{ij}}$ & $\mathbf{s}_{\mathrm{i}}$ & $\mathbf{s}_{\mathrm{j}}$ & $\mathrm{c}_{\mathrm{ij}}$ & $\mathrm{p}_{\mathrm{i}}$ & $\mathbf{p}_{\mathrm{j}}$ & $\mathrm{g}_{\mathrm{i}}$ & $\mathbf{g}_{\mathrm{j}}$ & STATE \\
\hline$(1,2)$ & 0 & 2 & 3 & 2 & 5 & 9 & 4 & 1 & 1 & BAL \\
$(1,3)$ & 2 & 2 & 3 & -1 & 1 & 9 & 0 & 1 & 1 & ACT \\
$(2,3)$ & 0 & 3 & 2 & -1 & 4 & 4 & 0 & 1 & 1 & BAL \\
$(2,4)$ & 1 & 1 & 2 & -4 & 2 & 4 & 0 & 1 & -3 & ACT \\
$(3,2)$ & 0 & 2 & -1 & 2 & 3 & 0 & 4 & 1 & 1 & INACT \\
$(3,4)$ & 0 & 5 & -1 & -4 & 0 & 0 & 0 & 1 & -3 & BAL
\end{tabular}

Dual Objective Function $=2+2+9 \cdot 1+4 \cdot 1=17$

\section{Step}

0. $\mathrm{L}=\{1\} ; \mathrm{g}_{1}>0$

1. $S=\{1\}$

2. $y^{\prime}=-\sum_{\text {active or balanced }} u_{i j}+\sum_{i \in S} s_{i}=(-2-2)+3=-1<0$

$L=L+\{j\}$ with label $(1,2)$ 
$\mathrm{L}=\{1,2\}$

Check if $\mathrm{g}_{2}>0$; Yes!

RETURN to Step 1

1. $\mathrm{S}=\{1,2\} ; \mathrm{L}=\{1,2\}$

2. $y^{\prime}=-\sum_{\text {active/balanced ouT }} u_{i j}+\sum_{i \in S} s_{i}=(-2-3-1)+5=-1<0$

$\mathrm{L}=\mathrm{L}+\{\mathrm{j}\}$ with label $(2,3)$

$L=\{1,2,3\}$

Check if $\mathrm{g}_{3}>0$; Yes!

RETURN to Step 1

1. $\mathrm{S}=\{1,2\} ; \mathrm{L}=\{1,2,3\}$

Select $i \in L-S=3$

2. $y^{\prime}=-\sum_{\text {active/balanced our }} u_{i j}+\sum_{i \in S} s_{i}=(-1-5)+(3+2-1)=-1<0$

$\mathrm{L}=\mathrm{L}+\{\mathrm{j}\}$ with label $(3,4)$

$\mathrm{L}=\{1,2,3,4\}$

Check if $\mathrm{g}_{4}=<0$; Yes! =-3; GOTO Step 3: Flow Augmentation

3. Path of flow augmentation $P$ is 1-2-3-4

[all forward arcs] ; so $\mathrm{P}^{+}=\mathrm{P}$

$\gamma=\min \left\{\begin{array}{c}\cdot 1\left[g_{1}\right] \\ \cdot-(-4)[- \\ \cdot 2\left[u_{12}-x_{1}\right. \\ \cdot 3\left[u_{23}-x\right. \\ \cdot 5\left[u_{34}-x_{3}\right.\end{array}\right.$

Flow Increase

Along Path

ITERATION \#6

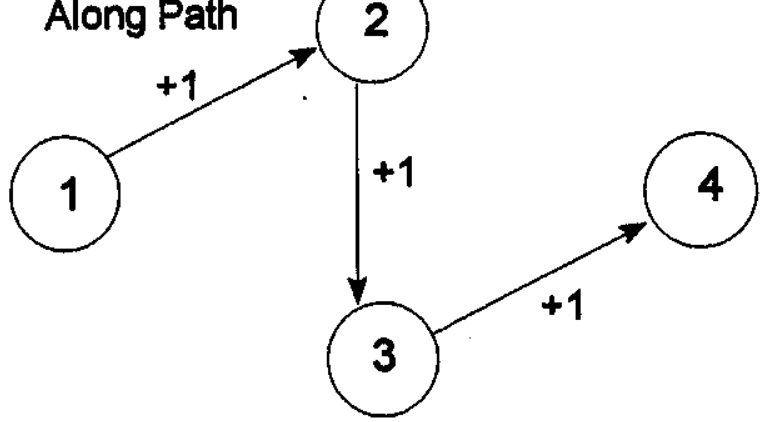

\begin{tabular}{lllllllll} 
ARC & $\mathbf{x}_{i j}$ & $\mathbf{u}_{i j}$ & $\mathbf{c}_{i j}$ & $\mathbf{p}_{i}$ & $\mathbf{p}_{j}$ & $\mathbf{g}_{i}$ & $\mathbf{g}_{j}$ & STATE \\
\hline$(1,2)$ & 1 & 2 & 5 & 9 & 4 & 0 & 1 & BAL \\
$(1,3)$ & 2 & 2 & 1 & 9 & 0 & 0 & 1 & ACT \\
$(2,3)$ & 1 & 3 & 4 & 4 & 0 & 1 & 1 & BAL \\
$(2,4)$ & 1 & 1 & 2 & 4 & 0 & 1 & -2 & ACT \\
$(3,2)$ & 0 & 2 & 3 & 0 & 4 & 1 & 1 & INACT \\
$(3,4)$ & 1 & 5 & 0 & 0 & 0 & 1 & -2 & BAL
\end{tabular}

Dual Objective Function $=5+2+4+2+4=17$ 
Step

0. $\mathrm{L}=\{2\} ; \mathrm{S}=\{\phi\} ;$ node $\mathrm{k}=2$

1. $\mathrm{S}=\{2\} ; \mathrm{i}=2$

2. $y /=-\sum_{\text {activelbalanced OUT }} u_{i j}+\sum_{i \in S} s_{i}=(-3-1)+2<0$

$\mathrm{L}=\mathrm{L}+\{\mathrm{j}\} ;$ add node 1 [label $(1,2)]$ and node 3 [label $(2,3)]$

$L=\{1,2,3\}$; check $g_{1}=0$ and $g_{3}=1$ [both $\geq 0$ ]

RETURN to Step 1

1. set $\mathrm{L}-\mathrm{S}=\{1,3\}$

Select node $\mathrm{i}=3$

Therefore: $S=\{2,3\}$

2. $y^{\prime}=\sum_{\text {active } I N} u_{j i}-\sum_{\text {active/balanced ouT }} u_{i j}+\sum_{i \in S} s_{i}=2-5+(2+1)=-2<0$

$\mathrm{L}=\mathrm{L}+\{\mathrm{j}\} ;$ add node 4

Check $\mathrm{g}_{4}=-2<0$; GOTO Step 3: Flow Augmentation

3. $\delta=\min \left\{1\left[\mathrm{~g}_{2}\right], 2\left[-\mathrm{g}_{4}\right]\right.$,

$$
\begin{aligned}
& 4\left[u_{34}-x_{34}\right], \\
& 2\left[u_{23}-x_{23}\right] \\
& =+1
\end{aligned}
$$

Path P: 2-3-4

All forward arcs--

Therefore, $\mathbf{P}_{+}=\mathbf{P}$

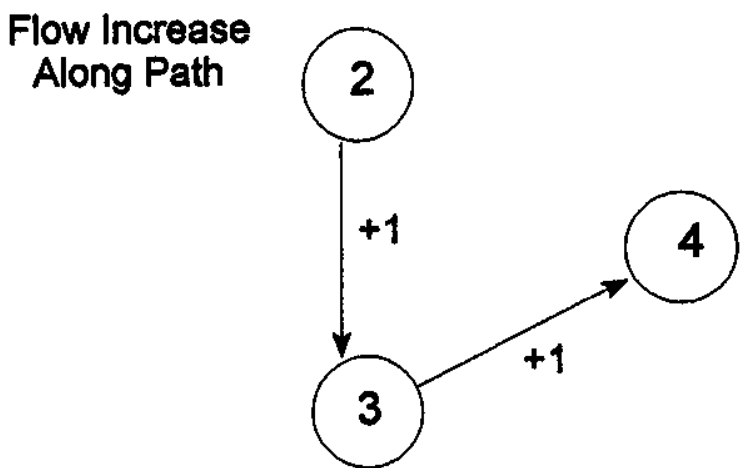

\section{ITERATION \#7}

\begin{tabular}{lllllllll} 
ARC & $\mathbf{x}_{\mathrm{ij}}$ & $\mathbf{u}_{\mathrm{ij}}$ & $\mathrm{c}_{\mathrm{ij}}$ & $\mathrm{p}_{\mathrm{i}}$ & $\mathrm{p}_{\mathrm{j}}$ & $\mathrm{g}_{\mathrm{i}}$ & $\mathbf{g}_{\mathrm{j}}$ & STATE \\
\hline$(1,2)$ & 1 & 2 & 5 & 9 & 4 & 0 & 0 & BAL \\
$(1,3)$ & 2 & 2 & 1 & 9 & 0 & 0 & 1 & ACT \\
$(2,3)$ & 2 & 3 & 4 & 4 & 0 & 0 & 1 & BAL \\
$(2,4)$ & 1 & 1 & 2 & 4 & 0 & 0 & -1 & ACT \\
$(3,2)$ & 0 & 2 & 3 & 0 & 4 & 1 & 0 & INACT \\
$(3,4)$ & 2 & 5 & 0 & 0 & 0 & 1 & -1 & BAL
\end{tabular}

Dual Objective Function $=5+2+8+2=17$ 
Step

0. $\mathrm{L}=\{3\} ; \mathrm{S}=\{0\} ;$ node $\mathrm{k}=3$

1. $\mathrm{S}=\{3\}$; node $\mathrm{i}=3$

2. $y^{\prime}=\sum_{\text {active } N N} u_{j i}-\sum_{\text {activelbalanced our }} u_{i j}+\sum_{i \in S} s_{i}=+2-5-1=-4<0$

$\mathrm{L}=\mathrm{L}+\{\mathrm{j}\} ;$ add node 2 [label $(2,3)]$ and node 4 [label $(3,4)$ ]

$\mathrm{L}=(2,3,4\}$

Check $\mathrm{g}_{2}=0 ; \mathrm{g}_{4}=-1$ [both $\leq 0$ ]

4. Path $\mathrm{P}^{+}=3-4 ;$ Path $\mathrm{P}^{-}=2-3$

node $k=3 ;$ node $j=4$

$\delta=\min \left\{1\left[\mathrm{~g}_{3}\right], 1\left[-\mathrm{g}_{4}\right], 3\left[\mathrm{u}_{34}-\mathrm{x}_{34}\right]\right\}=1$

\section{FINAL SOLUTION}

\begin{tabular}{lllllll|ll} 
ARC & $\mathbf{x}_{\mathrm{ij}}$ & $\mathrm{u}_{\mathrm{ij}}$ & $\mathbf{c}_{\mathrm{ij}}$ & $\mathbf{p}_{\mathrm{i}}$ & $\mathbf{p}_{\mathrm{j}}$ & $\mathrm{g}_{\mathrm{i}}$ & $\mathrm{g}_{\mathrm{j}}$ & STATE \\
\hline$(1,2)$ & $\mathbf{1}$ & 2 & 5 & 9 & 4 & 0 & 0 & BAL \\
$(1,3)$ & $\mathbf{2}$ & 2 & 1 & 9 & 0 & 0 & 0 & ACT \\
$(2,3)$ & $\mathbf{2}$ & 3 & 4 & 4 & 0 & 0 & 0 & BAL \\
$(2,4)$ & $\mathbf{1}$ & 1 & 2 & 4 & 0 & 0 & 0 & ACT \\
$(3,2)$ & $\mathbf{0}$ & 2 & 3 & 0 & 4 & 0 & 0 & INACT \\
$(3,4)$ & $\mathbf{3}$ & 5 & 0 & 0 & 0 & 0 & 0 & BAL
\end{tabular}

Notice that $\mathrm{g}_{\mathrm{i}}=0$ for all nodes. Therefore, dual objective $=$ primal objective and all complementary slackness conditions are satisfied. 


\section{APPENDIX B \\ PREPARING MODFLOW FILES USING IDRISI}

\section{B.1 Overview}

A number of computer models have been developed to simulate complex groundwater stream-aquifer conjunctive use problems. One of the most widely used is the USGS Modular Three-Dimensional Finite-Difference Groundwater Flow Model (MODFLOW) developed by McDonald and Harbaugh (1988). Groundwater flow is simulated using a block-centered finite difference approach. Layers can be simulated as confined, unconfined, or a combination of confined and unconfined. Flows associated with external stresses, such as wells, areal recharge, evapotranspiration, drains, and streams, can also be simulated.

\section{B.2 Background}

The movement of groundwater of constant density through saturated porous earth material can be described by the following partial differential equation:

$$
\frac{\partial}{\partial X}\left(K h \frac{\partial H}{\partial X}\right)+\frac{\partial}{\partial Y}\left(K h \frac{\partial H}{\partial Y}\right)+Q=S \frac{\partial H}{\partial t}
$$

where:

$\mathrm{K}=$ hydraulic conductivity or permeability

$\mathrm{h}=$ saturated thickness of aquifer

$\mathrm{H}=$ potential, referred to as an established datum

$S=$ storage coefficient or effective porosity (specific yield)

$Q=$ net groundwater withdrawal per unit area

$\mathrm{X}, \mathrm{Y}=$ space dimensions

$t=$ time dimensions

Specific yield is defined as the ratio of water that will drain freely from a volume of soil to the soil volume itself. For alluvial aquifers the value is about $\mathbf{0 . 2}$. Permeability or hydraulic conductivity is a velocity term expressed in $\mathrm{L}^{3} / \mathrm{t} / \mathrm{L}^{2}$, or $\mathrm{L} / \mathrm{t}$. Transmissivity is a flow term used to better describe the characteristics of an aquifer and is equal to the average permeability times the saturated thickness of the aquifer.

A finite difference model such as MODFLOW replaces the continuous system described by the groundwater equation with a finite set of discrete points in space and time, and the partial derivatives are replaced by terms calculated from the differences in head values at these points. This leads to a system of simultaneous linear algebraic difference equations. Important in the solution of the finite difference equations is proper simulation of the model boundary conditions. MODFLOW model allows specification of three types of boundary conditions:

- no flow
- $\quad$ under flow (i.e., constant head gradient) 
Typical data requirements for a finite difference model include:

- $\quad$ boundary conditions
- $\quad$ aquifer characteristics
- $\quad$ sell recharge and discharge
- $\quad$ recharge hydrography
-

\section{B.3 Procedure}

The following example serve to illustrate how to take groundwater and related data that have been digitized into IDRISI vector format, rasterize the data, perform required data manipulation, and output results for use in the USGS groundwater model, MODFLOW. Output from MODFLOW model will then be read back into IDRISI for presentation purposes. This example focuses on developing two input data files used by MODFLOW: a boundary data file and a transmissivity data file. After executing MODFLOW, aquifer water levels will then be read back into IDRISI. The finite difference network to be modeled is shown in Figure B.1.

\section{Step 1: Load Data Files}

The following files should be loaded into the IDRISI exercise directory:

IDRISI Files:

well.vec [project well locations]

trans.vec [transmissivity contour map]

aquifer.vec [aquifer boundaries]

stream.vec [stream location map]

head.img [head water levels output from MODFLOW]

MODFLOW Files:

modflow.exe [executable MODFLOW program]

unitl.dat [basic package input file]

unit11.dat [block-centered flow package input file]

unit12.dat [well package input file]

unit19.dat [strongly implicit procedure input file]

unit22.dat [output control input file]

bound.dat [boundary file from IDRISI]

trans.dat [transmissivity file from DRIS] 


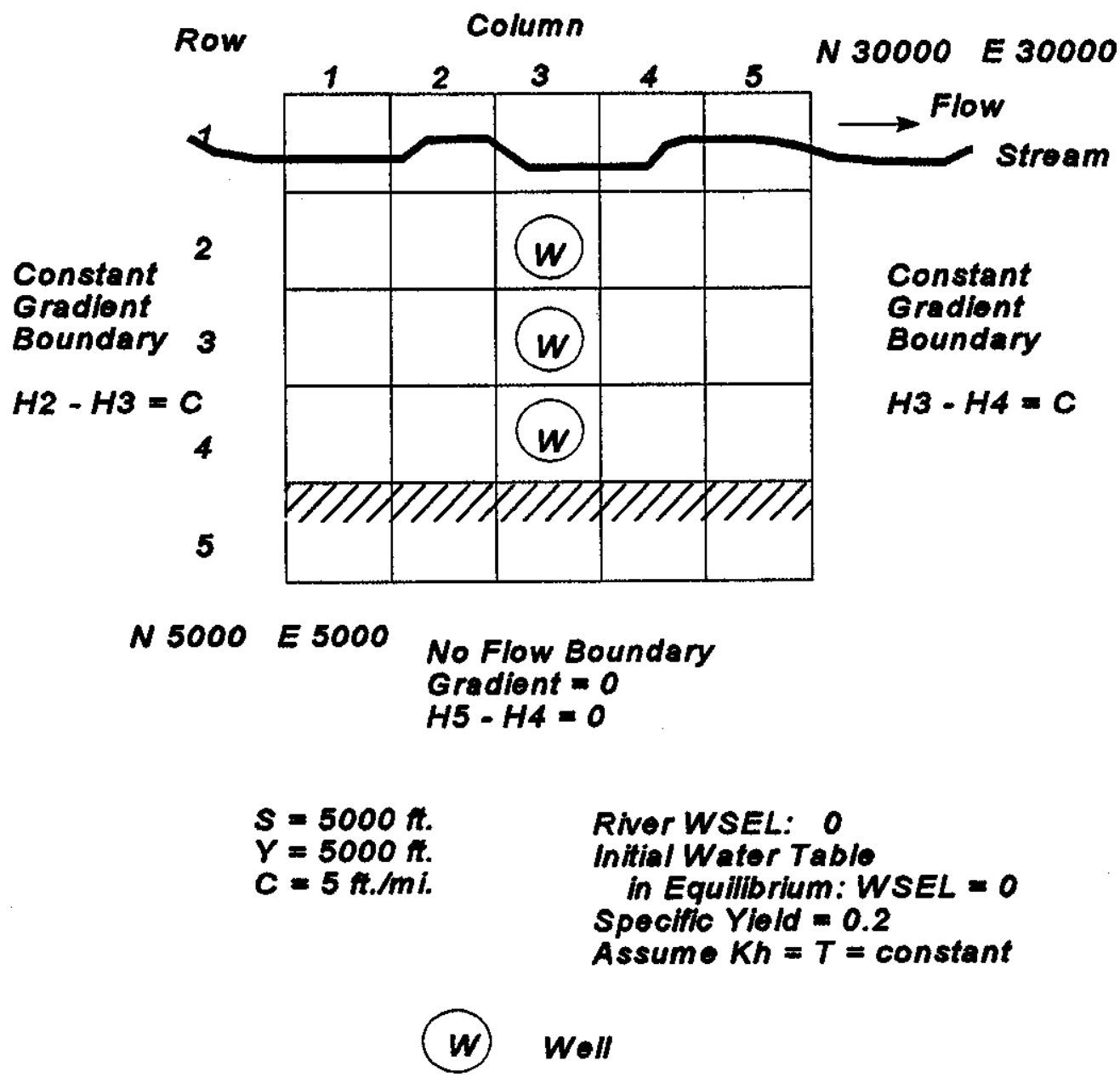

Figure B.1. Example Illustrating Data Preparation for Finite Difference Groundwater Flow Model Using GIS 


\section{Step 2: Create Document Files}

Four vector files have been digitized for use in IDRISI:

well.vec

trans.vec

aquifer.vecs

stream.vec

These files all have integer attribute values and are in ASCII format. The x-y coordinates were digitized in "feet" units in a plane coordinate reference system with 1 unit equal to 1 foot. in feet:

For this problem assume we have a study area which spans the following map coordinates

N 5000 E 5000

N 5000 E 30000

N 30000 E 30000

N 30000 E 5000

Proper vector document files are required before the hdata can be used by IDRISI. When making these document files, it is important that the raster grid is the same size for all files. The maximum and minimum coordinate values should be entered directly and should correspond to the study area map coordinates listed above.

$$
\begin{aligned}
& \min x=5000 \\
& \max x=30000 \\
& \min y=5000 \\
& \max y=30000
\end{aligned}
$$

Use the DOCUMENT command in IDRISI to make the proper vector document header files. Note the object type for each of the files, respectivey:

$\begin{array}{ll}\text { well } & \text { [point coverage] } \\ \text { aquifer } & \text { [polygon coverage] } \\ \text { stream } & \text { [line coverage] } \\ \text { trans } & \text { [line coverage] }\end{array}$

\section{Step 3: Plot Vector Files}

Data in the vector files may be displayed on the screen using the IDRISI PLOT command. To overlay and view each of the vector files on the screen at the same time, it is necessary to create a script file. The EDIT command is used to create the file PLOT.scr, which is composed of the following lines: 


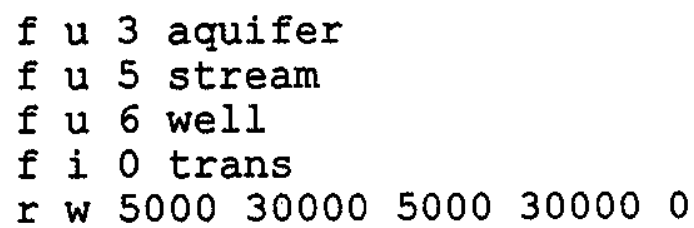

The PLOT command can now be used to load and display the vector files on the screen by entering the name of the script file PLOT when prompted for a file to load.

\section{Step 4: Convert Vector Files to Raster Files}

For the purpose of this example, it is only necessary to convert the aquifer, stream, and trans files to raster format.

(a) A raster file is first created using INITIAL that can be used to receive the transformed vector data. Each vector file requires its own raster or image file. The INITLAL command also creates the proper image DOCUMENT header file.

Image files are created with the following names and titles:

AQUIFER1 [aquifer raster file]

STREAMl [stream raster file]

TRANS1 [transmissivity contour file]

All image files used for vector conversion must be created in binary format.

To verify whether the original vector data is in integer, real, or byte format, the vector files can be directly viewed using EDIT or the DESCRIBE command can be used to view the vector document header file. It is important to remember that the data format specification is for the attribute values, and not for the $\mathrm{x}, \mathrm{y}$ coordinate points.

All image files will have the same number of rows, columns and $x$ and $y$ cell dimensions. This should correspond to the layout of the finite difference network, with rows and columns equal to 5 . In this example, the plane coordinate reference system is used with a unit distance of "1". As before, maximum and minimum coordinate values should be set as follows:

$$
\begin{aligned}
& \min x=5000 \\
& \max x=30000 \\
& \min y=5000 \\
& \max y=30000
\end{aligned}
$$

Assign "0" as the initial value for all cells for the AQULFER1 and STREAM1 image output files. Since it is possible that a "0" transmissivity value can occur outside the aquifer, a value of "-999" should be assigned as the initial value for the TRANS1 image output file. None of the files have a requirement for a special unit value. 
(b) IDRISI includes three modules for vector to raster conversion:

POINTRAS [for point conversion]

LINERAS [for line conversion]

POLYRAS [for polygon conversion]

The aquifer, stream, and trans vector files are converted to raster format using the raster image target files created using the INITIAL command in Step (a) above. If there is uncertainty as to which vector to raster conversion module should be used, the object type of a vector file can be examined using the DESCRIBE command.

(c) After the conversion process has been completed, the resulting image files can be viewed on the screen using the COLOR command.

View the AQUIFER1.img file using COLOR. After the image has been displayed on the screen, enter the letter " $\mathrm{V}$ " on the keyboard. A prompt then requests a file name, which should be typed in as STREAM from the keyboard. In response to the prompt "Enter Color Code:" type in 5. The well and transmissivity vector files can now be easily overlain.

\section{Step 5: Development of Finite Difference Grid Boundary File}

The boundary file required for input into MODFLOW for this example should have the following format:

$\begin{array}{rrrrr}-1 & -1 & -1 & -1 & -1 \\ 0 & 1 & 1 & 1 & 0 \\ 0 & 1 & 1 & 1 & 0 \\ 0 & 1 & 1 & 1 & 0 \\ 0 & 0 & 0 & 0 & 0\end{array}$

where:

-1 : constant head boundary (stream location)

0 : no flow boundary (aquifer boundary)

1: variable head and variable flow

Each value corresponds to a row and column in the finite difference model grid network. This can be compared to the network shown in Handout 5.

To develop this boundary file, raster image files AQUIFER1 and STREAM1, along with a combination of IDRISI OVERLAY, RECLASS, UPDATE, and INITIAL commands, are used:

(a) The AQUIFER1 image file was initially used to define the extent of the aquifer and the variable head and variable flow cells. The aquifer cells have an attribute value of "3". This can be checked by using the COLOR command and pressing the letter " $\mathrm{c}$ ", and then clicking the left mouse button on any cell. Note that the file must be in unpacked binary format for this to work. 
The aquifer cells can now be converted to a value of " 1 ", corresponding to the variable head and variable flow designations required by MODFLOW. The RECLASS command can be used to change all cell values from " 3 " to " 1 ". The output file can be named AQUIFER2, and no designation of unit values is required.

Since this example includes constant outflow and inflow along the eastern and western boundaries, these conditions can be simulated through the use of external source terms and no-flow cells. Therefore, the east and west boundaries should be defined as no-flow conditions using a cell attribute value of " 0 ". The UPDATE command can be applied to the AQUIFER2 image file for this purpose. It is important to note that the column and row numbers in IDRISI always begin with "0" not "1".

The COLOR command can now be used to display the modified aquifer file on the screen and the results checked results using VIEW.

(b) The process to assigning values of "-1" to cells representing the stream requires several steps since the RECLASS command does not allow the user to directly assign a "-1" value.

The RECLASS command is first applied to STREAM1, with "1" reassigned to the stream attribute value of " 5 ". The new output file can be named STREAM2.

Next, the INITIAL command is used to create a new image file similar to the procedure outlined in Step 4(a), with the exception that "-1" is assigned as the initial attribute value for all cells. This output image file can be named IDENT.

Using the OVERLAY command and the MULTIPLY option, a new file called STREAM3 is created from the STREAM2 and IDENT image files. This results in a new file with stream cells assigned an attribute value of "-1", which can be checked using the VIEW command.

(c) In order to complete the final raster boundary file, the AQUIFER2 image file must be overlain with the STREAM3 image file using the OVERLAY COVER option. The resulting output file is named BOUND.

(d) The VIEW command displays the BOUND image file with a field width of " 3 " and "0" decimal places. Starting with row "0", results can be compared with the BOUND.dat file used as input to MODFLOW.

\section{Step 6: Development of MODFLOW Transmissivity Input File}

The COLOR command can now be used to display the TRANS1 image file on the screen. Note that the raster file is still a contour file. IDRISI provides a special command, INTERCON, to interpolate a raster Digital Elevation Model (DEM) from a set of digitized contours using linear interpolation between contours. 
INTERCON is now executed using the TRANS1 image file. Notice that the background value is "-999". For our example, the corner transmissivity values in $\mathrm{ft}^{2} /$ day:

NW: 15

NE: 15

SW: 0

SE: 0

The resulting output image file can be named TRANS2.

The VILW command is now used to display the TRANS2 image file with a field width of "6" and "2" decimal places. Starting with row "0", results can be compared with the TRANS.dat file used as input to MODFLOW.

\section{Step 7: Execute Program MODFLOW}

The number of input data files required for use with MODFLOW depends on which modules the user requires to simulate a groundwater flow problem. For purposes of this example, a total of seven files are needed. Five of these files are defined as input files in the Basic Package Input File as part of the IUNTT variable element table. These carry the unitxx.dat name and include:

unit1.dat [Basic package input file]

unit11.dat [Block-centered flow package input file]

unit12.dat [Well package input file]

unit19.dat [Strongly implicit procedure input file]

unit22.dat [Output control input file]

The finite difference groundwater model can now be executed by typing at the DOS prompt:

MODELOW

The user is then prompted for two files:

unit24

unit23

Two types of files have been developed through IDRISI:

for unit 24, type: BOUND . dat [boundary file]

for unit 23, type: TRANS . dat [transmissivity file]

These two files will be listed by MODFLOW in the output files MODFLOW.out and HEAD.out. The output results of course reflect the fact that these input files have been created to simulate only two stress periods and one time period. 


\section{Step 8: Display of MODFLOW Output in IDRISI}

Output from MODFLOW for water levels in the aquifer after the end of simulation of stress period 1 have been transferred to IDRISI image format and saved in the file named HEAD.img. To use this file, a document header must be created. The DOCUMENT command in IDRISI is used to assign the title of "MODFLOW OUTPUT: HEAD LEVELS". The file is an ASCII real number file with 5 rows, 5 columns, and maximum and minimum $x-y$ coordinates as defined previously. The results can be viewed using VIEW or ORTHO. 


\section{B.4 MODFLOW Output File: MODFLOW.OUT}

U.S. GEOLOGICAL SURVEY MODULAR FINITE-DIFFERENCE GROUHD-HATER MOOEL

SAMPLE---1 LAYER, 5 ROUS, 5 COLLANS; STEADY STATE; CONSTANT HEAOS RON 1, LAYER 1; WELLS

$$
1 \text { LAYERS } 5 \text { ROUS } 5 \text { COLLHANS }
$$

2 STRESS PERIOO(S) IN SIMULATION

MOOEL TINE UNIT IS SECONS

1/0 units:

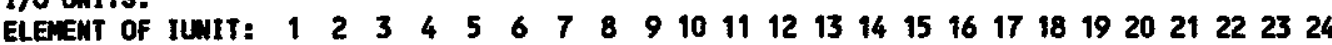

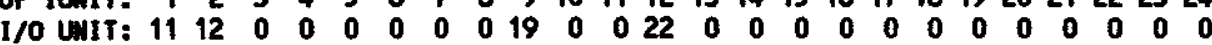

BAS1 -- BASIC MODEL PACKAGE, VERSION $1,9 / 1 / 87$ INPUT READ FRON UAIT 1

ARRAYS RHS AHD BUFF MILL SHARE MEMORY.

START HEAD UILL BE SAVED

239 ELEMENTS IN $X$ ARRAY ARE USED BY BAS

239 ELEMENTS OF $X$ ARRAY USED OUT OF 30000

BCF1 - BLOCK-CENTERED FLON PACKAGE, VERSION 1, 9/1/87 INPUT READ FRON UWIT 11

TRANSIERT SIIULATIOH

CONSTANT HEAD CELL-BY-CELL FLONS MILL BE PRINTED

LAYER AQUIFER TYPE

$$
10
$$

26 ELEMENTS IN $X$ ARRAY ARE USED BY BCF

265 ELEYENTS OF $X$ ARRAY USED OUT OF 30000

MEL1 - - WELL PACKAGE, VERSION 1, 9/1/87 IMPUT READ FRON 12

Maximin OF 9 WELLS

36 ELEMENTS IN $X$ ARRAY ARE USED FOR WELLS

301 ELEMENTS OF $x$ ARRAY USED OUT OF 30000

SIP1 -- STRONGLY INPLICIT. PROCEDURE SOLUTION PACKAGE, VERSION 1, 9/1/87 INPUT READ FROM UNIT 19 MAXIMW OF 50 ITERATIONS ALLOUED FOR CLOSURE

5 ITERATION PARAMETERS

305 ELEMENTS IN $X$ ARRAY ARE USED BY SIP

606 ELEMENTS OF $X$ ARRAY USED OUT OF 30000

ISAMPLE--.-1 LAYER, 5 ROUS, 5 COLLANS; STEADY STATE; COMSTANT HEADS ROA 1, LAYER 1; WELLS

BOUNDARY ARRAY FOR LAYER 1 MILL BE READ ON UNIT 24 USING FORMAT: (5I3)

$\begin{array}{lllll}1 & 2 & 3 & 4 & 5\end{array}$

$\begin{array}{rrrrrr}\cdots & -1 & -1 & -1 & -1 & -1 \\ 2 & 0 & 1 & 1 & 1 & 0 \\ 3 & 0 & 1 & 1 & 1 & 0 \\ 4 & 0 & 1 & 1 & 1 & 0 \\ 5 & 0 & 0 & 0 & 0 & 0\end{array}$


AOUIFER HEAD WILL BE SET TO 999.99 AT ALL NO-FLON NOOES (IBOUAD=0).

INITIAL HEAD $=.0000000$ FOR LAYER 1

HEAB PRIMT FORIMT IS FORMAT MUMBER 10 DRALDOUH PRIMT FORMUT IS FORMAT MUNBER 10

HEADS WILL BE SAVED ON UNIT 45 DRALDONS HILL BE SAVED ON UNIT 0

OUTPUT CONTROL IS SPECIFIED EVERY TIME STEP

COLUNA TO RON ANISOTROPY $=1.000000$

PRIMARY STORAGE COEF $=2000000$

FOR LAYER 1

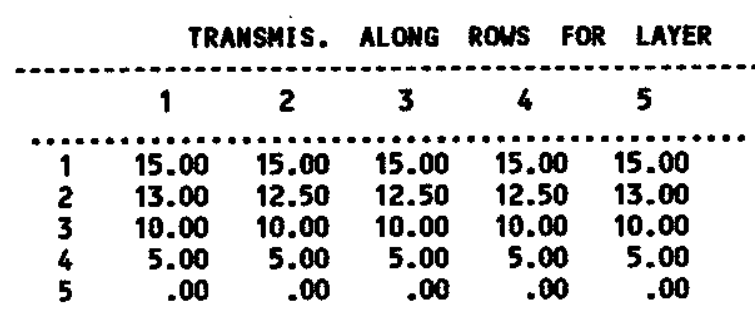

SOLUTION BY THE STRONGLY IMPLICIT PROCEDURE

MXIMN ITERATIOUS ALOUE FOQ CLOSURE = 50

ACCELERATION PARAMETER $=1.0000$

HEAD CHANGE CRITERION FOR CLOSURE $=$. $10000 E-02$

SIP HEAD CHANGE PRINTOUT INTERVAL = 1

5 ITERATION PARAMETERS CALCULATED FROM SPECIFIED USEED $=.00100000$ :

$\begin{array}{lllll}.0000000 E+00 & .8221720 E+00 & .9683772 E+00 & .9943766 E+00 & .9990000 E+00\end{array}$

1

STRESS PERICO NO. 1, LENGTH = 2592000.

MUHBER OF TIME STEPS $=1$

WLTIPLIER FOR DELT $=1.000$

9 vells

INITIAL TIME STEP SIZE $=2592000$. 


\section{ITERATIONS FOR TIME STEP 1 IN STRESS}

\begin{tabular}{ccccc} 
LAYER & ROH & COL & STRESS RATE & WELL WO. \\
\hline 1 & 2 & 2 & $.12000 E-01$ & 1 \\
1 & 2 & 4 & $-.12000 E-01$ & 2 \\
1 & 3 & 2 & $.60000 E-02$ & 3 \\
1 & 3 & 4 & $-.60000 E-02$ & 4 \\
1 & 4 & 2 & $.50000 E-02$ & 5 \\
1 & 4 & 4 & $-.50000 E-02$ & 6 \\
1 & 2 & 3 & -1.0000 & 7 \\
1 & 3 & 3 & .00000 & 8 \\
1 & 4 & 3 & .00000 & 9
\end{tabular}

\section{PERICO 1}

MAXIMUM HEAD CHAMGE FOR EACH ITERATION:

HEAD CHAHGE LAYER, ROH, COL HEAD CHANGE LAYER, ROH, COL HEAD CHANGE LAYER, ROW, COL HEAD CHAMGE LAYER, ROW, COL HEAD CHAMGE LAYER, ROH, COL

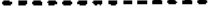

$-.2602 E-01(1,2,3)-.8198 E-02(1,4,2)-.5231 E-03(1,4,3)$

HEAD/DRALDOM PRINTOUT FLAG $=1$ TOTAL BUDGET PRIMTOUT FLAG = 1 CELL-BY-CELL FLOH TERM FLAG = 1 OUTPUT FLAGS FOR ALL LAYERS ARE THE SAME:

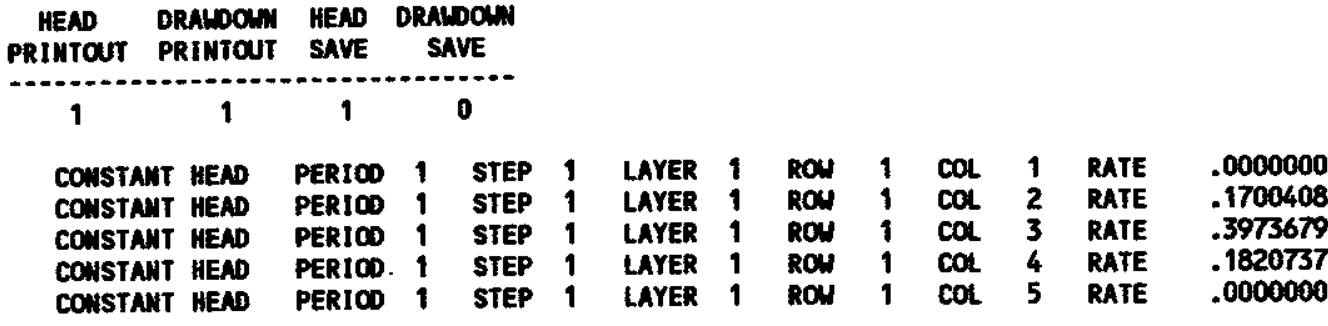

1

HEAD IN LAYER 1 AT END OF TIME STEP 1 IN STRESS PERIOO 1

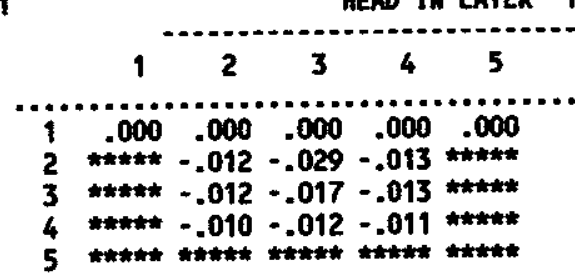

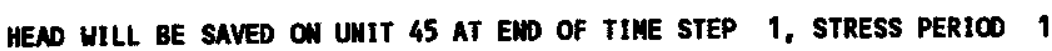




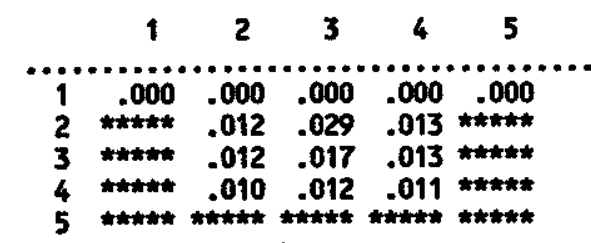

VOLUNETRIC BLDGET FOR ENTIRE MOOEL AT EAD OF TIME STEP 1 IN STRESS PERIOO 1

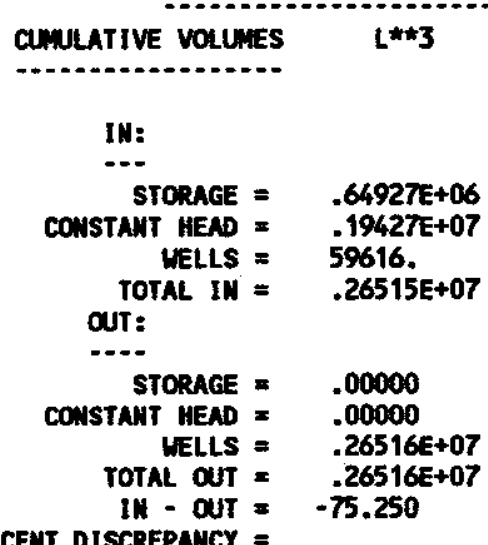

PERCENT DISCREPANCY =

RATES FCR THIS IIME STEP L**3/T

IN:

STORACE $=.25049$

COUSTANT HEAD $=.74948$

WELLS $=\quad .23000 \mathrm{E}-01$

TOTAL IN $=\quad 1.0230$

OUT:

STORAGE $=\quad .00000$

CONSTANT HEAD $=\quad .00000$

NELLS $=1.0230$

TOTAL OUT = $\mathbf{1 . 0 2 3 0}$

IN - OUT $=-.28968 E-O$

PERCENT DISCREPAMCY = 
MUMBER OF TIME STEPS $=1$

WLTIPLIER FOR DELT $=\quad 1.000$

6 WELLS

INITIAL TIME STEP SIZE $=2592000$.

\begin{tabular}{lllll} 
LAYER & ROW & COL & STRESS RATE & HELL NO. \\
\hline 1 & 2 & 2 & $.12000 E-01$ & 1 \\
1 & 2 & 4 & $-.12000 E-01$ & 2 \\
1 & 3 & 2 & $.60000 E-02$ & 3 \\
1 & 3 & 4 & $-.60000 E-02$ & 4 \\
1 & 4 & 2 & $.50000 E-02$ & 5 \\
1 & 4 & 4 & $-.50000 E-02$ & 6
\end{tabular}

3 ITERATIONS FOR TIME STEP 1 In STRESS PERIOO 2

MAXIMAN HEAD CHAHEE FOR EACH ITERATIOH:

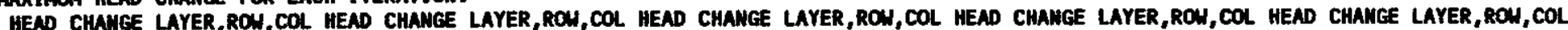
CHAME LAYER,

$.2309 E-01$ ( 1, 2, 3) .6258E-02 ( 1, 3, 2) .4044E-03 ( 1, 4, 3)

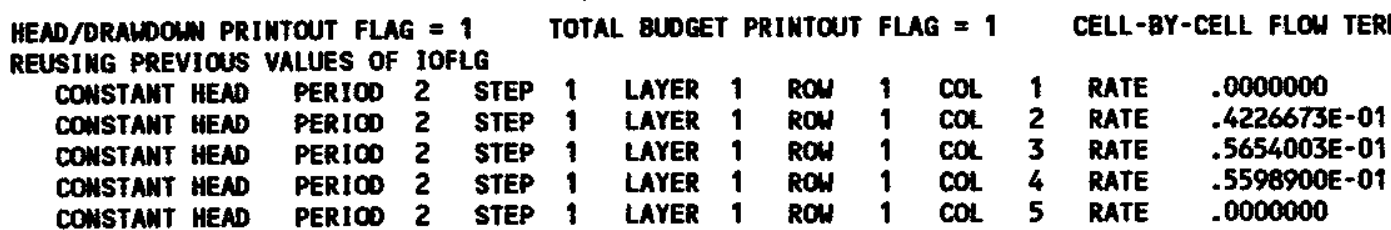

1

heAd IN LAYER 1 AT END OF TIME STEP 1 IN STRESS PERIOD 2

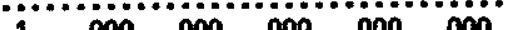

$2.000 \quad .000 \quad .000 \quad .000 \quad .000$

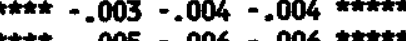

twtkt $=.006-.007-.008$ t*tktt

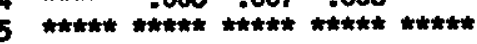

HEAD WILL BE SAVED ON UNIT 45 AT END OF TIME STEP 1, STRESS PERIOD 2

ORALDON IN LAYER 1 AT END OF TIME STEP 1 IN STRESS PERIOD 2 


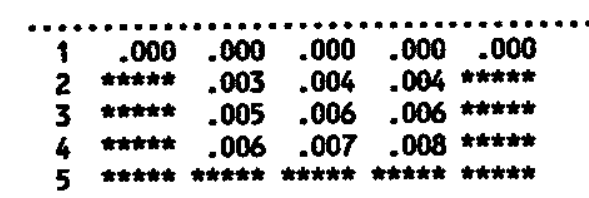

VOLUMETRIC BUDGET FOR ENTIRE MODEL. AT END OF TIME STEP 1 IN STRESS PERIOD 2

\begin{tabular}{|c|c|c|c|}
\hline $\begin{array}{c}\text { CUMULATIVE VOLUMES } \\
\text { IN: } \\
-\end{array}$ & $1 * * 3$ & $\begin{array}{c}\text { RATES FOR THIS TIME STEP } \\
\text { IN: } \\
\cdots\end{array}$ & $L * \star 3 / T$ \\
\hline $\begin{array}{r}\text { STORAGE }= \\
\text { CONSTANT HEAD }= \\
\text { WELLS }= \\
\text { TOTAL IN = }\end{array}$ & $\begin{array}{l}.64927 E+06 \\
.23439 E+07 \\
.11923 E+06 \\
.31124 E+07\end{array}$ & $\begin{array}{r}\text { STORAGE }= \\
\text { CONSTANT HEAD }= \\
\text { UELLS }= \\
\text { TOTAL IN }=\end{array}$ & $\begin{array}{l}.00000 \\
.15480 \\
.23000 E-01 \\
.17780\end{array}$ \\
\hline OUT: & & OUT: & \\
\hline $\begin{aligned} \text { STORACE } & = \\
\text { COMSTANT HEAD } & = \\
\text { WELLS } & = \\
\text { TOTAL OUT } & = \\
\text { IU - OUT } & = \\
\text { WT OISCREPANCY } & =\end{aligned}$ & $\begin{array}{l}.40032 E+06 \\
.00000 \\
.27112 E+07 \\
.31116 E+07 \\
835.25\end{array}$ & $\begin{array}{r}\text { STORACE }= \\
\text { CONSTANT HEAD }= \\
\text { WELLS }= \\
\text { TOTAL OUT }= \\
\text { IN - OUT }= \\
\text { PERCENT DISCREPANCY }=\end{array}$ & $\begin{array}{l}.15444 \\
.00000 \\
.23000 E-01 \\
.17744 \\
.35121 E-03\end{array}$ \\
\hline
\end{tabular}

\begin{tabular}{|c|c|c|c|c|c|}
\hline TIME STMAMRY A & $\begin{array}{l}\text { AT EMD OF TIME STEP } \\
\text { SECOHDS }\end{array}$ & $\begin{array}{l}1 \text { IN STRESS } \\
\text { MIMUTES }\end{array}$ & PERICO 2 & DAYS & YEARS \\
\hline $\begin{array}{l}\text { TIME STEP LENGTH } \\
\text { STRESS PERIOO TIME } \\
\text { TOTAL. SIMULATION TIME }\end{array}$ & $\begin{array}{l}.259200 E+07 \\
.259200 E+07 \\
.518400 E+07\end{array}$ & $\begin{array}{l}43200.0 \\
43200.0 \\
86400.0\end{array}$ & $\begin{array}{l}720.000 \\
720.000 \\
1440.00\end{array}$ & $\begin{array}{l}30.0000 \\
30.0000 \\
60.0000\end{array}$ & $\begin{array}{l}.821355 E-01 \\
.821355 E-01 \\
.164271\end{array}$ \\
\hline
\end{tabular}




\section{B.5 MODFLOW Input Files}

\section{BASIC PACKAGE INPUT FILE: UNIT1.DAT}

SAMPLE---1 ILAYER, 5 ROWS, 5 COLUMNS; STEADY STATE; CONSTANT HEADS ROW 1 , IAYER 1; WELLS

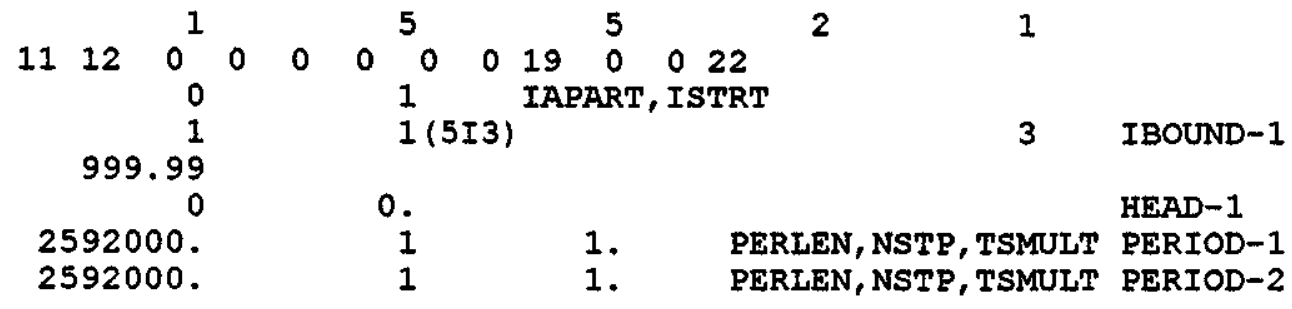

IBOUND ARRAY VALUES READ FROM UNIT 24: BOUND.DAT

$\begin{array}{rrrrr}-1 & -1 & -1 & -1 & -1 \\ 0 & 1 & 1 & 1 & 0 \\ 0 & 1 & 1 & 1 & 0 \\ 0 & 1 & 1 & 1 & 0 \\ 0 & 0 & 0 & 0 & 0\end{array}$

BLOCK-CENTERED FLOW PACKAGE INPUT FILE: UNIT11.DAT

0

$0 \quad-1$ ISS, IBCEBD

$\begin{array}{rc}0 & 1 . \\ 0 & 5000 . \\ 0 & 5000 . \\ 0 & \dot{i}^{2}(5 F 6.2)\end{array}$

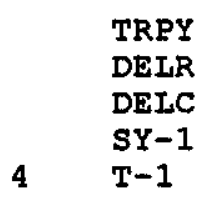

TRAN ARRAY VALUES FOR TRANSMISSIVITY READ FROM UNIT 23: TRANS.DAT

$\begin{array}{rrrrr}15.00 & 15.00 & 15.00 & 15.00 & 15.00 \\ 13.00 & 12.50 & 12.50 & 12.50 & 13.00 \\ 10.00 & 10.00 & 10.00 & 10.00 & 10.00 \\ 5.00 & 5.00 & 5.00 & 5.00 & 5.00 \\ .00 & .00 & .00 & .00 & .00\end{array}$

ROW 1

ROW 2

ROW 3

ROW 4

ROW 5 


\section{WELL PACKAGE INPUT FLE: UNIT12.DAT}

9
9
1
1
1
1
1
1
1
1
1
6
1
1
1
1
1
1$$
0
$$

STRONGLY IMPLICIT PROCEDURE PACKAGE INPUT FILE: UNIT19.DAT

$50 \quad 5$

1. .001
MXITER, NPARM

$0 \quad .001$
1 ACCL, ERR, I PCAIC, WSEED

\section{OUTPUT CONTROL INPUT FILE: UNIT22.DAT}

10
0
1
-1
-1

10
1
1
1
1

45
1
1
1
1

1

1

1 


\section{APPENDIX C \\ GENERATING STREAM-AQUIFER COEFFICIENTS USING MODRSP}

\section{C.1 Introduction}

This appendix presents the detailed procedures required to generate spatially distributed stream-aquifer response coefficients for use in a stream-aquifer management model using MODRSP (Maddock and Lacher,1991). The procedure is described graphically in Figure 5.5 of Chapter 5.

\section{C.2 Data Preprocessing for MODRSP}

The GIS and DBMS procedures used to prepare aquifer transmissivity, boundary, well, and river reach input data files used by MODRSP are presented below.

\section{C.2.1 Aquifer Transmissivity}

This example assumes that transmissivity data are available from published contour maps.

- Use AUTOCAD to digitize the transmissivity contour map using the PLINE command.

- Assign contour transmissivity values to each contour "polyline" using the THICK command.

- Draw in system boundary.

- Extend all open contour lines to the system boundary.

- If necessary, use GTCP to transform coordinates into UTM.

- Run the AUTOLISP program ACDTOIDR. lsp, which creates an IDRISI vector file with each contour polyline assigned with transmissivity as the attribute.

- Use the IDRISI DOCUMENT V command to create the header file for the new transmissivity vector file, and use the system boundary as the file coordinate limits.

- Prepare a blank raster file using the IDRISI command INITIAL for use with LINERAS. The grid size should correspond to the grid and cell size to be used by MODRSP. This must be defined as a binary file.

- Convert the IDRISI vector file to a raster file using LINERAS.

- Use the IDRISI INTERCON command to interpolate between the contour line values and assign transmissivity values to each raster grid.

- Use OVERLAY to convert transmissivity values to units to be used by MODRSP.

- Use OVERLAY with a rasterized aquifer boundary file and the transmissivity file to assign zero to all transmissivities outside the defined aquifer boundary.

- Use CONVERT to create an ASCII IDRISI image file of the final transmissivity raster file, and save this file for use with MODRSP. 


\section{C.2.2 Boundary File}

The groundwater system boundary data required for use by MODRSP requires that each finite grid be assigned a boundary value:

No flow: 0

Constant head: -1

Underflow: +1

This requires that a raster based aquifer file be developed that indicates which cells are inside the aquifer $(+1)$ and which are outside the aquifer $(0)$. This file can then be combined with a raster file indicating the aquifer cells that are reservoirs, ponds, or perennial streams. For this example, it is assumed that the source of the aquifer boundary is a published map and the hydrography data are available from TIGER files transferred to AUTOCAD.

- Use AUTOCAD to digitize in aquifer boundary as a polyline.

- Assign an attribute value to the boundary line using the command THICK.

- Run the AUTOLISP program ACDTOIDR.lsp to create an IDRISI vector file of the aquifer boundary.

- Read in hydrography data from TIGER files into AUTOCAD. THAW all layers with ponds, reservoirs, and perennial streams. Assign an attribute value different from that used for the aquifer boundary using the command THICK.

- Run the AUTOLISP program ACDTOIDR.lsp to create an IDRISI vector file of the constant head boundary data.

- Use the IDRISI DOCUMENT V command to make vector header files for the aquifer boundary and constant head boundary lines. Use the system boundary as the coordinate limits.

- Use INITIAL to prepare blank binary raster image files for both boundary vector files. Grid size and number of rows and columns should correspond to the MODRSP finite grid system.

- Use POLYRAS to rasterize the two vector boundary files.

- The constant head grid locations must be assigned a negative value. This requires several steps. Create an equivalent size raster file with an initial value of -1 using INITIAL. Use OVERLAY with the MULTIPLY option to create a new constant head raster file with negative values.

- Use OVERLAY with the COVER command to create a single file with constant head grids having negative value attributes, normal aquifer cells with positive value attributes, and no flow cells with a zero value attribute.

- Use CONVERT to make an ASCII image file. This file can be used directly by MODRSP as the groundwater system boundary file.

\section{C.2.3 Well Fule}

The MODRSP Well file is used to identify the location of each cell in the finite difference model for which response coefficients are to be generated. In the groundwater management model, these grid related response coefficients can be used to represent a single well, several wells located within the grid, or combined with response coefficients developed for other grids to model 
return flows from a recharge source, reservoir seepage, or channel loss. GIS and DBMS techniques are well suited for generating and managing this type of information. For this example, it is assumed that well or recharge locations are available in published maps, and non-geographical related data are available in separate databases. The Well File used by MODRSP requires the number of wells and their row/column locations. The process for identifying row/column grid locations for a single well is different than for a reservoir or a channel.

- Use AUTOCAD to digitize in well data from a map as POINT data.

- Use the GCTP transform package to convert well point data to UTM, if required.

- Use AUTOCAD (Autodesk, Inc, 1990) database related functions to create attributes, insert them into a drawing, and extract data:

- ATTDEF [defines attribute format]

ATTDISP [displays drawing attribute]

ATTEDIT [edits attribute values]

ATTEXT [extracts attribute data]

- Define an attribute with three attribute tags:

Type: Well

Well_no: Consecutive reference number

Name: $\quad$ Unique name for linking with external database

- Link attribute to a block using the BLOCK command.

- Use the INSERT command to recall the attribute block and assign it to each well location point. Fill in attribute tags with proper data. A short AUTOLISP program can be written to automate the process.

- Prepare an attribute template file with an ASCII text editor that includes the block name, type, well-no, name, and location.

- Extract attribute data, along with location, as an SDF (space delimited) file using ATTEXT.

- Import the well SDF file into DBASEIV.

- Using the following formulas calculate the equivalent finite difference grid row and column values from the $\mathrm{x}$ and $\mathrm{y}$ location fields.

$$
\begin{gathered}
\text { Column no. }=I N T\left[\frac{X_{v a l}-X_{\min }}{X_{\text {unit }}}\right]+1 \\
\text { and } \\
\text { Row no. }=I N T\left[\frac{Y_{\max }-Y_{v a l}}{Y_{u n t t}}\right]+1
\end{gathered}
$$

where

$I N T=$ integer value

$X_{\text {val }}, Y_{\text {val }}=$ well location $\mathrm{x}$ and $\mathrm{y}$ values

$X_{\min }, Y_{\max }=$ system boundary limits

$X_{\text {unit }}, Y_{\text {unit }}=$ grid dimension

if Column no. $>$ Column $_{\max }$, then Column no. $=$ Column $_{\max }$;

if Row no. $>$ Row $_{\max }$, then Row no. $=$ Row $_{\max }$. 
- Create another calculated field with the equivalent finite difference grid cell number using the following equation:

$$
\text { Location Array }(\text { cell no. })=\left(\text { Row no. } \times \mathrm{Col}_{\max }\right)-\left(\mathrm{Col}_{\max }-\mathrm{Col} \text { no. }\right)
$$

- Create a database boundary file from the IDRISI ASCII boundary image file. This is accomplished by importing the boundary file to DBASEIV, adding a field called CELL, and filling the CELL field with REC_NO() using the DBASE REPLACE ALL command.

- Use the boundary file to extract only those cell locations in the well database that are within the aquifer boundary.

- Create a new field in the extracted well database file called LAYER and fill this field with values of 1 , which represent Layer 1 in the aquifer.

- Modify the database structure so that the LAYER, ROW, and COLUMN fields are all integers with 10 places.

- Create an ASCI text file from the well database file that includes the LAYER, ROW, and COLUMN fields.

- Use an ASCII text editor to add a single header line to the ASCII well file which registers the number of wells in the data file. This file can be used as the well data file in MODRSP.

\section{C.2.4 Reservoir File}

- Read in data to AUTOCAD from TIGER files, or use AUTOCAD to digitize as polylines from published maps.

- Use the GTCP program to convert coordinates to UTM.

- Assign each reservoir a separate consecutive attribute value using the THICK command.

- Use the AUTOLISP program ACDTOIDR.lsp to create an IDRISI vector file.

- Use DOCUMENT V to make the appropriate header file setting the coordinate limits to those of the groundwater system.

- Create a blank binary raster file with grid size and row/column numbers equivalent to that required for MODRSP.

- Convert the reservoir IDRISI vector file to an IDRISI raster file using POLYRAS. If the reservoir polygon covers over 50 percent of a grid, the attribute corresponding to the reservoir attribute value will be assigned to the raster grid cell.

- Eliminate all reservoir grid cells outside the aquifer by using OVERLAY and MULTIPLY on the aquifer boundary IDRISI raster file. Use RECLASS to set all aquifer cells to 1 and non-aquifer cells to zero in the IDRISI aquifer boundary file, if necessary, prior to performing the overlay.

- Use CONVERT to create an ASCII file from the binary reservoir raster image file.

- Import the reservoir image file into DBASEIV.

- Create a new field called CELL.

- Use REPLACE ALL to fill this field with the RECNOO for each record.

- Use QUERY to extract only those records having a non-zero attribute value.

- Create calculated ROW and COLUMN fields using the following: 


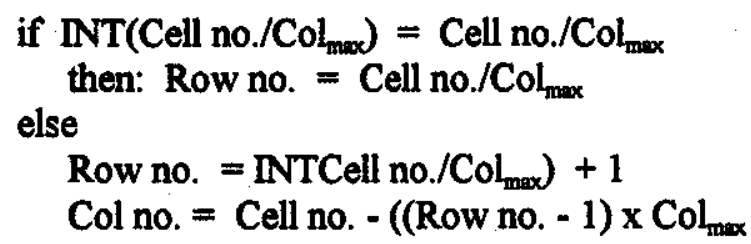

- Create a new field in the reservoir database file called LAYER. Fill this field with values of 1 , representing Layer 1 in the aquifer.

- Modify the database structure so that the LAYER, ROW, and COLUMN fields are all integers with 10 places.

- Create an ASCII text file from the reservoir database file that includes the LAYER, ROW, and COLUMN fields.

- Use an ASCII text editor to add a single header line to the ASCII reservoir file which registers the number of records in the data file. This file can be used as a Well Data File in MODRSP.

\section{C.2.5 Channel}

The preparation of a Well Data File for canals, drains, etc., as represented by a line source, is the same as for a reservoir, except that the IDRISI LINERAS command is utilized instead of POLYRAS to rasterize the channel vector file. Note that it is important that each channel or canal reach being modeled in the groundwater management model is assigned its own attribute value.

\section{C.2.6 River File}

The MODRSP River Data File provides the number of river segments and the unit number directing the program where to write the response function output file. Each grid containing a river cell must be identified by Layer, Row, and Column. A streambed conductance must also be assigned to each river cell. A series of time based response coefficients are generated at each river cell location as a result of unit pumping at each cell listed in the Well File. Since a river reach may constitute more than one grid cell, it is generally necessary to combine response coefficients from several grid cells for use in a groundwater management model. Therefore, it is necessary to identify which grid cells are associated with each river reach. The assignment of streambed conductance to each cell also requires external data manipulation and calculation. GIS and DBMS techniques are well suited for generating and managing this type of information. For this example, it is assumed that river and stream hydrography data are available from TIGER files. River conductance is expressed as a function of stream width, aquifer saturated thickness, grid reach length, and aquifer transmissivity. Stream width data are available from cross-section surveys; and saturated thickness and transmissivity data from published maps.

\section{Reach Number/Reach Length}

- Use AUTOCAD to view river and stream hydrography imported from TIGER files.

- Use GTCP to convert coordinates to UTM.

- Edit the AUTOCAD river and stream files so that each stream or river is represented by a single continuous polyline. 
- Locate and use the BREAK command to separate the river or stream into reach segments required for use in the groundwater management model.

- Use the PEDIT and WIDTH commands to assign a consecutive attribute value to each reach number.

- Modify the VECBRKW.lsp file using a standard ASCII text editor. Change the xmin, xmax, ymin, ymax, yunit, xunit values to match the groundwater system coordinates and grid cell sizes under study.

- Run the AUTOLISP program VECBRKW.1sp. This divides each river and stream line segment into a grid cell line segment and creates an ASCII script file.

- Load the script file into a new AUTOCAD layer.

- Run the AUTOLISP program VECDIST.Isp. This creates an ASCII text file which contains $\mathrm{x} 1, \mathrm{y} 1, \mathrm{x} 2, \mathrm{y} 2$, and the stream attribute number for each grid.

- Load this file into the QUATTRO PRO file ACDPRNIN.wq1 using /TOOLS IMPORT for comma delimited ascii text.

- Fill in the proper values for Xmax, Xmin, Ymin, Ymax, Row\#, Col\#, Xunit, and Yunit.

- Copy the equations for X1, Y1, COL, ROW, and CELL to all rows containing the grid data. The actual $x, y$, row, column, and cell values for each set of grid data are calculated, with reach numbers under the UNIT column and reach lengths under the DIST column.

- Create another column labeled REC, and use /EDIT FILL to place consecutive record values starting with 1.

- Use /TOOLS EXTRACT VALUES commands to create an xxx.DBF file with the following columns: REC, COL, ROW, CELL, UNIT, and DIST.

Width

- Follow the same procedures described above for assigning reach numbers, except use PEDIT and WIDTH command to assign a bed width attribute values to each reach segment.

- Modify the VECBRKW.lsp file using a standard ASCII text editor. Change the xmin, xmax, ymin, ymax, yunit, xunit values to match the groundwater system coordinates and grid cell sizes under study.

- Run the AUTOLISP program VECBRKW.Isp. This divides each river and stream line segment into a grid cell line segment, and creates an ASCII script file.

- Load the script file into a new AUTOCAD layer.

- Run the AUTOLISP program VECWDTH.lsp. This creates an ASCII text file which contains the same column values as the reach attribute file, except the distance column is absent.

- Load this file into the QUATTRO PRO file ACDPRNIN.wq1 using /TOOLS IMPORT as a comma delimited ascii text.

- Follow the same procedures described previously for the reach/distance calculation. Eliminate the DIST column and rename the UNIT column as WIDTH.

- Extract the REC and WIDTH columns to a xxx.dbf file.

- Join the WIDTH column to the REACH/DIST database linking on the REC field. 
This example assumes a published contour map as the source of saturated thickness data.

- Use AUTOCAD to digitize in saturated thickness contour map using PLINE command.

- Assign contour saturated thickness values to each contour "polyline" using THICK.

- Draw in system boundary.

- Extend all open contour lines to the system boundary.

- If necessary use GTCP to transform coordinates into UTM.

- Run the Autolisp program ACDTOIDR.Isp. This will create an IDRISI vector file with each contour polyline assigned saturated thickness as the attribute.

- Use the IDRISI DOCUMENT V command to make the header file for the new saturated thickness vector file. Use the system boundary as the file coordinate limits.

- Prepare a blank raster file using INITIAL for use with LINERAS. The grid size should correspond to the grid and cell size to be used by MODRSP. This must be defined as a binary file.

- Convert the IDRISI vector file to a raster file using LINERAS.

- Use the IDRISI INTERCON command to interpolate between the contour line values and assign saturated thickness values to each raster grid.

- Use OVERLAY to convert saturated thickness values to units to be used by MODRSP.

- Use OVERLAY with a rasterized aquifer boundary file and the saturated thickness file to assign zero to all cells outside the defined aquifer boundary.

- Use CONVERT to make an ASCII IDRISI image file of the final saturated thickness raster file.

\section{River Conductance}

- Import the IDRISI transmissivity and IDRISI saturated thickness files into DBASEIV.

- $\quad$ Add a CELL field to the transmissivity and saturated thickness files using MODIFY STRUCTURE and REPLACE ALL with RECNOO.

- Use the QUERY command to add transmissivity and saturated thickness fields to the REACH/DIST/WIDTH dbase file, and link on CELL.

- Calculate the new field COND using the following equation based on the method of flow nets:

$$
\text { Conductance }=\frac{T}{e} L\left(\frac{W_{p}+2 e}{e+10 W p}\right)
$$

where

$T=$ transmissivity of the aquifer underlying the reach

$e=$ average saturated thickness of the aquifer along the reach

$L=$ length of reach

$W_{p}=$ wetted perimeter of stream equal to width of reach

- Create a LAYER field and REPLACE ALL with 1.

- MODIFY STRUCTURE so that LAYER, ROW, and COLUMN fields have 10-digits and no decimals, and COND has 10-digits and 5 decimal places. 
- Export LAYER, ROW, COLUMN, and COND fields to an SDF river text file.

- Use an ASCII text editor to add a single header line to the ASCII river file which registers the number of records in the data file and the unit number for the response coefficient output file. This file can be used as the river data file in MODRSP.

\section{C.3 Execution of MODRSP}

MODRSP is written in the FORTRAN programming language. Large model simulations ( 50,000 cells) can be run on a microcomputer by compiling MODRSP using Microsoft Fortran 5.1 and running under Microsoft Windows. A well documented user manual is available for MODRSP (Maddock and Lacher, 1991).

\section{C.3.1 Input}

To run MODRSP, the following input files must be prepared:

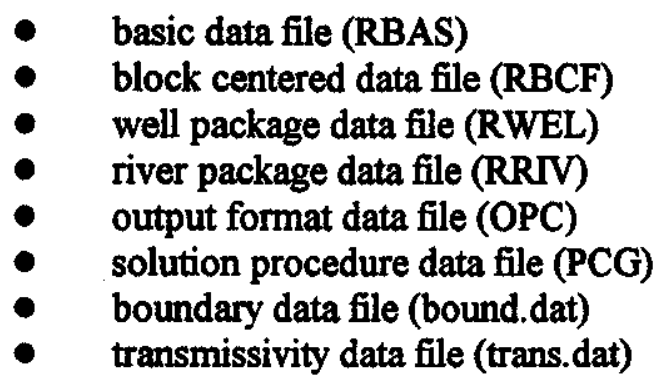

The basic data file (RBAS) is used to assign files and unit numbers for the packages to be used to run MODRSP.

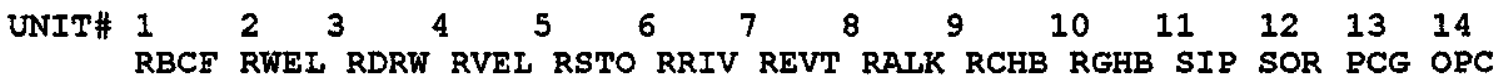

Instead of reading boundary data in from the basic data file (RBAS), data can be read in from a separate data file. To read the boundary data file prepared using IDRISI, line 6 of the RBAS file is written:

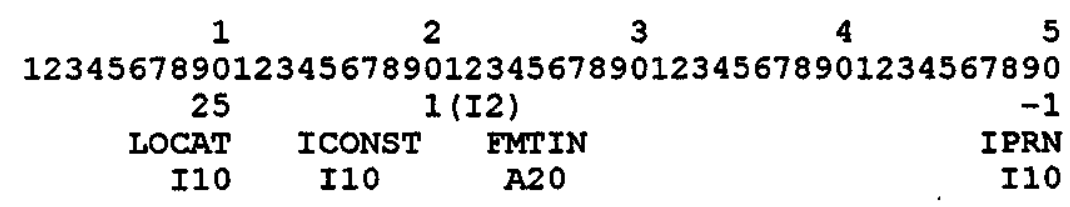

where

LOCAT: indicates the location of the data which will be put in the array

ICONST: every element in the array is multiplied by this constant

FMTIN: format of records containing the array values; the format must be enclosed in parentheses; for data read in from an IDRISI image file, read a single record per line.

IPRN: flag for printing array 
Instead of reading transmissivity data in from the block centered data file (RBCF), data can be read in from a separate data file. To read the transmissivity data file prepared using IDRISI, line 6 of the RBCF file is written:

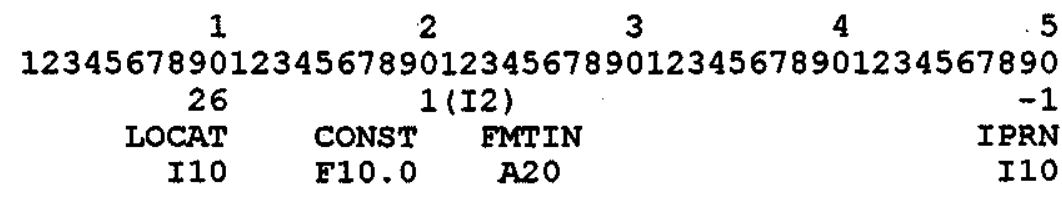

where

LOCAT: indicates the location of the data which will be put in the array

CONST: every element in the array is multiplied by this constant

FMTIN: format of records containing the array values; the format must be enclosed in parentheses; for data read in from an IDRISI image file, read a single record per line.

IPRN: flag for printing array

To run the program, type

MODRSP

After the command prompt, the screen clears, the title MODRSP appears, and the user is asked to supply the input and output file names for the various modules.

\section{C.3.2 Output}

The number of output files created by MODRSP depends on the packages being used. For this example, two output files are created: the main output file (MDRSP.out) and the river response file (RIV.RF). It is the river response file that contains the groundwater response coefficients.

\section{C.4 Data Postprocessing for MODRSP}

The coefficients produced by MODRSP represent groundwater flow responses over a user defined time period at a single river grid due to pumping of a unit discharge for a single period at a single well. These results must be summarized by river reach and by source before they can be used in a stream-aquifer management model. This can be a one, two, or three step process, depending on whether each record in the well data file represents a single well, a segment of channel reach, or reservoir, or if more than one well is located in a grid cell.

\section{C.4.1 River Reach Summary}

MODRSP determines the effects of well pumping on individual river reach grid cells. Usually, most reaches are composed of a number of grid cells. Data base concepts can be used to summarize MODRSP response coefficients by river reach.

- Use a text editor to eliminate the column titles from the river response output file.

- Import the response file to DBASEIV. 
- Use the river data base file which identifies which MODRSP grids are associated with each river reach segment prepared during the preprocessing stage

- Use the QUERY mode to sum response coefficients by linking the two files on river reach record number and grouping by well number, river reach unit number, and time period.

\section{C.4.2 Source Summary}

In the case of reservoirs or channels where more than one cell grid is used to represent the reservoir or channel system, the response coefficients of several grids can be superimposed by the following procedure.

- Use the river reach summary response coefficient data base

- Use the reservoir or channel database file originally developed during the preprocessing stage.

- Use the query mode to sum response coefficients by linking the two files on well record number and grouping by well number, reservoir or channel reach unit number, and time period.

\section{C.4.3 MODSIM Coefficient File}

Add the field TYPE to the source summary or river reach summary data base file. The value for TYPE is assigned based on the source and use of the response coefficients:

1. Reservoir

2. Demand

3. Link

Use MODIFY STRUCTURE to set field widths as follows:

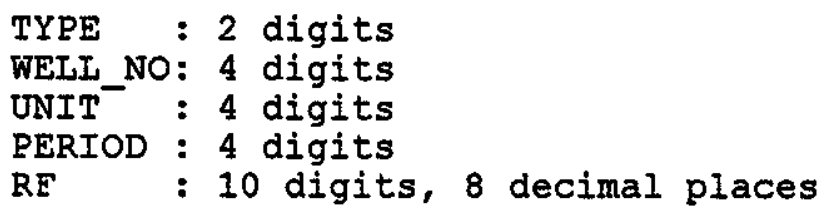

Export the TYPE, WELL_NO, UNIT, PERIOD, and RF fields to an SDF ASCII text file. Run MODCOEFF, exe to output a MODSIM compatible coefficient file. 


\section{APPENDIX D}

\section{CASE STUDY MODRSP FILES}

\section{D.1 Example Screen for Reading Input and Output File Names}

MODRS P

$\begin{array}{llll}\text { MAIN OUTPUT FILE (ODE) } & \text { ON UNIT } 36 & \text { ASSIGN TO FORMATTED FILE: MDRSE. OUT } \\ \text { BAS } & \text { ON UNIT } 35 & \text { ASSIGN TO FORMATTED FIIE: RBAS } \\ \text { BCE } & \text { ON UNIT } 2 & \text { ASSIGN TO FORMATTED FIIE: RBCE } \\ \text { WEL } & \text { ON UNIT } 3 & \text { ASSIGN TO FORMATTED FIIE: RWEI } \\ \text { RIV } & \text { ON UNIT } 9 & \text { ASSIGN TO FORMATTED FIIE: RRIV } \\ \text { RIVER CAPTURE RE } & \text { ON UNIT } 54 & \text { ASSIGN TO FORMATTED FIIE: RIV.RF } \\ \text { BOUNDARY FIIE } & \text { ON UNIT } 25 & \text { ASSIGN TO FORMATTED FIIE: BOUND.DAT } \\ \text { TRANSMISSIVITY EIIE } & \text { ON UNIT } 26 & \text { ASSIGN TO FORMATTED FILE: TRANS.DAT } \\ \text { PCG } & \text { ON UNIT } 13 & \text { ASSIGN TO FORMATTED FIIE: PCG }\end{array}$

D.2 Basic Package Input File: 7BAS

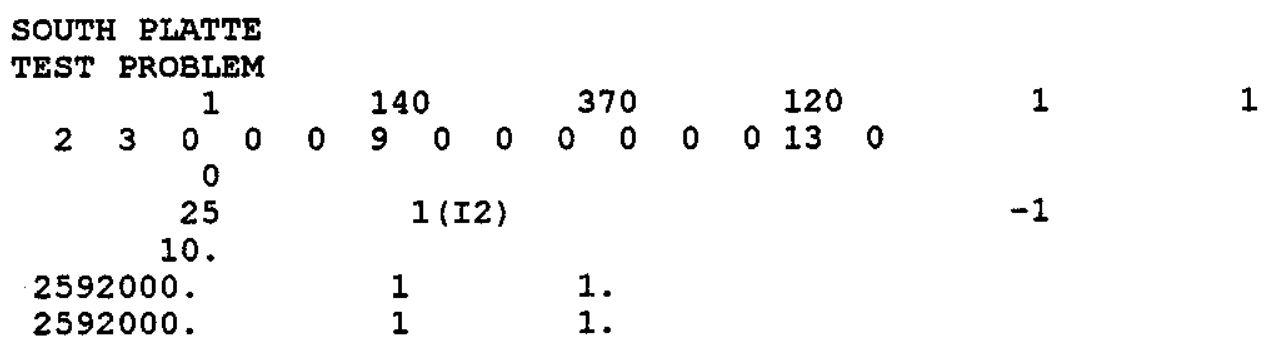

D.3 Block-Centered Flow Package Input File: 7BCF

$\begin{array}{rcr}0 & 0 & \\ 0 & 1 . \\ 0 & 1000 . & \\ & & \\ 0 & 1000 . & -1 \\ 30 & 0.16 & -1\end{array}$

\section{D.4 Well Package Input File: Well.dat}

$\begin{array}{rll}177 & 5^{-1} & \\ 1 & 54 & 165 \\ 1 & 54 & 167 \\ 1 & 55 & 184\end{array}$




\section{D.5 Well Package Input File: Drain.dat}

246

1

1

25

1

1

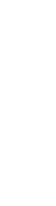

(1)

$\begin{array}{ll}-1 & \\ 63 & 152 \\ 65 & 184\end{array}$

\section{D.7 River Package Input File: River.dat}

889

1

1

1

D.8 Precoditioned Conjugate Gradient Input File: PCG

0.001

.000

.000

.000

.000

.000

D.9 Transmissivity Input File: TRANS2

0.00001
0.54616
0.16086

$\begin{array}{lll}10 & 343 & 0.54616 \\ 10 & 344 & 0.16086 \\ 11 & 343 & 1.02508\end{array}$

$11 \quad 343 \quad 1.02508$
50
0.001
0.97
0
0
0

0

D.10 Boundary Input File: BOUND2

\section{D.11 River Response Output File: Riv.rf}

$\begin{array}{lllll}2 & 18 & 11 & 1 & .57943450 \\ 2 & 18 & 11 & 2 & .04152328 \\ 2 & 18 & 11 & 3 & .00717168 \\ 2 & 18 & 11 & 4 & .00276704\end{array}$

D-2 
APPENDIX E

MODSIM AUGMENTATION PLAN INPUT FILES

\section{E.1 Control Data}

\begin{tabular}{|c|c|c|}
\hline $\begin{array}{l}\text { Item } \\
========\end{array}$ & $\begin{array}{c}\text { SDE } \\
\text { Control } \\
\text { Eile } \\
\text { Fe=m }\end{array}$ & $\begin{array}{l}\text { MODRSP } \\
\text { Control } \\
\text { File } \\
\end{array}$ \\
\hline UNITS & English & English \\
\hline PERIOD & Monthly & Monthly \\
\hline MODE & Calibration & Calibration \\
\hline GW COEF FILE & SPSDF.CEF & SPLAT.CEF \\
\hline MAX PRIORITY & 2450 & 2450 \\
\hline TITLE & BIJOU:SDF & BIJOU :MODRSP \\
\hline TOTAL NODES & 281 & 281 \\
\hline RESERVOIR NODES & 8 & 8 \\
\hline SPIII NODES & 8 & 8 \\
\hline DEMAND NODES & 232 & 232 \\
\hline IMPORT NODES & 0 & 0 \\
\hline IINKS & 81 & 81 \\
\hline RIVER IINKS & 0 & 0 \\
\hline TOTAI PERIODS & 7 & 7 \\
\hline START PERIOD & 1985 & 1985 \\
\hline FROM PERIOD & 1 & 1 \\
\hline END PERIOD & 7 & 7 \\
\hline
\end{tabular}


Time series data for inflows (Type 1), demands (Type 2), and reservoir evaporation rates (Type 3)-partial data set of 50 out of 1314 records listed as an example:

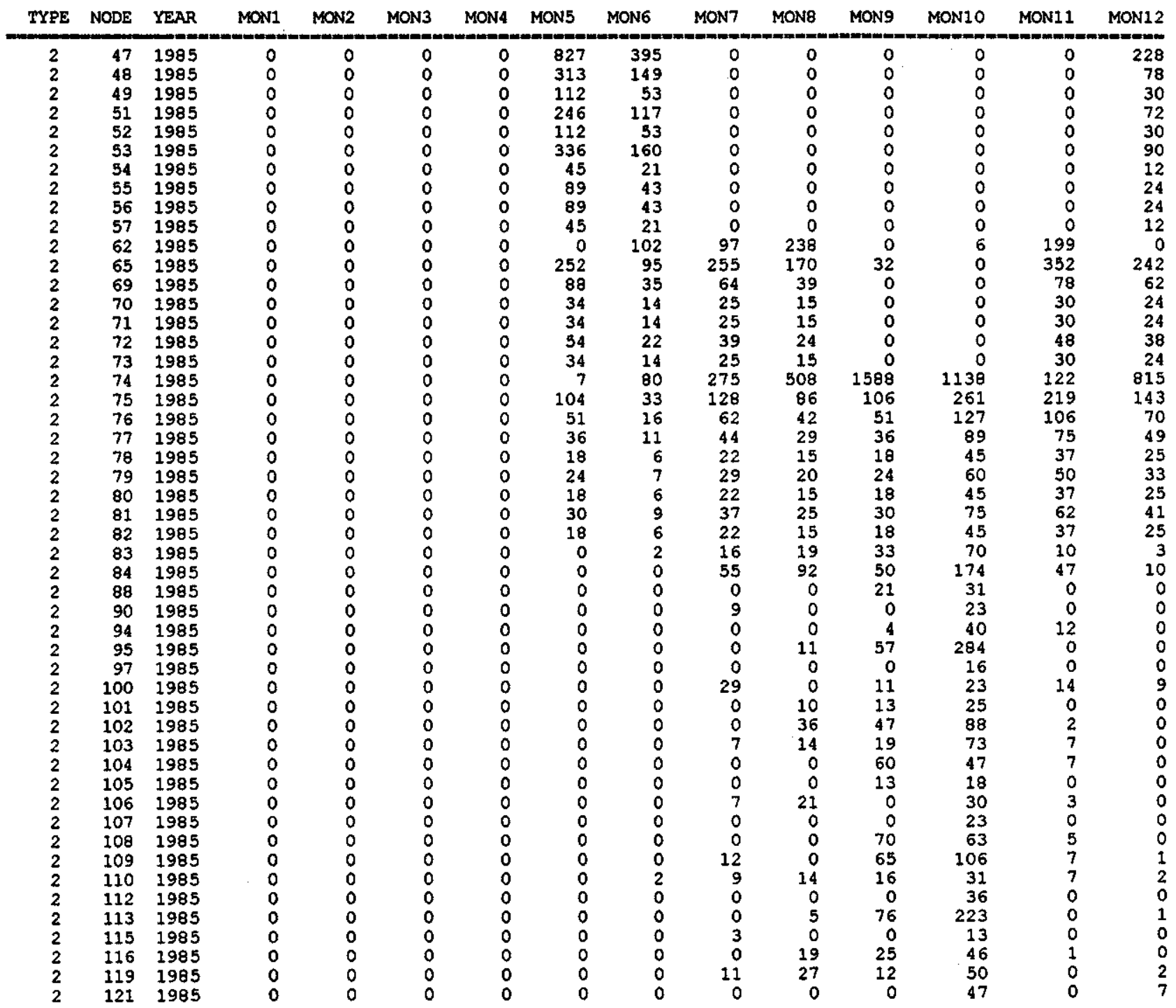




\section{E.3 Node Names: Nodes.dat (281 records)}

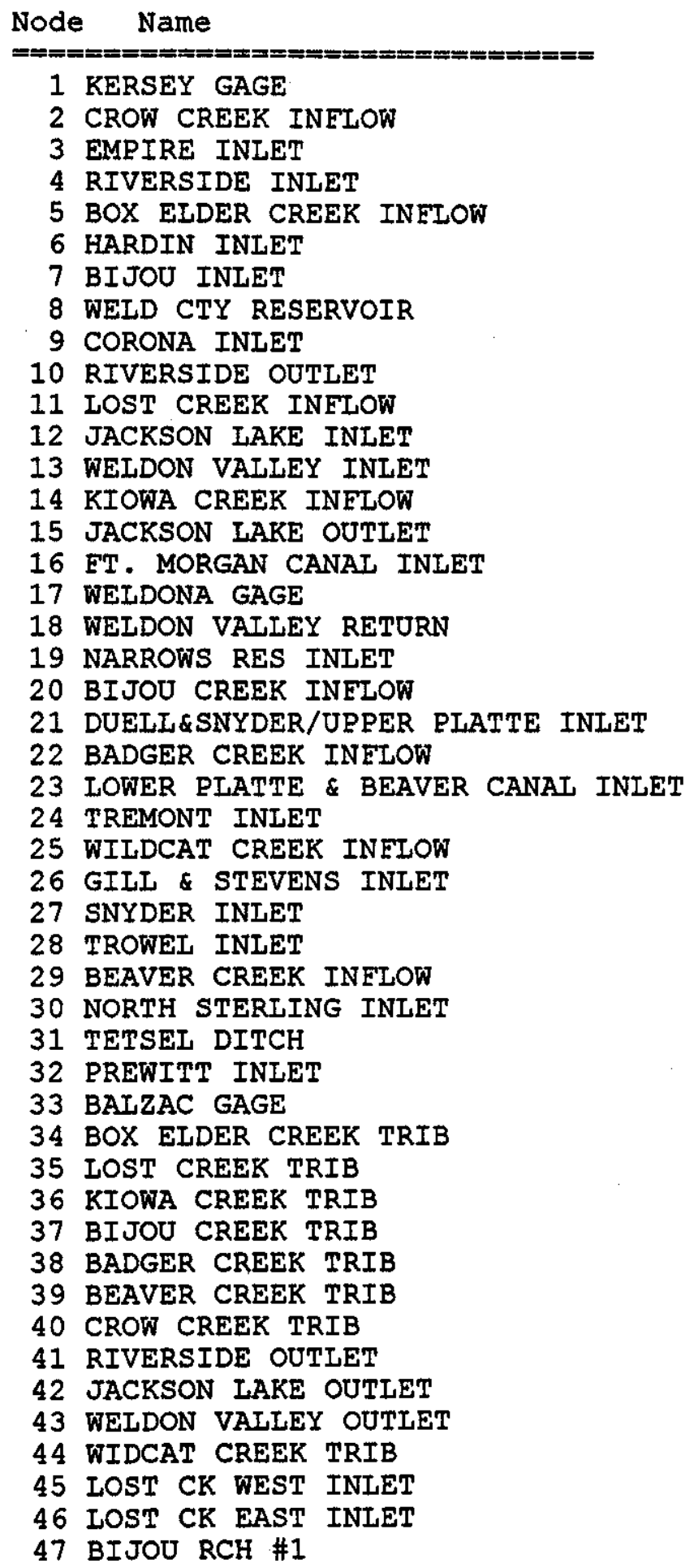




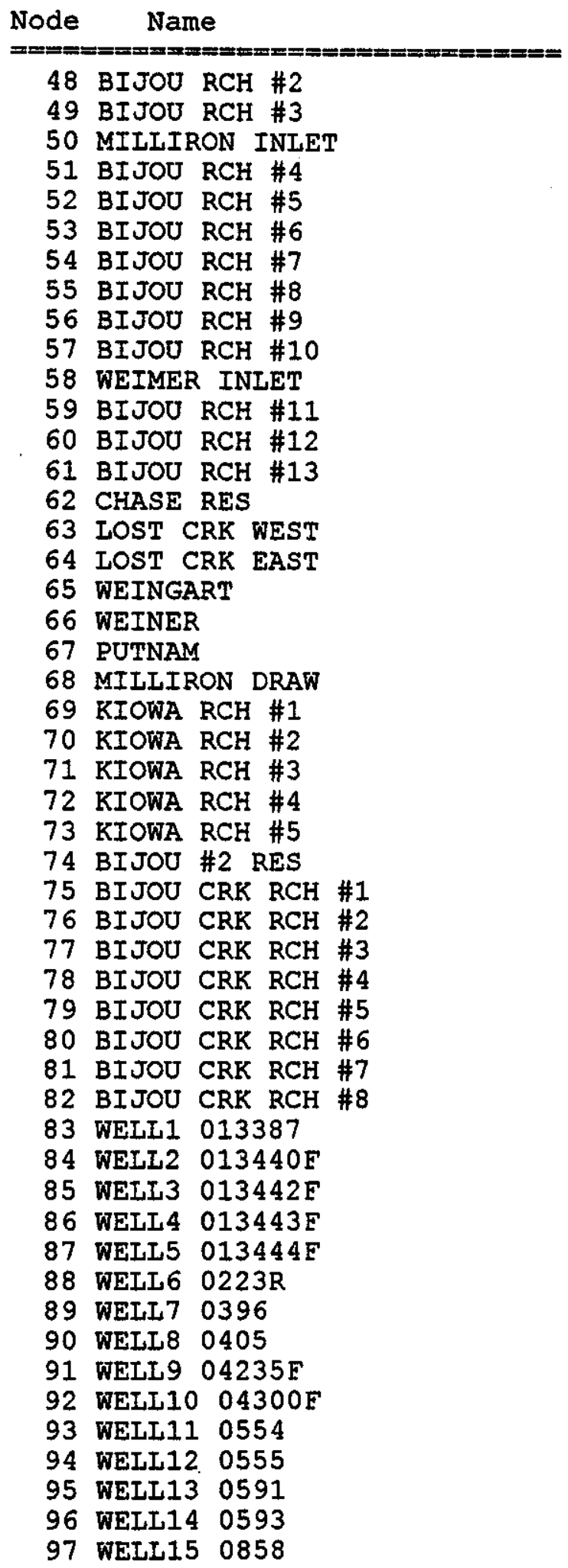


Node Name

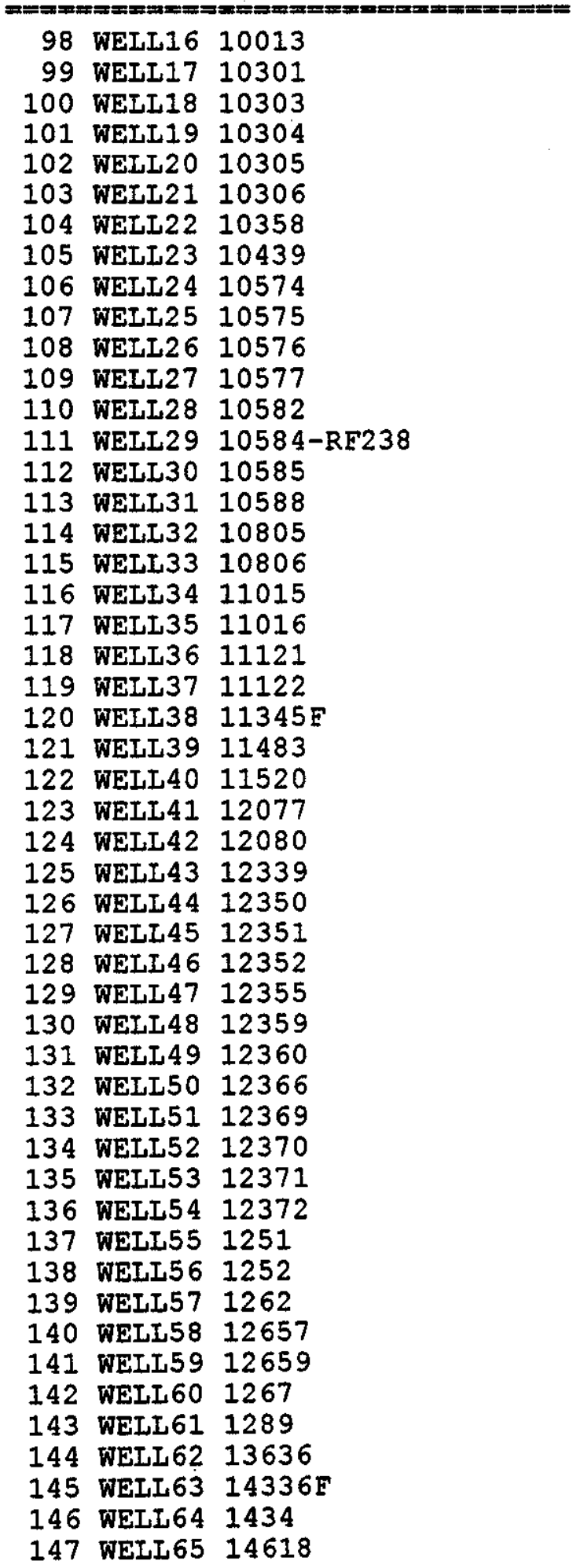

E-5 


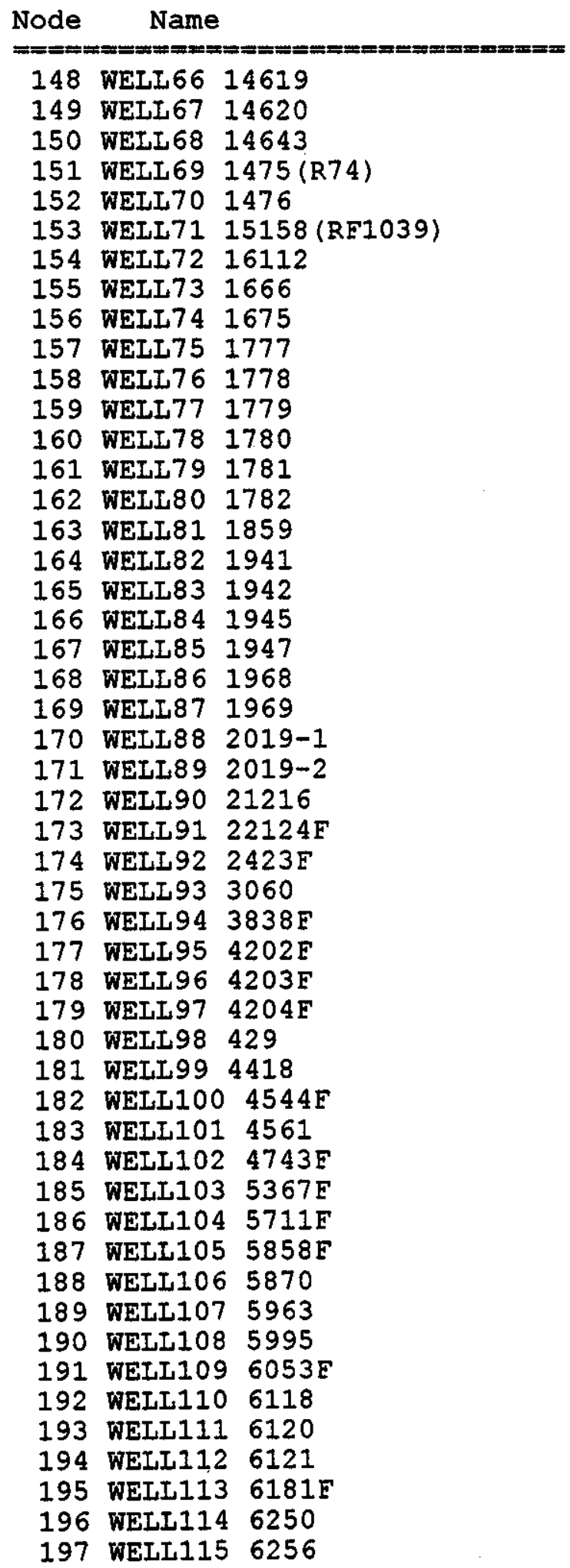




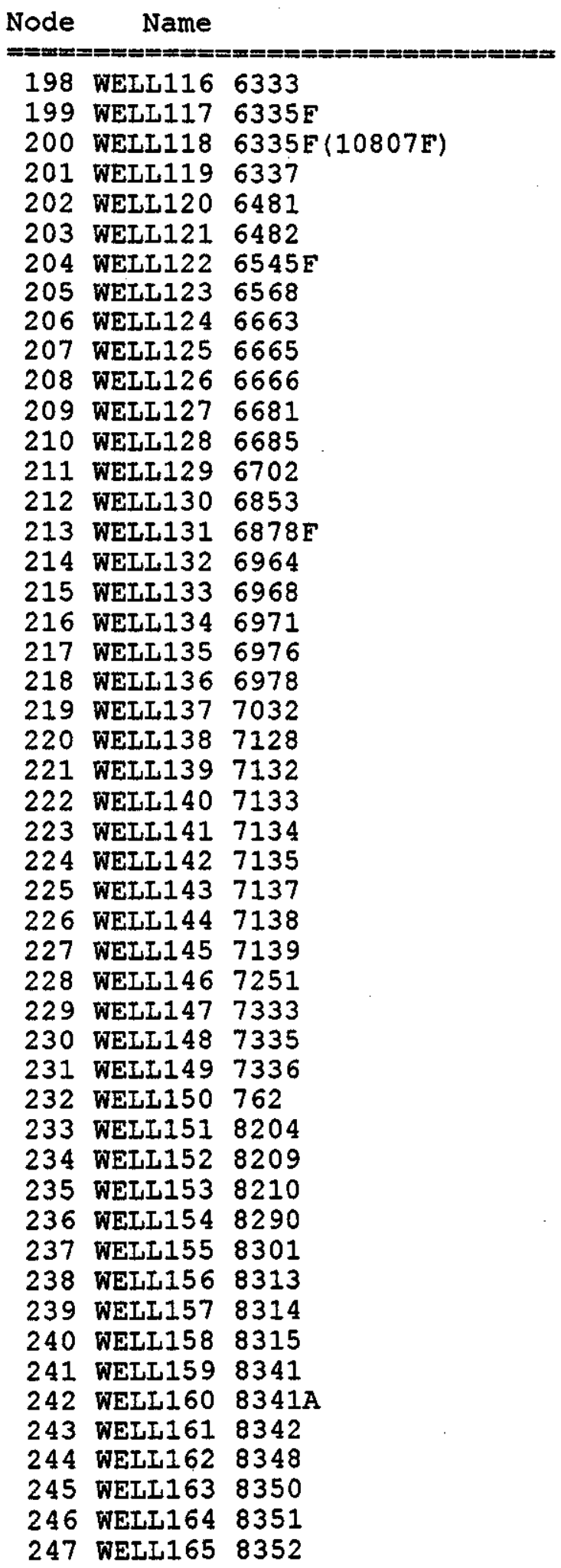




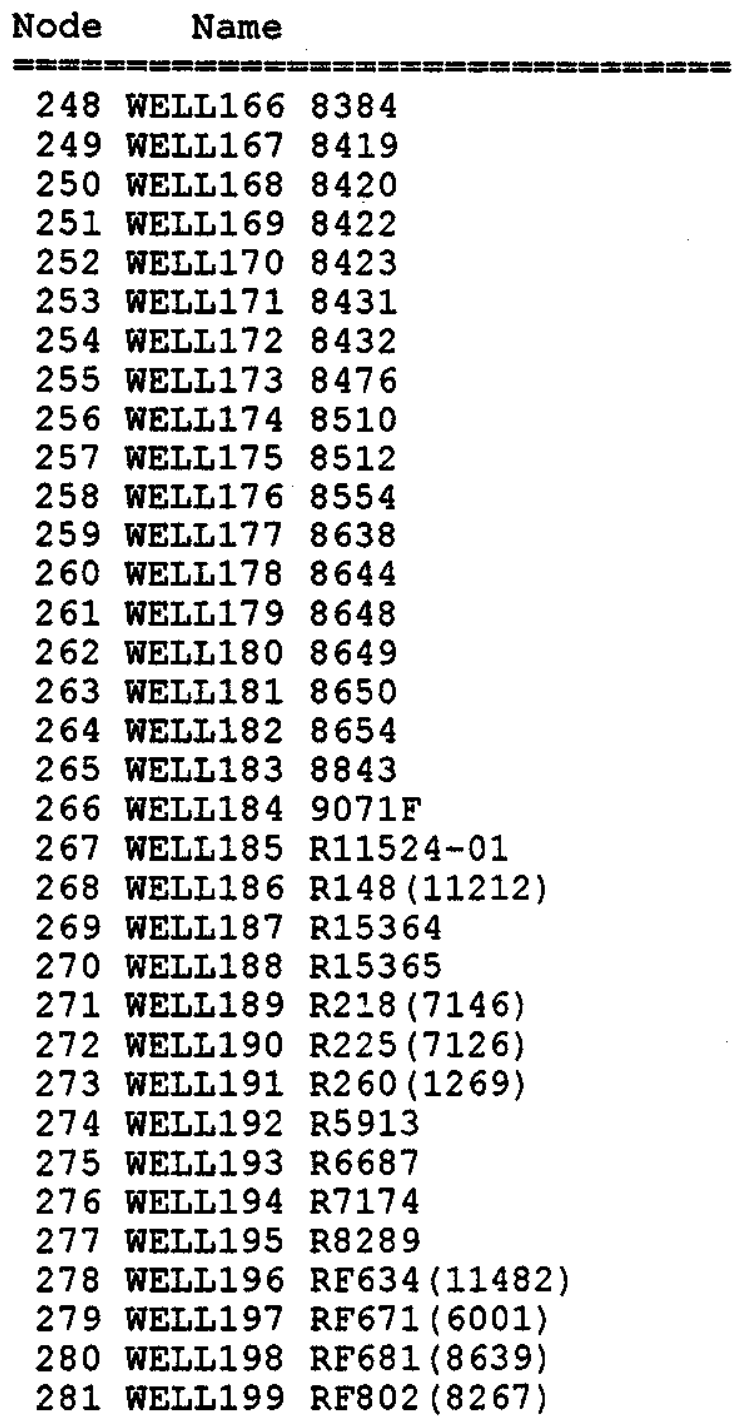


E.4 Reservoir Data File: Res.dat (9 records)

$\begin{array}{rrrrrrr}\text { NODE } & \text { CAP_MAX } & \text { CAP_MIN } & \text { CAP_BEG } & \text { PRIORITY } & \text { TARGET } & \text { SPI_PRI } \\ 1 & 900000 & 0 & 900000 & 10 & 0 & 2 \\ 33 & 900000 & 0 & 0 & 20 & 0 & 1 \\ 34 & 900000 & 0 & 900000 & 30 & 0 & 3 \\ 35 & 900000 & 0 & 900000 & 40 & 0 & 4 \\ 36 & 900000 & 0 & 900000 & 50 & 0 & 5 \\ 37 & 900000 & 0 & 900000 & 60 & 0 & 6 \\ 38 & 900000 & 0 & 900000 & 70 & 0 & 7 \\ 39 & 900000 & 0 & 900000 & 80 & 0 & 8\end{array}$


E.5 Demand Data File: Demand.dat (Partial listing - 50/232 records)

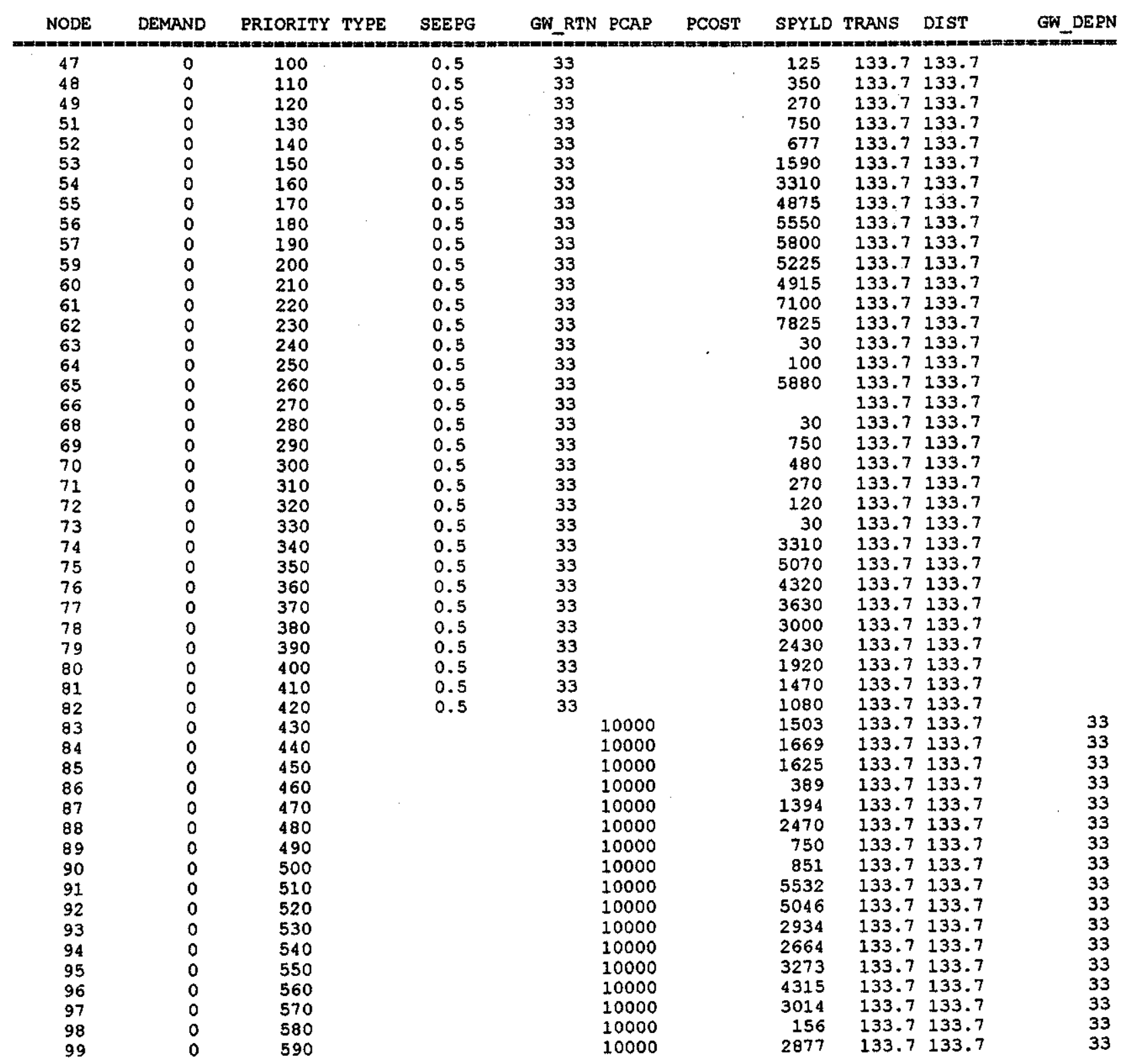


E.6 Link Data File: Link.dat (81 records)

\begin{tabular}{|c|c|c|c|c|c|}
\hline LINK & NAME & BEG_NODE & END_NODE & MAX_CAP & MIN_CAP \\
\hline 1 & SPLATTE_RCH1 & 1 & 2 & 10000 & 0 \\
\hline 2 & SPLATTE RCH2 & 2 & 3 & 10000 & 0 \\
\hline 3 & SELATTE_RCH3 & 3 & 4 & 10000 & 0 \\
\hline 4 & SPLATTE_RCH4 & 4 & 5 & 10000 & 0 \\
\hline 5 & SPIATTE RCH5 & 5 & 6 & 10000 & 0 \\
\hline 6 & SPLATTE-RCH 6 & 6 & 7 & 10000 & 0 \\
\hline 7 & SPLATTE RCH7 & 7 & 8 & 10000 & 0 \\
\hline 8 & SPLATTE RCH8 & 8 & 9 & 10000 & 0 \\
\hline 9 & SPLATTE_RCH9 & 9 & 10 & 10000 & 0 \\
\hline 10 & SPLATTE_RCH10 & 10 & 11 & 10000 & 0 \\
\hline 11 & SPLATTE_RCH11 & 11 & 12 & 10000 & 0 \\
\hline 12 & SPLATTE_RCH12 & 12 & 13 & 10000 & 0 \\
\hline 13 & SPLATTE_RCH13 & 13 & 14 & 10000 & 0 \\
\hline 14 & SPLATTE_RCH14 & 14 & 15 & 10000 & 0 \\
\hline 15 & SPIATTE_RCH15 & 15 & 16 & 10000 & 0 \\
\hline 16 & SPLATTE_RCH16 & 16 & 17 & 10000 & 0 \\
\hline 17 & SPLATTE_RCH17 & 17 & 18 & 10000 & 0 \\
\hline 18 & SPLATTE RCH18 & 18 & 19 & 10000 & 0 \\
\hline 19 & SPLATTE_RCH19 & 19 & 20 & 10000 & 0 \\
\hline 20 & SPLATTE_RCH20 & 20 & 21 & 10000 & 0 \\
\hline 21 & SPLATTE_RCH21 & 21 & 22 & 10000 & 0 \\
\hline 22 & SPLATTE_RCH22 & 22 & 23 & 10000 & 0 \\
\hline 23 & SPLATTERCH23 & 23 & 24 & 10000 & 0 \\
\hline 24 & SPLATTE_RCH24 & 24 & 25 & 10000 & 0 \\
\hline 25 & SPLATTE RCH25 & 25 & 26 & 10000 & 0 \\
\hline 26 & SPLATTE RCH 26 & 26 & 27 & 10000 & 0 \\
\hline 27 & SPLATTE_RCH27 & 27 & 28 & 10000 & 0 \\
\hline 28 & SPLATTE_RCH28 & 28 & 29 & 10000 & 0 \\
\hline 29 & SPLATTE_RCH29 & 29 & 30 & 10000 & 0 \\
\hline 30 & SPLATTE_RCH30 & 30 & 31 & 10000 & 0 \\
\hline 31 & SPLATTE_RCH31 & 31 & 32 & 10000 & 0 \\
\hline 32 & SPLATTE_RCH32 & 32 & 33 & 10000 & 0 \\
\hline 33 & CROW CREEEK & 40 & 2 & 10000 & 0 \\
\hline 34 & BOX ELDER CRK & 34 & 5 & 10000 & 0 \\
\hline 35 & RIVERSIDE OUT & 41 & 10 & 10000 & 0 \\
\hline 36 & LOST CREEK & 35 & 11 & 10000 & 0 \\
\hline 37 & KIOWA CREEK & 36 & 14 & 10000 & 0 \\
\hline 38 & JACKSON OUT & 42 & 15 & 10000 & 0 \\
\hline 39 & WELDONA RTN & 43 & 18 & 10000 & 0 \\
\hline 40 & BIJOU CREEK & 37 & 20 & 10000 & 0 \\
\hline 41 & BADGER CREEK & 38 & 22 & 10000 & 0 \\
\hline 42 & WILDCAT CREEK & 44 & 25 & 10000 & \\
\hline 43 & BEAVER CREEK & 39 & 29 & 10000 & \\
\hline 44 & BIJOU_RCH1A & 7 & 45 & 0 & 0 \\
\hline 45 & BIJOU_RCHIB & 45 & 46 & 0 & 0 \\
\hline 46 & BIJOU RCH1C & 46 & 47 & 0 & $v$ \\
\hline 47 & BIJOU_RCH2 & 47 & 48 & 0 & 5 \\
\hline 48 & BIJOU_RCH3 & 48 & 49 & 0 & 0 \\
\hline 49 & BIJOU_RCH4A & 49 & 50 & 0 & \\
\hline 50 & BIJOU_RCH4B & 50 & 51 & 0 & \\
\hline 51 & BIJOU_RCH5 & 51 & 52 & 0 & \\
\hline 52 & BIJOU_RCH6 & 52 & 53 & 0 & \\
\hline 53 & BIJOU_RCH7 & 53 & 54 & 0 & \\
\hline 54 & BIJOU_RCH8 & 54 & 55 & 0 & \\
\hline 55 & BIJOU RCH9. & 55 & 56 & 0 & \\
\hline 56 & BIJOU_RCH10 & 56 & 57 & 0 & \\
\hline 57 & BIJOU_RCH11A & 57 & 58 & 0 & \\
\hline 58 & BIJOU_RCH11B & 58 & 59 & 0 & 0 \\
\hline 59 & BIJOU_RCH12 & 59 & 60 & 0 & \\
\hline 60 & BIJOU_RCH13 & 60 & 61 & 0 & \\
\hline 61 & CHASE $^{-}$ & 61 & 62 & 0 & \\
\hline 62 & LOST CRK WEST & 62 & 63 & 0 & \\
\hline
\end{tabular}

\section{E-11}




$\begin{array}{lcccc}\text { LINK NAME } & \text { BEG_NODE } & \text { END_NODE } & \text { MAX_CAP } & \text { MIN_CAP } \\ \text { 63 LOST CRK EAST } & 63 & 64 & 0 & 0 \\ 64 \text { WEINGART } & 57 & 65 & 0 & 0 \\ \text { 65 WEIMER } & 58 & 66 & 0 & 0 \\ \text { 66 PUTMAN } & 47 & 67 & 0 & 0 \\ \text { 67 MILLIRON DRAW } & 50 & 68 & 0 & 0 \\ \text { 68 KIOWA_RCH1 } & 51 & 69 & 0 & 0 \\ \text { 69 KIOWA_RCH2 } & 69 & 70 & 0 & 0 \\ 70 \text { KIOWA_RCH3 } & 70 & 71 & 0 & 0 \\ 71 \text { KIOWA_RCH4 } & 71 & 72 & 0 & 0 \\ 72 \text { KIOWA_RCH5 } & 72 & 73 & 0 & 0 \\ 73 \text { BIJOU\#2_RES } & 53 & 74 & 0 & 0 \\ 74 \text { BIJOU_CRK1 } & 74 & 75 & 0 & 0 \\ 75 \text { BIJOU_CRK2 } & 75 & 76 & 0 & 0 \\ 76 \text { BIJOU_CRK3 } & 76 & 77 & 0 & 0 \\ 77 \text { BIJOU_CRK4 } & 77 & 78 & 0 & 0 \\ 78 \text { BIJOU_CRK5 } & 79 & 79 & 0 & 0 \\ 79 \text { BIJOU_CRK6 } & 80 & 80 & 0 & 0 \\ \text { 80 BIJOU_CRK7 } & 81 & 81 & 0 & 0 \\ \text { 81 BIJOU_CRK8 } & & 82 & 0 & 0\end{array}$




\section{E.7 Coefficient File Developed From MODRSP: SPLAT.cff (Partial listing- 50/1079 records,5/89 fields)}

\begin{tabular}{|c|c|c|c|c|}
\hline REC & $=$ & TO & TYPE & 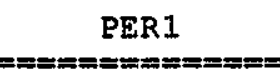 \\
\hline 1 & 47 & 33 & 1 & 0.53636610 \\
\hline 2 & 47 & 7 & 2 & 0.03102195 \\
\hline 3 & 47 & 10 & 2 & 0.14438130 \\
\hline 4 & 47 & 11 & 2 & 0.01065870 \\
\hline 5 & 47 & 12 & 2 & 0.01317517 \\
\hline 6 & 47 & 13 & 2 & 0.03215321 \\
\hline 7 & 47 & 14 & 2 & 0.00001510 \\
\hline 8 & 47 & 35 & 3 & 0.10303790 \\
\hline 9 & 48 & 33 & 1 & 0.31429420 \\
\hline 10 & 48 & 11 & 2 & 0.00000000 \\
\hline 11 & 48 & 12 & 2 & 0.00000287 \\
\hline 12 & 48 & 13 & 2 & 0.06543054 \\
\hline 13 & 48 & 14 & 2 & 0.02555172 \\
\hline 14 & 48 & 35 & 3 & 0.00000000 \\
\hline 15 & 48 & 36 & 3 & 0.00009090 \\
\hline 16 & 49 & 33 & 1 & 0.36024230 \\
\hline 17 & 49 & 13 & 2 & 0.00305342 \\
\hline 18 & 49 & 14 & 2 & 0.01998124 \\
\hline 19 & 49 & 36 & 3 & 0.00321241 \\
\hline 20 & 51 & 33 & 1 & 0.21155280 \\
\hline 21 & 51 & 13 & 2 & 0.00026886 \\
\hline 22 & 51 & 14 & 2 & 0.02015051 \\
\hline 23 & 51 & 15 & 2 & 0.00000000 \\
\hline 24 & 51 & 16 & 2 & 0.00000000 \\
\hline 25 & 51 & 36 & 3 & 0.13159960 \\
\hline 26 & 51 & 37 & 3 & 0.00000000 \\
\hline 27 & 52 & 33 & 1 & 0.22280620 \\
\hline 28 & 52 & 14 & 2 & 0.00036297 \\
\hline 29 & 52 & 15 & 2 & 0.00011321 \\
\hline 30 & 52 & 16 & 2 & 0.00027424 \\
\hline 31 & 52 & 17 & 2 & 0.00000000 \\
\hline 32 & 52 & 36 & 3 & 0.55826090 \\
\hline 33 & 52 & 37 & 3 & 0.00028512 \\
\hline 34 & 53 & 33 & 1 & 0.14946590 \\
\hline 35 & 53 & 14 & 2 & 0.00023619 \\
\hline 36 & 53 & 15 & 2 & 0.00046862 \\
\hline 37 & 53 & 16 & 2 & 0.00178601 \\
\hline 38 & 53 & 17 & 2 & 0.00012344 \\
\hline 39 & 53 & 18 & 2 & 0.00000000 \\
\hline 40 & 53 & 20 & 2 & 0.00000000 \\
\hline 41 & 53 & 36 & 3 & 0.05945479 \\
\hline 42 & 53 & 37 & 3 & 0.01826917 \\
\hline 43 & 54 & 33 & 1 & 0.11553850 \\
\hline 44 & 54 & 15 & 2 & 0.00000000 \\
\hline 45 & 54 & 16 & 2 & 0.00000000 \\
\hline 46 & 54 & 17 & 2 & 0.00000000 \\
\hline 47 & 54 & 36 & 3 & 0.00013715 \\
\hline 48 & 54 & 37 & 3 & 0.31816840 \\
\hline 49 & 55 & 33 & 1 & 0.10396390 \\
\hline 50 & 55 & 17 & 2 & 0.00000000 \\
\hline
\end{tabular}

\section{E-13}


E.8 Return Data File: Rtn.dat

(Partial listing 50/1079 records)

ITYPE INODE TYPE2 INODETO

\begin{tabular}{|c|c|c|c|}
\hline 2 & 47 & 1 & 7 \\
\hline 2 & 47 & 1 & 10 \\
\hline 2 & 47 & 1 & 11 \\
\hline 2 & 47 & 1 & 12 \\
\hline 2 & 47 & 1 & 13 \\
\hline 2 & 47 & 1 & 14 \\
\hline 2 & 47 & 1 & 35 \\
\hline 2 & 48 & 1 & 11 \\
\hline 2 & 48 & 1 & 12 \\
\hline 2 & 48 & 1 & 13 \\
\hline 2 & 48 & 1 & 14 \\
\hline 2 & 48 & 1 & 35 \\
\hline 2 & 48 & 1 & 36 \\
\hline 2 & 49 & 1 & 13 \\
\hline 2 & 49 & 1 & 14 \\
\hline 2 & 49 & 1 & 36 \\
\hline 2 & 51 & 1 & 13 \\
\hline 2 & 51 & 1 & 14 \\
\hline 2 & 51 & 1 & 15 \\
\hline 2 & 51 & 1 & 16 \\
\hline 2 & 51 & 1 & 36 \\
\hline 2 & 51 & 1 & 37 \\
\hline 2 & 52. & 1 & 14 \\
\hline 2 & 52 & 1 & 15 \\
\hline 2 & 52 & 1 & 16 \\
\hline 2 & 52 & 1 & 17 \\
\hline 2 & 52 & 1 & 36 \\
\hline 2 & 52 & 1 & 37 \\
\hline 2 & 53 & 1 & 14 \\
\hline 2 & 53 & 1 & 15 \\
\hline 2 & 53 & 1 & 16 \\
\hline 2 & 53 & 1 & 17 \\
\hline 2 & 53 & 1 & 18 \\
\hline 2 & 53 & 1 & 20 \\
\hline 2 & 53 & 1 & 36 \\
\hline 2 & 53 & 1 & 37 \\
\hline 2 & 54 & 1 & 15 \\
\hline 2 & 54 & 1 & 16 \\
\hline 2 & 54 & 1 & 17 \\
\hline 2 & 54 & 1 & 36 \\
\hline 2 & 54 & 1 & 37 \\
\hline 2 & 55 & 1 & 17 \\
\hline 2 & 55 & 1 & 36 \\
\hline 2 & 55 & 1 & 37 \\
\hline 2 & 56 & 1 & 22 \\
\hline 2 & 56 & 1 & 37 \\
\hline 2 & 57 & 1 & 20 \\
\hline 2 & 57 & 1 & 21 \\
\hline 2 & 57 & 1 & 22 \\
\hline 2 & 57 & 1 & 37 \\
\hline
\end{tabular}

E-14 


\section{APPENDIX F}

\section{BIJOU IRRIGATION COMPANY AUGMENTATION PLAN WELL DATA}

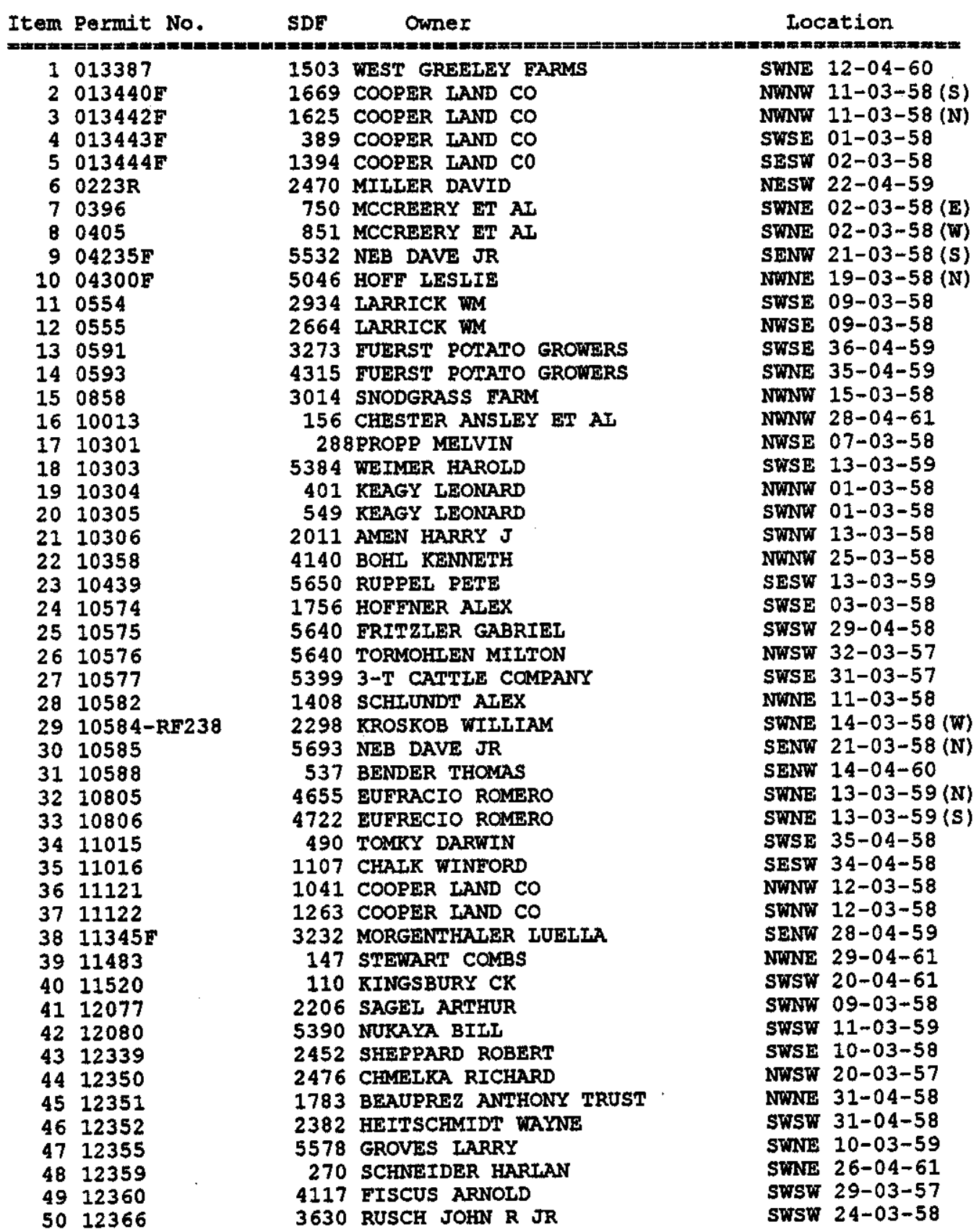




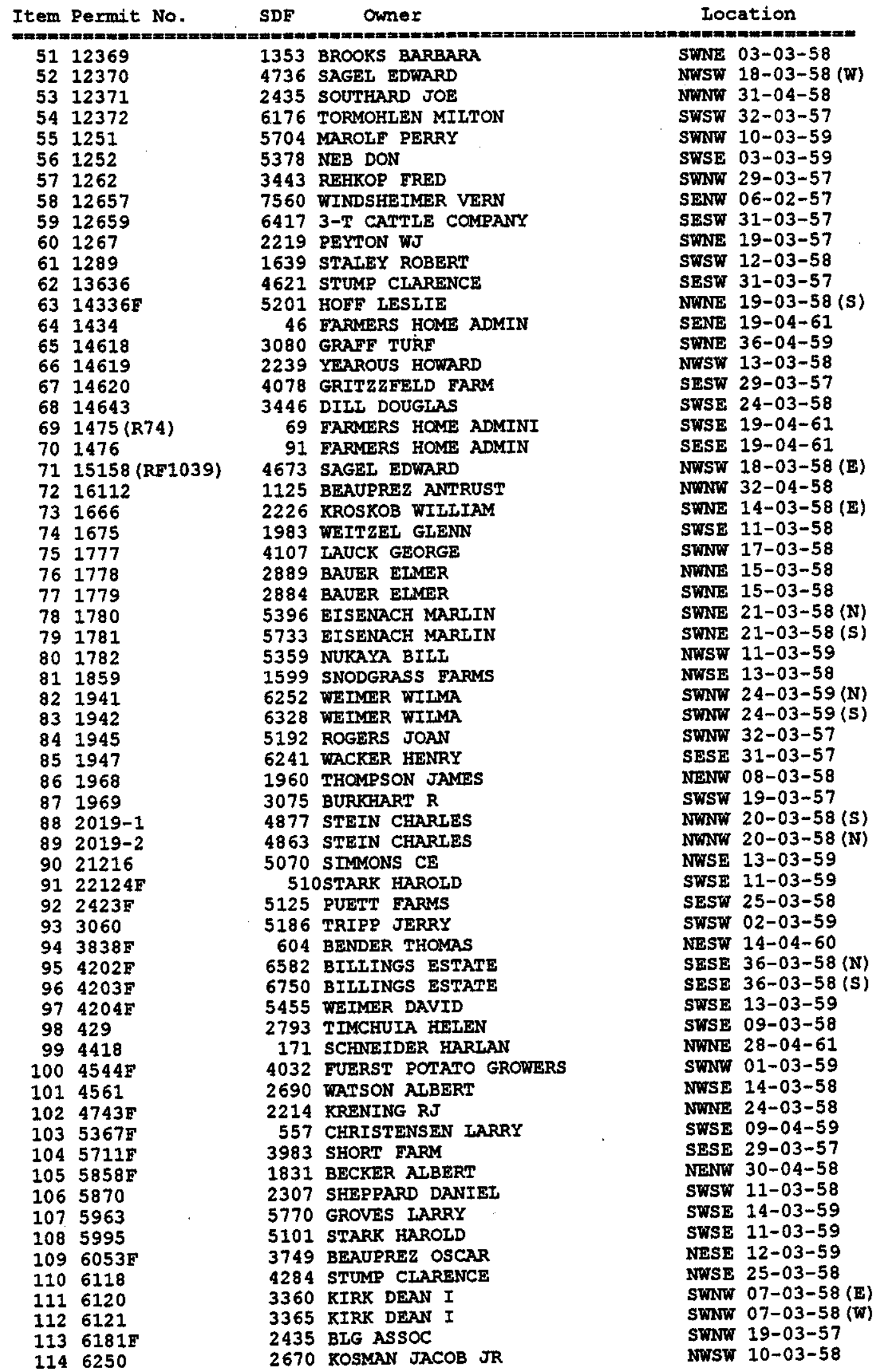




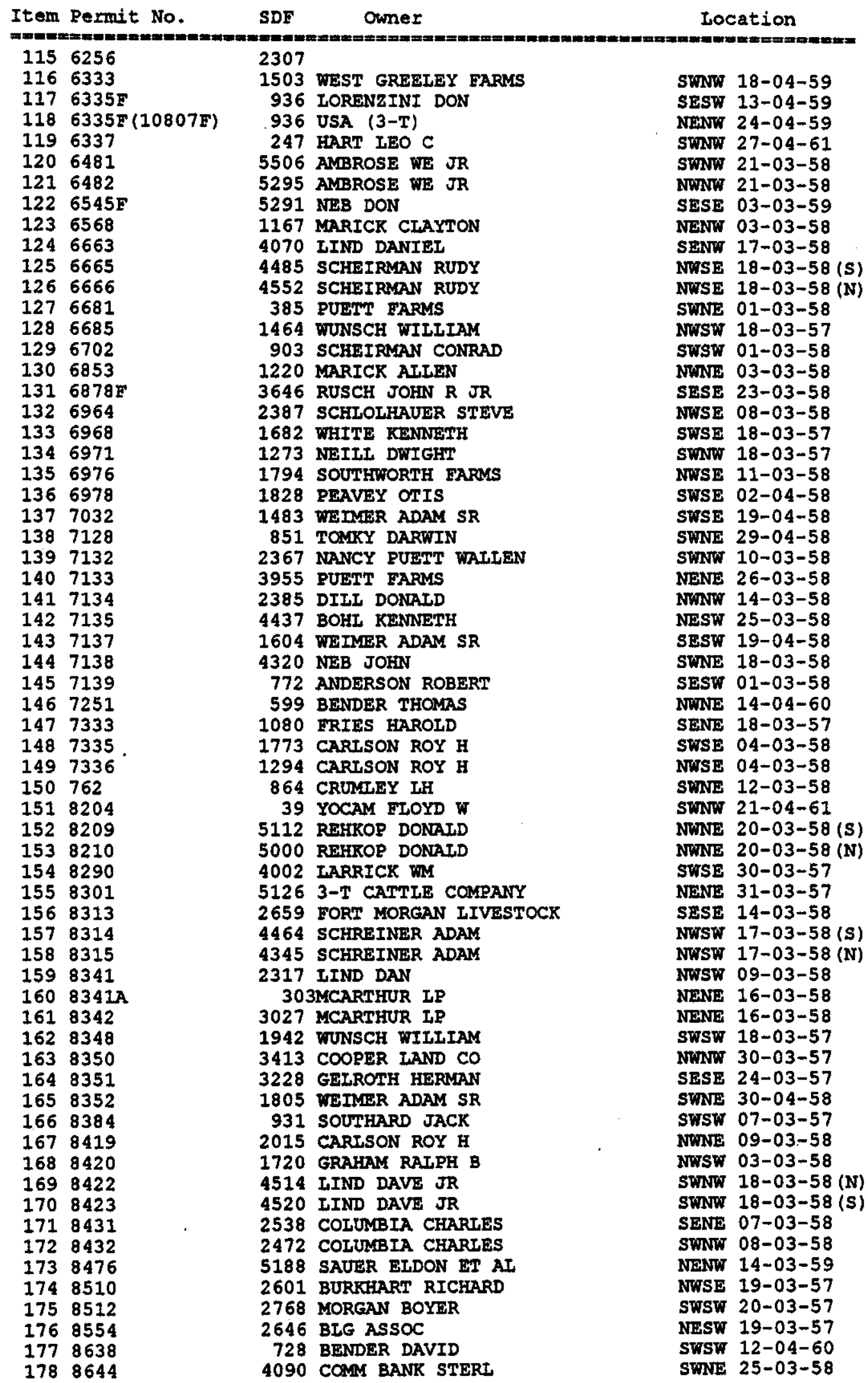




\begin{tabular}{|c|c|c|c|c|c|}
\hline tem & & SDF & 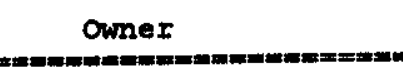 & & sation \\
\hline $\begin{array}{l}179 \\
180 \\
181 \\
182 \\
183 \\
184 \\
185 \\
186 \\
187 \\
188 \\
189 \\
190 \\
191 \\
192 \\
193 \\
194 \\
195 \\
196 \\
197 \\
198 \\
199\end{array}$ & $\begin{array}{l}8648 \\
8649 \\
8650 \\
8654 \\
8843 \\
9071 F \\
\text { R11524-01 } \\
\text { R148(11212) } \\
\text { R15364 } \\
\text { R15365 } \\
\text { R218(7146) } \\
\text { R225(7126) } \\
\text { R260(1269) } \\
\text { R5913 } \\
\text { R6687 } \\
\text { R7174 } \\
\text { R8289 } \\
\text { RF634(11482) } \\
\text { RF671(6001) } \\
\text { RF681(8639) } \\
\text { RF802 (8267) }\end{array}$ & $\begin{array}{r}1210 \\
1080 \\
3115 \\
1470 \\
1349 \\
4671 \\
3000 \\
245 \\
140 \\
250 \\
685 \\
1563 \\
2799 \\
3038 \\
1259 \\
2922 \\
4083 \\
120 \\
872 \\
373 \\
936\end{array}$ & 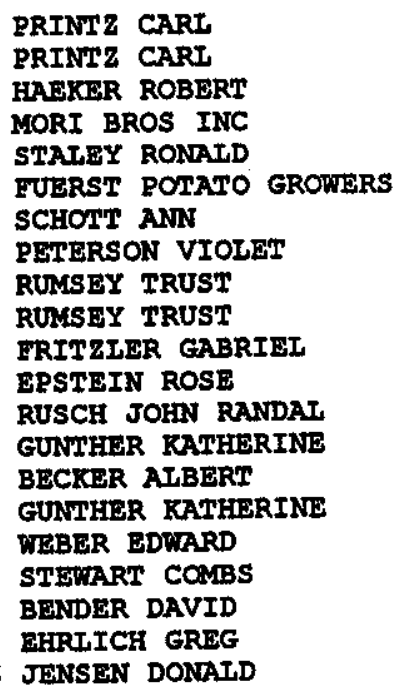 & $\begin{array}{l}\text { SWNW } \\
\text { SWNW } \\
\text { NWNW } \\
\text { SESW } \\
\text { SWSW } \\
\text { NWSE } \\
\text { NWNE } \\
\text { SWNW } \\
\text { SESE } \\
\text { SENE } \\
\text { SWSE } \\
\text { SWNE } \\
\text { NENE } \\
\text { SWNE } \\
\text { SWNW } \\
\text { SWNE } \\
\text { SENW } \\
\text { SWSE } \\
\text { SESE } \\
\text { SWNW } \\
\text { NWSE }\end{array}$ & $\begin{array}{l}02-03-58(\mathrm{~S}) \\
02-03-58(\mathrm{~N}) \\
24-03-57 \\
12-03-58 \\
04-03-58 \\
35-04-59 \\
30-03-57 \\
26-04-61 \\
23-04-61 \\
27-04-61 \\
29-04-58 \\
13-03-58 \\
23-03-58 \\
29-03-57(\mathrm{~N}) \\
29-04-58 \\
29-03-57(\mathrm{~S}) \\
17-03-58 \\
20-04-61 \\
12-04-60 \\
12-04-60 \\
13-4-59\end{array}$ \\
\hline
\end{tabular}




\section{APPENDIX G \\ BIJOU AUGMENTATION PLAN ACCOUNTS}

\section{G.1 Net Return Flow Calculations: Using SDF Coefincient Values}

NODE YEAR MON GWIN GWOUT Net

\begin{tabular}{|c|c|c|c|c|c|}
\hline 33 & 1985 & 1 & 0 & 0 & 0 \\
\hline 33 & 1985 & 2 & 0 & 0 & 0 \\
\hline 33 & 1985 & 3 & 0 & 0 & 0 \\
\hline 33 & 1985 & 4 & 0 & 0 & 0 \\
\hline 33 & 1985 & 5 & 0 & 159 & 159 \\
\hline 33 & 1985 & 6 & 16 & 264 & 248 \\
\hline 33 & 1985 & 7 & 34 & 249 & 215 \\
\hline 33 & 1985 & 8 & 12 & 199 & 187 \\
\hline 33 & 1985 & 9 & 12 & 163 & 151 \\
\hline 33 & 1985 & 10 & 71 & 132 & 61 \\
\hline 33 & 1985 & 11 & 81 & 141 & 60 \\
\hline 33 & 1985 & 12 & 101 & 174 & 73 \\
\hline 33 & 1986 & 1 & 100 & 187 & 87 \\
\hline 33 & 1986 & 2 & 103 & 160 & 57 \\
\hline 33 & 1986 & 3 & 99 & 142 & 43 \\
\hline 33 & 1986 & 4 & 94 & 132 & 38 \\
\hline 33 & 1986 & 5 & 87 & 144 & 57 \\
\hline 33 & 1986 & 6 & 85 & 181 & 96 \\
\hline 33 & 1986 & 7 & 87 & 199 & 112 \\
\hline 33 & 1986 & 8 & 83 & 215 & 132 \\
\hline 33 & 1986 & 9 & 85 & 208 & 123 \\
\hline 33 & 1986 & 10 & 112 & 198 & 86 \\
\hline 33 & 1986 & 11 & 139 & 206 & 67 \\
\hline 33 & 1986 & 12 & 156 & 224 & 68 \\
\hline 33 & 1987 & 1 & 179 & 225 & 46 \\
\hline 33 & 1987 & 2 & 181 & 225 & 44 \\
\hline 33 & 1987 & 3 & 178 & 218 & 40 \\
\hline 33 & 1987 & 4 & 172 & 214 & 42 \\
\hline 33 & 1987 & 5 & 169 & 321 & 152 \\
\hline 33 & 1987 & 6 & 173 & 397 & 224 \\
\hline 33 & 1987 & 7 & 162 & 412 & 250 \\
\hline 33 & 1987 & 8 & 154 & 412 & 258 \\
\hline 33 & 1987 & 9 & 159 & 362 & 203 \\
\hline 33 & 1987 & 10 & 170 & 327 & 157 \\
\hline 33 & 1987 & 11 & 182 & 360 & 178 \\
\hline 33 & 1987 & 12 & 181 & 346 & 165 \\
\hline 33 & 1988 & 1 & 179 & 343 & 164 \\
\hline 33 & 1988 & 2 & 167 & 342 & 175 \\
\hline 33 & 1988 & 3 & 149 & 333 & 184 \\
\hline 33 & 1988 & 4 & 145 & 316 & 171 \\
\hline 33 & 1988 & 5 & 133 & 350 & 217 \\
\hline 33 & 1988 & 6 & 133 & 474 & 341 \\
\hline 33 & 1988 & 7 & 116 & 519 & 403 \\
\hline 33 & 1988 & 8 & 114 & 531 & 417 \\
\hline 33 & 1988 & 9 & 130 & 476 & 346 \\
\hline 33 & 1988 & 10 & 162 & 441 & 279 \\
\hline
\end{tabular}

G-1 


$$
\sqrt{1}
$$


$\begin{array}{llllllllllllllllll}\mathrm{REC} & 1 & 2 & 3 & 4 & 5 & 6 & 7 & 8 & 9 & 10 & 11 & 12 & 13 & 14 & 15 & 16 & 17\end{array}$ MON NET DEPL RTN Node $7 \begin{array}{lllllllllllllllll} & 10 & 11 & 12 & 13 & 14 & 15 & 16 & 17 & 18 & 20 & 21 & 22 & 35 & 36 & 37 & 38\end{array}$

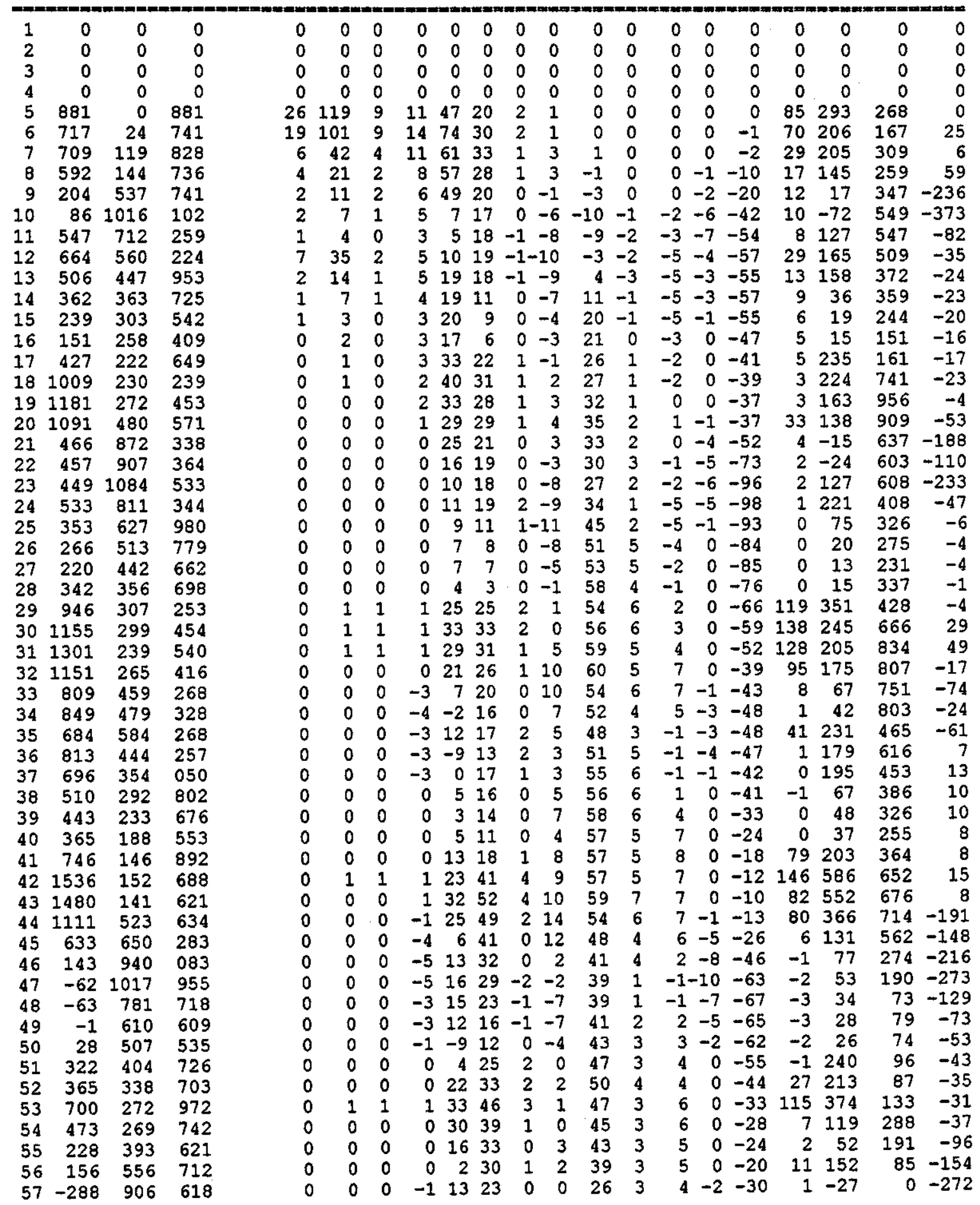




\begin{tabular}{|c|c|c|c|c|c|c|c|c|c|c|c|c|c|c|c|c|c|c|c|c|}
\hline 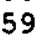 & 191 & 886 & 077 & 0 & 0 & 1 & 0 & -8 & 31 & 2 & $\begin{array}{l}-6 \\
-8\end{array}$ & $\begin{array}{r}18 \\
9\end{array}$ & $\begin{array}{l}2 \\
0\end{array}$ & $\begin{array}{l}-1 \\
-4\end{array}$ & -4 & -52 & 126 & 341 & -71 & $\begin{array}{l}-264 \\
-173\end{array}$ \\
\hline 60 & 496 & 674 & 170 & 0 & 0 & 0 & -1 & 0 & 42 & 4 & -9 & 11 & 0 & -4 & -3 & -56 & 8 & 436 & 129 & $\begin{array}{r}-1 / 2 \\
.\end{array}$ \\
\hline 61 & 168 & 527 & 695 & 0 & 0 & 0 & 0 & 5 & 29 & 1 & -6 & 12 & 0 & -4 & 0 & -57 & 2 & 82 & 132 & -28 \\
\hline 62 & 27 & 422 & 449 & 0 & 0 & 0 & 0 & 5 & 23 & 0 & -6 & 16 & 0 & -3 & 0 & -57 & 1 & 37 & 32 & -21 \\
\hline 63 & -18 & 347 & 329 & 0 & 0 & 0 & 0 & 5 & 17 & 0 & -7 & 14 & 0 & -2 & 0 & -54 & 0 & 26 & -1 & -16 \\
\hline 64 & -12 & 284 & 272 & 0 & 0 & 0 & 0 & 4 & 14 & 0 & -5 & 15 & -1 & 1 & 0 & -47 & 0 & 20 & -1 & -12 \\
\hline 65 & 1318 & 228 & 546 & 0 & 0 & 1 & 1 & 39 & 53 & 5 & -1 & 16 & -1 & 2 & 0 & -40 & 106 & 758 & 389 & -10 \\
\hline 66 & 1197 & 203 & 400 & 0 & 0 & 1 & 0 & 47 & 56 & 6 & 2 & 17 & 0 & 2 & 0 & -31 & 97 & 424 & 578 & -2 \\
\hline 67 & 918 & 266 & 184 & 0 & 0 & 0 & 0 & 39 & 48 & 3 & 6 & 22 & 1 & 2 & 0 & -25 & 17 & 135 & 723 & -53 \\
\hline 68 & 665 & 726 & 391 & 0 & 0 & 0 & 0 & 27 & 44 & 2 & 6 & 18 & 0 & 2 & -1 & -26 & 60 & 201 & 603 & -271 \\
\hline 65 & 726 & 555 & 281 & 0 & 0 & 0 & 0 & 20 & 30 & 1 & 3 & 18 & -1 & -2 & -4 & -37 & 5 & 56 & 678 & -41 \\
\hline 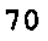 & 463 & 693 & 156 & 0 & 0 & 0 & 0 & 15 & 23 & 1 & 2 & 17 & -1 & -5 & -4 & -45 & 1 & 29 & 566 & -136 \\
\hline 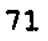 & 288 & 878 & 166 & 0 & 0 & 0 & -1 & -1 & 28 & 3 & -4 & 19 & -1 & -8 & -4 & -60 & 81 & 305 & 166 & -235 \\
\hline 72 & 248 & 679 & 927 & 0 & 0 & 1 & -1 & 10 & 18 & 2 & -7 & 26 & -1 & -10 & 0 & -65 & 102 & 165 & 117 & -89 \\
\hline 73 & 223 & 548 & 771 & 0 & 0 & 0 & 0 & -7 & 11 & 0 & -2 & 29 & -1 & -7 & -1 & -66 & 7 & 42 & 270 & -52 \\
\hline 7 & 219 & 445 & 664 & 0 & 0 & 0 & 0 & -6 & 7 & 0 & 1 & 39 & -1 & -5 & 0 & -59 & 2 & 30 & 250 & -39 \\
\hline 5 & 146 & 371 & 517 & 0 & 0 & 0 & 0 & -4 & 6 & 0 & 1 & 44 & 0 & -2 & 0 & -54 & 1 & 26 & 160 & -32 \\
\hline 76 & 385 & 30 & 689 & 0 & 0 & 1 & 0 & 7 & 14 & 0 & 3 & 44 & 1 & 2 & 0 & -42 & 89 & 80 & 208 & -22 \\
\hline 77 & 1388 & 246 & 634 & 0 & 1 & 1 & 1 & 33 & 42 & 3 & 5 & 47 & 1 & 4 & 0 & -35 & 142 & 536 & 624 & -17 \\
\hline 78 & 1125 & 230 & 355 & 0 & 0 & 0 & 1 & 31 & 42 & 1 & 5 & 47 & 2 & 5 & 0 & -31 & 30 & 190 & 816 & -14 \\
\hline 79 & 1075 & 327 & 402 & 0 & 0 & 0 & 0 & 19 & 37 & 0 & 9 & 53 & 4 & 6 & 0 & -27 & 4 & 103 & 973 & -106 \\
\hline 80 & 1238 & 668 & 906 & 0 & 0 & 0 & -1 & 11 & 49 & 4 & 10 & 56 & 4 & 6 & -1 & -3 & 72 & 517 & 776 & -213 \\
\hline 81 & 560 & 852 & 412 & 0 & 0 & 0 & -3 & 36 & 36 & 1 & 8 & 51 & 5 & 1 & -3 & -43 & 5 & 109 & 630 & -201 \\
\hline & 385 & 911 & 296 & 0 & 0 & 0 & -3 & 41 & 31 & 0 & 4 & 50 & 5 & -6 & -5 & -54 & 0 & 37 & 522 & -155 \\
\hline & 735 & 1038 & 773 & 0 & 1 & 1 & -1 & 42 & 39 & 4 & 1 & 53 & 3 & -6 & -6 & -58 & 136 & 457 & 430 & 77 \\
\hline 84 & 887 & 771 & 658 & 0 & 1 & 1 & 0 & 29 & 34 & 5 & 0 & 56 & 3 & -10 & -7 & -60 & 139 & 500 & 355 & -101 \\
\hline
\end{tabular}

